\author{
Helio Junji Shimozako
}

\title{
Modelo de otimização para o controle da leishmaniose: análise epidemiológica e econômica
}

Tese apresentada à Faculdade de Medicina da Universidade de São Paulo para obtenção do título de Doutor em Ciências

Programa de Patologia

Orientador: Prof. Dr. Eduardo Massad

\section{São Paulo}




\section{Dados Internacionais de Catalogação na Publicação (CIP)}

Preparada pela Biblioteca da

Faculdade de Medicina da Universidade de São Paulo

Creprodução autorizada pelo autor

Shimozako, Hélio Junji

Modelo de otimização para o controle da leishmaniose : análise epidemiológica e econômica / Hélio Junji Shimozako. -- São Paulo, 2015.

Tese(doutorado)--Faculdade de Medicina da Universidade de São Paulo.

Programa de Patologia.

Orientador: Eduardo Massad.

Descritores: 1.Leishmaniose visceral 2.Modelos teóricos 3.Modelos animais de doenças 4.Controle de doenças transmissíveis 5.Epidemiologia 6.Custos e análise de custo 7.Avaliação de custo-efetividade

USP/FM/DBD-249/15 
Eu dedico este trabalho para os meus avós: Shizuko Hashimoto, Hatsuko Iwabuchi, Masayoshi Hashimoto, Shigeru Shimoosako e Kesae Shimoosako (sim, eu tive cinco avós). Dedico também aos meus grandes amigos: Tora-kun, Florentina, Suzy, Menino, Galinho, Bunny e Nina. 
Este projeto teve apoio financeiro da FAPESP (Fundação de Amparo à Pesquisa do Estado de São Paulo), processos 2011/02633-5 e 2013/13347-9. 


\section{AGRADECIMENTOS}

Escrever os agradecimentos foi a etapa mais difícil na elaboração desta tese. Lendo muitas teses e dissertações, o usual tem sido dedicar o agradecimento a pessoas que contribuiram para o sucesso do estudo. Em princípio, seguirei a mesma linha.

Em primeiríssimo lugar, expresso aqui os meus agradecimentos à minha mãe, Satiko Shimosako, que é a principal orientadora em minha vida. Seus cuidados comigo e toda a formação moral que aprendi e que recebi (e que ainda venho aprendendo e recebendo) têm sido fundamentais para o meu equilíbrio e meu senso de responsabilidade na execução deste estudo.

Também sou muito grato ao Prof. Dr. Eduardo Massad. Sem dúvida, sua paciência e sua orientação foram importantíssimas para o desenvolvimento deste trabalho. Entretanto, da mesma forma, quero valorizar TODAS as oportunidades que recebi de suas mãos para crescer (não só academicamente e/ou profissionalmente, mas para a vida). Logo, pude seguir pelos caminhos corretos para o sucesso deste projeto.

Agradeço também ao Prof. Dr. Jianhong Wu e a sua família, que foram muito bons e generosos comigo durante meu estágio na York University (Canadá). Prof. Jianhong não apenas foi um excelente supervisor, como também um ser humano exemplar.

Não menos importante, expresso minha gratidão a Vilma Aparecida Duarte Sanchez e a Iracene Boccia. Todos os favores e toda a disposição em me ajudar ao longo desses anos de convivência foram fundamentais.

No momento do exame de qualificação, houve importantes críticas e considerações construtivas a respeito deste estudo. Portanto, sou muito grato ao Prof. Dr. Marcelo Nascimento Burattini, à Profa. Dra. Neli Regina Siqueira Ortega e ao Prof. Dr. Fernando Ferreira.

Agradeço à FAPESP pelo apoio financeiro para esta pesquisa (processos 2011/026335 e 2013/13347-9).

Ao longo desses quatro anos de doutoramento, tive o contato com pessoas que foram muito importantes e generosas por compartilhar suas experiências comigo. A com- 
panhia de cada pessoa proporcionou novos aprendizados e novas experiências de vida. O sucesso deste trabalho não dependeu apenas de desempenho e ajuda acadêmica, mas também de saber agir e tomar a decisão certa no momento certo. Então, deixo aqui o meu muito obrigado a todos. Em especial, agradeço aos amigos: Dr. Euro de Barros Couto Júnior, Edison Geraldo Araújo, Profa. Dra. Simone de Carvalho Balian, Prof. Dr. José Ribamar dos Santos Ferreira Júnior, Márcia da Silva Lozano, Olga Iwabuchi, Dr. Paulo Cesar Costa dos Santos, Prof. Dr. Luiz Fernandes Lopez, Teresa Maria Furlan, Ricardo de Lima, Rafael Martinez de Araujo, Luis Fernando da Costa, Hideki Ota, Hideto Miyamae, Hiroshi Morita, Berenice Ayako Miyamae, Lucia Naomi Ota, Maria Monica Matos Nakamoto, Hilda Sueko Hirata, Ana Shizuko Hirata, Dr. José Floro Sinatura Barros, Dr. Marek Laskowski, Prof. Dr. Seyed Moghadas, Li Le, Shu Zhang, Shaun Kuttiyil, Longhua Wang, Alice Hiroio Mori e Michele Hanami Asada.

E, como uma última consideração, faço um adendo muito especial e quebrarei um pouco o "protocolo".

Ao refletir profundamente, concluo que muito do sucesso alcançado foi devido aos momentos de adversidade e de dificuldade que surgiram durante o desenvolvimento deste projeto. "Um adversário poderoso obriga-nos a sermos disciplinados em tudo que fazemos. Há uma tensão constante no ar, não podemos nos permitir lapsos, pois caso contrário, o rival ataca. Sem inimigos, relaxamos e tornamo-nos negligentes. Presunçosos, deitamos sobre nossos louros e enfraquecemos-nos a cada ano"*. E também, "quando há certeza nos objetivos futuros, submetemo-nos às humilhações que surgem durante o caminho. (...) Quando os obstáculos nos impedem de atingir o propósito da nossa vida, não podemos ignorá-los"†. Assim, não há como não deixar de agradecer a todos que de alguma forma (consciente ou inconscientemente) impuseram dificuldades ao longo deste doutoramento. Se não fossem por esses obstáculos, eu jamais teria a oportunidade de amadurecer e de crescer na vida. E, também, não teria a chance de aprender a superar tais problemas e, consequentemente, atingir os objetivos deste estudo.

\footnotetext{
*Koichi Kimura, A Bagagem dos Viajantes (2014), p.39

${ }^{\dagger}$ Koichi Kimura, A Bagagem dos Viajantes (2014), p.53
} 
"Quem não conhece o dever da gratidão é inferior a um animal."

(Buda Sakyamuni) 
"A imaginação é mais importante que a ciência, porque a ciência é limitada, ao passo que a imaginação abrange o mundo inteiro."

(Albert Einstein)

"Pouco conhecimento faz com que as pessoas se sintam orgulhosas. Muito conhecimento, que se sintam humildes. $E$ assim que as espigas sem grãos erguem desdenhosamente a cabeça para o Céu, enquanto que as cheias as baixam para a terra, sua mãe." (Leonardo da Vinci) 
Esta tese está de acordo com as seguintes normas, em vigor no momento desta publicação:

Referências: adaptado de International Committee of Medical Journals Editors (Vancouver).

Universidade de São Paulo. Faculdade de Medicina. Divisão de Biblioteca e Documentação Guia de apresentação de dissertações, teses e monografias. Elaborado por Anneliese Carneiro da cunha, Maria Julia de A. L. Freddi, Maria F. Crestana, Marinalva de Souza Aragão, Suely Campos Cardoso, Valéria Vilhena. 3a ed. São Paulo: Divisão de Biblioteca e Documentação; 2011.

Abreviaturas dos títulos dos periódicos de acordo com List of Journals Indexed in Index Medicus.

Observação: esta tese foi corrigida em 5 de fevereiro de 2016. Entretanto, apenas pequenos erros ortográficos e de conceituação na revisão de literatura foram modificados. Todo o conteúdo referente à metodologia, aos resultados, à discussão e à conclusão foram mantidos. 


\section{Sumário}

Lista de Figuras

Lista de Tabelas

Resumo

Summary

1 INTRODUÇÃO 18

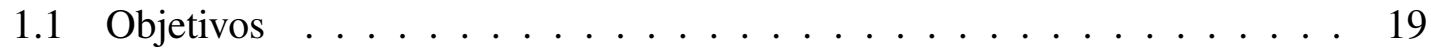

2 REVISÃO DE LITERATURA 22

2.1 A leishmaniose visceral . . . . . . . . . . . . . . . . . 22

2.2 Aspectos relacionados às estratégias de controle preventivo . . . . . . . . 25

2.2.1 Eliminação de cães positivos . . . . . . . . . . . . . . 26

2.2.2 Controle vetorial . . . . . . . . . . . . . . . 27

2.2.3 Coleira impregnada com inseticida (deltametrina 4\%) . . . . . . 27

2.2 .4 Vacinação canina . . . . . . . . . . . . . . . . . . 27

2.2.5 Tratamento canino . . . . . . . . . . . . . . . 28

2.3 Epidemiologia e Modelagem Matemática . . . . . . . . . . . . . . 28

2.4 A otimização do controle da leishmaniose visceral . . . . . . . . . . . . . 30

2.5 A avaliação econômica em saúde . . . . . . . . . . . . . . . 30

3 MÉTODOS 37

3.1 O modelo matemático inicial . . . . . . . . . . . . . . . 37

3.2 O modelo matemático com as estratégias de controle preventivo . . . . . 42

3.2.1 Modificações sobre a população de cães . . . . . . . . . . . . . . 44

3.2.2 Modificações sobre a população de mosquitos . . . . . . . . . . . 45

3.3 Número de casos humanos notificados por dia . . . . . . . . . . . . . 46

3.4 Determinação dos pontos de equilíbrio . . . . . . . . . . . . . . . . . 47

3.5 Análise de estabilidade . . . . . . . . . . . . . . . . . . . . 49

3.6 O número de reprodutibilidade basal $\mathscr{R}_{0} \ldots \ldots \ldots \ldots$

3.7 Análise de incerteza e sensibilidade . . . . . . . . . . . . . . 55

3.7.1 Análise de incerteza . . . . . . . . . . . . . . . 56

3.7.2 Análise de sensibilidade . . . . . . . . . . . . . . 58

3.8 Comparando o impacto das estratégias de controle preventivo . . . . . . . 60

3.9 O custo das estratégias de controle . . . . . . . . . . . . . . . . 62

3.10 Comparando o custo-efetividade das estratégias de controle . . . . . . . 70

3.10.1 Pacientes humanos que receberiam tratamento médico hospitalar . 72 
3.10.2 Cães diagnosticados como positivos e que seriam eliminados . . . 72

3.10.3 Cães diagnosticados como positivos e que seriam tratados . . . . 72

3.10.4 Cães que receberiam coleira impregnada com deltametrina 4\% . . 73

3.10 .5 Cães que seriam vacinados . . . . . . . . . . . . . 73

3.10.6 Casas que seriam tratadas (borrifadas ou manejo ambiental) visando o controle vetorial . . . . . . . . . . . . 74

3.10.7 Relação entre a taxa do controle e o investimento total . . . . . . 74

4 RESULTADOS $\quad 78$

4.1 Determinação do número de reprodutibilidade basal $\mathscr{R}_{0} \ldots \ldots$. . . . . 78

4.2 A dinâmica da doença . . . . . . . . . . . . . . . . . . . . . 84

4.3 Qual o impacto da incerteza dos parâmetros sobre o nosso modelo? . . . . 87

4.4 A estabilidade do modelo nos estados de equilíbrio . . . . . . . . . . . . 92

4.4.1 Estabilidade para o estado de equilíbrio livre da doença . . . . . . 94

4.4.2 Estabilidade para o estado de equilíbrio endêmico . . . . . . . . . 94

4.5 Qual a estratégia ótima de controle? . . . . . . . . . . . . . . . 95

4.6 Qual estratégia apresenta melhor desempenho econômico? . . . . . . . . 98

4.6.1 O custo total investido em cada estratégia . . . . . . . . . . . . . . 98

4.6.2 O custo total com pacientes humanos . . . . . . . . . . . 101

4.6.3 Custos totais entre a estratégia de controle e o tratamento médico

hospitalar por valor de taxa de controle . . . . . . . . . . . 102

4.7 Simulações numéricas para a intervenção de algumas estratégias . . . . . 105

4.7.1 Eliminação de cães positivos . . . . . . . . . . . . . . . 106

4.7 .2 Vacinação . . . . . . . . . . . . . . . . . . . . . 108

4.7.3 Coleira impregnada com deltametrina $4 \%$. . . . . . . . . . 110

4.7 .4 Controle vetorial . . . . . . . . . . . . . . . . 112

4.7.5 Casos humanos notificados por dia . . . . . . . . . . 114

5 DISCUSSÃO 118

5.1 As contribuições deste estudo . . . . . . . . . . . . . . . . . . . 118

5.2 Interpretação dos resultados . . . . . . . . . . . . . . . . . . 121

5.2.1 As características e os resultados do modelo . . . . . . . . . . . 121

5.2.2 Os custos das estratégias apresentados por este estudo . . . . . . . 124

5.3 Limitações do estudo . . . . . . . . . . . . . . . . . . . . . . . 127

6 CONCLUSÕES 132

7 REFERÊNCIAS 134

Apêndice 


\section{LISTA DE FIGURAS}

1 Evolução no número de casos e de óbitos no período de 2001 a 2013 . . . 19

2 Áreas de maior concentração de casos de leishmaniose visceral.Brasil, 2006 e 2007. . . . . . . . . . . . . . . . . . . . . 20

3 Ilustração da Leishmania infantum chagasi. . . . . . . . . . . . . . . . . . . . 22

4 Ilustração da fêmea do Lutzomyia longipalpis. . . . . . . . . . . . . . . . 23

5 Ilustração da sintomatologia clínica característica para leishmaniose visceral em humanos. . . . . . . . . . . . . . . . . . . . . . . . . 24

6 Ilustração da sintomatologia clínica característica para leishmaniose canina. 25

7 Casos de LV, segundo a região de residência. . . . . . . . . . . . . . . 31

8 Representação do modelo compartimental e o fluxograma entre eles. . . . 38

9 Representação do modelo compartimental com a inclusão das estratégias de controle. . . . . . . . . . . . . . . . . . 43

10 Esquema da análise de incerteza e de sensibilidade realizada com métodos de LHS e PRCC. . . . . . . . . . . . . . . . . . . . . . 57

11 Simulação numérica da dinâmica da LVZ sobre a população de mosquitos. 85

12 Simulação numérica da dinâmica da LVZ sobre a população canina. . . . 85

13 Simulação numérica da dinâmica da LVZ sobre a população humana. . . . 86

14 Dinâmica do número de casos humanos notificados por dia. . . . . . . . . 86

15 Contagem do número de parâmetros que foram identificados como sensíveis para cada variável. . . . . . . . . . . . . . . . . . . 91

16 Contagem do número de variáveis que foram identificados como sensíveis para o respectivo parâmetro. . . . . . . . . . . . . . . . . 92

17 Relação entre o número de casos humanos notificados por dia e os valores das taxas de controle, após 2000 dias. . . . . . . . . . . . . . 95

18 Relação entre o custo total investido em cada estratégia de controle e sua respectiva taxa. . . . . . . . . . . . . . . 100

19 Relação entre o valor da taxa de cada estratégia de controle e o valor gasto com tratamento médico-hospitalar após 2000 dias de atividades. . . . . . 101

20 Relação entre o custo total investido no controle vetorial e no tratamento médico-hospitalar de pacientes humanos e a respectiva taxa da estratégia.

21 Relação entre o custo total investido na vacinação de cães e no tratamento médico-hospitalar de pacientes humanos e a respectiva taxa da estratégia.

22 Relação entre o custo total investido na eliminação de cães positivos e no tratamento médico-hospitalar de pacientes humanos e a respectiva taxa da estratégia. . . . . . . . . . . . . . . . . . . . 104 
23 Relação entre o custo total investido na distribuição de coleiras impregnadas com inseticidas aos cães e no tratamento médico-hospitalar de pacientes humanos e a respectiva taxa da estratégia. . . . . . . . . . . . 105

24 Simulação numérica da dinâmica sobre a população de humanos, considerando a introdução da estratégia de eliminar cães positivos $\left(\xi_{d}=0,04 /\right.$ dia $)$ a partir do dia 2000. . . . . . . . . . . . . . . . 106

25 Simulação numérica da dinâmica sobre a população de cães, considerando a introdução da estratégia de eliminar cães positivos $\left(\xi_{d}=0,04 /\right.$ dia $)$ a partir do dia 2000. . . . . . . . . . . . . . . . . . . . . . . . 107

26 Simulação numérica da dinâmica sobre a população de mosquitos, considerando a introdução da estratégia de eliminar cães positivos $\left(\xi_{d}=\right.$ 0,04/dia) a partir do dia 2000.

27 Simulação numérica da dinâmica sobre a população de humanos, considerando a introdução da estratégia de vacinação canina $\left(v_{d}=0,025 /\right.$ dia $)$ a partir do dia 2000. . . . . . . . . . . . . . . . . . . . 108

28 Simulação numérica da dinâmica sobre a população de cães, considerando a introdução da estratégia de vacinação canina $\left(v_{d}=0,025 /\right.$ dia $)$ a partir do dia 2000. . . . . . . . . . . . . . . . . . . . .

29 Simulação numérica da dinâmica sobre a população de mosquitos, considerando a introdução da estratégia de vacinação canina $\left(v_{d}=0,025 /\right.$ dia $)$ a partir do dia 2000. . . . . . . . . . . . . . . . .

30 Simulação numérica da dinâmica sobre a população de humanos, considerando a introdução da estratégia de distribuição de coleiras impregnadas com deltametrina $4 \%\left(\theta_{d}=0,05 /\right.$ dia $)$ a partir do dia $2000 \ldots$. . . . . . . 110

31 Simulação numérica da dinâmica sobre a população de cães, considerando a introdução da estratégia de distribuição de coleiras impregnadas com

32 Simulação numérica da dinâmica sobre a população de mosquitos, considerando a introdução da estratégia de distribuição de coleiras impregnadas com deltametrina $4 \%\left(\theta_{d}=0,05 /\right.$ dia $)$ a partir do dia $2000 . . . . . . .$. Simulação numérica da dinâmica sobre a população de humanos, considerando a introdução da estratégia de controle vetorial $\left(\xi_{c}=0,01 /\right.$ dia $)$ a partir do dia $2000 \ldots$. . . . . . . . . . . . . . . . . . . . .

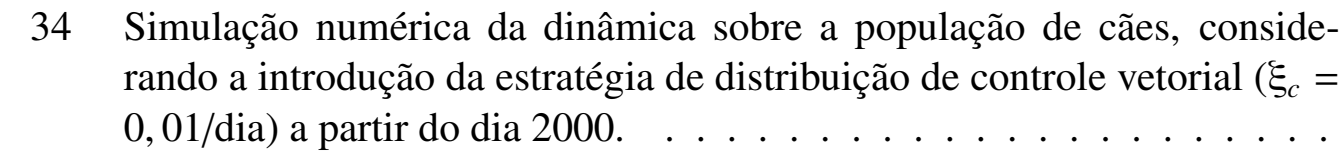

Simulação numérica da dinâmica sobre a população de cães, conside-
rando a introdução da estratégia de distribuição de controle vetorial $\left(\xi_{c}=\right.$
$0,01 /$ dia $)$ a partir do dia $2000 . \ldots \ldots \ldots \ldots \ldots \ldots \ldots \ldots \ldots \ldots \ldots$

35 Simulação numérica da dinâmica sobre a população de mosquitos, considerando a introdução da estratégia de controle vetorial $\left(\xi_{c}=0,01 /\right.$ dia $)$ a partir do dia 2000. . . . . . . . . . . . . . . . . . .

36 Simulação numérica da dinâmica sobre a quantidade de casos humanos notificados por dia. A partir do dia 2000, observamos as curvas que representam cada estratégia de controle. . . . . . . . . . . . 114

37 Valores do PRCC para os parâmetros do modelo em relação à categoria $x_{h} .184$

38 Valores do PRCC para os parâmetros do modelo em relação à categoria $l_{h}$. 185

39 Valores do PRCC para os parâmetros do modelo em relação à categoria $y_{h}$. 186

40 Valores do PRCC para os parâmetros do modelo em relação à categoria $z_{h} .187$ 
41 Valores do PRCC para os parâmetros do modelo em relação à categoria $x_{d} .188$

42 Valores do PRCC para os parâmetros do modelo em relação à categoria $x_{d}^{C} .189$

43 Valores do PRCC para os parâmetros do modelo em relação à categoria $l_{d}$. 190

44 Valores do PRCC para os parâmetros do modelo em relação à categoria $l_{d}^{C}$. 191

45 Valores do PRCC para os parâmetros do modelo em relação à categoria $y_{d} .192$

46 Valores do PRCC para os parâmetros do modelo em relação à categoria $y_{d}^{C}$. 193

47 Valores do PRCC para os parâmetros do modelo em relação à categoria $z_{d}$. 194

48 Valores do PRCC para os parâmetros do modelo em relação à categoria $z_{d}^{C} .195$

49 Valores do PRCC para os parâmetros do modelo em relação à categoria $v_{d} .196$

50 Valores do PRCC para os parâmetros do modelo em relação à categoria $v_{d}^{C} .197$

51 Valores do PRCC para os parâmetros do modelo em relação à categoria $s_{1}$. 198

52 Valores do PRCC para os parâmetros do modelo em relação à categoria $s_{2} .199$

53 Valores do PRCC para os parâmetros do modelo em relação à categoria $s_{3} .200$

54 Valores do PRCC para os parâmetros do modelo em relação ao número de casos notificados por dia $(R)$. . . . . . . . . . . . . . 201

55 Valores do PRCC para os parâmetros do modelo em relação à contribuição da categoria $l_{d}$ ao número de reprodutibilidade basal $\left(\mathscr{R}_{0}\right)$. . . . . . . . 202

56 Valores do PRCC para os parâmetros do modelo em relação à contribuição da categoria $l_{d}^{C}$ ao número de reprodutibilidade basal $\left(\mathscr{R}_{0}\right) . \ldots 203$

57 Valores do PRCC para os parâmetros do modelo em relação à contribuição da categoria $y_{d}$ ao número de reprodutibilidade basal $\left(\mathscr{R}_{0}\right)$. . . . . . . . 204

58 Valores do PRCC para os parâmetros do modelo em relação à contribuição da categoria $y_{d}^{C}$ ao número de reprodutibilidade basal $\left(\mathscr{R}_{0}\right)$. . . . . . . 205

59 Valores do PRCC para os parâmetros do modelo em relação ao número de reprodutibilidade basal $\left(\mathscr{R}_{0}\right) \ldots \ldots \ldots$. . . . . . . . . . 206 


\section{LISTA DE TABELAS}

1 Parâmetros usados no modelo, seus significados biológicos e respectivos valores. . . . . . . . . . . . . . . . . . . 39

2 Parâmetros usados no modelo, seus significados biológicos e respectivos valores (Continuação da Tabela 1). . . . . . . . . . . . . . . . . . . . 40

3 Sumário dos custos médios estimados por ciclo de atividade (eliminação de cães positivos) e a respectiva quantidade média de cães eliminados. . . 63

4 Sumário dos custos médios estimados por ciclo de atividade (exame sorológico de cães) e a respectiva quantidade média de cães que seriam tratados. . . . . . . . . . . . . . . . . 65

5 Sumário dos custos médios estimados por ciclo de atividade (controle do vetor) e a respectiva quantidade média de casas trabalhadas. . . . . . . . . 68

6 Sumário dos custos médios estimados para as estratégias de controle e para o tratamento médico-hospitalar por pacientes. . . . . . . . . . 71

7 Valores mínimos, médios e máximos atribuídos aos parâmetros para a análise de sensibilidade. . . . . . . . . . . . . . . . . . . 88

8 Valores mínimos, médios e máximos atribuídos aos parâmetros para a análise de sensibilidade (Continuação da Tabela 7). . . . . . . . . . . . . 89

9 Sumário dos resultados numéricos e da análise de sensibilidade pelo método PRCC . . . . . . . . . . . . . . . . . . . . . 90 


\section{RESUMO}

Shimozako HJ. Modelo de otimização para o controle da leishmaniose: análise epidemiológica e econômica [Tese]. São Paulo: Faculdade de Medicina, Universidade de São Paulo; 2015.

A leishmaniose visceral zoonótica (LVZ) é uma das mais importantes doenças parasitárias emergentes. Em particular, o Brasil é considerado um dos principais centros endêmicos para esta doença. Apesar da publicação de manuais de controle da leishmaniose visceral e dos investimentos aplicados na organização de serviços e no desenvolvimento de atividades preventivas e de controle, os vetores e os reservatórios em áreas urbanas são os maiores desafios para os programas de controle. Isto se deve (1) à necessidade por melhor compreensão do comportamento do vetor no meio urbano; (2) às dificuldades operacionais para realizar atividades em tempo suficiente para obter resultados de impacto; e (3) ao alto custo envolvido nessas atividades. O principal objetivo deste estudo foi elaborar um modelo de otimização para o controle da leishmaniose, baseado em 5 parâmetros de controle que correspondem às seguintes estratégias: (I) controle vetorial, (II) eliminação de cães positivos, (III) uso de coleiras impregnadas com inseticida, (IV) vacinação canina e (V) tratamento canino. Este modelo foi construído a partir de um sistema composto por 17 equações diferenciais, sendo que 4 representam a dinâmica da doença sobre a população humana (humanos suscetíveis $\left(x_{h}\right)$, latentes $\left(l_{h}\right)$, clinicamente doentes $\left(y_{h}\right) \mathrm{e}$ recuperados $\left.\left(z_{h}\right)\right), 10$ para a população de cães (cães suscetíveis $\left(x_{d}\right.$ e $\left.x_{d}^{C}\right)$, latentes $\left(l_{d}\right.$ e $\left.l_{d}^{C}\right)$, clinicamente doentes $\left(y_{d}\right.$ e $\left.y_{d}^{C}\right)$, recuperados $\left(z_{d}\right.$ e $\left.z_{d}^{C}\right)$ e vacinados $\left(v_{d}\right.$ e $\left.v_{d}^{C}\right)$, onde o índice $C$ representa as categorias com a aplicação da coleira inseticida) e 3 para a população de vetores (mosquitos não-infectados $\left(s_{1}\right)$, infectados (mas não-infectivos) $\left(s_{2}\right)$, infectados e infectivos $\left(s_{3}\right)$ ). Para a análise econômica dessas estratégias, foram estimados os custos de cada uma delas por cão (ou, no caso do controle vetorial, por casa tratada). Considerando a simulação sem a introdução das estratégias de controle, as densidades de equilíbrio endêmico para as categorias foram: $\mathbf{x}_{\mathbf{h}}=0,394, \mathbf{l}_{\mathbf{h}}=0,0305, \mathbf{y}_{\mathbf{h}}=0,00167$, $\mathbf{z}_{\mathbf{h}}=0,574, \mathbf{x}_{\mathbf{d}}=0,314, \mathbf{l}_{\mathbf{d}}=0,165, \mathbf{y}_{\mathbf{d}}=0,0163, \mathbf{z}_{\mathbf{d}}=0,505, \mathbf{s}_{\mathbf{1}}=0,709, \mathbf{s}_{\mathbf{2}}=0,0858$ e $\mathbf{s}_{\mathbf{3}}=0,205$. No estado de equilíbrio endêmico, o número de reprodutibilidade basal foi estimado em $\mathscr{R}_{0}=4,50$ e o número diário de casos humanos notificados, em $R=3,58 \times 10^{-6} /$ dia. Considerando a avaliação do impacto das estratégias de controle, o controle vetorial mostrou ser a estratégia que causa a diminuição mais rápida sobre o número diário de casos humanos notificados e, consequentemente, foi também a que mais reduz os custos médico-hospitalares. Entretanto, é a estratégia que exige o maior investimento. Por outro lado, a estratégia de eliminar cães positivos foi considerada a de menor custo. Dado que essas estratégias de controle atuam em pontos distintos na cadeia epidemiológica, o planejamento de um controle envolvendo a ação simultânea delas poderia não apenas apresentar resultados de controle mais interessantes, como também poderia otimizar ainda mais os investimentos sobre o controle da leishmaniose visceral.

Descritores: leishmaniose visceral zoonótica; modelagem matemática; estratégias de controle de doença; epidemiologia; análise econômica; avaliação de custo. 


\section{SUMMARY}

Shimozako HJ. Optimization Model for leishmaniasis control: epidemiological and economical analisis [Thesis]. São Paulo: "Faculdade de Medicina, Universidade de São Paulo"; 2015.

Zoonotic visceral leishmaniasis (ZVL) is one of the most important emerging parasitic diseases. Brazil, in particular, is considered one of the countries in which this disease is most endemic. Despite the publication of visceral leishmaniasis control guidelines and the investment in health services and control/preventive activities, the vectors and reservoirs in urban areas are the major challenge for those control programs. This is due to (1) the need for better comprehension regarding the vector behavior in the urban environment; (2) the operating difficulties in performing the activities in time to reach good results; and (3) the high cost of those activities. The main objective of this study was to elaborate an optimization model for leishmaniasis control. This model is based on 5 control parameters that correspond to the following strategies: (I) vector population control, (II) elimination of positive dogs, (III) use of insecticide-impregnated dog collars, (IV) dog vaccination and (V) dog treatment. This model was elaborated using an equation system, composed of 17 differential equations, 4 of which represent the disease dynamic on human population (susceptible $\left(x_{h}\right)$, latent $\left(l_{h}\right)$, clinically ill $\left(y_{h}\right)$ and recovered humans $\left(z_{h}\right)$ ), 10 for dog population (susceptible $\left(x_{d}\right.$ and $\left.x_{d}^{C}\right)$, latent $\left(l_{d}\right.$ and $\left.l_{d}^{C}\right)$, clinically ill $\left(y_{d}\right.$ and $\left.y_{d}^{C}\right)$, recovered $\left(z_{d}\right.$ and $\left.z_{d}^{C}\right)$ and vaccinated $\operatorname{dogs}\left(v_{d}\right.$ and $\left.v_{d}^{C}\right)$, where $C$ represents the categories using the insecticide-impregnated dog collars) and 3 for vector population (non-infected $\left(s_{1}\right)$, infected but not infective $\left(s_{2}\right)$, infected and infective sandflies $\left(s_{3}\right)$ ). For economic analysis of those control strategies, we estimated the cost of them per dog (in the case of vector control population, it was estimated per treated house). Regarding the numerical simulations without the control strategies, the endemic equilibrium densities were: $\mathbf{x}_{\mathbf{h}}=0.394, \mathbf{l}_{\mathbf{h}}=0.0305, \mathbf{y}_{\mathbf{h}}=0.00167, \mathbf{z}_{\mathbf{h}}=0.574, \mathbf{x}_{\mathbf{d}}=0.314, \mathbf{l}_{\mathbf{d}}=0.165, \mathbf{y}_{\mathbf{d}}=0.0163$, $\mathbf{z}_{\mathbf{d}}=0.505, \mathbf{s}_{\mathbf{1}}=0.709, \mathbf{s}_{\mathbf{2}}=0.0858$ and $\mathbf{s}_{\mathbf{3}}=0.205$. In endemic equilibrium state, the basic reproduction number and the rate of reported human cases per day were estimated as $\mathscr{R}_{0}=4.50$ and $R=3.58 \times 10^{-6} / \mathrm{day}$, respectively. Considering the impact evaluation of control strategies, the vector population control was the strategy that resulted in a faster decrease in the rate of human reported cases per day and, consequently, in the larger reduction of medical and hospital costs too. However, the investment (that is, the cost) of the vector population control was the highest one. On the other hand, the investment in eliminating positive dogs was considered the lowest one. Since those control strategies operate at different points within the epidemiological chain, the planning a control, while taking into account the simultaneous action of these strategies, could not only result in a more interesting control strategy, but could also improve the optimization of investments on visceral leishmaniasis control.

Descriptors: zoonotic visceral leishmaniasis; mathematical modeling; disease control strategies; epidemiology; economic analysis; cost evaluation. 


\section{INTRODUÇÃO}

A leishmaniose visceral zoonótica (LVZ) é uma das mais importantes doenças parasitárias emergentes. Em particular, o Brasil é considerado um dos principais centros endêmicos para esta doença ${ }^{1-3}$. Segundo dados do Ministério da Saúde ${ }^{4}$ (disponível pelo Sistema de Informação de Agravos de Notificação - SINAN), houve crescimento do número de casos confirmados entre 2001 a 2013 (média anual de 3588 casos humanos notificados) e de óbitos entre 2007 a 2013 (média anual de 228 óbitos por LVZ) (Figuras 1 e 2). Tal fato reflete a grande importância desta doença no Brasil. O aumento do número de casos pode estar relacionado a sua emergência em regiões não-endêmicas, principalmente devido à migração de cães de áreas endêmicas para às não-endêmicas e também devido às mudanças climáticas, que proporcionam a expansão do habitat geográfico favorável ao mosquito vetor ${ }^{5}$.

Além do cenário epidemiológico apresentado, anualmente 850 mil cães são investigados no Brasil e entre $20 \mathrm{mil}^{6}$ e $25 \mathrm{mil}^{7}$ cães são sacrificados por terem diagnóstico positivo. Esta conduta é a posição oficial das autoridades brasileiras de saúde, que proíbem o tratamento de cães infectados com drogas de uso humano (Portaria Interministerial No. 1.426, de 11 de julho de 2008) e impõem compulsoriamente a eliminação de cães soropositivos $^{8}$. Do ponto de vista ético, dois aspectos podem ser enfatizados: a ética do animal (ponto de vista do veterinário) e a ética das relações humanas, onde esses animais e seu relacionamento com a sociedade humana estão cada vez mais valorizados. Portanto, conflitos entre estes aspectos deveriam ser evitados sempre que possível. Para tanto, torna-se importante a busca por métodos de controles alternativos que gerem resultados iguais ou mais expressivos que aqueles que pouco valorizam as questões éticas.

Tendo em vista este cenário, este estudo propõe um modelo de otimização para o controle da leishmaniose. Para a confecção deste modelo, utilizaremos uma adaptação 
do modelo matemático de Burattini et al. ${ }^{9}$ e de Ribas et al. ${ }^{10}$. Junto a estas adaptações, iremos considerar as seguintes estratégias de controle preventivo: (1) sacrifício de cães; (2) coleiras impregnadas com insecticida; (3) vacina canina; (4) tratamento de cães; e (5) controle de vetores. A avaliação da estratégia ótima de controle também será analisada sob condições relativas aos custos. Espera-se que os resultados e as conclusões obtidas sejam úteis para as instituições de saúde pública no geral, auxiliando na otimização do planejamento das atividades de controle.

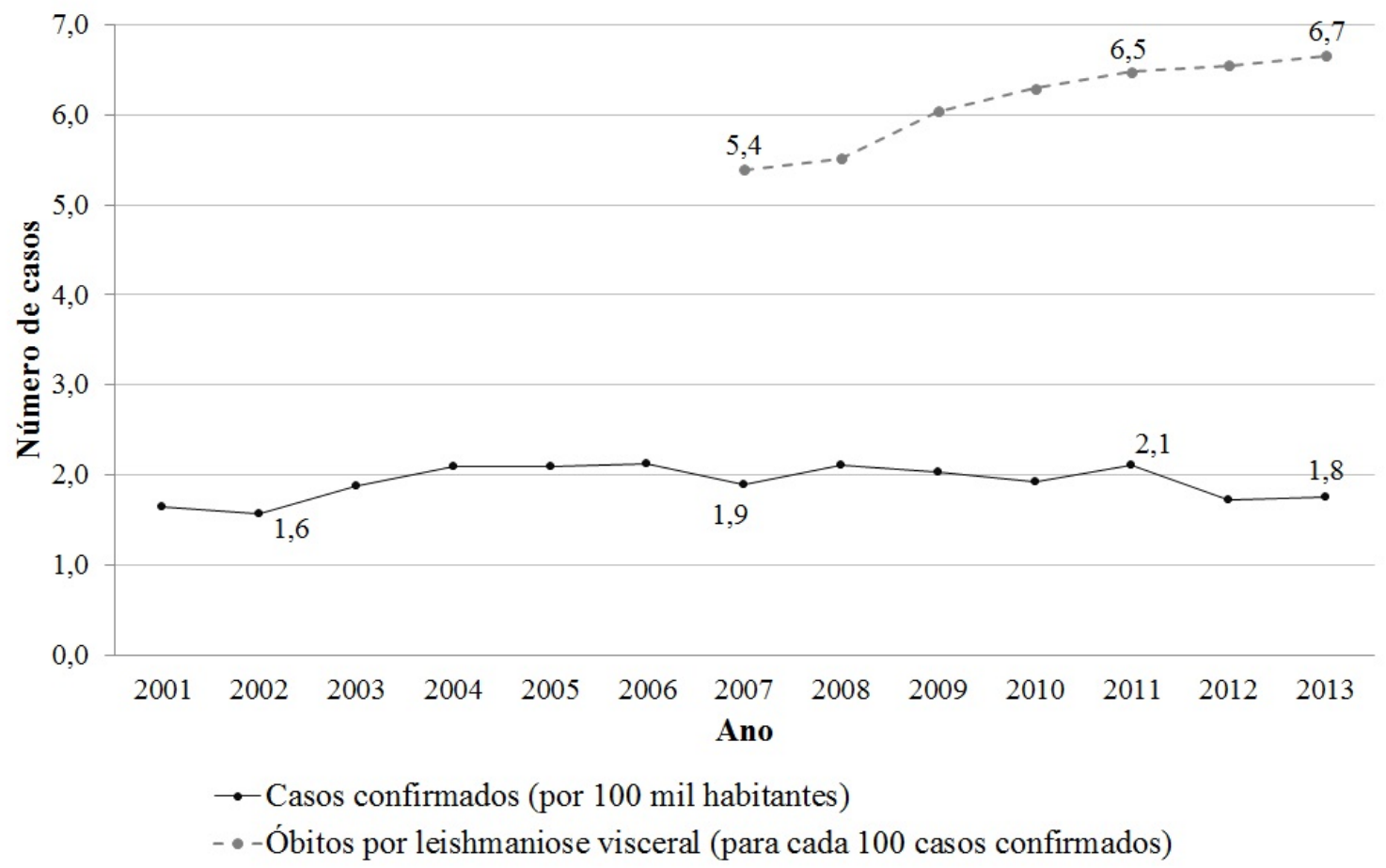

Figura 1 - Evolução no número de casos e de óbitos no período de 2001 a 2013. Não foi possível obter dados de óbitos por LVZ no período de 2001 a 2006. Fonte: SINAN/MS.

\subsection{Objetivos}

- Objetivos gerais:

Elaborar um modelo de otimização para o controle da leishmaniose visceral.

- Objetivos específicos: 

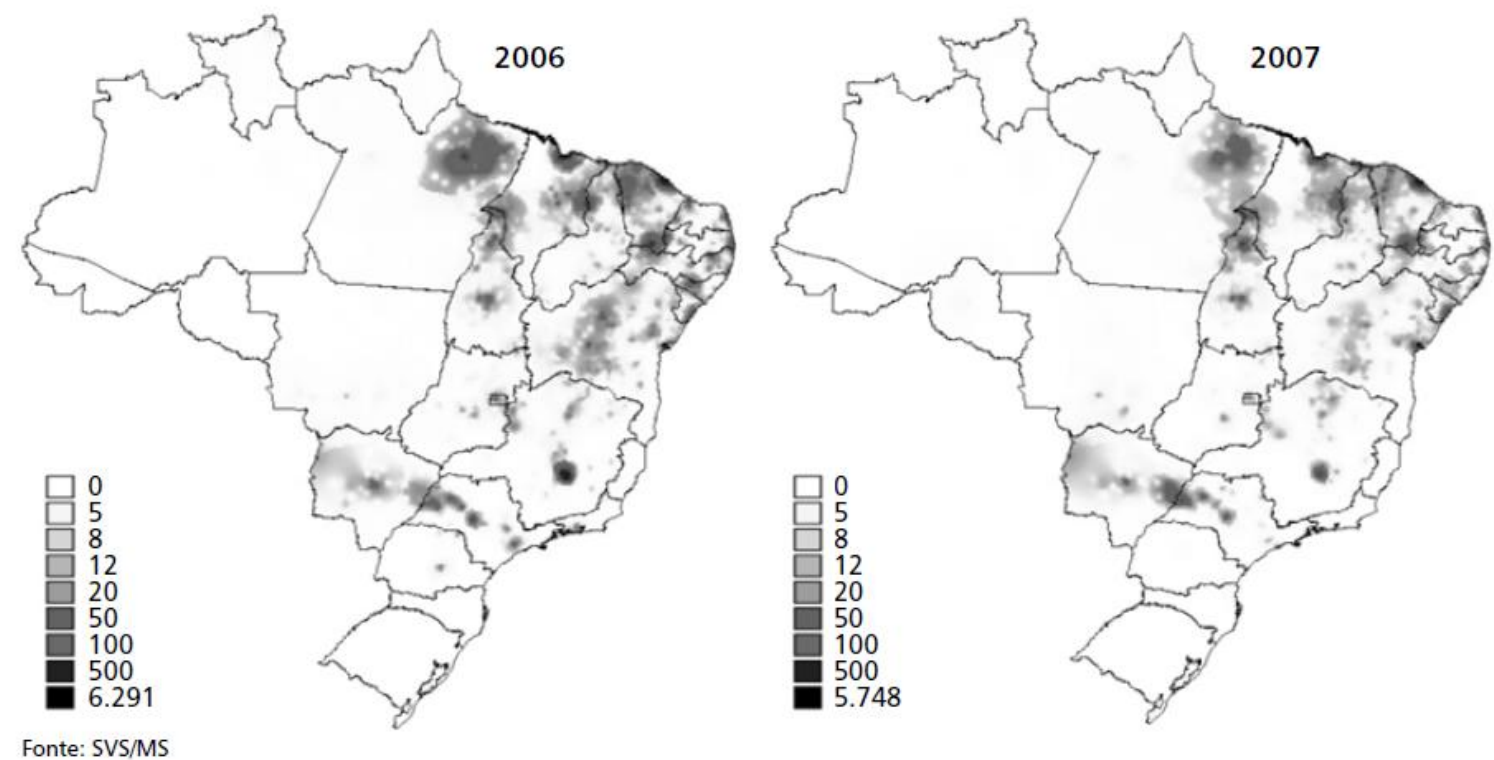

Figura 2 - Áreas de maior concentração de casos de leishmaniose visceral.Brasil, 2006 e 2007. Fonte: SVS/MS, Guia de Vigilância Epidemiológica, Caderno 11, Leishmaniose Visceral, 7a. ed..

1. Determinar, entre as cinco estratégias consideradas neste estudo, quais são aquelas consideradas ótimas (tendo em vista a redução de casos humanos);

2. Avaliar o custo mínimo de cada estratégia;

3. Determinar, entre as cinco estratégias consideradas neste estudo, quais são aquelas consideradas ótimas (tendo em vista os custos mínimos). 


\section{A trredutível rã}

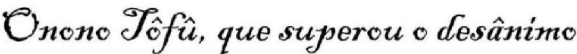

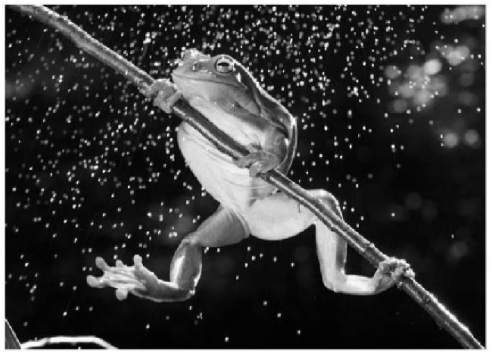

Chovia. Abrigado pelo guardachuva, um jovem caminhava cabisbaixo.

Tratava-se do estudante de caligrafia Onono Tôfù (894 - 966), que, por mais que praticasse, só recebia criticas do professor. Seu estado de espirito estava sombrio como as nuvens no céu.

- Não tenfio o menor talento, vou abandonar tudo... - murmurou enquanto observava a superficie da água. De repente, observou uma movimentação embaixo do salgueiro ao lado.

- Ah, é uma rã...

$O$ animal preparou-se para pular em um galho pendente empregou todas as forças, mas a distância era muito grande. Cruzou o vazio e caiu.

- Hahaha, se machucou pequena rã? $\mathcal{N}$ ão exagere - disse Tôfú. Indiferente, a rã tentou novo salto dessa vez, um pouco mais afto que o anterior.

- Nova queda. O galho está além das suas forças.
$\mathcal{A}$ rã pulou novamente, alguns centimetros mais alto.

- Você é um bicho persistente. Vamos, agora falta pouco. Não desista! - Inconscientemente, Tôfú incentivava a rã. $\mathcal{A}$ cada tentativa, ela ganhava mais impulso. Depois de uma grande quantidade de saltos, finalmente alcançou o galho.

- $\mathcal{E}$ não é que a rã não descansou até vencer o desafio? $\mathcal{A}$ meta que busco está além do meu talento. Por isso, mais do que nunca, devo persistir nos meus estudos - Ao testemunfiar a vitória da rã, Tôfû mudou sua postura pessimista e dedicou-se de corpo e alma à caligrafia.

Tempos depois, Tôfü abandonou o estilo de caligrafia que simulava escrita chinesa e desenvolveu um estilo pessoal, mais refinado e sensivel ao povo japonês. Sua contribuição foi enaltecida, e ele se tornou um dos caligrafos mais representativos do periodo Heian, influenciando as gerações posteriores. 


\section{REVISÃO DE LITERATURA}

\subsection{A leishmaniose visceral}

A leishmaniose visceral (LV) é uma enfermidade zoonótica causada pelos protozoários tripanosomatídeos do complexo Leishmania (Figura 3). Dentre as subespécies pertencentes a esse complexo, a Leishmania infantum chagasi é a espécie mais comumente envolvida no ciclo da LV nas Américas. Neste continente, o Brasil é a principal zona endêmica de $\mathrm{LV}^{1-3}$. Estima-se que uma população de aproximadamente 360 milhões de pessoas estão expostas ao risco de infecção por LV no globo terrestre. Cerca de dois milhões se infectam anualmente, fazendo uma prevalência anual de 12 milhões de pessoas infectadas. Hoje, a Organização Mundial da Saúde (OMS) reconhece a leishmaniose como um grande problema de saúde pública mundial, sendo notificada por 27 países do dito Novo Mundo e 67 países nos continentes do Velho Mundo ${ }^{3,11}$.

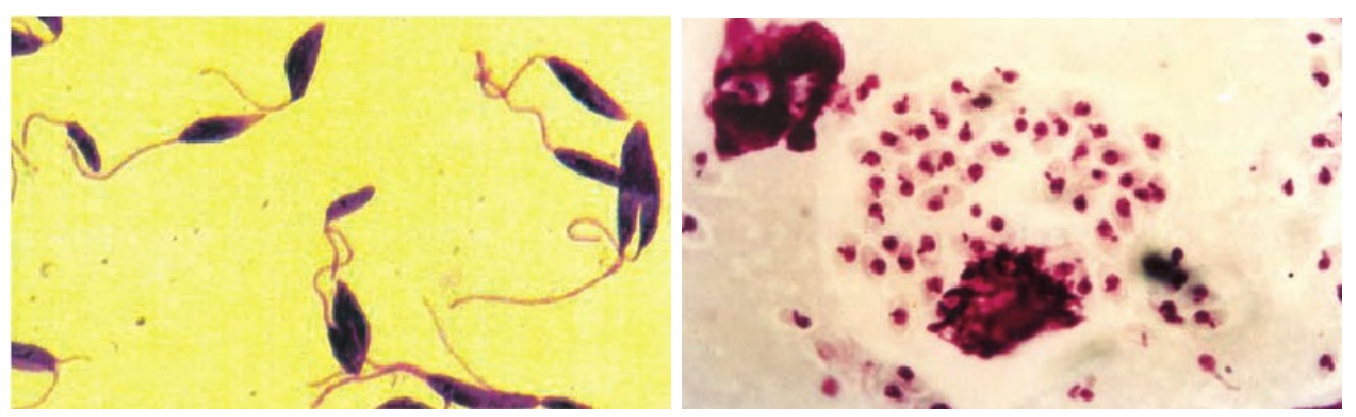

Figura 3 - Ilustração da Leishmania infantum chagasi. Na esquerda, o parasita na forma promastigota. Na direita, a forma amastigota. Fonte: Ministério da Saúde ${ }^{8}$.

A LV é transmitida ao homem e aos animais por meio da picada de fêmeas de flebotomíneos da espécie Lutzomyia longipalpis (Figura 4) e Lutzomyia cruzi (específico no estado do Mato Grosso e do Mato Grosso do Sul), conhecidos popularmente como ${ }^{12}$ : mosquito-palha, birigui, asa branca, tatuquira e cangalhinha. Estas fêmeas albergam em 
seu tubo digestivo o parasita na forma promastigota (forma flagelada) e são hematófagas obrigatórias $^{13}$.

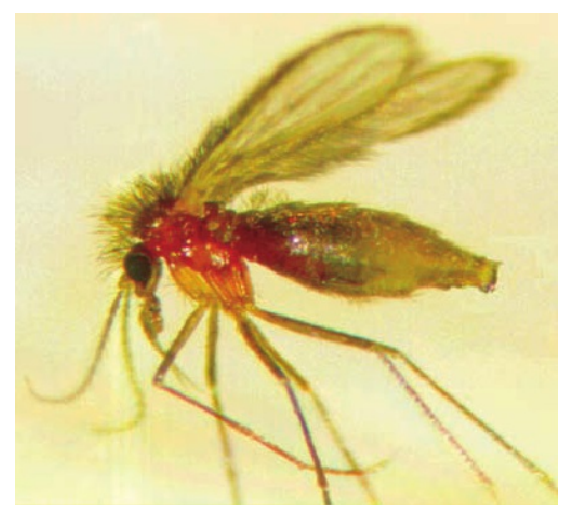

Figura 4 - Ilustração da fêmea do Lutzomyia longipalpis. Fonte: Ministério da Saúde ${ }^{8}$.

Para realizar o repasto sanguíneo, o vetor se alimenta do sangue de um hospedeiro vertebrado. Assim, as formas promastigotas são inoculadas no hospedeiro e são fagocitadas por células do sistema fagocítico mononuclear (SFM). Nelas, os promastigotas se transformam em amastigotas, onde se multiplicam até rompê-las para serem fagocitadas por novas células do SFM. Este processo se repete no organismo hospedeiro ${ }^{1,14}$. Por outro lado, caso um flebotomíneo sadio pique um vetebrado infectado, ele se alimentará do sangue contendo células do SFM parasitadas pelas formas amastigotas. Consequentemente, essas formas amastigotas, ao chegarem no tubo digestivo do flebotomíneo, transformam-se em promastigotas, que se multiplicam (diferenciando-se nas formas infectivas) e são inoculadas por ocasião de um novo repasto sanguíneo sobre outro hospedeiro vertebrado não infectado (ser humano ou outro reservatório), reiniciando o ciclo ${ }^{14}$.

Os hospedeiros vertebrados da $L$. $i$. chagasi, de acordo com o Ministério da Saúde ${ }^{8}$, são o ser humano, o cão doméstico (Canis familiaris), as raposas (Dusicyon vetulus e Cerdocyon thous) e o gambá-de-orelha-branca (Didelphis albiventris). O cão doméstico é considerado o principal reservatório no meio urbano, enquanto que as raposas e o gambá-de-orelha-branca são os reservatórios mais importantes para o meio silvestre.

O ser humano picado pelo vetor infectado passa a ter promastigotas inoculados em sua pele. Neste local, algumas das células do SFM parasitadas podem chegar até as 
vísceras (principalmente baço e fígado) por meio da corrente sanguínea. Em suma, o parasita invade o sistema retículo-endotelial, levando a uma retículo-endoteliose ${ }^{1}$. Assim, no quadro clássico da doença as manifestações clínicas são bastante exacerbadas, caracterizadas por hepatoesplenomegalia volumosa, febre e comprometimento do estado geral, perda de peso progressiva, anorexia e astenia. As alterações laboratoriais mais proeminentes são: anemia, leucopenia e/ou plaquetopenia e hipergamaglobulinemia ${ }^{14}$ (Figura 5). Estas manifestações clínicas surgem dentro de um intervalo de tempo muito variável (período de incubação variável). Em média, este tempo é de 2 a 6 meses, mas pode haver casos que levem de 10 dias a vários anos ${ }^{1,12,14}$.
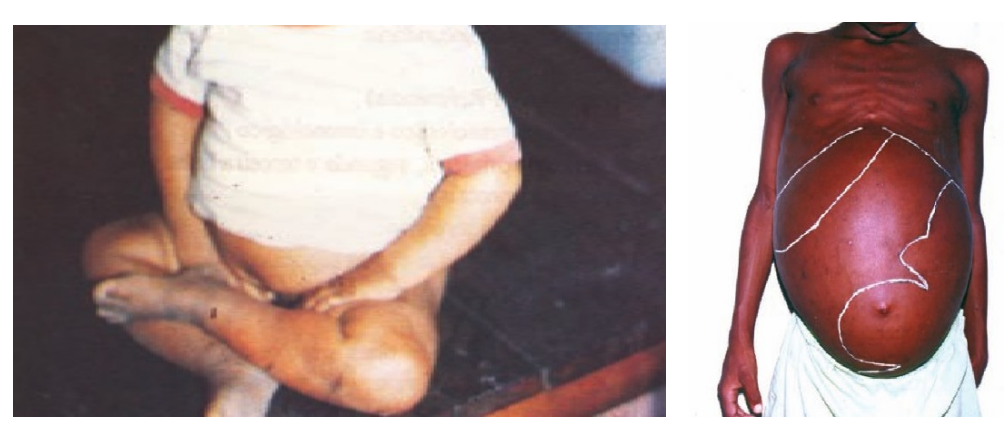

Figura 5 - Ilustração da sintomatologia clínica característica para leishmaniose visceral em humanos. Na figura da direita, criança com sinais e sintomas clínicos da forma oligossintomática. Na figura esquerda, paciente apresentando a doença em evolução final. Fonte: Ministério da Saúde ${ }^{8}$.

Por outro lado, o cão infectado também apresenta um período de incubação variado. Em média, esse período dura de 3 a 7 meses, mas pode levar vários anos ${ }^{1,12}$. Entretanto, diferentemente do ser humano que apresenta sinais e sintomas clínicos a nível visceral, no cão, as lesões cutâneas são mais frequentes e aparentes. Essas lesões consistem em áreas de alopecia, com descamação eczematosa, principalmente ao redor dos olhos (aspecto de "óculos"), nas articulações e pregas de pele. Além dessas lesões cutâneas, ocorrem com frequência: conjuntivite, queratite, anemia e o crescimento exagerado das unhas (onicogrifose), que é um sinal patognomônico dos cães para a infeção por leishmaniose $^{15}$ (Figura 6). Ressalta-se ainda as evidências de resistência do cão frente à infecção crônica por leishmaniose canina ${ }^{16-18}$. 

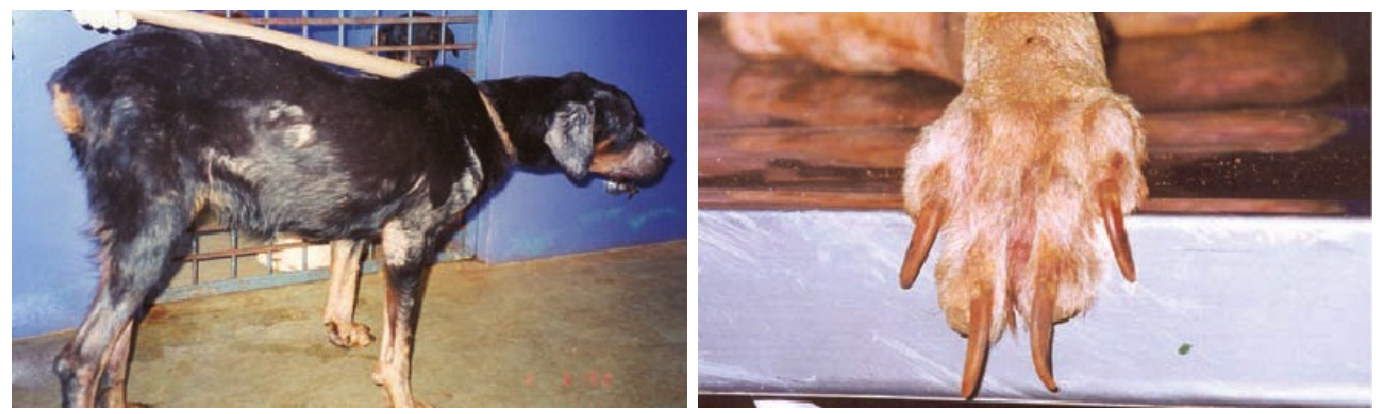

Figura 6 - Ilustração da sintomatologia clínica característica para leishmaniose canina. Na figura da direita, cão com sinais e sintomas clínicos clássicos para leishmaniose canina. Na figura da esquerda, crescimento exagerado das unhas (sinal patognomônico para leishmaniose canina), Fonte: Ministério da Saúde ${ }^{8}$.

Visto que a LV pode gerar um alto impacto negativo em saúde pública, medidas preventivas e de controle são necessárias. No Brasil, o Ministério da Saúde ${ }^{8}$ ressalta medidas preventivas em três níveis: aquelas dirigidas à população humana (como o uso de mosquiteiro com malha fina, telagem de portas e janelas, uso de repelentes), ao vetor (como a limpeza de quintais, terrenos e praças públicas) e à população canina (como o controle da população canina errante, uso de telas em canis individuais ou coletivos e de coleiras impregnadas com deltametrina à 4\%). Por outro lado, como medidas de controle, o Ministério da Saúde ${ }^{8}$ destaca que as estratégias estão centradas no diagnóstico e no tratamento precoce dos casos humanos, na redução da população de flebotomíneos, na eliminação dos reservatórios (cães) e nas atividades de educação em saúde.

\subsection{Aspectos relacionados às estratégias de controle preventivo}

Apesar da grande importância da leishmaniose visceral como um problema de saúde pública, tem se observado pouco desenvolvimento em estratégias para controlála. Este fato também pode ser reflexo da pouca atenção dada a doenças relacionadas à pobreza. Assim, o desenvolvimento de novas estratégias e tecnologias que auxiliem no controle da difusão da doença em pauta e na redução do seu impacto na sociedade tem sido fundamental ${ }^{19}$.

A necessidade de estudos que apontem para a otimização do controle da leishmaniose visceral é evidente segundo a literatura disponível. Há necessidade de estudos que 
apresentem informações sobre (1) as espécies de Leishmania específicas por localidade; (2) as diferentes espécies de vetores e os potenciais hospedeiros; (3) o perfil de resistência a medicamentos; (4) características socio-demográficas locais. Por ser uma doença transmitida por vetores, o seu controle é extremamente complexo e tem se baseado no controle da transmissão (incluindo o uso de vacinas), em técnicas de diagnósticos e em tratamento humano ${ }^{19}$.

Mesmo com a publicação de manuais de controle da leishmaniose visceral e com os investimentos aplicados na organização de serviços e no desenvolvimento de atividades preventivas e de controle da doença, os vetores e os reservatórios em áreas urbanas continuam sendo os maiores desafios para os programas de controle, dada (1) à necessidade por melhor compreensão do comportamento do vetor no meio urbano; (2) às dificuldades operacionais para realizar atividades em tempo suficiente para obter resultados de impacto; e (3) dado ao custo envolvido nessas atividades ${ }^{2,20}$. Embora no Brasil a estratégia de controle oficial ${ }^{8}$ se apoie na eliminação de cães positivos e no controle vetorial, outras estratégias alternativas são apresentadas na literatura ${ }^{10,20}$.

Entre as estratégias preventivas que consideraremos neste trabalho, temos (1) a eliminação de cães positivos, (2) o controle vetorial, (3) o uso de coleiras impregnadas com inseticida, (4) a vacinação canina e (5) o tratamento canino.

\subsubsection{Eliminação de cães positivos}

A eliminação de cães positivos é a estratégia oficial de controle da leishmaniose visceral no Brasil ${ }^{8}$. Todos os cães reagentes aos métodos de diagnósticos oficiais devem ser sacrificados. Atualmente, os métodos de diagnóstico oficiais são a reação de imuno fluorescência indireta (RIFI) e o ensaio imunoenzimático (ELISA). Essas duas técnicas sorológicas são recomendadas pelo Ministério da Saúde para avaliação da soroprevalência em inquéritos caninos amostrais e censitários. Assim, o ELISA é recomendado para a triagem de cães e a RIFI para a confirmação dos cães sororreagentes ao teste ELISA. A RIFI também é utilizada como técnica diagnóstica de rotina. 


\subsubsection{Controle vetorial}

As medidas referentes ao controle vetorial basicamente se concentram no manejo ambiental e no controle químico ${ }^{8}$. O manejo ambiental se refere às atividades de limpeza de quintais, terrenos e praças públicas, a fim de alterar as condições do meio, evitando o estabelecimento de criadouros de formas imaturas do vetor. Já o controle químico é a estratégia que atua por meio da utilização de inseticidas de ação residual e é recomendada no âmbito da proteção coletiva. Esta medida é dirigida apenas para o inseto adulto e tem como objetivo evitar e/ou reduzir o contato entre o inseto transmissor e a população humana, diminuindo o risco de transmissão da doença.

\subsubsection{Coleira impregnada com inseticida (deltametrina 4\%)}

O uso de coleiras impregnadas com inseticida é uma estratégia bem relatada na literatura e tem apresentado bons resultados ${ }^{20-23}$. As coleiras impregnadas com inseticida atuam repelindo o vetor, diminuindo a probabilidade de picadas do mosquito sobre o cão. E também, a coleira apresenta efeito letal para os flebotomíneos ${ }^{23}$, por impregnar inseticida sobre a superície corpórea do cão. Em média, o tempo de ação do colar é de 5 a 9 meses $^{23,24}$.

\subsubsection{Vacinação canina}

O desenvolvimento de vacinas caninas também tem sido relatado ${ }^{5,20,25,26}$ e tem apresentado resultados promissores. Entretanto, o uso dessa vacina em saúde pública ainda é restrito no Brasil, devido à falta de estudos conclusivos em relação aos impactos populacionais $^{8,27,28}$. Para o modelo matemático desenvolvido neste estudo, consideraremos que a vacina em questão é composta por um antígeno A2, uma proteína recombinante específica da forma amastigota de diferentes espécies Leishmania, contendo saponina 
como adjuvante ${ }^{26}$. Por hipótese, consideraremos que não é possível distinguir os anticorpos produzidos pelo efeito da vacina por aqueles causados pelo processo infeccioso.

\subsubsection{Tratamento canino}

Poderíamos adotar também a ação do tratamento canino como uma estratégia de controle, por ele diminuir a densidade de cães considerados fonte de infecção. Ainda, alguns autores afirmam que o tratamento canino diminui a carga parasitária e, consequentemente, diminui a infectividade dos cães infectados aos mosquitos ${ }^{27}$. Assim, assumiremos o protocolo de tratamento apresentado por Miró et al. ${ }^{29}$, em que foi relatado eficácia média de aproximadamente 0,85 na não-obtenção (por xenodiagnóstico) de flebotomíneos infectados a partir de cães tratados. Apesar do resultado positivo deste trabalho e de alguns países ${ }^{30-32}$ permitirem o tratamento canino, no Brasil, esta conduta não é recomendada ${ }^{8}$.

\subsection{Epidemiologia e Modelagem Matemática}

A física é a mais fundamental das disciplinas. Estas incluem direta ou indiretamente a filosofia natural que envolve aquela. Portanto, a física tem influência sobre o desenvolvimento científico e tem auxiliado na compreensão dos fenômenos naturais. Na realidade, tais fenômenos são, em geral, extremamente complexos, sendo impossível analisá-los em todos os seus detalhes. Consequentemente, nós deveremos nos limitar a analisar esses fenômenos dentro das questões minimamente essenciais. Se estas questões forem capazes de proporcionar uma descrição satisfatória do fenômeno, então seremos capazes de compreendê-lo ${ }^{33,34}$.

Assim, compreender o fenômeno está vinculado à análise e à discussão de uma forma a representá-lo, mimetizando-o. Ao mimetizarmos um fenômeno, estaremos lidando com um modelo ${ }^{35}$. Os modelos computacionais e os modelos matemáticos são exemplos de categorias de modelos usados como ferramenta de análise. Por hora, nosso 
interesse se limita aos modelos matemáticos.

Inicialmente, vamos definir a idéia de modelo matemático e o processo de modelagem. Por modelo matemático podemos entender como a representação de um fenômeno, baseado na utilização de componentes quantitativos. Já o processo de modelagem consiste em uma série de atividades complexas associadas ao desenho de modelos representando o mundo real e a sua solução ${ }^{36}$. Logo, por meio da modelagem matemática é possível descrever fenômenos (ou sistemas reais complexos) de diversas naturezas, incluindo aqueles provenientes da biologia e da medicina. E, no caso da medicina, os modelos matemáticos têm sido aplicados na epidemiologia, com enfoque nos estudos sobre a dinâmica de doenças infecciosas ${ }^{37,38}$.

Ao estudarmos a dinâmica das doenças infecciosas por meio de modelos matemáticos, podemos nos basear em duas abordagens. Em uma delas, o modelo é construído a partir de um conjunto de dados, sem considerar a história natural da doença sobre a população. Nesse caso, o modelo é construído a partir da tendência apresentada pelos dados, determinando a sua estrutura a partir de uma família de modelos previamente conhecidos. Na outra abordagem, o processo contrário: a elaboração do modelo incorpora a física e a história natural da doença estudada. Portanto, nesse caso, o modelo procura imitar a realidade. Esta segunda abordagem, que representa os modelos estruturados, é elaborada a partir de um sistema de equações diferenciais (ou de diferença). Utilizando estas equações, espera-se reproduzir a dinâmica das doenças da forma mais precisa possível. Consequentemente, elas podem ser submetidas a análises de caráter preditivo e para fins de controle, de tomadas de decisão e de otimização de processos $^{36,38,39}$.

Em suma, a idéia de se modelar fenômenos é muito comum em física, visto que os físicos são hábeis em abstrair, desenhar modelos e simular fenômenos ${ }^{40}$. Assim, simular a dinâmica de uma doença infecciosa em uma população é uma forma de analisar e compreender a realidade envolvida nesse processo. Portanto, é possível sugerir métodos de controle e avaliar a sua eficácia.

Atualmente, as técnicas de modelagem matemática em epidemiologia abordam uma grande variedade de métodos matemáticos ${ }^{41}$. Logo, conhecer novos métodos ma- 
temáticos é fundamental não apenas para termos mais opções de análise, mas também para aprimorar os modelos e torná-los mais realistas ${ }^{39,42}$.

\subsection{A otimização do controle da leishmaniose visceral}

Com base em um modelo matemático para a dinâmica das doenças infecciosas, pode se avaliar os métodos de controle por meio de simulações computacionais ${ }^{10,43-46}$. A avaliação dos cenários significaria analisar diferentes combinações de valores dos parâmetros relacionados ao controle da doença. Consequentemente, seria bastante natural chegarmos a um cenário (ou combinação de parâmetros) tal que conseguiríamos a melhor eficácia em termos de controle. Entretanto, além desse resultado não ser obrigatoriamente factível, ele poderia ser conseguido de forma totalmente empírica. Portanto, é interessante considerarmos os resultados dentro de restrições práticas e reais. Dentro de tais limitações é que devemos encontrar o ponto de otimização da eficácia do controle.

Em resumo, temos que otimizar a estratégia de controle da doença dentro dos limites impostos pela realidade prática. Isso significa que devemos distribuir recursos limitados entre atividades que estão competindo por elas da melhor maneira possível (isto é, da maneira ótima).

\subsection{A avaliação econômica em saúde}

A leishmaniose visceral (LV) está entre as seis principais doenças tropicais negligenciadas, segundo a Organização Mundial de Saúde (OMS). Se não tratada a tempo, ela pode ser altamente danosa, causando desde o prejuízo no desenvolvimento econômico de países em desenvolvimento ou até mesmo a morte ${ }^{47}$. Em especial, o Brasil detém cerca de $90 \%$ dos casos de LV na América Latina ${ }^{20,48}$.

Segundo dados epidemiológicos emitidos pelo Ministério da Saúde (MS), apesar de a região Nordeste concentrar a maioria dos casos de LV, desde o ano 2000 tem sido ob- 
servado que a doença vem se expandindo para as regiões Norte, Sudeste e Centro Oeste ${ }^{49}$ (Figura 7).

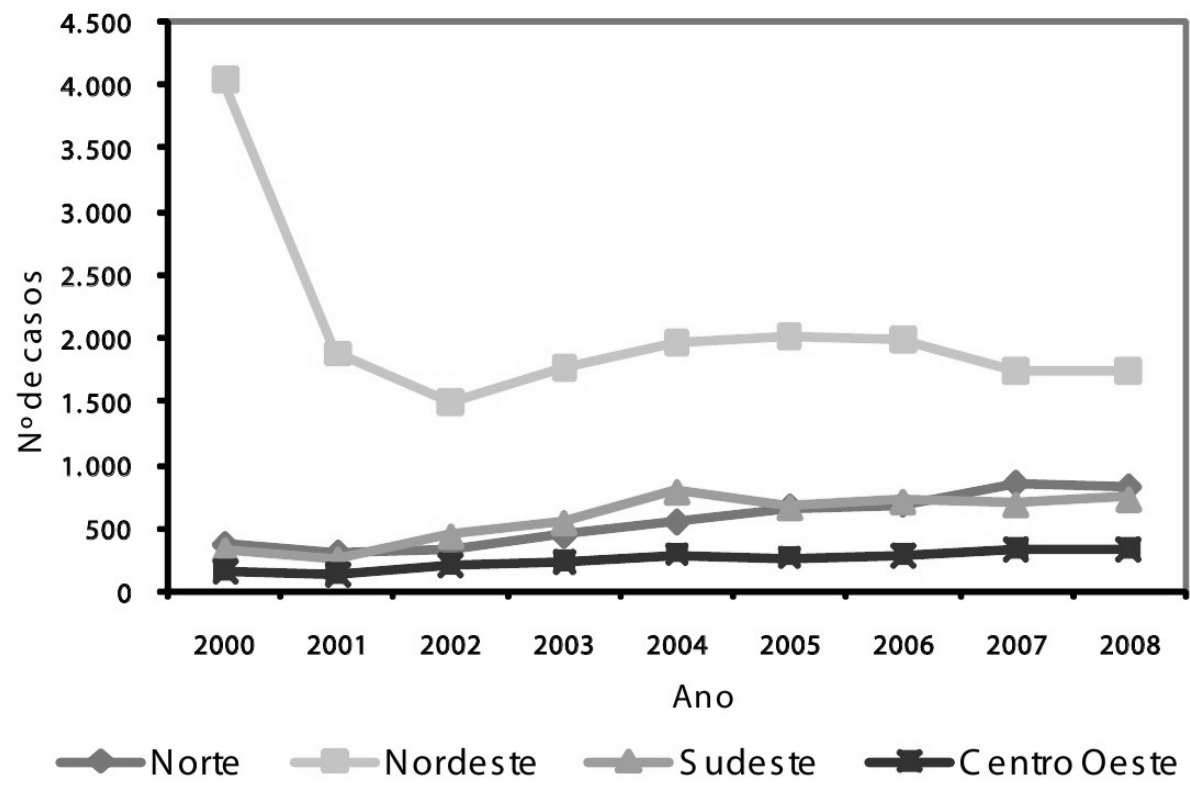

Figura 7 - Casos de LV, segundo a região de residência. Brasil, 2000 a 2008. Fonte: Boletim Eletrônico Epidemiológico ${ }^{49}$.

Diante deste cenário de expansão da doença, um grande desafio para os gestores de saúde é o crescente número de casos de LV em área urbana, pois, além das dificuldades operacionais na realização das ações de vigilância e controle, destaca-se o elevado custo $^{20,49}$. Além disso, a disponibilidade de novos tratamentos tem sido limitada e a escassez de novas estratégias para gerir esta doença (em termos de controle, diagnóstico e tratamento) ressalta a importância de se avaliar as tecnologias já existentes no mercado e de se prever cenários que incorporem novas tecnologias ${ }^{19}$.

A saúde não é habitualmente analisada (pelos profissionais de saúde) como uma atividade econômica. Entretanto, a análise econômica em saúde é importante para a compreensão da dinâmica e das tendências dos sistemas de saúde. A partir dos resultados dessas análises, obtém-se subsídios para a formulação, a implementação e o acompanhamento de políticas setoriais. Em suma, a economia da saúde reflete o desejo universal de alcançar o melhor investimento não apenas em termos de efetividade clínica, mas também na abordagem custo-efetividade sobre a prestação dos cuidados à saúde ${ }^{50-52}$. 
Há varias maneiras de se desenvolver uma análise econômica. A maneira mais simples é a análise de custo-minimização. Este tipo de análise consiste em comparar apenas os custos relacionados ao uso de uma nova tecnologia com a de uma alternativa e verificar qual é a opção de menor custo. Um outro tipo de análise é a de custo-efetividade. Nesta análise, uma comparação de várias opções de tecnologias são tomadas e os custos são medidos em unidades monetárias. Em seguida, os resultados dessa análise de custoefetividade são apresentados em termos de unidades naturais (não-monetárias), como por exemplo, o DALY (disability-adjusted life years, ou, em português, anos de vida ajustados por incapacidade $)^{19}$.

Na revisão de literatura elaborada por Marinho et al. ${ }^{19}$, os 14 artigos selecionados para compor a revisão foram publicados entre 1996 a 2012. Desses apenas um é proveniente do continente americano (Brasil) ${ }^{53}$, enquanto que 7 são originários da Índia. Os estudos de custo-efetividade foram os mais frequentes, representando 7 (50\%) dos 14 estudos. Considerando os tipos de tecnologias analisadas, encontrou-se um foco maior sobre a aplicação de drogas (ainda que exista poucos estudos discorrendo sobre as drogas mais recentes disponíveis). Tecnologias para a avaliação de métodos de diagnóstico também foram destacados, sendo apenas dois artigos comentando sobre o novo teste rápido para o diagnóstico de leishmaniose visceral. É também importante salientar que as tecnologias que abordam a transmissão da leishmaniose visceral têm sido pouco discutidas na literatura. Com relação a estudos que enfatizam a transmissão, foi encontrado apenas um artigo sobre o custo-da-doença (traduzido do inglês "cost-of-illness") que considerou o uso de inseticidas. Houve também uma análise de custo-eficácia das vacinas, em que foi possível visualizá-la apenas pela simulação de cenários ${ }^{19,54}$.

Akhavan ${ }^{53}$ desenvolveu um estudo que analisou o custo-efetividade contido na prevenção da leishmaniose visceral no Brasil. Durante os anos de 1989 a 1996, foram comparados os gastos evitados ou prevenidos com os recursos utilizados no controle e na prevenção da leishmaniose visceral pelo Projeto de Controle de Endemias do Nordeste (PCDEN). Os custos foram definidos como os recursos usados para prevenir e controlar a endemia (tratamento precoce, prevenção e educação), enquanto que benefícios referiam- 
se aos gastos necessários na ausência de prevenção ou controle (tratamento curativo ou paliativo de complicações). Logo, neste período, o total de gastos médico-hospitalares evitados pela prevenção de casos de calazar no Nordeste e Minas Gerais foi de aproximadamente USD 362.787,00. Um estudo similar foi desenvolvido por Adhikari e Supakankunti ${ }^{55}$ no Nepal, onde foi analisado o possível custo-benefício da eliminação da leishmaniose visceral de 2003 a 2015. Neste estudo, o benefício líquido foi estimado em USD 67,18 milhões.

Assim como o Brasil, a Índia também é um dos países mais afetados pela leishmaniose visceral e tem registrado uma das taxas de incidência mais alta do mundo ${ }^{19}$. Lee et al. ${ }^{54}$ desenvolveram uma simulação computacional para avaliar o custo-efetividade da introdução de uma vacina humana no estado de Bihar (Índia). Segundo os resultados deste estudo, mesmo para cenários onde a eficácia da vacina foi abaixo de 0,25 , houve substancial benefício econômico. Além disso, a introdução de vacinas humanas poderia ser uma alternativa muito valiosa em localidades como Bihar, onde a resistência aos medicamentos de primeira linha (como o antimônio pentavalente) tem surgido como resultado do uso longo e repetido. Contudo, ainda há necessidade de estudos que demonstrem a eficácia da vacinação em campo.

Ainda referente a análises econômicas sobre a aplicação de estratégias de controle, podemos considerar o trabalho de Das et al. ${ }^{56}$, a respeito da análise econômica do controle vetorial em Nepal e Bangladesh. Segundo os resultados deste estudo, o custo médio do controle vetorial por casa/ano foi em torno de USD 20, 00 e foi destacado como de alto custo-efetividade. Já Camargo-Neves ${ }^{57,58}$ desenvolveu dois estudos avaliando estratégias de controle preventivas para a leishmaniose visceral. Em um deles, foi analisado o impacto do controle vetorial e a eliminação de cães positivos ${ }^{57}$ no município de Araçatuba/SP, em que a estratégia de se eliminar cães foi considerada economicamente mais favorável (enquanto o controle da fonte de infecção canina apresentou o custo entre USD 3.045, 07 a USD 3.572, 82, a borrifação custou USD 11.186, 17 e o manejo ambiental, USD 4815,38). Em outro estudo, realizado em Andradina/SP ${ }^{23,58}$, ao se comparar o custo-efetividade da combinação entre a eliminação de cães e o uso de coleiras impreg- 
nadas com deltametrina $4 \%$ e a eliminação de cães com o controle vetorial, concluiu-se que a primeira estratégia apresentou melhor resultado de custo-efetividade, sendo o custo em torno de USD 5.000, 00 .

É possível também encontrar referências a estudos de análise econômica relativos aos custos do tratamento humano da leishmaniose visceral ${ }^{59}$ e à intervenção de testes de diagnósticos ${ }^{60}$. Entretanto, apesar dos benefícios de técnicas diagnósticas mais eficazes e de protocolos de tratamentos inovadores, ainda é mais econômico investir em atividades preventivas.

Segundo Marinho et al. ${ }^{19}$, poucos trabalhos têm se referido ao impacto econômico da leishmaniose visceral considerando a abordagem social e coletiva. Além disso, há muitas dificuldades em se avaliar economicamente o controle da transmissão devido (1) ao intervalo entre a invervenção e o impacto epidemiológico ou (2) à dificuldade de relacionar a intervenção ao impacto ${ }^{19}$. Diante dessas dificuldades e dessas questões ainda em aberto sobre a dinâmica e o impacto da leishmaniose visceral, a utilização de modelos matemáticos torna-se uma alternativa muito interessante.

Mesmo que o resultado de um modelo matemático indique a viabilidade epidemiológica para o controle da leishmaniose visceral, devemos avaliar criteriosamente a viabilidade prática e econômica. Neste caso, em se tratando de saúde pública, sabemos que as ações de controle de doenças devem procurar a melhor relação custo-benefício, visto que os recursos disponíveis são (via de regra) limitados. Sabemos também que é importante atentarmos às relações tempo-resposta e aplicabilidade-praticidade. Isto é, a relação entre o tempo de investimento e de aplicação de um método, e do respectivo retorno esperado. No caso da epidemiologia da leishmaniose visceral, a variável "tempo"é especialmente importante, visto que dados recentes têm apontado que esta doença está em franca expansão ${ }^{4,8}$.

Aqui em nosso estudo, ressaltamos que a proposta original é otimizar o controle da leishmaniose visceral. Esta otimização deverá ser demonstrada por meio da estimativa dos pontos (cenários) ótimos relacionados aos 5 métodos de controle (em relação ao cão teríamos o sacrifício, o uso de coleiras repelentes, a vacinação, o tratamento; em relação 
ao vetor, poderíamos considerar o seu controle populacional). Portanto, estamos lidando com otimização de metas. Por meta, podemos entender como a obtenção de um novo processo logístico que otimize resultados ${ }^{61-63}$. Dentro desse ponto de vista, poucos estudos têm propostos novos métodos para encontrar dinâmicas de políticas de saúde ótimas para epidemias $^{63}$.

Uma abordagem alternativa em se tratando de otimização em saúde é a análise de custo ou da relação custo-benefício. Como exemplo, citaremos os trabalhos de Edmunds e Postma ${ }^{64}$ e Chaiyakunapruk et al. ${ }^{65}$. Em ambos os trabalhos são avaliados o custobenefício da aplicação de vacinas. Em se tratando de vacinas, fatores como o custo (preço e número de doses), a eficácia da vacina, o público alvo (por exemplo, se são crianças ou adultos) e os parâmetros epidemiológicos são decisivos na tomada de decisão a respeito da aplicação ou não da vacina. Além disso, o impacto da vacinação deve ser avaliada em termos populacionais, e não a nível individual ${ }^{64,65}$.

Para finalizar, destacamos que, apesar de haver estudos internacionais sobre economia da saúde anteriores a 1950, no Brasil esta área de pesquisa é considerada recente. Desde 1993 a produção científica sobre este tema vem se institucionalizando, em especial por meio de programas de cooperação técnica entre Reino Unido e Brasil. Ainda assim é necessária maior consolidação desses estudos no Brasil ${ }^{52}$. 


\section{A palavra da mãe}

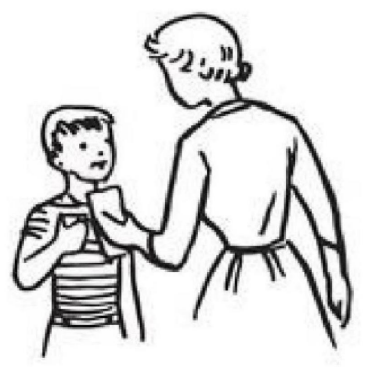

León Gambetta (1838 - 1882) nasceu numa famía de comerciantes pobres e tornou-se um grande politico francês.

Quando completou 15 anos, o pai - levou a uma alfaiataria para afi trabalhar como aprendiz. Menos de seis meses depois, Gambetta voltou para casa. O pai, irascivel, zangou-se e o mandou trabalhar na mercearia da familia.

Ao ver o filho deprimido, a mãe sentiu pena e perguntou por que ele havia abandonado o trabalho de aprendiz de alfaiate. respondeu

"Nõo é trabalho para mim", ele

"Que tipo de trabalho você quer fazer?”, a mãe perguntou.

"Quero ser um grande politico e trabalhar pelo povo".

"Grandes aspirações não levam a nada quando se desiste no meio do caminho", aconselhou a mãe.

"Seguirei adiante mesmo que precise enfrentar muitas dificuldades."

"De quanto você precisa para perseguir seu sonfio?"

"Se tiver trezentos francos, posso ir a Paris e procurar um emprego. Prometo que realizarei o meu plano", disse Gambetta.

"Se está assim tão determinado, darei um jeito de arranjar o dinfeiro", disse a mãe.

com firme e inabalável resolu- ção, ela empenhou-se em ajuntar o dinheiro.

"Aqui estão os trezentos francos", disse ela. "Realize o seu sonho. Gambetta ficou perplexo. "Somos pobres. De onde veío todo esse dinheiro?"

"Um confiecido me emprestou", ela respondeu.

"Ninguém empresta tanto dinheiro assim sem uma garantia."

"Claro. Eu dei uma garantia para conseguir o empréstimo", disse ela.

"Mas não temos nada de valor que sirva de fiança”, protestou o fitho.

"Claro que temos! Dei a minha palavra como fiança. Disse que você será um grande politico e para isso precisa desse dinheiro. Prometi que você realizará os seus objetivos e, assim que você se tornar um estadista, devolverá o dinheiro."

Gambetta ficou emocionado $e$ prometeu a si mesmo que não permitiria que sua mãe fosse vista como uma mentirosa.

Esforçou-se, trabalhou dia $e$ noite, e por fim tornou-se um grande politico na França.

A palavra da mãe pode terminar o rumo do filho.

Mesmo deficada, a mulher possui uma força gigantesca quando se trata de proteger o seu filho.

o homem controla o poder; a muther controla o homem. 


\section{MÉTODOS}

Por se tratar de um estudo teórico, a metodologia consistiu (1) no desenvolvimento do modelo matemático (isto é, na elaboração do sistema de equações diferenciais e na estimativa dos parâmetros/taxas), (2) na estimativa do número de casos humanos notificados por dia, (3) na determinação da expressão do número de reprodutibilidade basal, (4) na análise de sensibilidade dos pontos fixos, (5) na avaliação das taxas ótimas para as estratégias de controle, (6) na análise do custo mínimo.

\subsection{O modelo matemático inicial}

A ideia do nosso modelo está baseada nos trabalhos publicados por Burattini et al. ${ }^{9}$ e Ribas et al. ${ }^{10}$. Assim, assumimos que:

1. O sistema envolve uma população de humanos, de cães e de mosquitos (vetor biológico), sendo este último o transmissor da infecção;

2. No total, há onze categorias de sub-populações;

3. As três populações são constantes ao longo do tempo.

O modelo matemático usado neste estudo consiste em um sistema de equações diferenciais, onde algumas delas incorporam termos com atraso (do tipo $g(t-T)$ ). Essas equações representam a população humana (com o índice $h$ ) e a população canina (com o índice $d$ ). Em ambas as populações encontram-se indivíduos suscetíveis (indicados por $x_{i}$ ), latentes (estão infectados, mas não estão clinicamente doentes) $\left(l_{i}\right)$, infectados e clinicamente doentes $\left(y_{i}\right)$ e recuperados $\left(z_{i}\right)$.

Além das populações humana e canina, incluímos também a população de vetores (flebotomíneos), onde $s_{1}$ representa a categoria de indivíduos não infectados; $s_{2}$, a 
categoria de indivíduos infectados, mas não infectivos; e $s_{3}$, a categoria dos indivíduos infectados e infectivos. Portanto, a categoria $s_{3}$ é aquela capaz de infectar humanos e cães suscetíveis.

A Figura 8 representa esquematicamente os compartimentos e os fluxos entre eles. Os parâmetros utilizados estão descritos na Tabela 1 e 2.

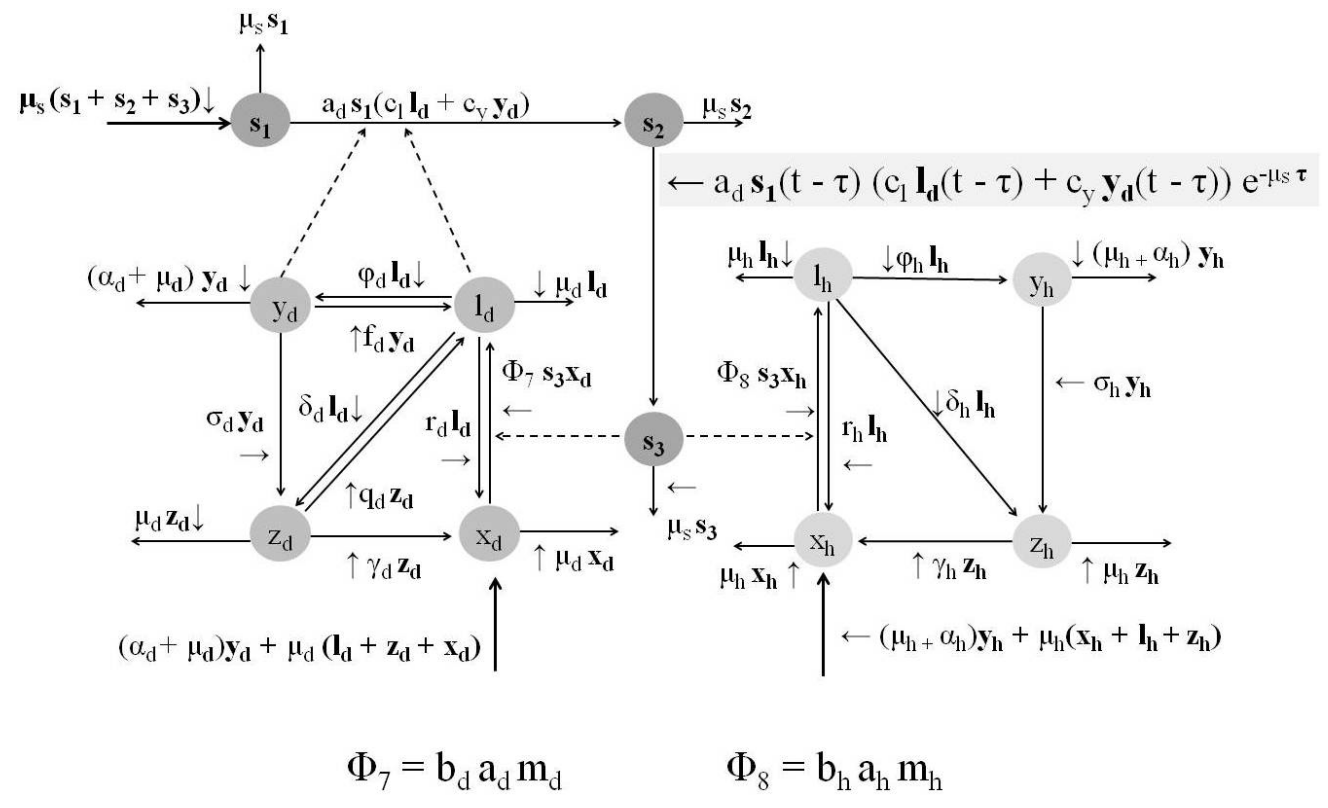

Figura 8 - Representação do modelo compartimental e o fluxograma entre eles.

Com base na Figura 8, o sistema de equações diferenciais para a população humana é representada pelas Eq. (1) a (4).

$$
\begin{aligned}
\dot{x}_{h}(t)= & \mu_{h}\left(l_{h}(t)+y_{h}(t)+z_{h}(t)\right)+r_{h} l_{h}(t)+\alpha_{h} y_{h}(t)+\gamma_{h} z_{h}(t) \\
& -\left(b_{h} a_{h} m_{h} s_{3}(t)\right) x_{h}(t) \\
\dot{l_{h}}(t)= & \left(b_{h} a_{h} m_{h} s_{3}(t)\right) x_{h}(t)-\left(\mu_{h}+r_{h}+\delta_{h}+\varphi_{h}\right) l_{h}(t) \\
\dot{y_{h}}(t)= & \varphi_{h} l_{h}(t)-\left(\mu_{h}+\alpha_{h}+\sigma_{h}\right) y_{h}(t) \\
\dot{z_{h}}(t)= & \delta_{h} l_{h}(t)+\sigma_{h} y_{h}(t)-\left(\mu_{h}+\gamma_{h}\right) z_{h}(t)
\end{aligned}
$$


Tabela 1 - Parâmetros usados no modelo, seus significados biológicos e respectivos valores. Na tabela, $h$ relaciona o parametro para os humanos, $d$ para cães e $s$ para flebotomíneos.

\begin{tabular}{|c|c|c|c|}
\hline Parâmetro & Significado biológico & Fonte & Valor \\
\hline$\mu_{h}$ & Taxa de mortalidade natural & $\mathrm{IBGE}^{66}$ & $3,67 \times 10^{-5} \mathrm{dia}^{-1}$ \\
\hline$\alpha_{h}$ & $\begin{array}{l}\text { Taxa de letalidade calazar es- } \\
\text { pecífica }\end{array}$ & Pearson e Sousa ${ }^{67}$ & $5,48 \times 10^{-3} \mathrm{dia}^{-1}$ \\
\hline$a_{h}$ & Taxa média de picadas diárias & Forattini ${ }^{68}$ & $1,25 \times 10^{-1} \mathrm{dia}^{-1}$ \\
\hline$m_{h}$ & $\begin{array}{l}\text { Densidades de vetores por hos- } \\
\text { pedeiro }\end{array}$ & Camargo-Neves ${ }^{57}$ & 3,62 \\
\hline$w_{h c}$ & $\begin{array}{l}\text { Razão entre habitantes por casa } \\
\text { para Araçatuba/SP }\end{array}$ & IBGE $^{69}$ & 3 \\
\hline$r_{h}$ & Taxa de recuperação espontânea & Badaro et al. ${ }^{70}$ & $5,48 \times 10^{-4} \mathrm{dia}^{-1}$ \\
\hline$\gamma_{h}$ & Taxa de perda de imunidade & $\begin{array}{l}\text { Estimado conforme } \\
\text { Kault e March }\end{array}$ & $5,48 \times 10^{-4} \mathrm{dia}^{-1}$ \\
\hline$\delta_{h}$ & Taxa de recuperação de latentes & Badaro et al. ${ }^{70}$ & $1,10 \times 10^{-2} \mathrm{dia}^{-1}$ \\
\hline$\varphi_{h}$ & Inverso do período de incubação & Pearson e Sousa ${ }^{67}$ & $4,00 \times 10^{-4} \mathrm{dia}^{-1}$ \\
\hline$\sigma_{h}$ & $\begin{array}{l}\text { Taxa de recuperação para imu- } \\
\text { nes }\end{array}$ & Badaró et al. ${ }^{70}$ & $1,81 \times 10^{-3} \mathrm{dia}^{-1}$ \\
\hline$b_{h}$ & Proporção de picadas infectivas & $\begin{array}{l}\text { Molineaux e Gramic- } \\
\text { cia }^{72}\end{array}$ & $1,00 \times 10^{-2}$ \\
\hline$\eta_{h}$ & $\begin{array}{l}\text { Proporção de casos subnotifica- } \\
\text { dos }\end{array}$ & Maia-Elkhoury et al. ${ }^{73}$ & $7,05 \times 10^{-1}$ \\
\hline$\mu_{d}$ & Taxa de mortalidade natural & Selman et al. ${ }^{74}$ & $2,28 \times 10^{-4} \mathrm{dia}^{-1}$ \\
\hline$\alpha_{d}$ & $\begin{array}{l}\text { Taxa de letalidade calazar es- } \\
\text { pecífica }\end{array}$ & Lanotte et al. ${ }^{75}$ & $1,81 \times 10^{-3} \mathrm{dia}^{-1}$ \\
\hline$a_{d}$ & Taxa média de picadas diárias & Forattini $^{68}$ & $1,25 \times 10^{-1} \mathrm{dia}^{-1}$ \\
\hline$w_{d h}$ & $\begin{array}{l}\text { Razão humano:cão para o mu- } \\
\text { nicípio de Araçatuba/SP }\end{array}$ & Andrade et al. ${ }^{76}$ & 5,55 \\
\hline$m_{d}$ & $\begin{array}{l}\text { Densidades de vetores por hos- } \\
\text { pedeiro }\end{array}$ & $\begin{array}{l}\text { Estimado conforme An- } \\
\text { drade et al. }{ }^{76} \text { e Camargo- } \\
\text { Neves }{ }^{57}\end{array}$ & $w_{d h} \times m_{h}=2,01 \times 10^{1}$ \\
\hline$p_{d}$ & $\begin{array}{l}\text { Taxa de perda de imunidade } \\
\text { oferecida pela vacina }\end{array}$ & $\begin{array}{l}\text { Zoetis Brasil }{ }^{77} \text { e Mo- } \\
\text { reira }^{78}\end{array}$ & $2,74 \times 10^{-3}$ \\
\hline$\varphi_{d}$ & Inverso do período de incubação & Lanotte et al. ${ }^{75}$ & $1,10 \times 10^{-3} \mathrm{dia}^{-1}$ \\
\hline$b_{d}$ & Proporção de picadas infectivas & $\begin{array}{l}\text { Molineaux e Gramic- } \\
\text { cia }^{72}\end{array}$ & $1,00 \times 10^{-2}$ \\
\hline$r_{d}$ & Taxa de recuperação espontânea & Lanotte et al. ${ }^{75}$ & $2,74 \times 10^{-4} \mathrm{dia}^{-1}$ \\
\hline$\gamma_{d}$ & $\begin{array}{l}\text { Taxa de perda de imunidade (de } \\
\text { recuperados para suscetíveis) }\end{array}$ & Kault and March ${ }^{71}$ & $2,74 \times 10^{-3} \mathrm{dia}^{-1}$ \\
\hline$\sigma_{d}$ & $\begin{array}{l}\text { Taxa de recuperação de clinica- } \\
\text { mente doentes para imunes }\end{array}$ & Lanotte et al. $^{75}$ & $9,04 \times 10^{-3} \mathrm{dia}^{-1}$ \\
\hline$\delta_{d}$ & Taxa de recuperação de latentes & Lanotte et al. ${ }^{75}$ & $8,22 \times 10^{-3} \mathrm{dia}^{-1}$ \\
\hline$f_{d}$ & $\begin{array}{l}\text { Taxa de recuperação de clinica- } \\
\text { mente doentes para latentes }\end{array}$ & Assumido & 0 \\
\hline
\end{tabular}


Tabela 2 - Parâmetros usados no modelo, seus significados biológicos e respectivos valores. Na tabela, $h$ relaciona o parâmetro para os humanos, $d$ para cães e $s$ para flebotomíneos (Continuação da Tabela 1).

\begin{tabular}{|c|c|c|c|}
\hline Parâmetro & Significado biológico & Fonte & Valor \\
\hline$q_{d}$ & $\begin{array}{l}\text { Taxa de perda de imunidade (re- } \\
\text { cuperados para latentes) }\end{array}$ & Assumido & 0 \\
\hline$\psi_{d}$ & $\begin{array}{l}\text { Proporção de cães que não de- } \\
\text { sistem do tratamento }\end{array}$ & Assumido & 1,0 \\
\hline$u_{c}$ & $\begin{array}{l}\text { Inverso do período de atividade } \\
\text { do colar }\end{array}$ & Scalibor $\circledR^{24}$ & $6,70 \times 10^{-3} \mathrm{dia}^{-1}$ \\
\hline$\zeta_{c}$ & Taxa de perda do colar & Reithinger et al. ${ }^{22}$ & $6,00 \times 10^{-3} \mathrm{dia}^{-1}$ \\
\hline$\mu_{s}$ & Taxa de mortalidade natural & Ministério da Saúde ${ }^{8}$ & $5,00 \times 10^{-2} \mathrm{dia}^{-1}$ \\
\hline$\varepsilon_{v}$ & Eficácia da vacinação & Fernandes et al. ${ }^{26}$ & $9,64 \times 10^{-1}$ \\
\hline$\varepsilon_{c}$ & $\begin{array}{l}\text { Diminuição da taxa de picadas } \\
\text { devido ao uso do colar }\end{array}$ & Halbig et al. ${ }^{21}$ & $8,00 \times 10^{-1} \mathrm{dia}^{-1}$ \\
\hline$\tau$ & Período de incubação extrínseco & Neva e Sacks ${ }^{79}$ & 7,00 dias \\
\hline$c_{l}$ & $\begin{array}{l}\text { Fração de flebotomíneos que } \\
\text { adquirem a infecção após picar } \\
\text { um cão latente }\end{array}$ & Rossi ${ }^{80}$ & $9,30 \times 10^{-1}$ \\
\hline$c_{y}$ & $\begin{array}{l}\text { Fração de flebotomíneos que } \\
\text { adquirem a infecção após picar } \\
\text { um cão clinicamente doente }\end{array}$ & Rossi ${ }^{80}$ & $6,70 \times 10^{-1}$ \\
\hline$c_{k}$ & $\begin{array}{l}\text { Proporção de cães clinicamente } \\
\text { curados, mas que continuam pa- } \\
\text { rasitados }\end{array}$ & Miro et al. ${ }^{29}$ & $1,54 \times 10^{-1}$ \\
\hline
\end{tabular}

O seguinte sistema de equações (Eq. (5) a (8)) representam a dinâmica sobre a população de cães.

$$
\begin{aligned}
\dot{x}_{d}(t)= & \mu_{d}\left(l_{d}(t)+y_{d}(t)+z_{d}(t)\right)+r_{d} l_{d}(t)+\alpha_{d}(t) y_{d}(t)+\gamma_{d} z_{d}(t) \\
& -\left(b_{d} a_{d} m_{d} s_{3}(t)\right) x_{d}(t) \\
\dot{l_{d}}(t)= & b_{d} a_{d} m_{d} s_{3}(t) x_{d}(t)-\left(r_{d}+\delta_{d}+\mu_{d}+\varphi_{d}\right) l_{d}+f_{d} y_{d}+q_{d} z_{d} \\
\dot{y_{d}}(t)= & \varphi_{d} l_{d}(t)-\left(f_{d}+\sigma_{d}+\mu_{d}+\alpha_{d}\right) y_{d}(t) \\
\dot{z_{d}}(t)= & \delta_{d} l_{d}(t)+\sigma_{d} y_{d}(t)-\left(q_{d}+\gamma_{d}+\mu_{d}\right) z_{d}(t)
\end{aligned}
$$

Finalmente, a dinâmica sobre a população de mosquitos é represenada pelas Eq. (9) a (11). 


$$
\begin{aligned}
\dot{s_{1}}(t)= & \mu_{s}\left(s_{2}(t)+s_{3}(t)\right)-a_{d}\left(c_{l} l_{d}(t)+c_{y} y_{d}(t)\right) s_{1}(t) \\
\dot{s_{2}}(t)= & a_{d}\left(c_{l} l_{d}(t)+c_{y} y_{d}(t)\right) s_{1}(t) \\
& -a_{d}\left(c_{l} l_{d}(t-\tau)+c_{y} y_{d}(t-\tau)\right) e^{-\mu_{s} \tau} s_{1}(t-\tau)-\mu_{s} s_{2}(t) \\
\dot{s_{3}}(t)= & a_{d}\left(c_{l} l_{d}(t-\tau)+c_{y} y_{d}(t-\tau)\right) e^{-\mu_{s} \tau} s_{1}(t-\tau)-\mu_{s} s_{3}(t)
\end{aligned}
$$

Os detalhes sobre a elaboração das Eq. (1) a (11) estão no Apêndice. Aqui, daremos uma breve introdução sobre a estrutura delas.

Observe que as Eq. (1) e (5) são similares, diferindo pelo índice $h$ (para humanos) e $d$ (para cães). Note que temos 4 termos lineares e 1 termo não-linear. Cada um desses termos tem um significado biológico (o índice $i$ é o índice genérico que representa tanto $h$ quanto $d)$ :

1. $\mu_{i}\left(l_{i}(t)+y_{i}(t)+z_{i}(t)\right)$ : pela Tabela 1 e 2 , observa-se que o parâmetro $\mu_{i}$ representa a taxa de mortalidade natural. Portanto, dado que os indivíduos da população naturalmente morrem e assumindo que a população se mantém constante, temos que os indivíduos que morrem naturalmente são repostos por novos indivíduos. Assim, este termo representa o nascimento diário de novos indivíduos na população;

2. $r_{i} l_{i}(t)$ : o parâmetro $r_{i}$ significa a taxa de recuperação espontânea de indivíduos latentes para suscetíveis. Logo, este termo representa a quantidade diária de indivíduos latentes que voltam à condição de suscetíveis;

3. $\alpha_{i} y_{i}(t)$ : sendo que $\alpha_{i}$ é a taxa de mortalidade devido à leismaniose visceral, temos que este termo representa a quantidade diária de indivíduos doentes que morreram pela doença e que estão sendo numericamente repostos por novos indivíduos na população;

4. $\gamma_{i} z_{i}(t)$ : dado que $\gamma_{i}$ é a taxa de perda de imunidade dos indivíduos recuperados (imunes), este termo representa o número de indivíduos que 
perdem a condição de resistentes e que voltam a se tornar suscetíveis;

5. $b_{i} a_{i} m_{i} s_{3}(t) x_{i}(t)$ : tendo em mente que $b_{i} a_{i} m_{i}$ representa o funcional para a taxa de contato $\beta^{38,81}$, temos que este termo representa o número de indivíduos que se infectam por dia, migrando da categoria de suscetíveis para a de infectados (latentes). Note que este termo é proporcional a fração de vetores infectivos $\left(s_{3}\right)$. Portanto, quanto maior a proporção dessa categoria de mosquitos, maior é a probabilidade de se adquirir a infecção.

E, para exemplificarmos a dinâmica referente à população de vetores, comentaremos brevemente sobre a Eq. (9).

1. $\mu_{s}\left(s_{2}(t)+s_{3}(t)\right)$ : trata-se da mesma ideia comentada para humanos e cães com relação à mortalidade natural;

2. $a_{d}\left(c_{l} l_{d}(t)+c_{y} y_{d}(t)\right) s_{1}(t)$ : neste caso, temos uma ideia muito parecida com a do termo $b_{i} a_{i} m_{i} s_{3}(t) x_{i}(t)$. Porém, este termo representa a quantidade diária de vetores suscetíveis que adquirem a infecção e que se tornam infectados (mas não-infectivos $\left(s_{2}\right)$ ). Note que este termo depende das proporções de cães latentes $\left(l_{d}\right)$ e clinicamente doentes $\left(y_{d}\right)$. Portanto, quanto maior for a proporção de cães nestas categorias, maior será a probabilidade do vetor adquirir a infecção.

Assim, o mesmo raciocínio segue para se compreender a elaboração das demais equações. Cada termo tem um significado biológico e este significado corresponde ao parâmetro (ou ao funcional) que o acompanha.

\subsection{O modelo matemático com as estratégias de controle preventivo}

Este estudo foca o impacto das estratégias de controle preventivo sobre a dinâmica da LV. Portanto, as populações alvo dessas estratégias são a de cães e a de mosquitos 
(vetores). Consequentemente, ao incluirmos tais estratégias em nosso modelo, estamos alterando a dinâmica da doença sobre essas duas populações. Todavia, ressaltamos que o sistema de equações referente à população de humanos se mantém inalterada.

Primeiramente, vamos apresentar quais modificações recaem sobre a população de cães ao introduzirmos as estratégias de controle. Em seguida, comentaremos sobre a população de mosquitos. A Figura 9 representa o fluxograma do modelo modificado.

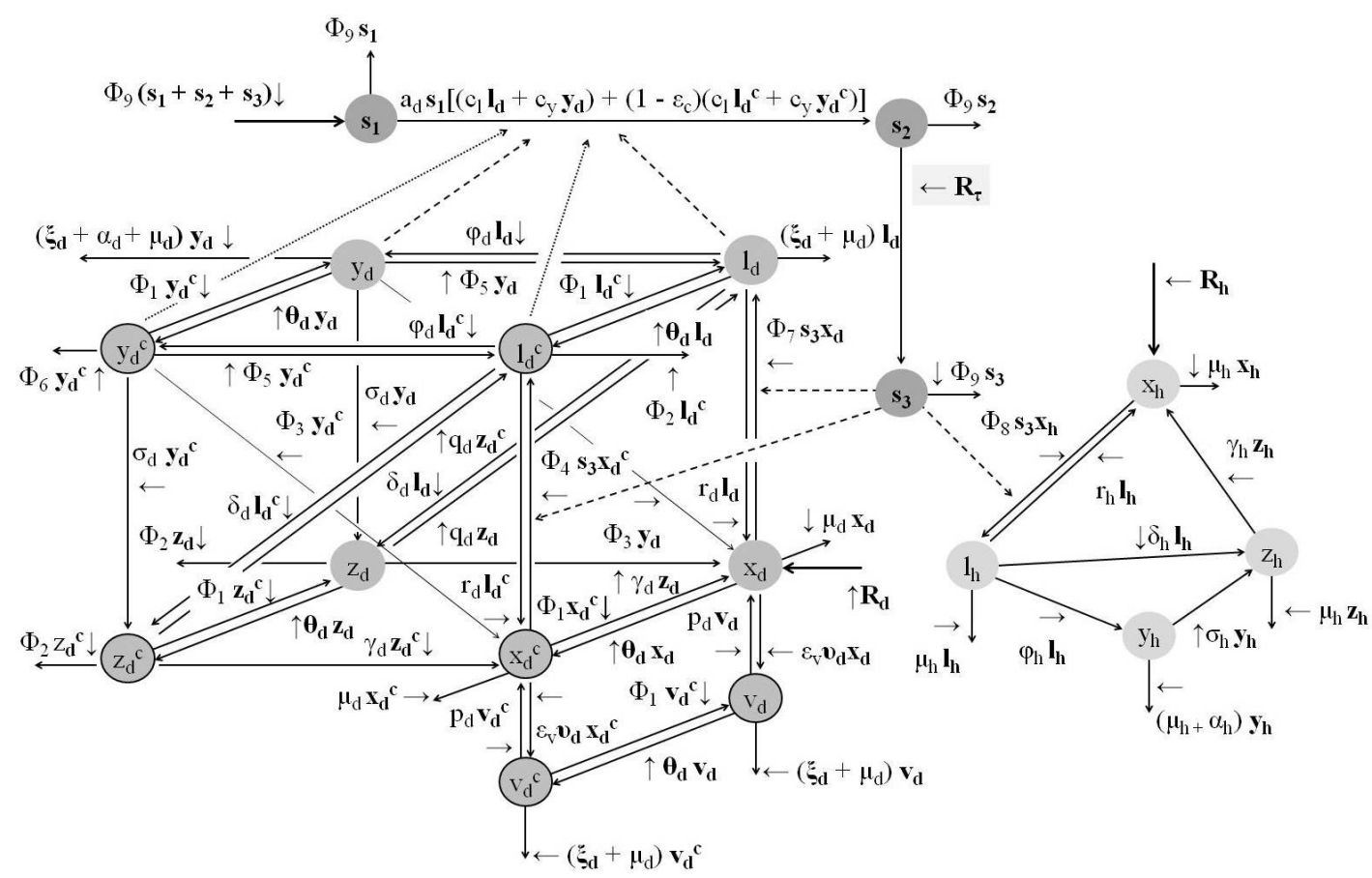

$$
\begin{aligned}
& \mathbf{R}_{\tau}=a_{d} \mathbf{s}_{\mathbf{1}}(\mathbf{t}-\tau)\left[\left(\mathrm{c}_{\mathbf{l}} \mathbf{l}_{\mathbf{d}}(\mathbf{t}-\tau)+\mathrm{c}_{\mathrm{y}} \mathbf{y}_{\mathbf{d}}(\mathbf{t}-\tau)\right)+\left(\mathbf{1}-\varepsilon_{\mathrm{c}}\right)\left(\mathrm{c}_{\mathrm{l}} \mathbf{l}_{\mathbf{d}} \mathbf{c}^{\mathbf{c}}(\mathbf{t}-\tau)+\mathrm{c}_{\mathrm{y}} \mathbf{y}_{\mathbf{d}} \mathbf{c}^{\mathbf{c}}(\mathbf{t}-\tau)\right)\right] \mathrm{e}^{-\left(\mu_{s}+\xi_{s}\right) \tau}
\end{aligned}
$$

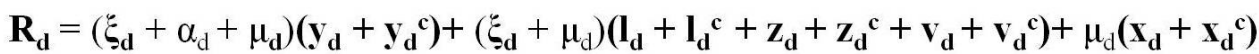

$$
\begin{aligned}
& \mathbf{R}_{\mathbf{h}}=\left(\mu_{\mathrm{h}}+\alpha_{\mathrm{h}}\right) \mathbf{y}_{\mathbf{h}}+\mu_{\mathrm{h}}\left(\mathbf{x}_{\mathbf{h}}+\mathbf{l}_{\mathbf{h}}+\mathbf{z}_{\mathbf{h}}\right) \\
& \Phi_{1}=\left(\mathbf{u}_{\mathrm{c}}+\zeta_{\mathrm{c}}\right) \quad \Phi_{6}=\left(\xi_{\mathrm{d}}+\alpha_{\mathrm{d}}+\mu_{\mathrm{d}}\right) \\
& \Phi_{2}=\left(\xi_{\mathrm{d}}+\mu_{\mathrm{d}}\right) \quad \Phi_{7}=\mathrm{b}_{\mathrm{d}} \mathrm{a}_{\mathrm{d}} \mathrm{m}_{\mathrm{d}} \\
& \Phi_{3}=\left(1-c_{k}\right) \psi_{d} \omega_{d} \quad \Phi_{8}=b_{h} a_{h} m_{h} \\
& \Phi_{4}=b_{\mathrm{d}}\left(1-\varepsilon_{\mathrm{c}}\right) \mathrm{a}_{\mathrm{d}} \mathrm{m}_{\mathrm{d}} \quad \Phi_{9}=\left(\xi_{\mathrm{s}}+\mu_{\mathrm{s}}\right) \\
& \Phi_{5}=\mathrm{f}_{\mathrm{d}}+\mathrm{c}_{\mathrm{k}} \psi_{\mathrm{d}} \omega_{\mathrm{d}}
\end{aligned}
$$

Figura 9 - Representação do modelo compartimental com a inclusão das estratégias de controle.

\subsubsection{Modificações sobre a população de cães}


Quatro das cinco estratégias consideradas neste estudo estão diretamente relacionadas à população canina: (1) eliminação de cães positivos $\left(\xi_{d}\right),(2)$ vacinação $\left(v_{d}\right),(3)$ colar inseticida $\left(\theta_{d}\right),(4)$ tratamento $\left(\omega_{d}\right)$. Antes de descrevermos as modificações que o modelo sofre ao introduzirmos estas estratégias, vamos assumir que:

1. A população canina permanece constante;

2. Há o recrutamento de cães suscetíveis para a reposição de cães elimina$\operatorname{dos}$

3. Todos os cães podem ser vacinados. Entretanto, a vacina apenas surte efeito sobre os cães suscetíveis;

4. Todos os cães podem receber colar. Neste caso, há uma subdivisão de todas as categorias de cães em com e sem colar;

5. Somente os cães clinicamente doentes são submetidos a tratamento. Porém, parte dos cães tratados deixam efetivamente o status de fonte de infecção $\left(1-c_{k}\right)$, passando a migrar para a categoria de suscetíveis. Por outro lado, outra parte mantém o status $\left(c_{k}\right)$, passando a migrar para a categoria de cães latentes.

Diante dessas premissas, nós acrescentamos categorias para cães que utilizam a coleira (indicada pelo índice sobrescrito $C$ ) e para cães vacinados (indicados por $v_{d}$ ) (Figura 9).

Finalmente, a dinâmica sobre a população de cães, considerando as estratégias de controle, é represenada pelas Eq. (12) a (21).

$$
\begin{aligned}
\dot{x}_{d}(t)= & -\left(\varepsilon_{v} v_{d}+\theta_{d}+b_{d} a_{d} m_{d} s_{3}(t)\right) x_{d}(t)+\mu_{d}\left(1-x_{d}(t)\right) \\
& +\xi_{d}\left(1-x_{d}(t)-x_{d}^{C}(t)\right)+\alpha_{d}\left(y_{d}(t)+y_{d}^{C}(t)\right)+\left(1-c_{k}\right) \psi_{d} \omega_{d} y_{d}(t) \\
& +\left(u_{c}+\zeta_{c}\right) x_{d}^{C}(t)+r_{d} l_{d}(t)+p_{d} v_{d}(t)+\gamma_{d} z_{d}(t) \\
\dot{x}_{d}^{C}(t)= & \theta_{d} x_{d}(t)-\left(\varepsilon_{v} v_{d}+\mu_{d}+\zeta_{c}+u_{c}+\left(1-\varepsilon_{c}\right) b_{d} a_{d} m_{d} s_{3}(t)\right) x_{d}^{C}(t) \\
& +r_{d} l_{d}^{C}(t)+\left(1-c_{k}\right) \psi_{d} \omega_{d} y_{d}^{C}(t)+\gamma_{d} z_{d}^{C}(t)+p_{d} v_{d}^{C}(t)
\end{aligned}
$$




$$
\begin{aligned}
\dot{l_{d}}(t)= & b_{d} a_{d} m_{d} s_{3}(t) x_{d}(t)+\left(\zeta_{c}+u_{c}\right) l_{d}^{C}(t)+\left(f_{d}+c_{k} \psi_{d} \omega_{d}\right) y_{d}(t)+q_{d} z_{d}(t) \\
& -\left(\mu_{d}+r_{d}+\delta_{d}+\varphi_{d}+\xi_{d}+\theta_{d}\right) l_{d}(t) \\
\dot{l_{d}}(t)= & \theta_{d} l_{d}(t)+\left(1-\varepsilon_{c}\right) b_{d} a_{d} m_{d} s_{3}(t) x_{d}^{C}(t)+\left(f_{d}+c_{k} \psi_{d} \omega_{d}\right) y_{d}^{C}(t)+q_{d} z_{d}^{C}(t) \\
& -\left(\xi_{d}+\mu_{d}+\zeta_{c}+u_{c}+r_{d}+\delta_{d}+\varphi_{d}\right) l_{d}^{C}(t) \\
\dot{y_{d}}(t)= & \varphi_{d} l_{d}(t)+\left(\zeta_{c}+u_{c}\right) y_{d}^{C}(t)-\left(f_{d}+\mu_{d}+\alpha+\sigma_{d}+\theta_{d}+\xi_{d}+\psi_{d} \omega_{d}\right) y_{d}(t) \\
\dot{y_{d}^{C}}(t)= & \varphi_{d} l_{d}^{C}(t)+\theta_{d} y_{d}(t)-\left(f_{d}+\mu_{d}+\alpha_{d}+\sigma_{d}+\zeta_{c}+u_{c}+\xi_{d}+\psi_{d} \omega_{d}\right) y_{d}^{C}(t) \\
\dot{z_{d}}(t)= & \delta_{d} l_{d}(t)+\sigma_{d} y_{d}(t)+\left(\zeta_{c}+u_{c}\right) z_{d}^{C}(t)-\left(q_{d}+\mu_{d}+\gamma_{d}+\theta_{d}+\xi_{d}\right) z_{d}(t) \\
\dot{z_{d}^{C}}(t)= & \delta_{d} l_{d}^{C}(t)+\sigma_{d} y_{d}^{C}(t)+\theta_{d} z_{d}(t)-\left(q_{d}+\mu_{d}+\gamma_{d}+\zeta+u_{c}+\xi_{d}\right) z_{d}^{C}(t) \\
\dot{v_{d}}(t)= & \varepsilon_{v} v_{d} x_{d}(t)+\left(\zeta_{c}+u_{c}\right) v_{d}^{C}(t)-\left(p_{d}+\mu_{d}+\theta_{d}+\xi_{d}\right) v_{d}(t) \\
\dot{v_{d}^{C}}(t)= & \varepsilon_{v} v_{d} x_{d}^{C}(t)+\theta_{d} v_{d}(t)-\left(p_{d}+\mu_{d}+\zeta_{c}+u_{c}+\xi_{d}\right) v_{d}^{C}(t)
\end{aligned}
$$

\subsubsection{Modificações sobre a população de mosquitos}

Para o caso da nova dinâmica referente à população de vetores, fazemos uma ressalva ao parâmetro $\xi_{s}$, que representa a taxa de mortalidade adicional devido às ações de controle vetorial. Esta taxa é referente à contagem por indivíduos. Entretanto, em termos práticos, é mais simples contabilizar o número de residências tratadas ao invés do número de mosquitos eliminados. Assim, adotamos um cálculo simplificado para estimar o número de mosquitos eliminados por residência.

Considerando que $w_{h c}$ representa a razão entre o número de habitantes por residência e $m_{h}$, a densidade de mosquitos por humano, o produto entre $w_{h c} \times m_{h}$ determina o número de mosquitos por residência. Assim, para uma taxa de tratamento sobre as residências $\xi_{c}$ (onde usamos o índice $c$ de "casa"), o produto $\xi_{c} \times w_{h c} \times m_{h}$ se traduz na es- 
timativa do número de mosquitos eliminados por dia $\left(\xi_{s}\right)($ Eq. (22)). Estamos assumindo que todos os mosquitos de uma residência tratada são eliminados.

$$
\xi_{s}=\xi_{c} \times w_{h c} \times m_{h}
$$

Portanto, o sistema que representa a nova dinâmica sobre a população de mosquitos está representado a seguir (Eq. (23) a (25)).

$$
\begin{aligned}
\dot{s}_{1}(t)= & -a_{d}\left(c_{l} l_{d}(t)+c_{y} y_{d}(t)+\left(1-\varepsilon_{c}\right)\left(c_{l} l_{d}^{C}(t)+c_{y} y_{d}^{C}(t)\right)\right) s_{1}(t) \\
& +\left(\mu_{s}+\xi_{s}\right)\left(s_{2}(t)+s_{3}(t)\right) \\
\dot{s_{2}}(t)= & a_{d}\left(c_{l} l_{d}(t)+c_{y} y_{d}(t)+\left(1-\varepsilon_{c}\right)\left(c_{l} l_{d}^{C}(t)+c_{y} y_{d}^{C}(t)\right)\right) s_{1}(t)-\left(\mu_{s}+\xi_{s}\right) s_{2}(t) \\
& -a_{d}\left(c_{l} l_{d}(t-\tau)+c_{y} y_{d}(t-\tau)+\left(1-\varepsilon_{c}\right)\left(c_{l} l_{d}^{C}(t-\tau)+c_{y} y_{d}^{C}(t-\tau)\right)\right) \times \\
& s_{1}(t-\tau) e^{-\left(\mu_{s}+\xi_{s}\right) \tau} \\
\dot{s}_{3}(t)= & a_{d}\left(c_{l} l_{d}(t-\tau)+c_{y} y_{d}(t-\tau)+\left(1-\varepsilon_{c}\right)\left(c_{l} l_{d}^{C}(t-\tau)+c_{y} y_{d}^{C}(t-\tau)\right)\right) \times \\
& s_{1}(t-\tau) e^{-\left(\mu_{s}+\xi_{s}\right) \tau}-\left(\mu_{s}+\xi_{s}\right) s_{3}(t)
\end{aligned}
$$

\subsection{Número de casos humanos notificados por dia}

Para entender a estimativa do número de casos notificados por dia, vamos considerar a Eq. (3):

$$
\dot{y}_{h}(t)=\varphi_{h} l_{h}(t)-\left(\mu_{h}+\alpha_{h}+\sigma_{h}\right) y_{h}(t)
$$

A leishmaniose visceral zoonótica é uma doença de notificação compulsória no Brasil $^{8}$. Em uma situação ideal, os casos notificados corresponderiam ao fluxo de indivíduos que procurariam atendimento médico e, consequentemente, seriam diagnosticados com leishmaniose visceral. Assim, ao fazermos uma analogia com o modelo matemático utilizado, esses indivíuos notificados seriam aqueles que estariam "migrando"da categoria de latentes para de clinicamente doentes.

Observando atentamente as equações que correspondem à dinâmica de humanos 
latentes (Eq. (2)) e clinicamente doentes (Eq. (3)), o termo que representa essa migração do indivíduo da categoria de latentes para clinicamente doentes é $\varphi_{h} l_{h}(t)$. Porém, atualmente, sabe-se que há uma proporção de casos que não são corretamente notificados ${ }^{73}$. Do total de indivíduos que passam a fazer parte da categoria de clinicamente doentes, apenas uma parte $\left(1-\eta_{h}\right)$, seria corretamente notificada. Portanto, em nosso modelo, nós estimamos o número de casos notificados por dia pela Eq. (26).

$$
R(t)=\left(1-\eta_{h}\right) \varphi_{h} l_{h}(t)
$$

onde $R(t)$ representa os casos humanos notificados por dia e $\eta_{h}$ é a proporção de casos subnotificados.

\subsection{Determinação dos pontos de equilíbrio}

Para a determinação dos pontos de equilíbrio deste modelo, basicamente devemos igualar todas as equações diferenciais do sistema a zero. Em seguida, devemos calcular os respectivos valores das variáveis em termos dos parâmetros. Estas variáveis, que destacaremos em negrito, são os pontos de equilíbrio do sistema. Aqui apresentaremos os resultados finais. Os detalhes podem ser encontrados no Apêndice.

As expressões dos estados de equilíbrio para as categorias que compõem a população de mosquitos estão representadas pelas Eq. (27) a (29).

$$
\begin{aligned}
& \mathbf{s}_{\mathbf{3}}=\frac{-q_{2}-\sqrt{q_{2}^{2}-4 q_{1} q_{3}}}{2 q_{1}} \\
& \mathbf{s}_{\mathbf{1}}=\frac{\left(\mu_{s}+\xi_{s}\right) p_{1}\left(g_{1}\left(b_{d} a_{d} m_{d}\right)^{2} \mathbf{s}_{\mathbf{3}}^{2}+g_{2} b_{d} a_{d} m_{d} \mathbf{s}_{\mathbf{3}}+g_{3}\right)}{q_{1} \mathbf{s}_{\mathbf{3}}^{2}+\left(p_{1}\left(\mu_{s}+\xi_{s}\right) g_{2}+a_{d} p_{2}\right) b_{d} a_{d} m_{d} \mathbf{s}_{\mathbf{3}}+p_{1}\left(\mu_{s}+\xi_{s}\right) g_{3}} \\
& \mathbf{s}_{\mathbf{2}}=1-\mathbf{s}_{\mathbf{1}}-\mathbf{s}_{\mathbf{3}}
\end{aligned}
$$

As expressões dos estados de equilíbrio para as categorias que compõem a população 
de cães estão representadas pelas Eq. (30) a (39).

$$
\begin{aligned}
& \mathbf{x}_{\mathbf{d}}^{\mathbf{C}}=\frac{d_{7}-f_{3} b_{d} a_{d} m_{d} \mathbf{s}_{\mathbf{3}}}{g_{1}\left(b_{d} a_{d} m_{d}\right)^{2} \mathbf{s}_{\mathbf{3}}^{2}+g_{2} b_{d} a_{d} m_{d} \mathbf{s}_{\mathbf{3}}+g_{3}} \\
& \mathbf{x}_{\mathbf{d}}=-\frac{d_{8}+f_{4}\left(1-\varepsilon_{c}\right) b_{d} a_{d} m_{d} \mathbf{s}_{\mathbf{3}}}{g_{1}\left(b_{d} a_{d} m_{d}\right)^{2} \mathbf{s}_{\mathbf{3}}^{2}+g_{2} b_{d} a_{d} m_{d} \mathbf{s}_{\mathbf{3}}+g_{3}} \\
& \mathbf{y}_{\mathbf{d}}=\left(\frac{h_{1}+h_{2}\left(1-\varepsilon_{c}\right) b_{d} a_{d} m_{d} \mathbf{s}_{\mathbf{3}}}{h_{3}\left(g_{1}\left(b_{d} a_{d} m_{d}\right)^{2} \mathbf{s}_{\mathbf{3}}{ }^{2}+g_{2} b_{d} a_{d} m_{d} \mathbf{s}_{\mathbf{3}}+g_{3}\right)}\right) b_{d} a_{d} m_{d} \mathbf{s}_{\mathbf{3}} \\
& \mathbf{y}_{\mathbf{d}}^{\mathbf{C}}=-\left(\frac{d_{1} h_{1}+h_{3}\left(1-\varepsilon_{c}\right) d_{7}+\left(d_{1} h_{2}-h_{3} f_{3}\right)\left(1-\varepsilon_{c}\right) b_{d} a_{d} m_{d} \mathbf{s}_{\mathbf{3}}}{d_{2} h_{3}\left(g_{1}\left(b_{d} a_{d} m d\right)^{2} \mathbf{s}_{3}^{2}+g_{2} b_{d} a_{d} m_{d} \mathbf{s}_{\mathbf{3}}+g_{3}\right)}\right) b_{d} a_{d} m_{d} \mathbf{s}_{\mathbf{3}} \\
& \mathbf{z}_{\mathbf{d}}=\left(\frac{j_{2}+j_{3}\left(1-\varepsilon_{c}\right) b_{d} a_{d} m_{d} \mathbf{s}_{\mathbf{3}}}{j_{1}\left(g_{1}\left(b_{d} a_{d} m_{d}\right)^{2} \mathbf{s}_{\mathbf{3}}^{2}+g_{2} b_{d} a_{d} m_{d} \mathbf{s}_{\mathbf{3}}+g_{3}\right)}\right) b_{d} a_{d} m d \mathbf{s}_{\mathbf{3}} \\
& \mathbf{z}_{\mathbf{d}}^{\mathbf{C}}=\left(\frac{k_{2}+k_{3}\left(1-\varepsilon_{c}\right) b_{d} a_{d} m d \mathbf{s}_{\mathbf{3}}}{k_{1}\left(g_{1}\left(b_{d} a_{d} m_{d}\right)^{2} \mathbf{s}_{\mathbf{3}}^{2}+g_{2} b_{d} a_{d} m_{d} \mathbf{s}_{\mathbf{3}}+g_{3}\right)}\right) b_{d} a_{d} m d \mathbf{s}_{\mathbf{3}} \\
& \mathbf{v}_{\mathbf{d}}^{\mathbf{C}}=\frac{l_{2}-l_{3} b_{d} a_{d} m_{d} \mathbf{s}_{\mathbf{3}}}{l_{1}\left(g_{1}\left(b_{d} a_{d} m_{d}\right)^{2} \mathbf{s}_{\mathbf{3}}^{2}+g_{2} b_{d} a_{d} m_{d} \mathbf{s}_{\mathbf{3}}+g_{3}\right)} \\
& \mathbf{l}_{\mathbf{d}}=\left(\frac{m_{2}+m_{3}\left(1-\varepsilon_{c}\right) b_{d} a_{d} m_{d} \mathbf{s}_{\mathbf{3}}}{m_{1}\left(g_{1}\left(b_{d} a_{d} m_{d}\right)^{2} \mathbf{s}_{\mathbf{3}}^{2}+g_{2} b_{d} a_{d} m_{d} \mathbf{s}_{\mathbf{3}}+g_{3}\right)}\right) b_{d} a_{d} m_{d} \mathbf{s}_{\mathbf{3}} \\
& \mathbf{l}_{\mathbf{d}}^{\mathbf{C}}=-\left(\frac{n_{2}+n_{3}\left(1-\varepsilon_{c}\right) b_{d} a_{d} m_{d} \mathbf{s}_{\mathbf{3}}}{n_{1}\left(g_{1}\left(b_{d} a_{d} m_{d}\right)^{2} \mathbf{s}_{\mathbf{3}}{ }^{2}+g_{2} b_{d} a_{d} m_{d} \mathbf{s}_{\mathbf{3}}+g_{3}\right)}\right) b_{d} a_{d} m_{d} \mathbf{s}_{\mathbf{3}} \\
& \mathbf{v}_{\mathbf{d}}^{\mathbf{C}}=\frac{a_{4} l_{2}-\varepsilon_{v} v_{d} l_{1} d_{8}-\left(a_{4} l_{3}+\varepsilon_{v} v_{d} l_{1} f_{4}\left(1-\varepsilon_{c}\right)\right) b_{d} a_{d} m_{d} \mathbf{s}_{\mathbf{3}}}{a_{9} l_{1}\left(g_{1}\left(b_{d} a_{d} m_{d}\right)^{2} \mathbf{s}_{\mathbf{3}}^{2}+g_{2} b_{d} a_{d} m_{d} \mathbf{s}_{\mathbf{3}}+g_{3}\right)}
\end{aligned}
$$

As expressões dos estados de equilíbrio para as categorias que compõem a população de humanos estão representadas pelas Eq. (40) a (43).

$$
\begin{aligned}
& \mathbf{x}_{\mathbf{h}}=\frac{1}{1+r_{1} b_{h} a_{h} m_{h} \mathbf{s}_{3}} \\
& \mathbf{z}_{\mathbf{h}}=\frac{\delta_{h}\left(\mu_{h}+\alpha_{h}+\sigma_{h}\right)+\varphi_{h} \sigma_{h}}{\left(\mu_{h}+r_{h}+\delta_{h}+\varphi_{h}\right)\left(\mu_{h}+\alpha_{h}+\sigma_{h}\right)\left(\mu_{h}+\gamma_{h}\right)} b_{h} a_{h} m_{h} \mathbf{s}_{3} \mathbf{x}_{\mathbf{h}}
\end{aligned}
$$




$$
\begin{aligned}
& \mathbf{y}_{\mathbf{h}}=\frac{\varphi_{h}\left(\mu_{h}+\gamma_{h}\right)}{\left(\delta_{h}\left(\mu_{h}+\alpha_{h}+\sigma_{h}\right)+\varphi_{h} \sigma_{h}\right)} \mathbf{z}_{\mathbf{h}} \\
& \mathbf{l}_{\mathbf{h}}=\frac{\left(\mu_{h}+\alpha_{h}+\sigma_{h}\right) \mathbf{y}_{\mathbf{h}}}{\varphi_{h}}
\end{aligned}
$$

\subsection{Análise de estabilidade}

Para a análise de estabilidade do sistema em relação aos pontos fixos, adotaremos o método descrito por Roussel ${ }^{82}$.

De forma geral, uma equação diferencial com atraso pode ser representada genericamente pela Eq. (44).

$$
\dot{\mathbf{x}}(t)=\mathbf{f}\left(\mathbf{x}(t), \mathbf{x}\left(t-\tau_{1}\right), \mathbf{x}\left(t-\tau_{2}\right), \ldots, \mathbf{x}\left(t-\tau_{n}\right)\right)
$$

onde as quantidades $\tau_{i}$ são valores positivas. Em nosso modelo, podemos simplificar a Eq. (44), visto que há apenas um único valor de $\tau$.

$$
\dot{\mathbf{x}}(t)=\mathbf{f}(\mathbf{x}(t), \mathbf{x}(t-\tau))
$$

Para simplificar nossa escrita, vamos adotar que variáveis sem índice são as variáveis instantâneas $(\mathbf{x} \equiv \mathbf{x}(t))$, enquanto variáveis com índice $\tau$ são as variáveis com atraso $\left(\mathbf{x}_{\tau}(t) \equiv \mathbf{x}(t-\tau)\right)$.

Um ponto de equilíbrio representa o conjunto de estados das variáveis para o qual temos $\mathbf{x}(t)=\mathbf{x}^{*}$ como solução do sistema representado pela Eq. (46) para qualquer valor de $t$.

$$
\mathbf{f}\left(\mathbf{x}^{*}, \mathbf{x}^{*}, \ldots, \mathbf{x}^{*}\right)=0
$$


Quando estudamos a estabilidade dos estados de equilíbrio de um sistema de equações diferenciais ordinárias, assume-se que o sistema é deslocado de seu estado de equilíbrio por uma pequena perturbação. Entretanto, considerando um sistema de equações diferencias com atraso, os deslocamentos são funções dependentes do tempo $\delta \mathbf{x}(t)$ persistindo sobre um intervalo mínimo de $\tau_{\max }$ (isto é, o atraso de maior duração no sistema) ${ }^{82}$.

Seja $\mathbf{x}^{*}$ o estado de equilíbrio da Eq. (44). Suponhamos que este sistema seja deslocado de seu estado de equilíbrio por uma pequena perturbação, que perdure de $t=$ $t_{0}-\tau_{\max }$ para $t_{0}$. Seja $\delta \mathbf{x}(t)$ o pequeno deslocamento do estado de equilíbrio, em qualquer instante $t$, em um intervalo aberto $\left[t_{0}-\tau_{\max }\right)$, então:

$$
\mathbf{x}=\mathbf{x}^{*}+\delta \mathbf{x}
$$

Logo:

$$
\dot{\mathbf{x}}=\dot{\delta} \mathbf{x}=\mathbf{f}\left(\mathbf{x}(t)^{*}+\delta \mathbf{x}_{\tau_{1}}, \mathbf{x}^{*}+\delta \mathbf{x}_{\tau_{2}}, \ldots, \mathbf{x}^{*}+\delta \mathbf{x}_{\tau_{n}}\right)
$$

Sendo que as quantidades $\delta \mathbf{x}_{\tau_{1}}, \delta \mathbf{x}_{\tau_{2}}, \ldots, \delta \mathbf{x}_{\tau_{n}}$ são pequenas, é possível linearizar o sistema de equações diferenciais em torno dos pontos de equilíbrio por meio do usual método de série de Taylor ${ }^{82,83}$ :

$$
\dot{\delta \mathbf{x}} \simeq \mathbf{J}_{0} \delta \mathbf{x}+\mathbf{J}_{\tau_{1}} \delta \mathbf{x}_{\tau_{1}}+\cdots+\mathbf{J}_{\tau_{n}} \delta \mathbf{x}_{\tau_{n}}
$$

Para obter a Eq. (49), partimos do pressuposto da Eq.(46). A quantidade $\mathbf{J}_{0}$ é o jacobiano usual com relação a $\mathbf{x}$ avaliados nos pontos de equilíbrio. Por outro lado, as quantidades $\mathbf{J}_{\tau_{i}}$ com relação ao correspondente $\mathbf{x}_{\tau_{i}}$, e novamente calculado em $\mathbf{x}=\mathbf{x}_{\tau_{1}}=$ $\mathbf{x}_{\tau_{2}}=\cdots=\mathbf{x}_{\tau_{n}}=\mathbf{x}^{*}$

Em sistemas de equações diferenciais ordinárias lineares, as soluções são funções exponenciais (dependentes do tempo), com os expoentes dados pelos autovalores da matriz Jacobiana. Suponhamos que a Eq. (49) também apresente soluções exponenciais, do 
tipo:

$$
\delta \mathbf{x}(t)=\mathbf{A} e^{\lambda t}
$$

Substituindo a Eq. (50) na Eq.(49), obtemos:

$$
\lambda A=\left(\mathbf{J}_{0}+e^{-\lambda \tau_{1}} \mathbf{J}_{\tau_{1}}+e^{-\lambda \tau_{2}} \mathbf{J}_{\tau_{2}}+\cdots+e^{-\lambda \tau_{n}} \mathbf{J}_{\tau_{n}}\right) A
$$

A teoria da algebra linear nos diz que a Eq. (51) só é satisfeita com amplitudes de deslocamentos não nulos se:

$$
\operatorname{det}\left|\mathbf{J}_{0}+e^{-\lambda \tau_{1}} \mathbf{J}_{\tau_{1}}+e^{-\lambda \tau_{2}} \mathbf{J}_{\tau_{2}}+\cdots+e^{-\lambda \tau_{n}} \mathbf{J}_{\tau_{n}}-\lambda \mathbf{I}\right|=0
$$

onde I é a matriz identidade. A Eq. (52) é chamada de equação característica dos pontos de equilíbrio. Em nosso modelo, a Eq. (52) se reduz a:

$$
\operatorname{det}\left|\mathbf{J}_{0}+e^{-\lambda \tau} \mathbf{J}_{\tau}-\lambda I\right|=0
$$

A Eq. (52) parece um pouco como um problema de autovalor comum, exceto pelo aparecimento dos termos exponenciais. Se expandirmos o determinante, vamos obter equações que têm partes polinomiais, mas que também incluem alguns termos do tipo $e^{\lambda \tau_{i}}$. Estes são chamados quase-polinômios* ${ }^{*}$ Em princípio, o nosso trabalho é o mesmo:

- Se qualquer uma das soluções da equação característica tem partes reais positivas, então o ponto de equilíbrio é instável;

- Se todos eles têm partes reais negativas, o ponto de equilíbrio é estável;

- Se os valores característicos forem iguais a zero, a estabilidade não pode ser definida (em se considerando equações de ordem linear).

As equações polinomiais que usualmente resolvemos para problemas de estabilidade de equações diferenciais ordinárias costumam ser bem familiares: um polinômio

\footnotetext{
*Tradução literal do termo em inglês "quasi-polynomials"
} 
de grau $n$ tem raízes exatamente $n$ complexos. Podemos, portanto, obter todas as raízes e determinar a estabilidade de um equilíbrio. Por outro lado, quase-polinômios geralmente têm um número infinito de raízes no plano complexo ${ }^{82}$. Encontrar todas as raízes é a principal dificuldade, logo, uma maneira de obtê-las é por meio de softwares, como o Maple 12.0.

\subsection{O número de reprodutibilidade basal $\mathscr{R}_{0}$}

O estado de equilíbrio livre da doença (ELD) é aquele em que, em uma dada população, a doença se encontra completamente ausente. No estado ELD, não há casos de indivíduos infectados, nem mesmo em situação latente ${ }^{38}$.

De acordo com van den Driessche e Watmough ${ }^{84}, \mathscr{R}_{0}$ (conhecido por número de reprodutibilidade basal) é o número esperado de casos secundários produzidos, em uma população completamente suscetível, por um indivíduo infectivo típico. Assim, para avaliar o $\mathscr{R}_{0}$ do nosso modelo, nós adotamos o método desenvolvido por van den Driessche e Watmough ${ }^{84}$.

Aqui, nós ressaltamos que, apesar do trabalho publicado por van den Driessche e Watmough ${ }^{84}$ não considerar a presença de termos com atraso, nós desenvolvemos uma adaptação em nosso cálculo para determinar $\mathscr{R}_{0}$. De acordo com Röst G e Wu J $\mathbf{J}^{\dagger}$, os termos com atraso em nosso modelo podem ser considerados como termos instantâneos (ou seja, podemos aplicar $\tau=0$ ), mas devemos manter o termo $e^{-\left(\mu_{s}+\xi_{s}\right) \tau}$ (isto é, para este termo, nós mantemos $\tau \neq 0)$. Ressaltamos que $e^{-\left(\mu_{s}+\xi_{s}\right) \tau}$ representa a probabilidade de um vetor em $s_{2}$ sobreviver ao período de incubação extrínseca e migrar para $s_{3}{ }^{9,81}$.

No contexto dos modelos epidemiológicos, normalmente levamos em conta a avaliação de $\mathscr{R}_{0}$, tal que se ${ }^{84}$ :

- $\mathscr{R}_{0}<1$, então o estado de ELD é local e assintoticamente estável, portanto a doença não é capaz de invadir a população;

\footnotetext{
${ }^{\dagger}$ Röst G e Wu J. (Department of Mathematics and Statistics, York University). Delay Differential Equations; 2014 [Em elaboração].
} 
- $\mathscr{R}_{0}>1$, então o estado de ELD é instável e a invasão da doença é sempre possível.

Para computar o $\mathscr{R}_{0}$ é importante diferenciar os casos de novas infecções de todas as outras alterações na população. Vamos supor que $\mathscr{F}_{i}(x)$ seja a taxa de aparecimento de novos casos em cada categoria deste modelo, $\mathscr{V}_{i}(x)^{+}$como a taxa de transferência de indivíduos (mas sem incluir os infectados) para a categoria $i$ por todas outras vias, e $\mathscr{V}_{i}(x)^{-}$ como a taxa de saída de indivíduos (incluindo infectados) de cada categoria (onde $x$ é o vetor de variáveis do nosso modelo). O índice $i$ representa (nesta secção) a categoria das populações relacionadas à respectiva equação $i$ (as equações foram enumeradas e apresentadas na secções sobre a descrição do modelo (secções 3.1 e 3.2)). Assim, as equações do nosso modelo podem ser organizadas conforme a Eq. (54).

$$
\dot{x}_{i}=\mathscr{F}_{i}(x)-\mathscr{V}_{i}(x)
$$

onde $\mathscr{V}_{i}(x)=\mathscr{V}_{i}(x)^{-}-\mathscr{V}_{i}(x)^{+}$

A Eq. (54) pode ser usada para determinar o destino de um pequeno número de indivíduos infectados introduzidos em uma população livre da doença. O estado de ELD é estável na ausência de novas infecções. Se nós supormos a introdução de poucos indivíduos infectivos em uma população livre da doença, mas que não resulte em uma epidemia, então a população continuará em seu estado ELD, conforme o sistema linearizado (Eq. (55)).

$$
\frac{d}{d t} x=D f\left(x_{0}\right)\left(x-x_{0}\right)
$$

onde:

1. $\frac{d}{d t} x=f_{i}(x)=\mathscr{F}_{i}(x)-\mathscr{V}_{i}(x)$;

2. $D f\left(x_{0}\right)$ é a derivada $\frac{\partial}{\partial x_{i}} f_{i}$ calculada no estado ELD, $x_{0}$.

A partir deste ponto, nós não iremos descrever todos os estágios deste método. 
Entretanto, todos os detalhes estão bem descritos no trabalho de van den Driessche e Watmough ${ }^{84}$. Assim, antes de continuarmos, nós definimos:

$$
\begin{aligned}
& F\left(x_{0}\right)=\left[\frac{\partial \mathscr{F}_{i}}{\partial x_{j}}\right] \\
& V\left(x_{0}\right)=\left[\frac{\partial\left(\mathscr{V}^{-}-\mathscr{V}^{+}\right)_{i}}{\partial x_{j}}\right]
\end{aligned}
$$

onde $i$ é o total de variáveis do modelo e $j$ é o número de variáveis (ou categorias) onde há indivíduos infectados. Assim, $1<i<17$ e $1<j<8$, com $i<j$.

Para determinar a trajetória de um indivíduo infectivo "típico"na população, nós consideramos a dinâmica do sistema acima linearizado, sem levar em conta o aparecimento de novas infecções.

$$
\frac{d}{d t} x=D \mathscr{V}\left(x_{0}\right)\left(x-x_{0}\right)
$$

Seja $\psi_{i}(0)$ o número inicial de indivíduos infectados na categoria $i$ e seja $\psi(t)$ $=\left(\psi_{i}(t), \ldots, \psi_{m}(t)\right)^{t} \mathrm{o}$ número desses indivíduos inicialmente infectados remanescentes nas categorias infectadas após $t$ unidades de tempo. Assim, estamos considerando que o vetor $\psi$ é composto pelos $m$ componentes de $x$. A partição de $D \mathscr{V}\left(x_{0}\right)$ implica que $\psi(t)$ satisfaz $\dot{\psi}(t)=-V \psi(t)$, o qual tem a única solução $\psi(t)=e^{-V t} W(0)$. Logo, integrando $F \psi(t)$ de zero ao infinito, obtemos o número esperado de novas infecções produzidas pelos indivíduos inicialmente infectados, conforme o vetor $F V^{-1} \psi(0)$.

Para interpretar as entradas de $F V^{-1}$ e desenvolver uma definição significativa de $\mathscr{R}_{0}$, considere o destino de um indivíduo infectado introduzido em um compartimento $k$ de uma população livre da doença. A entrada $(j, k)$ de $V^{-1}$ é a duração média de tempo que este indivíduo leva no compartimento $j$ durante sua vida (assumindo que a população permanece próximo do estado de ELD e ignorando-se casos de reinfecção). A entrada $(i, j)$ de $F$ é a taxa no qual indivíduos infectados na categoria $j$ produzem novas infecções no compartimento $i$. Portanto, a entrada $(i, k)$ do produto $F V^{-1}$ é o número esperado de 
novas infecções na categoria $i$ produzidas pelo indivíduo infectado introduzido originalmente para a categoria $k$.

Finalmente, van den Driessche e Watmough ${ }^{84}$ denominam $F V^{-1}$ por Matriz de próxima geração (next generation matrix) para o modelo e determinam (Eq. (59)):

$$
\mathscr{R}_{0}=\rho\left(F V^{-1}\right)
$$

onde $\rho\left(F V^{-1}\right)$ raio espectral da matriz $F V^{-1}$.

\subsection{Análise de incerteza e sensibilidade}

A precisão dos resultados de modelos matemáticos e computacionais de sistemas biológicos é diretamente dependente do quão certo estão os valores dos parâmetros utilizados. Tais parâmetros são normalmente estimados através de resultados experimentais. Em outros casos, certos parâmetros estão sujeitos a incertezas devido à falta de informações completas sobre suas fontes ${ }^{55}$. Logo, a presença de incertezas nos dados experimentais pode gerar incertezas nos parâmetros estimados ${ }^{85}$. Consequentemente, parâmetros incertos podem propagar suas incertezas para os resultados dos modelos matemáticos. Muitos modelos matemáticos apresentam análise de sensibilidade de parâmetros simples ou local. No entanto, esses métodos não avaliam a incerteza e a sensibilidade no sistema de forma acurada, pois (por padrão) eles detém todos os outros parâmetros fixos em valores basais.

Além disso, mesmo quando uma abordagem parcimoniosa é seguida durante a construção do modelo, o conhecimento disponível dos fenômenos é muitas vezes incompleto, e as medidas experimentais são escassas, ambíguas ou contraditórias. Portanto, a questão de como lidar com as incertezas surge naturalmente como parte do processo. Para tanto, técnicas de análise de incerteza e sensibilidade (IS) ajudam a avaliar e a controlar estas incertezas. Análise de incerteza (AI) visa investigar a incerteza sobre o resultado do modelo, que é obtido a partir das incertezas dos parâmetros. Por outro lado, a análise 
de sensibilidade (AS) segue naturalmente a AI. Em poucas palavras, a AS avalia como a variabilidade dos resultados do modelo pode estar relacionada (qualitativa ou quantitativamente) com os parâmetros do modelo ${ }^{86}$.

Neste estudo, utilizamos a Latin Hypercube Sampling (LHS) (em tradução livre, amostragem por hipercubo latino) como técnica de AI e a Partial Rank Correlation Coefficient (PRCC) (em tradução livre, coeficiente de correlação de ranques parciais), como técnica (ou índices) para AS.

\subsubsection{Análise de incerteza: Latin Hypercube Sampling (LHS)}

Fatores de entrada para a maioria dos modelos matemáticos consistem em parâmetros e condições iniciais para as variáveis independentes e dependentes do modelo. Como mencionado, estes nem sempre são conhecidos com um grau suficiente de certeza por causa da variação natural, do erro nas medições ${ }^{85}$, ou simplesmente pela falta de técnicas modernas e/ou atualizadas para medi-los. A finalidade da AI é quantificar o grau de confiança nas estimativas de dados e parâmetros experimentais existentes ${ }^{86}$.

A LHS permite uma estimativa não-tendenciosa da média do resultado do modelo. Esta estimativa é realizada a partir de distribuições aleatórias dos valores dos parâmetros. Para cada parâmetro é assumido que seu valor segue uma determinada função densidade de probabilidade (fdp) e que seu valor está sujeito a um valor mínimo e máximo. Assim, a amplitude de cada parâmetro é dividida em $N$ sub-intervalos de probabilidade iguais. A escolha pelo $N$ deve ser, pelo menos $k+1$, onde $k$ é o número de parâmetros que esta sujeito à variação. Quanto maior for o $N$ (digamos, $N=1000)$, maior será a precisão da análise.

A Figura 10 ilustra o método da LHS. Podemos dizer que há um ”conjunto de amostragens". Um valor é sorteado dentro de cada conjunto $N$ de valores de cada parâmetro. Assim, cada valor é amostrado exatamente uma vez (sem reposição), de modo que todo o intervalo (composto por $N$ valores) é explorado (Fig. (10A)). Em seguida, uma matriz é gerada (o que chamamos de Matriz LHS). Essa matriz consiste de $N$ li- 
nhas (onde cada linha corresponde a uma determinada combinação sorteada de valores de parâmetros) e de $k$ colunas (que correspondem ao número de parâmetros a serem analisados) (Fig. (10B)). Finalmente, $N$ soluções numéricas do modelo são obtidas, utilizando cada conjunto de valores dos parâmetros (isto é cada linha da matriz LHS, Figura 10B). A partir de cada simulação, o respectivo resultado (isto é, a solução numérica) do modelo é então coletado. Se o modelo tiver mais de uma saída (por exemplo, duas ou mais variáveis de estado), os resultados referentes a elas também podem ser coletados para futuramente serem estudados.

A

$$
\begin{gathered}
\text { Modelo matemático } \\
\dot{\mathbf{x}}=g(\mathbf{x}, \boldsymbol{\theta}), \mathbf{x} \in \mathbb{R}^{2} \\
\boldsymbol{\theta} \in \mathbb{R}^{3}, \boldsymbol{\theta} \equiv\{a, b, c\}
\end{gathered}
$$
Latin Hipercube Sampling $\quad$ Tamanho de amostra (Funções densidade de
Normal e Uniforme)$$
a \sim \operatorname{Unif}\left(a_{\min }, a_{\max }\right)
$$

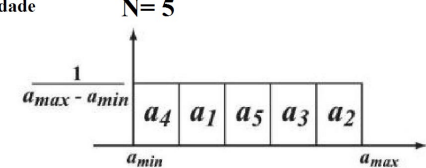

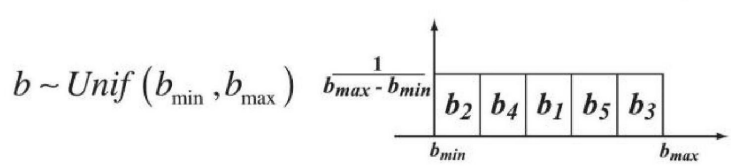

$c \sim \operatorname{Normal}\left(\mu_{c}, \sigma_{c}\right)$

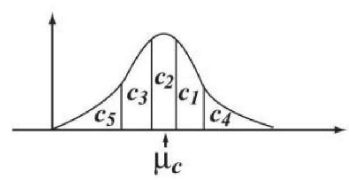

B Matriz de Resultados

B Matriz LHS (Matriz de Saída)

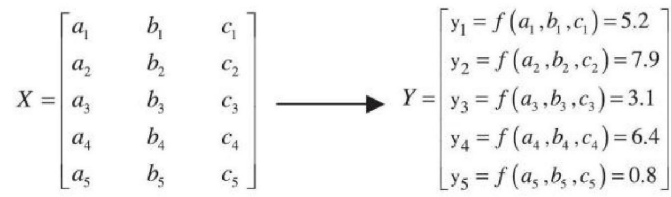

Ranqueamento

$X_{R}=\left[\begin{array}{lll}2 & 3 & 4 \\ 5 & 1 & 3 \\ 4 & 5 & 2 \\ 1 & 2 & 5 \\ 3 & 4 & 1\end{array}\right]$

C

Índices de sensibilidade baseados em amostragem

$$
\begin{aligned}
& C C_{\text {Pearson }}(X, Y) \\
& C C_{\text {Spearman }}\left(X_{R}, Y_{R}\right) \\
& \operatorname{PRCC}\left(X_{R}, Y_{R}\right)
\end{aligned}
$$

Figura 10 - Esquema da análise de incerteza e de sensibilidade realizada com métodos de LHS e PRCC. O modelo matemático é representado como um sistema de equações diferenciais ordinárias, onde $\mathbf{x}$ é $\mathbf{o}$ vetor de variáveis de estado em um espaço $n$-dimensional $\mathscr{R}^{n}$ : (como exemplo definimos $n=2$ e $\theta$ é o vetor de parâmetros em $\mathscr{R}^{k}, k=3 \mathrm{em}$ funções neste exemplo). Para facilitar a notação, a saída y é unidimensional e é uma função de $\mathbf{x}$ e $\theta$. (A) Especificação do modelo matemático (sistema dinâmico, parâmetros de saída) e o esquema de LHS correspondente. Funções densidade de probabilidade (fdp's) são atribuídas aos parâmetros do modelo (por exemplo, $a, b, c$ ). Nós mostramos um exemplo com tamanho de amostra $N=5$. Cada intervalo é dividido em cinco sub-intervalos equiprováveis e amostras independentes são retiradas de cada fdp (uniforme e normal). O índice subscrito representa a sequência de amostragem. (B) A matriz LHS $(X)$ é então construída por coletas de amostras a partir de cada fdp. Cada linha da matriz LHS representa uma combinação única de valores dos parâmetros amostrados sem reposição. $\mathrm{O}$ modelo hipotético $\dot{\mathbf{x}}=g(\mathbf{x}, \theta)$ é resolvido e a saída correspondente gerada é armazenada na matriz $Y$. Cada matriz é, em seguida, transformada em ranques (ranqueamento) $\left(\mathbf{X}_{R}\right.$ e $\left.Y_{R}\right)$. (C) A matriz LHS (X) e a matriz de saída $(Y)$ são utilizados para calcular o coeficiente de correlação de Pearson $\left(C C_{\text {Pearson }}\right)$. A matriz transformada em ranques LHS $\left(\mathbf{X}_{R}\right)$ e matriz de saída $\left(Y_{R}\right)$ são usadas para calcular o coeficiente de correlação de Spearman ou o coeficiente de correlação de ranques $\left(C C_{S \text { pearman }}\right)$ e o coeficiente de correlação de ranques parcial $(P R C C)$. Figura adaptada de Marino et al. ${ }^{86}$ 


\subsubsection{Análise de sensibilidade: Partial Rank Correlation Coefficient (PRCC)}

Análise de sensibilidade (AS) é um método para quantificar a incerteza em qualquer tipo de modelo complexo. O objetivo da AS é identificar valores de entrada críticos (parâmetros e condições iniciais) de um modelo e quantificar como a incerteza dos valores de entrada impacta sobre o(s) resultado(s) do modelo. Quando os fatores de entrada, como parâmetros ou condições iniciais são conhecidos com pouca incerteza, podemos examinar a derivada parcial da função de saída com respeito aos fatores de entrada. Esta medida de sensibilidade pode ser facilmente calculada numericamente através da realização de diversas simulações, variando fatores de entrada em torno de um valor nominal. Esta técnica é chamada de AS local, porque investiga o impacto sobre a produção do modelo, com base em mudanças nos fatores só muito próximos aos valores nominais. Em biologia, fatores de entrada são frequentemente muito incertos e, portanto, técnicas de AS locais não são apropriadas para uma análise quantitativa; ao invés delas, são necessárias técnicas de AS globais. Estas técnicas globais geralmente são implementadas por meio de métodos baseados em amostragem ${ }^{86}$.

Para relacionamentos não-lineares, mas com relações monotônicas entre saídas e entradas, medidas que funcionam bem são baseadas em ranqueamento ${ }^{\ddagger}$, tais como o Partial Rank Correlation Coefficient $(P R C C)^{86}$.

Um coeficiente de correlação $(C C)$ fornece uma medida da força de associação linear entre um valor de entrada e um de saída. Um $C C$ entre $x_{j}$ e $y$ varia entre -1 e +1 e é calculado como apresentado na Eq. (60).

$$
\begin{aligned}
r_{x_{j} y} & =\frac{\operatorname{Cov}\left(x_{x_{j}, y}\right)}{\sqrt{\operatorname{Var}\left(x_{j}\right) \operatorname{Var}(y)}}=\frac{\sum_{i=1}^{N}\left(x_{i j}-\bar{x}\right)\left(y_{i}-\bar{y}\right)}{\sqrt{\sum_{i=1}^{N}\left(x_{i j}-\bar{x}\right)^{2} \sum_{i=1}^{N}\left(y_{i}-\bar{y}\right)^{2}}} \\
j & =1,2, \cdots, k
\end{aligned}
$$

\footnotetext{
‡Ranqueamento: ao menor valor de uma variável é atribuída uma classificação de posição 1, o segundo maior valor é atribuído uma classificação de posição 2, aos valores vinculados (isto é, mais de um elemento possuem o mesmo valor) são atribuídos uma classificação média (ou seja, esses valores assumem uma posição que equivale a uma média entre os elementos), e ao maior valor é atribuído uma classificação de posição igual ao tamanho da amostra. ${ }^{86}$
} 
$\operatorname{Cov}\left(x_{j}, y\right)^{\S}$ representa a covariância entre $x_{j}$ e $y$, enquanto $\operatorname{Var}\left(x_{j}\right)$ e $\operatorname{Var}(y)$ são, respectivamente, a variância de $x_{j}$ e a variância de $y(\bar{x}$ e $\bar{y}$ são as respectivas médias amostrais). Se $x_{j}$ e $y$ são os dados brutos, então o coeficiente $r$ é chamado de $C C$ de amostra ou de Pearson (Figura 10C). Se os dados são transformados em ranques, o resultado é o coeficiente de correlação de ranques ou de Spearman (Figura 10C). É importante notar que o processo de transformação de dados em ranqueamento supõe que os valores de entrada amostrados do modelo são valores reais ou que podem adotar muitos valores possíveis. Se um parâmetro tem apenas valores inteiros e a gama de possíveis valores que pode assumir é menor do que $\mathrm{N}$, pode haver informação insuficiente para desempatar ${ }^{\mathbb{I I}}$ durante o ranqueamento, resultando em correlações pobres ${ }^{86}$.

A correlação parcial $(C P)$ caracteriza a relação linear entre uma determinada entrada $x_{j}$ e a saída $y$, após os efeitos lineares em $y$ devido aos demais valores de entradas serem descontados. Assim, o coeficiente de correlação parcial $(C C P)$ entre $x_{j}$ e $y$ é o $C C$ (Eq. (60)) entre os dois resíduos $\left(x_{j}-\bar{x}_{j}\right)$ e $(y-\bar{y})$, onde $x_{j}$ e $y$ são os seguintes modelos de regressão linear (Eq. (61) e (62)).

$$
\begin{aligned}
& \hat{x}_{j}=c_{0}+\sum_{\substack{p=1 \\
p \neq j}}^{k} c_{p} x_{p} \\
& \hat{y}_{j}=b_{0}+\sum_{\substack{p=1 \\
p \neq j}}^{k} b_{p} x_{p}
\end{aligned}
$$

A correlação de ranques parciais $(C R P)$ realiza uma correlação parcial em dados transformados em ranqueamento, à semelhança da $C P$. Assim, $x_{j}$ e $y$ são primeiramente transformados em ranqueamento. Em seguida, os modelos de regressão linear descrito nas Eq. (61) e (62) são construídos. O coeficiente de correlação de ranques parciais (PRCC) é uma medida de sensibilidade robusta para relações não-lineares, porém monotônicas,

\footnotetext{
${ }^{\S}$ Covariância (também conhecida por variância conjunta) é uma medida do grau de interdependência (ou inter-relação) numérica entre duas variáveis aleatórias ${ }^{87}$. Assim, variáveis independentes têm covariância zero.

"O procedimento padrão quando os empates são encontrados é o de atribuir aos valores empatados uma espécie de "rateio". Por exemplo, se o valor 5 for o causador do empate para 3 posições (isto é, 3 posições obtiveram o mesmo valor 5), devemos dividir o valor 5 entre os 3 ranques. Portanto, cada posição corresponderia ao valor 1,67 .
} 
entre $x_{j}$ e $y$, desde que pouca ou nenhuma correlação exista entre os valores de entrada. Este coeficiente é calculado a partir dos dados $x_{j}$ e $y$ ranqueados que são aplicados na Eq. (60). Ao combinar as AIs com PRCC, somos capazes de avaliar razoavelmente a sensibilidade da nossa variável de saída para a variação dos parâmetros ${ }^{86}$.

\section{Inferência sobre o PRCC}

Testes de significância podem ser realizados para avaliar se um PRCC é significativamente diferente de zero (assim, mesmo as pequenas correlações podem ser significativas) e se dois valores de $P R C C$ são significativamente diferentes uns dos outros. Cada PRCC $(\gamma)$ gera um valor de $T$ de acordo com a Eq. (62).

$$
T=\gamma \sqrt{\frac{N-2-p}{1-\gamma^{2}}} \sim t_{N-2-p}
$$

onde $T$ segue a distribuição $t$ de Student com $(N-2-p)$ graus de liberdade. $N$ é o tamanho da amostra e $p$ é o número de entradas/parâmetros cujos efeitos são descontados quando o $P R C C$ é calculado. Por exemplo, se nós variarmos 6 entradas/parâmetros $\left(x_{i}\right.$, $i=1,2, \cdots, 6)$ em LHS, $p$ seria igual a $5\left(\operatorname{PRCC}\left(x_{i}, y\right)=\gamma_{x_{i} y / x_{j}}, j=1, \ldots, 6 j \neq i\right)$.

\subsection{Comparando o impacto das estratégias de controle preventivo}

Nas secções anteriores, foi descrita a natureza das equações utilizadas neste modelo (seções 3.1 e 3.2). Também foi apresentada a expressão do número de casos humanos notificados por dia (seção 3.3). Em seguida, foram determinados os estados de equilíbrio de todas as subpopulações (seção 3.4) e a respectiva análise de estabilidade (seção 3.5). Da mesma forma, desenvolvemos o cálculo do número de reprodutibilidade basal $\left(\mathscr{R}_{0}\right)$ (seção 3.6). E, finalmente, mostramos a análise de incerteza e de sensibilidade em relação aos parâmetros do modelo (seção 3.7). Agora, descreveremos como foram analisadas as estratégias de controle preventivo. 
Todas as cinco estratégias de controle consideradas $\left(\xi_{d}, \theta_{d}, v_{d}, \omega_{d}, \xi_{s}\right)$ estão inseridas no modelo matemático por meio da forma geral $\kappa f(t)$, em que $\kappa$ representa um parâmetro generalizado e o $f(t)$, uma categoria qualquer do modelo. Considerando que a forma genérica da equação diferencial apresentada neste modelo é do tipo $\dot{g}(t)=\kappa f(t)$, e que $\dot{g}(t)$ representa a variação da categoria $g(t)$ por unidade de tempo, temos que a dimensão do parâmetro $\kappa$ é 1/dia (visto que as categorias em nosso modelo são adimensionais). Portanto, os parâmetros relativos às estratégias de controle devem apresentar dimensão $1 /$ dia.

A avaliação da eficiência das estratégias de controle foi realizada de forma individual. Em outras palavras, foi estudada uma estratégia por vez. Para cada estratégia, foram avaliados 200 valores homogêneamente distribuídos no intervalo de 0 a 0,1 , sendo que foi realizada uma simulação para cada valor (portanto, 200 simulações para avaliar cada estratégia, totalizando $5 \times 200=1000$ simulações).

Para simplificar, iremos descrever o passo a passo desta avaliação.

1. Vamos considerar um cenário inicial em que a doença se encontra estabelecida na população. Assim, as condições iniciais passam a ser os resultados numéricos da simulação sem as estratégias de controle. A partir deste cenário inicial, executamos a simulação para um tempo de 2000 dias, com a inclusão de uma estratégia de controle, por exemplo, $\xi_{d}=0,0005$

2. Após o término desta simulação, armazenamos os valores finais de cada categoria em um banco de dados, juntamente com o correspondente valor do controle;

3. Retornamos ao passo 1 e, em seguida, ao passo 2. Porém, simulamos para o valor de $\xi_{d}$ acrescido de 0,0005 (ou seja $\xi_{d}=0,001$ );

4. Repetimos os passos 1 a 3 até que o valor do controle seja 0,1 (por exemplo, quando $\left.\xi_{d}=0,1\right)$; 
5. Repetimos os passos 1 a 4 para cada uma dos outros 4 controles (por exemplo, $\theta_{d}, v_{d}, \omega_{d}$ e $\left.\xi_{s}\right)$.

Ao final, obtemos um banco de dados contendo os valores de cada categoria ao final de 2000 dias de simulação, para um dado valor do controle. Entre esses valores finais, os mais importantes são aqueles referentes à categoria $l_{h}$, visto que o número de casos humanos notificados é estimado por $R=\left(1-\eta_{h}\right) \varphi_{h} l_{h}$. Portanto, tomamos como referência o impacto sobre o número de casos humanos notificados $(R)^{53}$ para a análise do impacto das estratégias e controle preventivo.

\section{9 $O$ custo das estratégias de controle}

A análise da efetividade de cada controle estratégico considerada na secção 3.8 considera uma situação "ideal", isto é, sem levar em conta o ponto de vista econômico. Entretanto, é de se imaginar que no planejamento das atividades de controle seja abordada a relação custo-benefício de cada estratégia.

Neste estudo, todas as 5 estratégias de controle $\left(\xi_{d}, \theta_{d}, v_{d}, \omega_{d}\right.$ e $\left.\xi_{s}\right)$ são tratadas como taxas. Em outras palavras, tratar esses parâmetros como taxas significa que eles devem ser interpretados com a dimensão de "indivíduos"/dia.

Portanto, se, por exemplo, uma determinada estratégia apresentar o valor de $n$ "indivíduos"/dia, devemos investigar qual o custo $(C)$ por "indivíduo". Ao obtermos a estimativa deste custo estimado, o produto entre $C \times n$ nos proporcionará o custo da estratégia por dia.

A seguir, apresentaremos a estimativa dos custos por indivíduo para cada estratégia de controle. Parte das estimativas são provenientes das atividades desenvolvidas nas proximidades da cidade de Araçatuba (estado de São Paulo), a qual é atualmente considerada uma região endêmica.

Os custos serão estimados em dólar americano (USD) por ser uma moeda de ampla referência e por ser mais estável (assim, minimizamos os efeitos da inflação na 
moeda brasileira $)^{53}$.

\section{Estimativa do custo da eliminação de cães positivos $\left(\xi_{d}\right)$}

Durante os anos de 1999 a 2001, Camargo-Neves ${ }^{57}$ estimou os custos investidos para o controle do reservatório canino em três áreas do município de Araçatuba/SP. A autora nomeou essas três áreas por Testemunha, Tratada e Calagem.

Para a estimativa do custo desta estratégia de controle foi tomado como base um ciclo de atividades. O ciclo de atividades é composto por (1) coleta de amostras para exame, (2) diagnóstico (exame de imunofluorescência indireta) e (3) sacrifício dos cães $\operatorname{positivos}^{58}$.

A Tabela 3 resume os custos médios por ciclo de atividade do controle do reservatório canino. Esta tabela traz informações a respeito do custo médio em cada uma das áreas de estudadas em Araçatuba e do respectivo número médio de cães sacrificados por ciclo.

Tabela 3 - Sumário dos custos médios estimados por ciclo de atividade (eliminação de cães positivos) e a respectiva quantidade média de cães eliminados. Tabela adaptada do trabalho de Camargo-Neves ${ }^{57}$.

\begin{tabular}{lcccc}
\hline \multicolumn{4}{c}{ Áreas do município de Araçatuba } \\
\hline & Testemunha & Tratada & Calagem & Soma \\
\hline $\begin{array}{l}\text { Custo (média por ciclo de } \\
\text { atividade) }\end{array}$ & USD 3.099,83 & USD 3.639, 54 & USD 3.545, 63 & USD 10285, 00 \\
$\begin{array}{l}\text { Cães eliminados (média por } \\
\text { ciclo de atividades) }\end{array}$ & 17,75 & 18,25 & 24,25 & $\mathbf{6 0 , 2 5}$ \\
\hline
\end{tabular}

Para termos uma estimativa geral a respeito do custo da eliminação de um cão positivo, tomamos como referência a coluna "Soma"da Tabela 3. A partir dela, podemos definir a estimativa do custo $\mathscr{C}_{\xi_{d}}$ (Eq. (63)).

$$
\mathscr{C}_{\xi_{d}}=\frac{10.285,00}{60,25} \simeq 170,71
$$

Portanto, o custo para se eliminar um cão diagnosticado como positivo para leish- 
maniose visceral foi em torno de $\mathscr{C}_{\xi_{d}}=$ USD 170, 71/cão.

\section{Estimativa do custo do coleira impregnada com deltametrina $\left(\theta_{d}\right)$}

Camargo-Neves ${ }^{23,58,88}$ desenvolveu um estudo sobre a eficácia das coleiras impregnadas com deltametrina $4 \%$ no controle da leishmaniose visceral. Neste estudo, desenvolvido no município de Andradina/SP, foram planejadas a distribuição e a reposição da coleira, além da supervisão e manutenção do uso das coleiras pela população canina. Além disso, também houve uma análise de custo-efetividade desta estratégia de controle. Nesta análise, foram consideradas não apenas o custo da coleira, mas também as atividades operacionais e os recursos humanos.

Em nosso modelo, adotaremos uma hipótese mais simples e uma situação idealizada. Assumiremos que as coleiras poderiam ser disponibilizadas nos postos de saúde. Portanto, em um cenário ideal, cada proprietário seria responsável pela própria aquisição e aplicação da coleira em seu cão. Adotando esta ideia, podemos considerar que o único custo envolvido nesta estratégia seria a aquisição (compra) das coleiras.

Segundo Camargo-Neves ${ }^{23,58,88}$, o custo da compra da coleira para o estudo desenvolvido em Andradina/SP foi em torno de USD 12,00. Portanto, temos (Eq. (64)):

$$
\mathscr{C}_{\theta_{d}}=12,0
$$

\section{Estimativa do custo do tratamento de cães $\left(\omega_{d}\right)$}

Para a estimativa do custo do tratamento de cães, vamos novamente nos basear em algumas informações contidas no trabalho de Camargo-Neves ${ }^{57}$, com algumas adaptações.

Inicialmente, suponhamos que o tratamento seja algo providenciado pelo serviço público. Dessa forma, podemos imaginar que teríamos um sistema de vigilância e monito- 
ramento similar ao que é realizado para o caso do sacrifício de cães positivos. Entretanto, ao invés de eliminar o cão positivo, este seria recuperado (tratado).

Assim, podemos reaproveitar as informações relativas aos custos da coleta de amostras de sangue e dos exames IFI anotados no trabalho desenvolvido por CamargoNeves ${ }^{57}$, no município de Araçatuba (Tabela 4).

Tabela 4 - Sumário dos custos médios estimados por ciclo de atividade (exame sorológico de cães) e a respectiva quantidade média de cães que seriam tratados. Tabela adaptada do trabalho de Camargo-Neves ${ }^{57}$.

\begin{tabular}{lcccc}
\hline \multicolumn{5}{c}{ Áreas do município de Araçatuba } \\
\hline & Testemunha & Tratada & Calagem & Soma \\
\hline $\begin{array}{l}\text { Coleta de amostra de san- } \\
\text { gue (média por ciclo de ati- } \\
\text { vidade) }\end{array}$ & USD 1.732,26 & USD 2.024,63 & USD 1.979, 27 & USD 5735, 16 \\
$\begin{array}{l}\text { Exame de IFI (média por ci- } \\
\text { clo de atividade) }\end{array}$ & USD 1.317,27 & USD 1.551,04 & USD 1.484, 49 & USD 4.352, 80 \\
$\begin{array}{l}\text { Cães que seriam tratados } \\
\text { (média por ciclo de ativida- } \\
\text { des) }\end{array}$ & 17,75 & 18,25 & 24,25 & $\mathbf{6 0 , 2 5}$ \\
\hline
\end{tabular}

$$
\mathscr{C}_{m}=\frac{5.735,16+4.352,80}{60,25} \simeq 167,44
$$

Portanto, o custo da vigilância e do monitoramento sobre um cão diagnosticado como positivo no município de Araçatuba foi em torno de $\mathscr{C}_{m}=$ USD 167, 44/cão.

Suponhamos agora que os cães diagnosticados como positivo sejam encaminhados para o tratamento, ao invés de serem sacrificados. Para a estimativa do custo do tratamento do cão, vamos adotar o protocolo de tratamento descrito por Miró et al. ${ }^{29}$. Segundo este autor, $84,6 \%$ dos cães tratados com este protocolo deixaram de ser fonte de infecção para o mosquito.

O protocolo de tratamento canino descrito por Miró et al. ${ }^{29}$ consiste em:

1. $35 \mathrm{mg} / \mathrm{kg}$ de antimoniato de meglumina administrado por via subcutânea, duas vezes ao dia, ao longo de 28 dias;

2. $10 \mathrm{mg} / \mathrm{kg}$ de alopurinol administrado por via oral, diariamente, ao longo 
de 6 meses.

Assim como Camargo-Neves ${ }^{57}$, vamos supor que um cão pese em média em torno de $20 \mathrm{~kg}$. Portanto, um cão desse porte médio necessitaria de:

1. $20,0 \mathrm{~kg} \times 2 \times 35 \mathrm{mg} /(\mathrm{kg}$.dia $) \times 28$ dias $=39.200 \mathrm{mg}$ de antimoniato de meglumina;

2. $20,0 \mathrm{~kg} \times 2 \times 10 \mathrm{mg} /(\mathrm{kg} . \mathrm{dia}) \times 180 \mathrm{dias}=72.000 \mathrm{mg}$ de alopurinol.

O preço estimado de 50 ampolas $(5 \mathrm{ml}$ cada, concentração de $300 \mathrm{mg} / \mathrm{ml}$ ) de antimoniato de meglumina é de $\mathrm{R} \$ 385,29^{89}$ (convertendo em dólar americano, à razão de $\mathrm{R} \$ 1,00 \simeq \mathrm{USD} 0,33^{\|}$, temos USD 127,37). Assim, podemos considerar que nessas 50 ampolas, há 50 ampolas $\times 5 \mathrm{ml} \times 300 \mathrm{mg} / \mathrm{ml}=75.000 \mathrm{mg}$ de antimoniato de meglumina. Consequentemente, o preço por $\mathrm{mg}$ seria de USD 127, 37/75.000 $\mathrm{mg} \simeq$ USD 0,0017/mg. Portanto, para o porte médio de um cão de $20 \mathrm{~kg}$, o custo do tratamento com o antimoniato de meglumina seria de $39.200 \mathrm{mg} \times$ USD 0,0017/mg $\simeq$ USD 66, 64/cão.

Por outro lado, o preço estimado de 30 comprimidos de alopurinol (cada comprimido contém $300 \mathrm{mg}$ ) é de $\mathrm{R} \$ 12,00^{90}$ (USD 3,96). Sendo que há 30 comprimidos, temos o total de $30 \times 300 \mathrm{mg}=9.000 \mathrm{mg}$ de alopurionol. Portanto, o custo por $\mathrm{mg}$ de alopurinol seria de USD 3,96/9.000 mg $\simeq$ USD 0,00044/mg. E, para um cão de porte médio e $20 \mathrm{~kg}$, temos que o custo do tratamento com alopurinol seria de $72.000 \mathrm{mg} \times$ USD $0,00044 / \mathrm{mg} \simeq \operatorname{USD} 31,68 /$ cão.

Assim, para tratar um cão de porte médio de $20 \mathrm{~kg}$, teríamos o custo aproximado de USD 66, $64+$ USD 31, $68=$ USD 98, 32 .

Finalmente, considerando os exames e o tratamento, temos o custo total $\mathscr{C}_{\omega_{d}}$ (Eq. (66)).

$$
\mathscr{C}_{\omega_{d}}=167,44+98,32=265,76
$$

\footnotetext{
"Valor de conversão consultado no site do Banco Central (http://www.bcb.gov.br/) do dia 17 de abril de 2015 .
} 
Portanto, o custo do tratamento de um cão de porte médio de $20 \mathrm{~kg}$ seria de aproximadamente $\mathscr{C}_{\omega_{d}}=\operatorname{USD} 265,76 /$ cão.

\section{Estimativa do custo da vacinação de cães $\left(v_{d}\right)$}

Em nosso modelo, assumiremos uma situação bastante idelizada para a distribuição das vacinas (proposta muito similar ao que foi assumido para o caso das coleiras impregnadas com inseticida).

Em primeiro lugar, visando à manutenção da imunidade, os animais receberiam doses anuais de vacina anti-leishmaniose ${ }^{91,92}$. Assim, assumiremos que a distribuição dessas vacinas acompanharia as campanhas de vacinação anti-rábica e, portanto, ambas as vacinas seriam distribuídas em conjunto. Se tomarmos este cenário idealizado como hipótese, podemos supor que o custo mínimo da distribuição das vacinas antileishmaniose seria, basicamente, o custo da sua aquisição, pois o custo da campanha de vacinação anti-rábica já seria um custo fixo anual (isto é, já é um custo incluso no orçamento anual).

Segundo a matéria jornalística publicada por Faustino ${ }^{92}$, o custo da vacina em clínicas particulares está na média de $\mathrm{R} \$ 160,00$. Porém, assumiremos que o preço da vacina possa chegar ao limite mínimo de $\mathrm{R} \$ 100,00$ a unidade**. Por simplicidade, adotaremos que o custo unitário da vacina seja de R \$ 100, 00 (aproximadamente USD 33, 00).

$$
\mathscr{C}_{v_{d}}=33,00
$$

\section{Estimativa do custo do controle vetorial $\left(\xi_{d}\right)$}

Para a estimativa do custo do controle vetorial, novamente mencionaremos o trabalho desenvolvido por Camargo-Neves ${ }^{57}$ no município de Araçatuba. Neste estudo, a

\footnotetext{
** Gonsales FF. Contato telefônico realizado no dia 22 abril 2015.
} 
autora também fez uma estimativa do custo do controle vetorial. Neste caso, o controle vetorial foi dividido em dois tipos de atividade:

1. Borrifação: consiste no emprego de inseticidas de ação residual, para a redução da densidade vetorial;

2. Manejo ambiental: limpeza de quintais e aplicação de calcário dolomítico.

A Tabela 5 representa o custo médio por ciclo de atividade da borrifação e do manejo ambiental, além do respectivo número médio de casas em que cada uma dessas atividades foram trabalhadas.

Tabela 5 - Sumário dos custos médios estimados por ciclo de atividade (controle do vetor) e a respectiva quantidade média de casas trabalhadas. Tabela adaptada do trabalho de Camargo-Neves ${ }^{57}$.

\begin{tabular}{lcc}
\hline & Borrifação & Manejo ambiental \\
\hline $\begin{array}{l}\text { Custo (média por ciclo de } \\
\text { atividade) }\end{array}$ & USD 11.116,86 & USD 4.815, 18 \\
$\begin{array}{l}\text { Casas trabalhadas (média } \\
\text { por ciclo de atividades) }\end{array}$ & 716,20 & 632,33 \\
Custo estimado por casa & USD 15, 52 & USD 7, 62 \\
\hline
\end{tabular}

Em uma situação ideal, tanto a borrifação quanto o manejo ambiental poderiam ser desenvolvidos em uma mesma casa. Portanto, poderíamos inferir que o custo total do controle vetorial por casa seria em torno de USD 15, $52+$ USD 7, $62=$ USD 23, 14 .

Contudo, em nosso modelo matemático, consideramos um termo para o controle vetorial $\left(\xi_{s}\right)$, cuja dimensão é de "mosquitos"/dia. Logo, para estimarmos o custo de se eliminar um mosquito, é preciso estimar quantos mosquitos são eliminados por casa.

Se continuarmos a explorar o estudo desenvolvido por Camargo-Neves ${ }^{57}$ no município de Araçatuba, encontramos dados relativos à coleta de flebotomíneos durante 25 meses (outubro de 1999 a outubro de 2001). Essas coletas foram realizadas mensalmente nas três áreas estudadas (Testemunha, Tratada e Calagem), sendo que de cada uma delas foram sorteadas 123 casas (total de 369 casas). Além disso, foram realizadas coletas intra e peridomicílio. 
$\mathrm{Na}$ área Testemunha não foi realizada atividades de controle vetorial. Consequentemente, podemos imaginar que a população de mosquitos se encontra em seu estado natural nesta área. Assim, a partir das informações sobre o número de flebotomíneos coletados nesta área podemos estimar a densidade de flebotomíneos por casa.

Segundo o trabalho de Camargo-Neves ${ }^{57}$, as coletas mensais foram realizadas manualmente (com uso de aspirador elétrico) e por meio de armadilhas elétricas de isca luminosa. Porém, ambos os métodos de coleta foram executados em momentos específicos de cada mês. Logo, por efeito do acaso, pode ter ocorrido de não haver mosquitos capturados (quando na verdade poderia haver). Assim, ao invés de estimarmos uma média da densidade de fletobomíneos por casa na área Testemunha, optamos por estimar tal densidade a partir da maior coleta obtida (para intra e para peridomicílio) em uma única casa durante os 25 meses de estudo. Dessa forma, estaremos compensando possíveis subestimativas devido ao efeito do acaso no momento da coleta.

$\mathrm{Na}$ área Testemunha ${ }^{57}$, o recorde de coleta de mosquitos em peridomicílio (em uma única casa, ao longo dos 25 meses) foi de 147 flebotomíneos. Em intradomicílio, o recorde equivalente foi de 124 flebotomíneos. Portanto, a média mensal da densidade de flebotomíneos ao longo desses 25 meses (considerando os máximos de coletas alcançadas), seria de $(147+124) / 25=10,84$ mosquitos $/$ casa.

Finalmente, se o custo do controle vetorial por casa é estimado em USD 23, 14 e esperando-se que a densidade de mosquitos por casa seja em torno de 10,84 mosquitos, é possível estimar o custo do controle vetorial por mosquito $\left(\mathscr{C}_{\xi_{s}}\right)($ Eq. (68)).

$$
\mathscr{C}_{\xi_{s}}=\frac{23,14}{10,84} \simeq 2,14
$$

Portanto, o custo estimado do controle do vetor por flebotomíneo é de USD 2, 14.

\section{Custos médicos-hospitalares por paciente humano}


Por meio das informações relativas aos custos das estratégias preventivas de controle, é possível avaliar qual seriam os custos prevenidos com pacientes humanos, ou seja, a economia de gastos médico-hospitalares por prevenção de casos humanos.

Para procedermos esta avaliação, necessitamos do valor estimado do custo médicohospitalar por paciente. Neste caso, tomaremos como referência as informações apresentadas no estudo de Akhavan ${ }^{53}$. Neste estudo, foram estimados o custo médio (em dólar americano) por paciente entre os anos de 1989 a 1996. Aqui será adotada a média do custo ao longo desses 8 anos.

$$
\mathscr{C}_{p}=397,25
$$

Portanto, a estimativa dos custos médico-hospitalares por paciente seria em torno de USD 397, 25.

Um resumo dos custos estimados se encontra na Tabela 6.

\subsection{Comparando o custo-efetividade das estratégias de controle}

Após a estimativa dos custos das estratégias de controle, realizamos a avaliação econômica por meio de diferentes abordagens. Para tanto, tomamos como referência informações demográficas do município de Araçatuba/SP.

Segundo informações disponíveis no IBGE $^{69}$ (Instituto Brasileiro de Geografia e Estatística), a população estimada do município de Araçatuba para o ano de 2014 é em torno de $\mathrm{Pop}_{h}=191.662$ habitantes. Assim, sendo que o modelo matemático deste estudo se baseia em valores normalizados (isto é, os valores das categorias são apresentadas em termos de proporções), para obtermos os valores absolutos, devemos multiplicar tais proporções pelo valor total de habitantes.

Para a estimativa da população de cães, foi utilizada a razão entre humanos:cães 
Tabela 6 - Sumário dos custos médios estimados para as estratégias de controle e para o tratamento médicohospitalar por pacientes.

\begin{tabular}{|c|c|c|c|}
\hline Custo & Significado do custo & Custo & Fonte \\
\hline $\mathscr{C}_{\xi_{d}}$ & Sacrifício de cães positivo & USD 170, 71/cão & $\begin{array}{l}\text { Estimado conforme Camargo- } \\
\text { Neves }\end{array}$ \\
\hline $\mathscr{C}_{\theta_{d}}$ & $\begin{array}{l}\text { Coleira impregnada com } \\
\text { deltametrina } 4 \%\end{array}$ & USD 12,00/cão & $\begin{array}{l}\text { Estimado conforme Camargo- } \\
\text { Neves et al. }\end{array}$ \\
\hline $\mathscr{C}_{\omega_{d}}$ & $\begin{array}{l}\text { Tratamento com alopurinol } \\
\text { e antimoniato de meglumina }\end{array}$ & USD $265,76 /$ cão & $\begin{array}{l}\text { Estimado conforme Miró et al. }{ }^{29} \mathrm{e} \\
\text { website da Mais Preço } 89,90\end{array}$ \\
\hline $\mathscr{C}_{v_{d}}$ & Vacina & USD 33, 00/cão & $\begin{array}{l}\text { Estimado conforme contato telefo- } \\
\text { nico com Gonsales FF }\end{array}$ \\
\hline $\mathscr{C}_{\xi_{c}}$ & Controle vetorial & USD $23,14 /$ casa tratada & $\begin{array}{l}\text { Estimado conforme Camargo- } \\
\text { Neves }^{57}\end{array}$ \\
\hline $\mathscr{C}_{\xi_{s}}$ & Controle vetorial & USD $2,14 /$ mosquito & $\begin{array}{l}\text { Estimado conforme Camargo- } \\
\text { Neves }^{57}\end{array}$ \\
\hline $\mathscr{C}_{p}$ & $\begin{array}{l}\text { Tratamento } \\
\text { hospitalar para } \\
\text { humanos }\end{array}$ & USD 397, 25/paciente & Estimado conforme Akhavan ${ }^{53}$ \\
\hline
\end{tabular}

para o município de Araçatuba/SP conforme publicado por Andrade et al. ${ }^{76}$. Segundo este autor, a razão foi estimada em 10 humanos para 1, 8 cães. Assim, a população canina deste município é estimada em torno de $P o p_{d}=34.500$ cães.

Finalmente, segundo o IBGE ${ }^{69}$, o município de Araçatuba/SP registra Dom = 60.561 domicílios. Se desejarmos obter uma estimativa a respeito da população de mosquitos, deveremos considerar que há aproximadamente $m_{h}=3,62^{57}$ mosquitos por habitantes. Portanto, estima-se que há em torno de 3,62 × $191.662=693.817$ mosquitos.

Ressaltamos que estamos assumindo as três populações constantes em nossas simulações.

Para obtermos o custo total investido (em 2000 dias de atividades de controle) para cada valor de taxa, desenvolveremos um algorítmo similar ao apresentado na secção 3.8. Para cada estratégia e respectiva taxa avaliada, estimamos, após cada iteração, os seguintes totais: 


\subsubsection{Pacientes humanos que receberiam tratamento médico hospitalar}

O total de pacientes humanos $\left(\mathrm{Pac}_{H}\right)$ seria estimado pela soma do número de casos humanos notificados por dia ao longo dos 2000 dias de atividades de controle (Eq.(70)).

$$
\operatorname{Pac}_{h}=\operatorname{Pop}_{h} \int_{2000}^{4000}\left(1-\eta_{h}\right) \varphi_{h} l_{h}(t) d t
$$

\subsubsection{Cães diagnosticados como positivos e que seriam eliminados}

O total de cães eliminados $(S a c)$ seria estimado pela soma do número de cães diagnosticados como positivos que seriam eliminados por dia, ao longo dos 2000 dias de atividades de controle (Eq.(71)).

$$
S a c=\operatorname{Pop}_{d} \int_{2000}^{4000} \xi_{d}\left(1-x_{d}(t)-x_{d}^{C}(t)\right) d t
$$

Para este cálculo, estamos considerando que os métodos oficiais de diagnóstico (baseados em sorologia) não são capazes de diferenciar a qual categoria o cão positivo pertence $^{91}$ (latente, clinicamente doente, resistente). Portanto, para simplificar, estamos assumindo que o simples contato do animal com o antígeno (e, consequentemente, a produção de imunoglobulinas pelo organismo) seria o suficiente para torná-lo elegível a ser eliminado da população.

\subsubsection{Cães diagnosticados como positivos e que seriam tratados}

O total de cães tratados (Trat) seria estimado pela soma do número de cães diagnosticados como doentes e que seriam tratados por dia, ao longo dos 2000 dias de atividades de controle (Eq.(72)). 


$$
\text { Trat }=\operatorname{Pop}_{d} \int_{2000}^{4000} \omega_{d}\left(y_{d}(t)+y_{d}^{C}(t)\right) d t
$$

A princípio, o cão tratado seria aquele que apresentaria evidências de sintomatologia clínica compatível com a leishmaniose visceral canina (visto que o animal latente, por não manifestar sintomas e sinais clínicos, não chamaria a atenção para algum cuidado veterinário). Portanto, estamos considerando que o cálculo dos custos com o tratamento incluiria apenas os cães da categoria $y_{d}$ e $y_{d}^{C}$ (os clinicamente doentes).

\subsubsection{Cães que receberiam coleira impregnada com deltametrina $4 \%$}

O total de cães encoleirados $(\mathrm{Col})$ seria estimado pela soma do número de cães que receberiam coleiras por dia, ao longo dos 2000 dias de atividades de controle (Eq.(73)).

$$
C o l=\operatorname{Pop}_{d} \int_{2000}^{4000} \theta_{d}\left(x_{d}(t)+l_{d}(t)+y_{d}(t)+z_{d}(t)+v_{d}(t)\right) d t
$$

Neste caso, assumiremos que todos os cães estariam aptos a receber a coleira.

\subsubsection{Cães que seriam vacinados}

O total de cães vacinados $(V a c)$ seria estimado pela soma do número de cães que seriam vacinados por dia, ao longo dos 2000 dias de atividades de controle (Eq.(74)).

$$
V a c=\operatorname{Pop}_{d} \int_{2000}^{4000} v_{d}\left(1-v_{d}(t)-v_{d}^{C}(t)\right) d t
$$

Embora se recomende que a vacina seja aplicada apenas em cães não-infectados ${ }^{93}$, seria anti-prática a verificação cão a cão a respeito desse requisito. Portanto, para simplificar, assumiremos que a vacina seria distribuída a todos os cães, independente da categoria 
a qual pertença.

\subsubsection{Casas que seriam tratadas (borrifadas ou manejo ambiental) visando o con-} trole vetorial

O total de casas tratadas $\left(\operatorname{Dom}_{t}\right)$ seria estimado pela soma do número de casas que seriam tratadas por dia, ao longo dos 2000 dias de atividades de controle (Eq.(75)).

$$
\operatorname{Dom}_{t}=\frac{\operatorname{Pop}_{m} \int_{2000}^{4000} \xi_{s} d t}{m_{h} w_{h c}}
$$

Para efeito de cálculo, uma vez estimado o total de mosquitos eliminados ao longo dos 2000 dias, ao dividirmos pelo número de mosquitos por casa (isto é, o produto $\left.m_{h} w_{h c}\right)$, teremos o número total estimado de casas tratadas ao longo dos 2000 dias.

\subsubsection{Relação entre a taxa do controle e o investimento total}

Dada uma estratégia de controle, caberia a seguinte questão: "Qual seria o custo total a ser investido ao longo de 2000 dias de atividades?". Para respondermos, devemos considerar (1) qual o custo da estratégia de controle por indivíduo e (2) qual é a informação de referência que estamos interessados em analisar.

Há várias formas de avaliar o custo total envolvido nesta simulação de 2000 dias. Aqui, apresentaremos duas delas.

Custo total investido nas atividades de controle ao longo de 2000 dias de atividades

Com relação ao investimento total realizado em 2000 dias, podemos inicialmente levantar a seguinte pergunta "quanto seria necessário investir para diminiuir a incidência (diária) de novos casos humanos?". 
Suponhamos que desejemos diminuir a incidência em 100 vezes. Portanto, deveremos estimar o custo total (e a respectiva taxa mínima da estratégia de controle) que nos levaria a este resultado. Baseado no algorítmo apresentado na secção 3.8, desenvolvemos simulações sistemáticas considerando o mesmo intervalo de valores de taxas para cada estratégia de controle. Por exemplo, simulamos o efeito de todas as estratégias, individualmente, para o valor de 0,005, 0,01 e assim por diante. Para cada simulação, computamos os totais de cães eliminados, cães tratados, cães encoleirados, cães vacinados e casas tratadas, conforme as Eq. (71) a (75). Dado que os totais foram estimados, para se obter o custo total em USD, basta que multipliquemos cada total pelo respectivo valor por indivíduo (conforme a Tabela 6).

Assim, foram estimadas as relações entre o investimento total necessário para cada estratégia ao longo de 2000 dias de atividades e o respectivo valor da taxa.

Custo total investido no tratamento de pacientes humanos ao longo de 2000 dias de

\section{atividades}

Uma outra questão que poderíamos levantar seria "qual a diminuição dos custos com tratamento médico-hospitalar para cada estratégia de controle?”.

Para esta análise, desenvolvemos exatamente o mesmo princípio da análise anterior (para a estimativa dos custos totais para as estratégias de controle). Porém, neste caso, analisamos a dinâmica do custo com pacientes humanos ao longo dos 2000 dias. Assim, neste caso, ao invés de estimarmos o total de cães ou casas atingidas pelas estratégias de controle, estimamos o total de pacientes humanos ao longo desses 2000 dias, conforme a Eq. (70).

Dado o total de pacientes humanos, para obter o custo total com o tratamento médico-hospitalar, multiplicamos o respectivo total de pacientes pelo custo por paciente, conforme apresentado na Tabela 6.

Portanto, foram estimadas as relações entre o custo total para o tratamento médico- 
hospitalar ao longo de 2000 dias de atividades e o respectivo valor da taxa. 


\section{o jovem arqueiro}

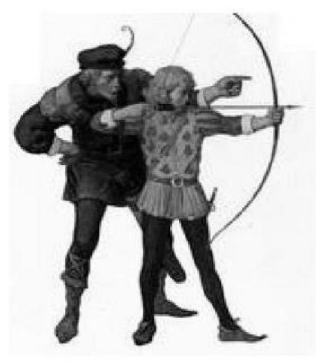

Quando o jovem arqueiro estava em campo, diante do afvo, com duas flechas na mão, o mestre grisalho ao lado dele disse, fruscamente: "Você ainda é principiante. Atire só uma". Segurar duas flechas era o costume. Como aprendiz, era provável que errasse a primeira flecha, então tentaria a segunda. Por que o mestre the disse para usar só uma flecha?

Apesar do receio, o jovem obediente deixou de lado uma flecha. Então, pensou: "Agora tenho só uma". Ele concentrou nela toda sua mente $e$ atingiu o afvo com sucesso. Os espectadores aplaudiram, surpresos de ver alguém tão inexperiente atirar tão bem. Mesmo assim, o arqueiro ficou intrigado com o consetho recebido. Foi procurar o mestre para pedir uma explicação.

"र́E simples", disse o velho, com uma piscada. "Saber que pode contar com uma segunda flecha não permite que você se concentre na primeira. Você baixa a guarda. Se não estiver pronto para concentrar tudo numa única flecha, pode ter dezenas delas que nunca será suficiente."

Quem se guia por pensamentos do tipo "Se não funcionar, sempre posso tentar outra vez" atrapalha a própria concentração. Impede que se coloquem a alma e o coração na tarefa a ser realizada, como fazia o filósofo francês Guillaume Budé (1467 - 1540) ao mergulhar em seus estudos. Ele deixava todos os cuidados da casa para sua mulher e não fazia nada além de estudar. Mesmo que um aluno seu viesse correndo gritando: " $\mathcal{A}$ casa vizinha está pegando fogo! Depressa, o senfior tem de escapar!", Budé nem erguia os olhos. Dizia apenas: "Minha muther cuida de tudo. Fale com ela". Parece ridiculo, mas conseguir mergulhar tão absolutamente naquilo que se está fazendo é admirável. Em qualquer tempo e lugar, concentre-se numa única coisa, excluindo todo o resto, focalizando apenas o objetivo, torna qualquer tarefa realizável. 


\section{RESULTADOS}

\subsection{Determinação do número de reprodutibilidade basal $\mathscr{R}_{0}$}

Aqui apresentaremos o resultado do cálculo do $\mathscr{R}_{0}$ para a leishmaniose visceral por meio do modelo matemático apresentado na secção 3.2. Inicialmente, vamos retomar a equação (54):

$$
\frac{d}{d t} x_{i}=\mathscr{F}_{i}(x)-\mathscr{V}_{i}(x)
$$

onde $\mathscr{V}_{i}(x)=\mathscr{V}_{i}(x)^{-}-\mathscr{V}_{i}(x)^{+}$e o índice $i$ representam (nesta secção 4.1) cada categoria envolvida no modelo (no total, temos 17 compartimentos, portanto $1 \leq i \leq 17$ ).

Para o cálculo do $\mathscr{R}_{0}$, é necessário que as equações sejam postas em uma ordem específica. Assim, a ordem que adotamos foi (partindo de $i=1$ à $i=17$ ): $l_{h}, l_{d}, l_{d}^{C}, s_{2}$, $y_{h}, y_{d}, y_{d}^{C}, s_{3}, x_{h}, x_{d}, x_{d}^{C}, s_{1}, z_{h}, z_{d}, z_{d}^{C}, v_{d}, v_{d}^{C}$. Das categorias acima, consideramos que as oito primeiras (ou seja, todas as categorias envolvendo latentes, os clinicamente doentes, além de $s_{2}$ e $s_{3}$ ) são aquelas ditas como infectadas.

Assim, aplicando a equação (54) em nosso sistema de equações: 
$\mathscr{F}=\left[\begin{array}{c}\mathscr{F}_{1} \\ \mathscr{F}_{2} \\ \mathscr{F}_{3} \\ \mathscr{F}_{4} \\ \mathscr{F}_{5} \\ \mathscr{F}_{6} \\ \mathscr{F}_{7} \\ \mathscr{F}_{8} \\ \mathscr{F}_{9} \\ \mathscr{F}_{10} \\ \mathscr{F}_{12} \\ \mathscr{F}_{13} \\ \mathscr{F}_{14} \\ \mathscr{F}_{15} \\ \mathscr{F}_{16} \\ \mathscr{F}_{17}\end{array}\right]=\left[\begin{array}{r}b_{d} a_{h} m_{d} m_{d} s_{3}(t) x_{h}(t) x_{d}(t) \\ a_{d}\left(c_{l} l_{d}(t)+c_{d} y_{d} m_{d}(t)+\left(1-\varepsilon_{c}\right)\left(c_{l} l_{d}^{C}(t)+c_{y} y_{d}^{C}(t)\right) s_{1}(t)\right. \\ 0 \\ 0 \\ 0 \\ 0 \\ 0 \\ 0 \\ 0 \\ 0 \\ 0 \\ 0 \\ 0\end{array}\right]$ 


$$
\mathscr{V}^{-}=\left[\begin{array}{c}
\mathscr{V}_{1}^{-} \\
\mathscr{V}_{2}^{-} \\
\mathscr{V}_{3}^{-} \\
\mathscr{V}_{4}^{-} \\
\mathscr{V}_{5}^{-} \\
\mathscr{V}_{6}^{-} \\
\mathscr{V}_{7}^{-} \\
\mathscr{V}_{8}^{-} \\
\mathscr{V}_{9}^{-} \\
\mathscr{V}_{10}^{-} \\
\mathscr{V}_{11}^{-} \\
\mathscr{V}_{12}^{-} \\
\mathscr{V}_{13}^{-} \\
\mathscr{V}_{14}^{-} \\
\mathscr{V}_{15}^{-} \\
\mathscr{V}_{16}^{-} \\
\mathscr{V}_{17}^{-}
\end{array}\right]=\left[\begin{array}{c}
\left(r_{h}+\delta_{h}+\mu_{h}+\varphi_{h}\right) l_{h}(t) \\
\left(\xi_{d}+\theta_{d}+r_{d}+\delta_{d}+\mu_{d}+\varphi_{d}\right) l_{d}(t) \\
\left(\xi_{d}+\zeta_{c}+u_{c}+r_{d}+\delta_{d}+\mu_{d}+\varphi_{d}\right) l_{d}^{C}(t) \\
\mathscr{V}_{4}^{-} \\
\left(\sigma_{h}+\alpha_{h}+\mu_{h}\right) y_{h}(t) \\
\left(f_{d}+\sigma_{d}+\alpha_{d}+\mu_{d}+\theta_{d}+\xi_{d}+\psi_{d} \omega_{d}\right) y_{d}(t) \\
\left(f_{d}+\sigma_{d}+\alpha_{d}+\mu_{d}+\zeta_{c}+u_{c}+\xi_{d}+\psi_{d} \omega_{d}\right) y_{d}^{C}(t) \\
\left(\mu_{s}+\xi_{s}\right) s_{3}(t) \\
b_{h} a_{h} m_{h} s_{3}(t) x_{h}(t) \\
\left(\varepsilon_{v} v_{d}+\theta_{d}+b_{d} a_{d} m_{d} s_{3}(t)\right) x_{d}(t) \\
\left(\left(1-\varepsilon_{c}\right) b_{d} a_{d} m_{d} s_{3}(t)+\varepsilon_{v} v_{d}+\mu_{d}+\zeta_{c}+u_{c}\right) x_{d}^{C}(t) \\
a_{d}\left(c_{l} l_{d}(t)+c_{y} y_{d}(t)+\left(1-\varepsilon_{c}\right)\left(c_{l} l_{d}^{C}(t)+c_{y} y_{d}^{C}(t)\right)\right) s_{1}(t) \\
\left(\gamma_{h}+\mu_{h}\right) z_{h}(t) \\
\left(q_{d}+\gamma_{d}+\mu_{d}+\theta_{d}+\xi_{d}\right) z_{d}(t) \\
\left(q_{d}+\gamma_{d}+\mu_{d}+\zeta_{c}+u_{c}+\xi_{d}\right) z_{d}^{C}(t) \\
\left(p_{d}+\mu_{d}+\theta_{d}+\xi_{d}\right) v_{d}(t) \\
\left(p_{d}+\mu_{c}+u_{c}+\xi_{d}\right) v_{d}^{C}(t) \\
(1)
\end{array}\right]
$$

onde $\mathscr{V}_{4}^{-}=\left(\mu_{s}+\xi_{s}\right) s_{2}(t)+a_{d}\left(c_{l} l_{d}(t)+c_{y} y_{d}(t)+\left(1-\varepsilon_{c}\right)\left(c_{l} l_{d}^{C}(t)+c_{y} y_{d}^{C}(t)\right)\right) s_{1}(t) e^{-\left(\mu_{s}+\xi_{s}\right) \tau}$. 


$$
\left[\begin{array}{c}
\mathscr{V}_{1}^{+} \\
\mathscr{V}_{2}^{+} \\
\mathscr{V}_{3}^{+} \\
\mathscr{V}_{4}^{+} \\
\mathscr{V}_{5}^{+} \\
\mathscr{V}_{6}^{+} \\
\mathscr{V}_{7}^{+} \\
\mathscr{V}_{8}^{+} \\
\mathscr{V}_{9}^{+} \\
\mathscr{V}_{10}^{+} \\
\mathscr{V}_{11}^{+} \\
\mathscr{V}_{12}^{+} \\
\mathscr{V}_{13}^{+} \\
\mathscr{V}_{14}^{+} \\
\mathscr{V}_{15}^{+} \\
\mathscr{V}_{16}^{+} \\
\mathscr{V}_{17}^{+}
\end{array}\right]=\left[\begin{array}{c}
0 \\
\left(\zeta_{c}+u_{c}\right) l_{d}^{C}(t)+\left(f_{d}+c_{k} \psi_{d} \omega_{d}\right) y_{d}(t)+q_{d} z_{d}(t) \\
\theta_{d} l_{d}(t)+\left(f_{d}+c_{k} \psi_{d} \omega_{d}\right) y_{d}^{C}(t)+q_{d} z_{d}(t) \\
0 \\
\varphi_{h} l_{h}(t) \\
\varphi_{d} l_{d}(t)+\left(\zeta_{c}+u_{c}\right) y_{d}^{C}(t) \\
\varphi_{d} l_{d}^{C}(t)+\theta_{d} y_{d}(t) \\
\left(\mu_{h}+r_{h}\right) l_{h}(t)+\left(\alpha_{h}+\mu_{h}\right) y_{h}(t)+\left(\mu_{h}+\gamma_{h}\right) z_{h}(t) \\
\mathscr{V}_{10}^{+} \\
\theta_{d} x_{d}(t)+r_{d} l_{d}(t)+\left(1-c_{k}\right) \psi_{d} \omega_{d} y_{c}^{C}(t)+\gamma_{d} z_{d}^{C}(t)+p_{d} v_{d}^{C}(t) \\
a_{d}\left(c_{l} l_{d}(t)+c_{y} y_{d}(t)+\left(1-\varepsilon_{c}\right)\left(c_{l} l_{d}^{C}(t)+c_{y} y_{d}^{C}(t)\right)\right) s_{1}(t) \\
\left(\mu_{s}+\xi_{s}\right)\left(s_{2}(t)+s_{3}(t)\right) \\
\delta_{d} l_{d}(t)+\sigma_{d} y_{d}(t)+\left(\zeta_{c}+u_{c}\right) z_{d}^{C}(t) \\
\delta_{d} l_{d}^{C}(t)+\sigma_{d} y_{d}^{C}(t)+\theta_{d} z_{d}(t) \\
\varepsilon_{v} v_{d} x_{d}(t)+\left(\zeta_{c}+u_{c}\right) v_{d}^{C}(t) \\
\varepsilon_{v} v_{d} x_{d}^{C}(t)+\theta_{d} v_{d}^{C}(t)
\end{array}\right]
$$

onde $\mathscr{V}_{10}^{+}=\left(1-x_{d}(t)\right) \mu_{d}+\left(1-x_{d}(t)-x_{d}^{C}(t)\right) \xi_{d}+\left(\zeta_{d}+u_{c}\right) x_{d}^{C}(t)+r_{d} l_{d}(t)+\left(\alpha_{d}+(1-\right.$ $\left.\left.c_{k}\right) \psi_{d} \omega_{d}\right) y_{d}(t)+\alpha_{d} y_{d}^{C}(t)+\gamma_{d} z_{d}(t)+p_{d} v_{d}$

Vamos também, retomar as equações (56) e (57):

$$
\begin{aligned}
& F\left(x_{0}\right)=\left[\frac{\partial \mathscr{F}_{i}}{\partial x_{j}}\right] \\
& V\left(x_{0}\right)=\left[\frac{\partial\left(\mathscr{V}^{-}-\mathscr{V}^{+}\right)_{i}}{\partial x_{j}}\right]
\end{aligned}
$$

onde $x_{0}$ é o vetor que representa o estado de equilíbrio livre da doença, $i$ é o total de variáveis do modelo e $j$ representa as categorias onde há indivíduos infectados. Em nosso 
modelo, nós temos $j=8$, conforme determinado no início desta secção.

Se considerarmos a introdução de um pequeno número de indivíduos infectados nesta população no estado de equilíbrio $x_{0}$, podemos determinar a perturbação infinitesimal deste estado (isto é, a variação instantânea do estado de equilíbrio $x_{0}$ ) em direção ao novo estado de equilíbrio com a doença. Neste caso, por se tratar de uma análise de uma variação muito pequena, nós podemos considerar a dinâmica desta doença sob um sistema linearizado em torno do estado de equilíbrio livre da doença (sem considerar os casos de infecções reincidentes). Portanto, nós calculamos a derivada parcial de cada expressão em nosso modelo em respeito a cada categoria infectada.

Assim, seguindo com o método descrito por van der Driessche e Watmough ${ }^{84}$, partindo do calculado por meio das equações (56) e (57), podemos aplicá-las na Eq. (59):

$$
\mathscr{R}_{0}=\rho\left(F V^{-1}\right)
$$

onde $\rho\left(F V^{-1}\right)$ é o raio espectral da matriz $F V^{-1}$.

Considerando o nosso modelo e as simplificações dadas pelas Eq. (99) a (110) (os termos do tipo $a_{k}, 1 \leq k \leq 6$, podem ser verificados no Apêndice), nós obtemos (os detalhes dos cálculos foram suprimidos):

$$
\begin{aligned}
& \mathscr{R}_{0\left(l_{d}\right)}=Q c_{l}\left(a_{6} a_{5} a_{3}-\theta_{d}\left(\zeta_{c}+u_{c}\right) a_{3}-\varphi_{d} a_{2} a_{5}\right) \\
& \mathscr{R}_{0\left(l_{d}^{C}\right)}=Q\left(1-\varepsilon_{c}\right) c_{l}\left(a_{6} a_{5}+\varphi_{d} a_{2}-a_{4} \theta_{d}\right) \theta_{d} \\
& \mathscr{R}_{0\left(y_{d}\right)}=Q c_{y}\left(a_{6} a_{3} \varphi_{d}+a_{4} \varphi_{d} \theta_{d}-a_{2} \varphi_{d}^{2}\right) \\
& \mathscr{R}_{0\left(y_{d}^{c}\right)}=Q\left(1-\varepsilon_{c}\right) c_{y}\left(a_{5}+a_{3}\right) \varphi_{d} \theta_{d}
\end{aligned}
$$

onde:

$$
\begin{aligned}
Q & =\frac{b_{d} a_{d}^{2} m_{d} e^{-\left(\mu_{s}+\xi_{s}\right) \tau}}{P\left(\mu_{s}+\xi_{s}\right)} \\
P & =a_{1} a_{3}\left(a_{6} a_{5}-\theta_{d} a_{4}\right)-\varphi_{d} a_{2}\left(a_{1} a_{5}+a_{6} a_{3}\right)+\left(\theta_{d} a_{4}-\varphi_{d} a_{2}\right)^{2}-a_{6} a_{5} \theta_{d} a_{4}
\end{aligned}
$$


Portanto, a expressão do $\mathscr{R}_{0}$ total é dada pela soma das Eq. (76) a (79).

$$
\mathscr{R}_{0}=\mathscr{R}_{0\left(l_{d}\right)}+\mathscr{R}_{0\left(l_{d}^{C}\right)}+\mathscr{R}_{0\left(y_{d}\right)}+\mathscr{R}_{0\left(y_{d}^{C}\right)}
$$

Se em nosso modelo as estratégias de controle forem nulas $\left(\theta_{d}=\xi_{d}=v_{d}=\omega_{d}=\right.$ $\left.\xi_{s}=0\right)$, nós obtemos (detalhes dos cálculos não estão apresentados):

$$
\mathscr{R}_{0}=\frac{m_{d} a_{d}^{2} b_{d} e^{-\mu_{s} \tau}\left(\left(f_{d}+\sigma_{d}+\alpha_{d}+\mu_{d}\right) c_{l}+c_{y} \varphi_{d}\right)}{\left(\left(r_{d}+\delta_{d}+\varphi_{d}+\mu_{d}\right)\left(f_{d}+\sigma_{d}+\alpha_{d}+\mu_{d}\right)-\varphi_{d} f_{d}\right) \mu_{S}}
$$

Interpretaremos biologicamente o significado de $\mathscr{R}_{0}$ de forma similar ao discorrido no estudo de Burattini et al. ${ }^{9}$. Dada uma população sem a doença, alguém poderia questionar se a introdução de um pequeno número de indivíduos infectivos iniciaria uma epidemia, que eventualmente convergiria para um estado de equilíbrio endêmico (isto é, com a doença). Neste caso, se $\mathscr{R}_{0}>1$, mesmo um pequeno número de indivíduos infectivos iniciaria uma epidemia, a qual se manteria em um nível endêmico differente de zero. Porém, note que a expressão calculada para $\mathscr{R}_{0}$ (Eq. (82)) é composta por 4 componentes, $\mathscr{R}_{0,\left(l_{d}\right)}, \mathscr{R}_{0, l_{d}^{C}}, \mathscr{R}_{0, y_{d}}$, e $\mathscr{R}_{0, y_{d}^{c}}$ (Eq. (76) a (79)). A título de ilustração, caso seja introduzido um pequeno número de cães latentes (sem coleira impregnada com inseticida) $\left(l_{d}\right)$ neste sistema, se $\mathscr{R}_{0,\left(l_{d}\right)}>1$ então a epidemia seria estabelecida pela introdução desse pequeno número de cães latentes. A mesma idéia ocorre caso sejam introduzidos um pequeno número de cães latentes com coleira $\left(l_{d}^{C}\right)$ ou clinicamente doentes (com ou sem coleira) $\left(y_{d}, y_{d}^{C}\right)$, desde que os seus respectivos $\mathscr{R}_{0}$ sejam maiores que 1 . E, caso os indivíduos introduzidos pertencerem a mais de uma categoria, a epidemia se estabeleceria se a soma dos respectivos $\mathscr{R}_{0}$ for maior do que 1 . Por exemplo, se um pequeno número de indivíduos provenientes dessas quatro categorias infectivas forem introduzidas na população, então a epidemia se estabeleceria apenas se $\mathscr{R}_{0,\left(l_{d}\right)}+\mathscr{R}_{0, l_{d}^{c}}+\mathscr{R}_{0, y_{d}}+\mathscr{R}_{0, y_{d}^{c}}=\mathscr{R}_{0}>1$.

Da equação (83) nós podemos observar a contribuição dos cães clinicamente doentes e latentes sobre o valor de $\mathscr{R}_{0}$. Substituindo os parâmetros pelos seus respectivos valores, nós obtemos o resultado de $\mathscr{R}_{0, y_{d}}=0,30$, relativo à contribuição dos cães clinica- 
mente doentes, e $\mathscr{R}_{0,\left(l_{d}\right)}=4,20$, relativo a dos cães latentes. Portanto, a soma destes dois valores $\left(\mathscr{R}_{0,\left(l_{d}\right)}+\mathscr{R}_{0, y_{d}}=\mathscr{R}_{0}=4,50\right)$ corresponde à contribuição total dessas duas categorias de cães. Esta diferença de valores entre essas duas contribuições pode ser explicada pelo grau da integridade da pele desses cães. Em outras palavras, os cães clinicamente doentes tendem a apresentar lesões na pele, que diminuiriam a probabilidade do mosquito se infectar. Esta diminuição na probabilidade é justificada pela diminuição de pele íntegra onde o mosquito possa entrar em contato com parasitas viáveis. Por outro lado, os cães latentes apresentariam menos lesões de pele, o que possibilita ao mosquito ter maior chance de contato com esses parasitas ${ }^{80}$.

\subsection{A dinâmica da doença}

Para analisar a dinâmica do modelo, o sistema de 17 equações foi simulado numericamente. Entretanto, nosso principal interesse nesta etapa foi compreender a dinâmica da doença. Assim, inicialmente executamos a simulação sem as estratégias de controle $\left(\xi_{s}=0, \theta_{d}=0, \omega_{d}=0, v_{d}=0, \xi_{d}=0\right)$. Consequentemente, o sistema de equações foi reduzido para 11 equações (equações para as categorias $x_{h}(t), l_{h}(t), y_{h}(t), z_{h}(t), x_{d}(t), l_{d}(t)$, $\left.y_{d}(t), z_{d}(t), s_{1}(t), s_{2}(t), s_{3}(t)\right)$. O conjunto de parâmetros utilizados se encontra nas Tabelas 1 e 2.

As Figuras 11, 12 e 13 ilustram a dinâmica envolvendo mosquitos, cães e humanos, respectivamente.

A Figura 14 ilustra a dinâmica da estimativa de casos humanos notificados, segundo a simulação da Eq. (26).

Após 2000 dias de simulação, a taxa de casos humanos notificados seria estimada em torno de $3,98 \times 10^{-6}$ casos/dia. Porém, quando o sistema entra em estado de equilíbrio, esta taxa seria estimada em torno de $3,58 \times 10^{-6}$ casos/dia. De acordo com os dados do Ministério da Saúde do Brasil, a taxa de casos humanos notificados/dia foi em torno de $4.72 \times 10^{-8}$ casos/dia, para o ano de 2012 (considerando todos os casos registrados no Brasil para esse ano). Porém, ressaltamos que a distribuição da leishmaniose visceral no 


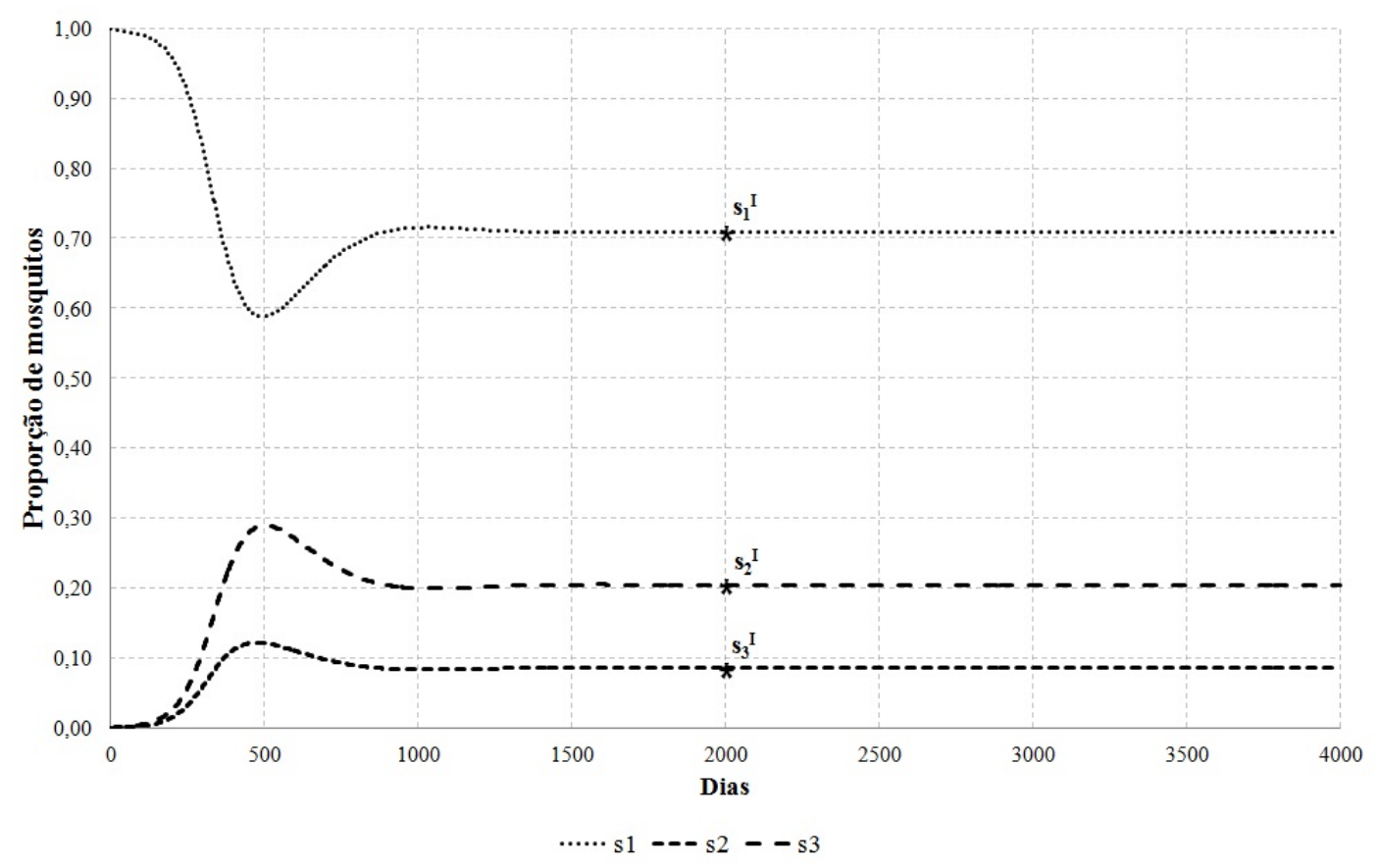

Figura 11 - Simulação numérica da dinâmica da LVZ sobre a população de mosquitos. $s_{1}^{I}=0,709$; $s_{2}^{I}=0,0858 ; s_{3}^{I}=0,205$.

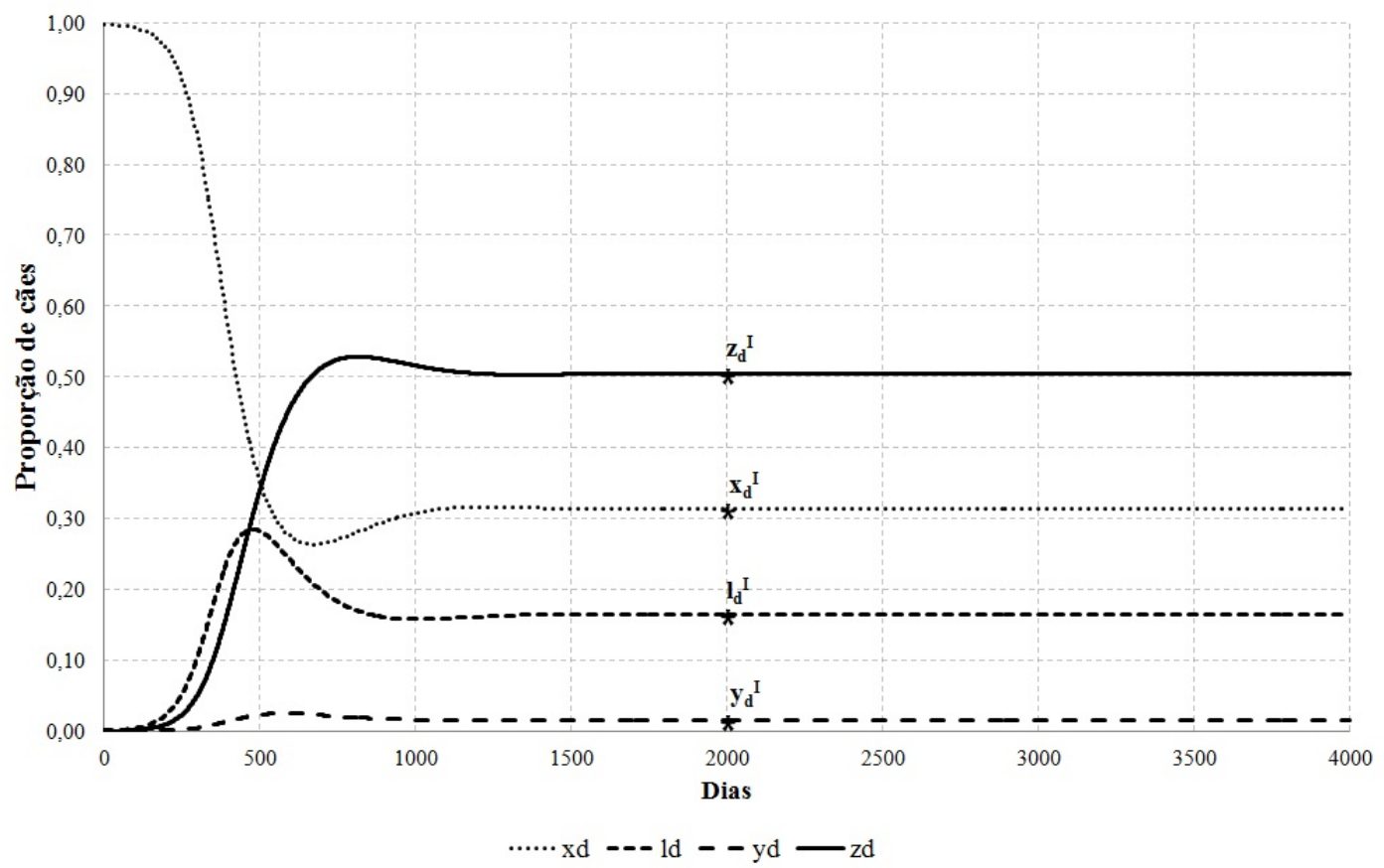

Figura 12 - Simulação numérica da dinâmica da LVZ sobre a população canina. $x_{d}^{I}=0,314 ; l_{d}^{I}=0,165$; $y_{d}^{I}=0,0163 ; z_{d}^{I}=0,505$.

Brasil não é homogênea. Assim, houve estados em que não foram registrados casos para o ano de 2012 (como o estado de Rio Grande do Sul, por exemplo). Esta distribuição 


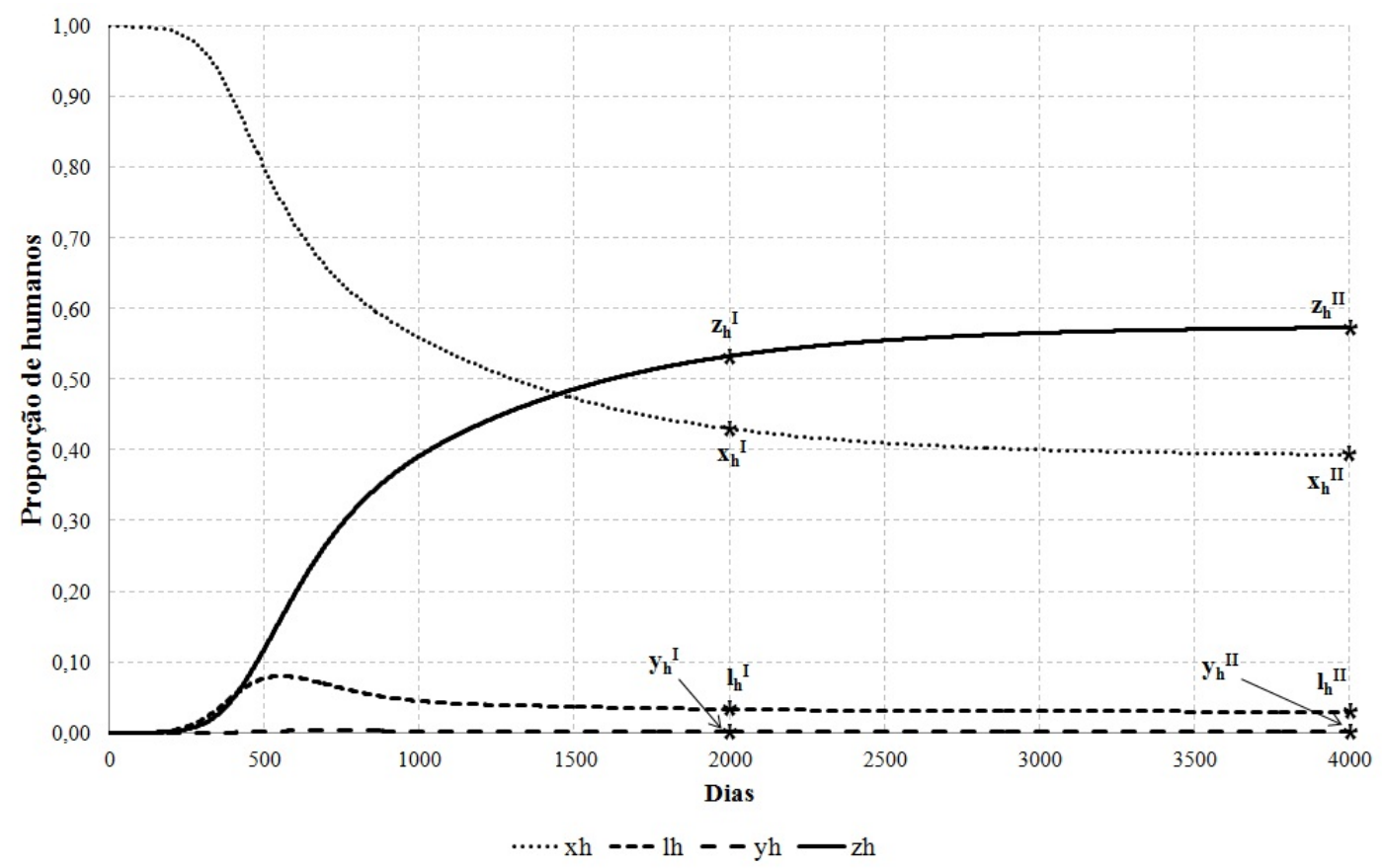

Figura 13 - Simulação numérica da dinâmica da LVZ sobre a população humana. $x_{h}^{I}=0,431 ; l_{h}^{I}=0,0338$; $y_{h}^{I}=0,00189 ; z_{h}^{I}=0,534 ; x_{h}^{I I}=0,394 ; l_{h}^{I I}=0,0305 ; y_{h}^{I I}=0,00167 ; z_{h}^{I I}=0,574$.

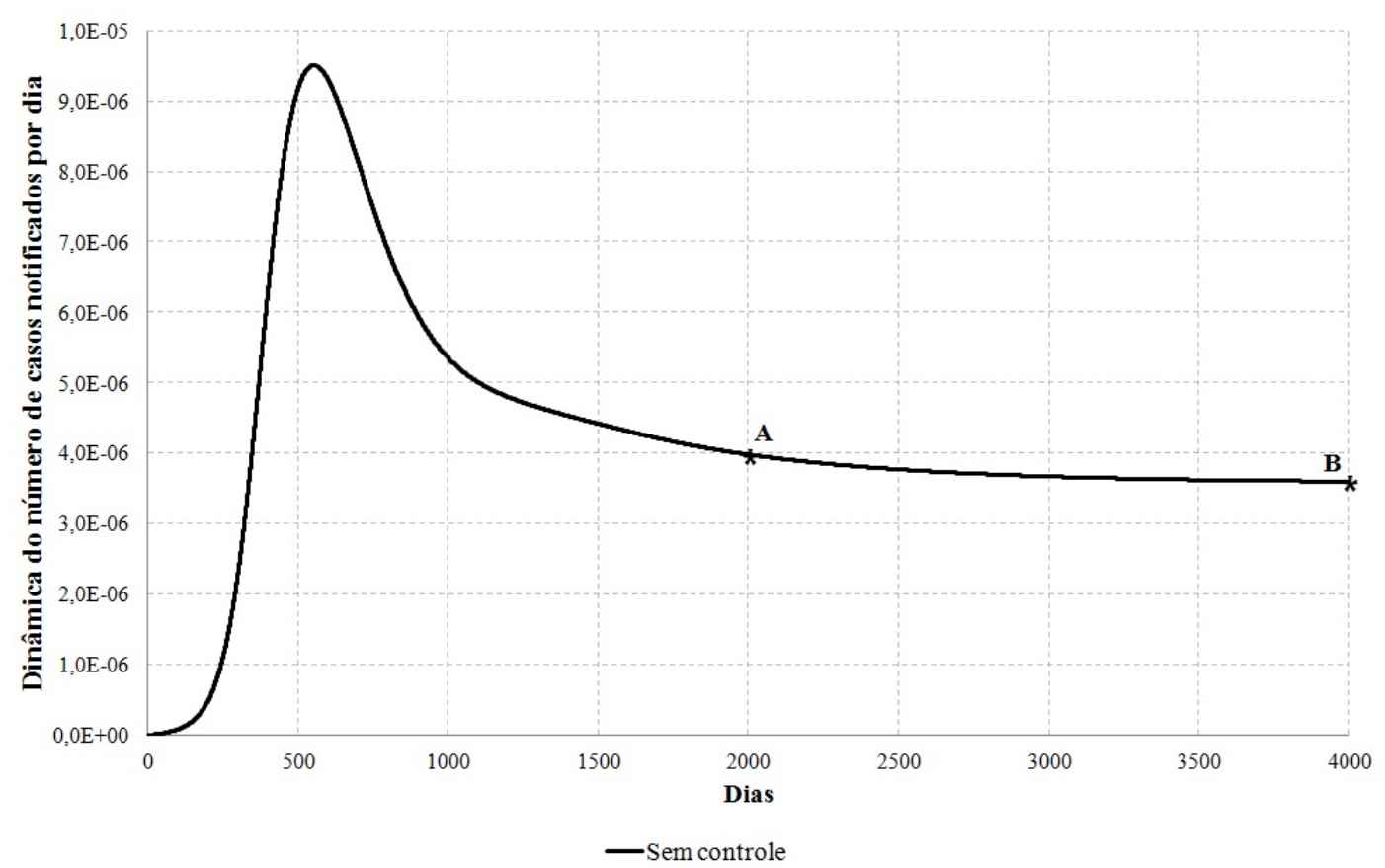

Figura 14 - Dinâmica do número de casos humanos notificados por dia. $A$ : $\left(2000 ; 3,98 \times 10^{-6}\right) ; B$ : $\left(4000 ; 3,60 \times 10^{-6}\right)$.

não-homogênea está relacionada às características geográficas e às mudanças climáticas, as quais provavelmente têm influenciado na dinâmica populacional dos mosquitos ${ }^{94}$. Por- 
tanto, este é uma dos argumentos para explicar a discrepância entre os nossos resultados e os dados reais.

\subsection{Qual o impacto da incerteza dos parâmetros sobre o nosso modelo?}

Para a análise de sensibilidade, foram adotados os seguintes valores mínimos, médios e máximos referentes aos parâmetros do modelo (Tabelas 7 e 8).

A Tabela 9 apresenta de forma sumarizada os resultados da análise de incerteza e sensibilidade. Os gráficos referentes a cada linha da tabela podem ser conferidos no Apêndice.

As Figuras 15 e 16 apresentam as contagens do número de parâmetros sensíveis por variável e do número de variáveis cujo parâmetro é sensível, respectivamente.

Embora o método LHS/PRCC possibilite a análise da sensibilidade do modelo em qualquer momento do tempo ${ }^{86}$, para esta análise de sensibilidade tomamos como critério desenvolvê-la com relação aos pontos de equilíbrio do sistema.

Pela análise de sensibilidade empregada neste estudo, obtemos como resultado um padrão de sensibilidade muito interessante. Pela Figura 15, nota-se que as variáveis podem ser sensíveis a parâmetros correspondentes a qualquer uma das populações. Este achado é diferente do que foi constatado por Burattini et al. ${ }^{9}$, em que foi observada uma corresponência entre o fato da variável e os parâmetros para o qual é sensível serem da mesma população. Entretanto, devemos ressaltar que os métodos de análise de sensibilidade foram diferentes, bem como a estrutura dos modelos.

Observando a Figura 16, notamos que 10 parâmetros foram sensíveis para mais de 10 variáveis. Desses 10 parâmetros, 7 estão diretamente relacionados com a população de vetores: $m_{h}, a_{d}, w_{d h}, b_{d}, \mu_{s}, \tau$ e $c_{l}$. Estes 7 parâmetros se mostraram sensíveis para pelo menos 17 variáveis (sendo que o parâmetro $a_{d}$ foi o considerado mais influente de todos, sendo sensível para 22 variáveis). Esta dominância dos parâmetros relacionados à população de vetores sobre a sensibilidade do sistema sugere o quão a dinâmica da doença pode ser dependente desses aspectos apontados por tais parâmetros. Além disso, 
Tabela 7 - Valores mínimos, médios e máximos atribuídos aos parâmetros para a análise de sensibilidade. Na tabela, $h$ relaciona o parâmetro para os humanos, $d$ para cães e $s$ para flebotomíneos.

\begin{tabular}{|c|c|c|c|c|}
\hline Parâmetro & Significado biológico & Valor mínimo & Valor médio & Valor máximo \\
\hline$\mu_{h}$ & $\begin{array}{l}\text { Taxa de mortalidade natu- } \\
\text { ral }\end{array}$ & $2,75 \times 10^{-5} \mathrm{dia}^{-1}$ & $3,67 \times 10^{-5} \mathrm{dia}^{-1}$ & $4,58 \times 10^{-5} \mathrm{dia}^{-1}$ \\
\hline$\alpha_{h}$ & $\begin{array}{l}\text { Taxa de letalidade calazar } \\
\text { específica }\end{array}$ & $4,11 \times 10^{-3} \mathrm{dia}^{-1}$ & $5,48 \times 10^{-3} \mathrm{dia}^{-1}$ & $6,85 \times 10^{-3} \mathrm{dia}^{-1}$ \\
\hline$a_{h}$ & $\begin{array}{l}\text { Taxa média de picadas } \\
\text { diárias }\end{array}$ & $9,37 \times 10^{-2} \mathrm{dia}^{-1}$ & $1,25 \times 10^{-1} \mathrm{dia}^{-1}$ & $1,56 \times 10^{-1} \mathrm{dia}^{-1}$ \\
\hline$m_{h}$ & $\begin{array}{l}\text { Densidades de vetores por } \\
\text { hospedeiro }\end{array}$ & 2,71 & 3,62 & 4,52 \\
\hline$w_{h c}$ & $\begin{array}{l}\text { Razão entre habitantes por } \\
\text { casa para Araçatuba/SP }\end{array}$ & 2,25 & 3,00 & 3,75 \\
\hline$r_{h}$ & $\begin{array}{l}\text { Taxa de recuperação es- } \\
\text { pontânea }\end{array}$ & $4,11 \times 10^{-4} \mathrm{dia}^{-1}$ & $5,48 \times 10^{-4} \mathrm{dia}^{-1}$ & $6,85 \times 10^{-4} \mathrm{dia}^{-1}$ \\
\hline$\gamma_{h}$ & $\begin{array}{l}\text { Taxa de perda de imuni- } \\
\text { dade }\end{array}$ & $4,11 \times 10^{-4} \mathrm{dia}^{-1}$ & $5,48 \times 10^{-4} \mathrm{dia}^{-1}$ & $6,85 \times 10^{-4} \mathrm{dia}^{-1}$ \\
\hline$\delta_{h}$ & $\begin{array}{l}\text { Taxa de recuperação de la- } \\
\text { tentes }\end{array}$ & $8,25 \times 10^{-3}{d i a^{-1}}^{-1}$ & $1,10 \times 10^{-2} \mathrm{dia}^{-1}$ & $1,37 \times 10^{-2} \mathrm{dia}^{-1}$ \\
\hline$\varphi_{h}$ & $\begin{array}{l}\text { Inverso do período de } \\
\text { incubação }\end{array}$ & $3,00 \times 10^{-4} \mathrm{dia}^{-1}$ & $4,00 \times 10^{-4} \mathrm{dia}^{-1}$ & $5,00 \times 10^{-4} \mathrm{dia}^{-1}$ \\
\hline$\sigma_{h}$ & $\begin{array}{l}\text { Taxa de recuperação para } \\
\text { imunes }\end{array}$ & $1,35 \times 10^{-3} \mathrm{dia}^{-1}$ & $1,81 \times 10^{-3} \mathrm{dia}^{-1}$ & $2,26 \times 10^{-3} \mathrm{dia}^{-1}$ \\
\hline$b_{h}$ & $\begin{array}{l}\text { Proporção de picadas in- } \\
\text { fectivas }\end{array}$ & $7,50 \times 10^{-3}$ & $1,00 \times 10^{-2}$ & $1,25 \times 10^{-2}$ \\
\hline$\eta_{h}$ & $\begin{array}{l}\text { Proporção de casos subno- } \\
\text { tificados }\end{array}$ & $5,28 \times 10^{-1}$ & $7,05 \times 10^{-1}$ & $8,81 \times 10^{-1}$ \\
\hline$\mu_{d}$ & $\begin{array}{l}\text { Taxa de mortalidade natu- } \\
\text { ral }\end{array}$ & $1,71 \times 10^{-4} \mathrm{dia}^{-1}$ & $2,28 \times 10^{-4}{d i a^{-1}}^{-1}$ & $2,85 \times 10^{-4} \mathrm{dia}^{-1}$ \\
\hline$\alpha_{d}$ & $\begin{array}{l}\text { Taxa de letalidade calazar } \\
\text { específica }\end{array}$ & $1,35 \times 10^{-3} \mathrm{dia}^{-1}$ & $1,81 \times 10^{-3} \mathrm{dia}^{-1}$ & $2,26 \times 10^{-3} \mathrm{dia}^{-1}$ \\
\hline$a_{d}$ & $\begin{array}{l}\text { Taxa média de picadas } \\
\text { diárias }\end{array}$ & $9,37 \times 10^{-2}{d i a^{-1}}^{-1}$ & $1,25 \times 10^{-1} \mathrm{dia}^{-1}$ & $1,56 \times 10^{-1} \mathrm{dia}^{-1}$ \\
\hline$w_{d h}$ & $\begin{array}{l}\text { Razão humano:cão } \\
\text { para o município de } \\
\text { Araçatuba/SP }\end{array}$ & 4,16 & 5,55 & 6,93 \\
\hline$p_{d}$ & $\begin{array}{l}\text { Taxa de perda de imuni- } \\
\text { dade oferecida pela vacina }\end{array}$ & $2,05 \times 10^{-3} \mathrm{dia}^{-1}$ & $2,74 \times 10^{-3} \mathrm{dia}^{-1}$ & $3,42 \times 10^{-3} \mathrm{dia}^{-1}$ \\
\hline$\varphi_{d}$ & $\begin{array}{l}\text { Inverso do período de } \\
\text { incubação }\end{array}$ & $8,25 \times 10^{-4} \mathrm{dia}^{-1}$ & $1,10 \times 10^{-3} \mathrm{dia}^{-1}$ & $1,37 \times 10^{-3} \mathrm{dia}^{-1}$ \\
\hline$b_{d}$ & $\begin{array}{l}\text { Proporção de picadas in- } \\
\text { fectivas }\end{array}$ & $7,05 \times 10^{-3} \mathrm{dia}^{-1}$ & $1,00 \times 10^{-2} \mathrm{dia}^{-1}$ & $1,25 \times 10^{-2} \mathrm{dia}^{-1}$ \\
\hline$r_{d}$ & $\begin{array}{l}\text { Taxa de recuperação es- } \\
\text { pontânea }\end{array}$ & $2,05 \times 10^{-4} \mathrm{dia}^{-1}$ & $2,74 \times 10^{-4} \mathrm{dia}^{-1}$ & $3,42 \times 10^{-4} \mathrm{dia}^{-1}$ \\
\hline
\end{tabular}

essa informação pode ser uma importante diretriz para o planejamento das atividades de controle voltadas para a dinâmica da população de vetores.

Os outros 3 parâmetros que foram indicados como sensíveis para mais de 10 variáveis foram $\gamma_{d}, \delta_{d}$ e $\sigma_{d}$. Entre esses 3 parâmetros, o $\delta_{d}$ se mostrou sensível para 18 variáveis. Tanto os parâmetros $\delta_{d}$ quanto $\sigma_{d}$ contribuem para diminuir naturalmente a 
Tabela 8 - Valores mínimos, médios e máximos atribuídos aos parâmetros para a análise de sensibilidade. Na tabela, $h$ relaciona o parâmetro para os humanos, $d$ para cães e $s$ para flebotomíneos (Continuação da Tabela 7).

\begin{tabular}{|c|c|c|c|c|}
\hline Parâmetro & Significado biológico & Valor mínimo & Valor médio & Valor máximo \\
\hline$\gamma_{d}$ & $\begin{array}{l}\text { Taxa de perda de imuni- } \\
\text { dade (de recuperados para } \\
\text { suscetíveis) }\end{array}$ & $2,05 \times 10^{-3} \mathrm{dia}^{-1}$ & $2,74 \times 10^{-3} \mathrm{dia}^{-1}$ & $3,42 \times 10^{-3} \mathrm{dia}^{-1}$ \\
\hline$\sigma_{d}$ & $\begin{array}{l}\text { Taxa de recuperação de } \\
\text { clinicamente doentes para } \\
\text { imunes }\end{array}$ & $6,78 \times 10^{-3} \mathrm{dia}^{-1}$ & $9,04 \times 10^{-3} \mathrm{dia}^{-1}$ & $1,13 \times 10^{-2} \mathrm{dia}^{-1}$ \\
\hline$\delta_{d}$ & $\begin{array}{l}\text { Taxa de recuperação de la- } \\
\text { tentes }\end{array}$ & $6,16 \times 10^{-3} \mathrm{dia}^{-1}$ & $8,22 \times 10^{-3} \mathrm{dia}^{-1}$ & $1,03 \times 10^{-2} \mathrm{dia}^{-1}$ \\
\hline$f_{d}$ & $\begin{array}{l}\text { Taxa de recuperação de cli- } \\
\text { nicamente doentes para la- } \\
\text { tentes }\end{array}$ & 0 & 0 & 0,5 \\
\hline$q_{d}$ & $\begin{array}{l}\text { Taxa de perda de imuni- } \\
\text { dade (recuperados para la- } \\
\text { tentes) }\end{array}$ & 0 & 0 & 0,5 \\
\hline$\psi_{d}$ & $\begin{array}{l}\text { Proporção de cães que não } \\
\text { desistem do tratamento }\end{array}$ & 0,5 & 1,0 & 1,0 \\
\hline$u_{c}$ & $\begin{array}{l}\text { Inverso do período de ati- } \\
\text { vidade do colar }\end{array}$ & $5,02 \times 10^{-3} \mathrm{dia}^{-1}$ & $6,70 \times 10^{-3} \mathrm{dia}^{-1}$ & $8,37 \times 10^{-3} \mathrm{dia}^{-1}$ \\
\hline$\zeta_{c}$ & Taxa de perda do colar & $4,50 \times 10^{-3} \mathrm{dia}^{-1}$ & $6,00 \times 10^{-3} \mathrm{dia}^{-1}$ & $7,50 \times 10^{-3} \mathrm{dia}^{-1}$ \\
\hline$\mu_{s}$ & $\begin{array}{l}\text { Taxa de mortalidade natu- } \\
\text { ral }\end{array}$ & $3,75 \times 10^{-2} \mathrm{dia}^{-1}$ & $5,00 \times 10^{-2}{d i a^{-1}}^{-1}$ & $6,25 \times 10^{-2} \mathrm{dia}^{-1}$ \\
\hline$\varepsilon_{v}$ & Eficácia da vacinação & $7,23 \times 10^{-1}$ & $9,64 \times 10^{-1}$ & 1,0 \\
\hline$\varepsilon_{c}$ & $\begin{array}{l}\text { Diminuição da taxa de pi- } \\
\text { cadas devido ao uso do co- } \\
\text { lar }\end{array}$ & $6,00 \times 10^{-1}$ & $8,00 \times 10^{-1}$ & 1,0 \\
\hline$\tau$ & $\begin{array}{l}\text { Período de incubação } \\
\text { extrínseco }\end{array}$ & 5,25 dias & 7,00 dias & 8,75 dias \\
\hline$c_{l}$ & $\begin{array}{l}\text { Fração de flebotomíneos } \\
\text { que adquirem a infecção } \\
\text { após picar um cão latente }\end{array}$ & $6,97 \times 10^{-1}$ & $9,30 \times 10^{-1}$ & 1,0 \\
\hline$c_{y}$ & $\begin{array}{l}\text { Fração de flebotomíneos } \\
\text { que adquirem a infecção } \\
\text { após picar um cão clinica- } \\
\text { mente doente }\end{array}$ & $5,02 \times 10^{-1}$ & $6,70 \times 10^{-1}$ & $8,37 \times 10^{-1}$ \\
\hline$c_{k}$ & $\begin{array}{l}\text { Proporção de cães clinica- } \\
\text { mente curados, mas que } \\
\text { continuam parasitados }\end{array}$ & $1,15 \times 10^{-1}$ & $1,54 \times 10^{-1}$ & $1,92 \times 10^{-1}$ \\
\hline$\xi_{d}$ & $\begin{array}{l}\text { Taxa de eliminação de cães } \\
\text { positivos }\end{array}$ & 0 & 0 & 0,5 \\
\hline$\theta_{d}$ & $\begin{array}{l}\text { Taxa de cães que recebem } \\
\text { coleira impregnada com } \\
\text { inseticida }\end{array}$ & 0 & 0 & 0,5 \\
\hline$v_{d}$ & $\begin{array}{l}\text { Taxa de cães que são vaci- } \\
\text { nados }\end{array}$ & 0 & 0 & 0,5 \\
\hline$\omega_{d}$ & $\begin{array}{l}\text { Taxa de cães doentes que } \\
\text { são tratados }\end{array}$ & 0 & 0 & 0,5 \\
\hline$\xi_{c}$ & $\begin{array}{l}\text { Taxa de casas que são tra- } \\
\text { tadas (controle vetorial) }\end{array}$ & 0 & 0 & 0,5 \\
\hline
\end{tabular}


Tabela 9 - Sumário dos resultados numéricos e da análise de sensibilidade pelo método PRCC. As variáveis indicadas por $*$ representam os estados de equilíbrio na ausência de estratégias de controle preventivo $\left(\xi_{d}=\theta_{d}=\omega_{d}=v_{d}=\xi_{s}=0\right)$.

\begin{tabular}{|c|c|c|}
\hline Variável & Valor numérico & Parâmetros para os quais o valor calculado é mais sensível \\
\hline $\mathbf{x}_{\mathbf{h}}{ }^{*}$ & $3,92 \times 10^{-1}$ & $\mu_{h}, a_{h}, m_{h}, \gamma_{h}, b_{h}, a_{d}, w_{d h}, \gamma_{d}, \delta_{d}, \sigma_{d}, b_{d}, \mu_{s}, \tau, c_{l}$ \\
\hline $\mathbf{l}_{\mathbf{h}}{ }^{*}$ & $3,03 \times 10^{-2}$ & $a_{h}, m_{h}, \gamma_{h}, \delta_{h}, b_{h}, a_{d}, w_{d h}, \gamma_{d}, \delta_{d}, \sigma_{d}, b_{d}, \mu_{s}, \tau, c_{l}, c_{y}$ \\
\hline $\mathbf{y}_{\mathbf{h}}{ }^{*}$ & $1,70 \times 10^{-3}$ & $\alpha_{h}, a_{h}, m_{h}, \gamma_{h}, \delta_{h}, \varphi_{h}, \sigma_{h}, b_{h}, a_{d}, w_{d h}, \gamma_{d}, \delta_{d}, \sigma_{d}, b_{d}, \mu_{s}, \tau, c_{l}$ \\
\hline $\mathbf{z}_{\mathbf{h}}^{*}$ & $5,75 \times 10^{-1}$ & $\mu_{h}, a_{h}, m_{h}, \gamma_{h}, \delta_{h}, b_{h}, a_{d}, w_{d h}, \gamma_{d}, \delta_{d}, \sigma_{d}, b_{d}, \mu_{s}, \tau, c_{l}$ \\
\hline $\mathbf{x}_{\mathbf{d}}^{*}$ & $3,14 \times 10^{-1}$ & $m_{h}, a_{d}, w_{d h}, \gamma_{d}, \delta_{d}, \sigma_{d}, b_{d}, \zeta_{c}, \mu_{s}, \tau, c_{l}$ \\
\hline $\mathbf{x}_{\mathbf{d}}^{\mathbf{C}^{*}}$ & 0,00 & $m_{h}, a_{d}, w_{d h}, \delta_{d}, b_{d}, \zeta_{c}, u_{c}, \mu_{s}, \tau, c_{l}, \theta_{d}$ \\
\hline $\mathbf{l}_{\mathbf{d}}^{*}$ & $1,64 \times 10^{-1}$ & $m_{h}, \eta_{h}, \mu_{d}, a_{d}, w_{d h}, \gamma_{d}, \delta_{d}, \varphi_{d}, b_{d}, \mu_{s}, \tau, \tau, c_{l}, c_{k}$ \\
\hline $\mathbf{l}_{\mathbf{d}}^{\mathbf{C}^{*}}$ & 0,00 & $a_{d}, \theta_{d}$ \\
\hline $\mathbf{y}_{\mathbf{d}}{ }^{*}$ & $1,63 \times 10^{-2}$ & $m_{h}, \delta_{h}, \eta_{h}, \alpha_{d}, a_{d}, w_{d h}, \gamma_{d}, \delta_{d}, \varphi_{d}, \sigma_{d}, b_{d}, \mu_{s}, \tau, c_{l}, c_{y}$ \\
\hline $\mathbf{y}_{\mathbf{d}}^{\mathbf{C}^{*}}$ & 0,00 & $a_{d}, \theta_{d}$ \\
\hline $\mathbf{z}_{\mathbf{d}}^{*}$ & $5,05 \times 10^{-1}$ & $m_{h}, \delta_{h}, \eta_{h}, a_{d}, w_{d h}, \gamma_{d}, \sigma_{d}, b_{d}, \mu_{s}, \tau, c_{l}$ \\
\hline $\mathbf{z}_{\mathbf{d}}^{\mathbf{C}^{*}}$ & 0,00 & $a_{d}, \theta_{d}$ \\
\hline $\mathbf{v}_{\mathbf{d}}^{*}$ & 0,00 & $m_{h}, a_{d}, w_{d h}, r_{d}, \delta_{d}, b_{d}, p_{d}, f_{d}, \varepsilon_{v}, \mu_{s}, \tau, c_{l}, v_{d}$ \\
\hline $\mathbf{v}_{\mathbf{d}}^{\mathbf{C}^{*}}$ & 0,00 & $\alpha_{d}, m_{h}, v_{d}, \theta_{d}$ \\
\hline $\mathbf{s}^{*}$ & $7,10 \times 10^{-1}$ & $m_{h}, \eta_{h}, a_{d}, w_{d h}, \gamma_{d}, \delta_{d}, \sigma_{d}, b_{d}, \mu_{s}, \tau, c_{l}, c_{y}, c_{k}, \xi_{d}$ \\
\hline $\mathbf{S}_{\mathbf{2}}{ }^{*}$ & $8,58 \times 10^{-2}$ & $\mu_{h}, m_{h}, \eta_{h}, a_{d}, w_{d h}, \gamma_{d}, \delta_{d}, \sigma_{d}, b_{d}, \mu_{s}, \tau, c_{l}, c_{y}, c_{k}$ \\
\hline $\mathbf{S}_{3}{ }^{*}$ & $2,05 \times 10^{-1}$ & $m_{h}, \eta_{h}, a_{d}, w_{d h}, \gamma_{d}, \delta_{d}, \sigma_{d}, b_{d}, \mu_{s}, \tau, c_{l}, c_{y}, c_{k}, \xi_{d}$ \\
\hline$R$ & $3,58 \times 10^{-6} / \mathrm{dia}$ & $a_{h}, m_{h}, w_{h c}, \gamma_{h}, \delta_{h}, \varphi_{h}, b_{h}, \eta_{h}, a_{d}, w_{d} h, \gamma_{d}, \delta_{d}, b_{d}, \mu_{s}, \tau, c_{l}, c_{y}, v_{d}$ \\
\hline $\mathscr{R}_{0,\left(l_{d}\right)}$ & 4,20 & $m_{h}, \eta_{h}, a_{d}, w_{d h}, \delta_{d}, \varphi_{d}, b_{d}, \mu_{s}, \tau, c_{l}, c_{k}, \xi_{d}$ \\
\hline $\mathscr{R}_{0,\left(l_{d}^{C}\right)}$ & 0,00 & $m_{h}, a_{d}, w_{d h}, \delta_{d}, b_{d}, \varepsilon_{c}, \mu_{s}, \tau, c_{l}, \theta_{d}$ \\
\hline $\mathscr{R}_{0,\left(y_{d}\right)}$ & 0,30 & $\alpha_{h}, m_{h}, \alpha_{d}, a_{d}, w_{d h}, \delta_{d}, \varphi_{d}, \sigma_{d}, b_{d}, \mu_{s}, \tau, c_{y}$ \\
\hline $\mathscr{R}_{0,\left(y_{d}^{C}\right)}$ & 0,00 & $m_{h}, \alpha_{d}, a_{d}, w_{d h}, \delta_{d}, \varphi_{d}, \sigma_{d}, b_{d}, \varepsilon_{c}, \mu_{s}, \tau, c_{y}, \theta_{d}$ \\
\hline $\mathscr{R}_{0}$ & 4,50 & $m_{h}, \eta_{h}, a_{d}, w_{d h}, \delta_{d}, \sigma_{d}, b_{d}, \mu_{s}, \tau, c_{l}, c_{y}, c_{k}, \xi_{d}$ \\
\hline
\end{tabular}

fonte de infecção (isto é, eles diminuem, respectivamente, a quantidade de cães latentes $\left(l_{d}\right.$ e $\left.l_{d}^{C}\right)$ e de clinicamente doentes $\left(y_{d}\right.$ e $\left.y_{d}^{C}\right)$ por transferi-los para a categoria de cães recuperados $\left(z_{d}\right.$ e $\left.\left.z_{d}^{C}\right)\right)$. Em particular, o parâmetro $\delta_{d}$ torna-se mais impactante por se relacionar diretamente com a categoria de cães latentes $l_{d}$ (visto que a probabilidade do 


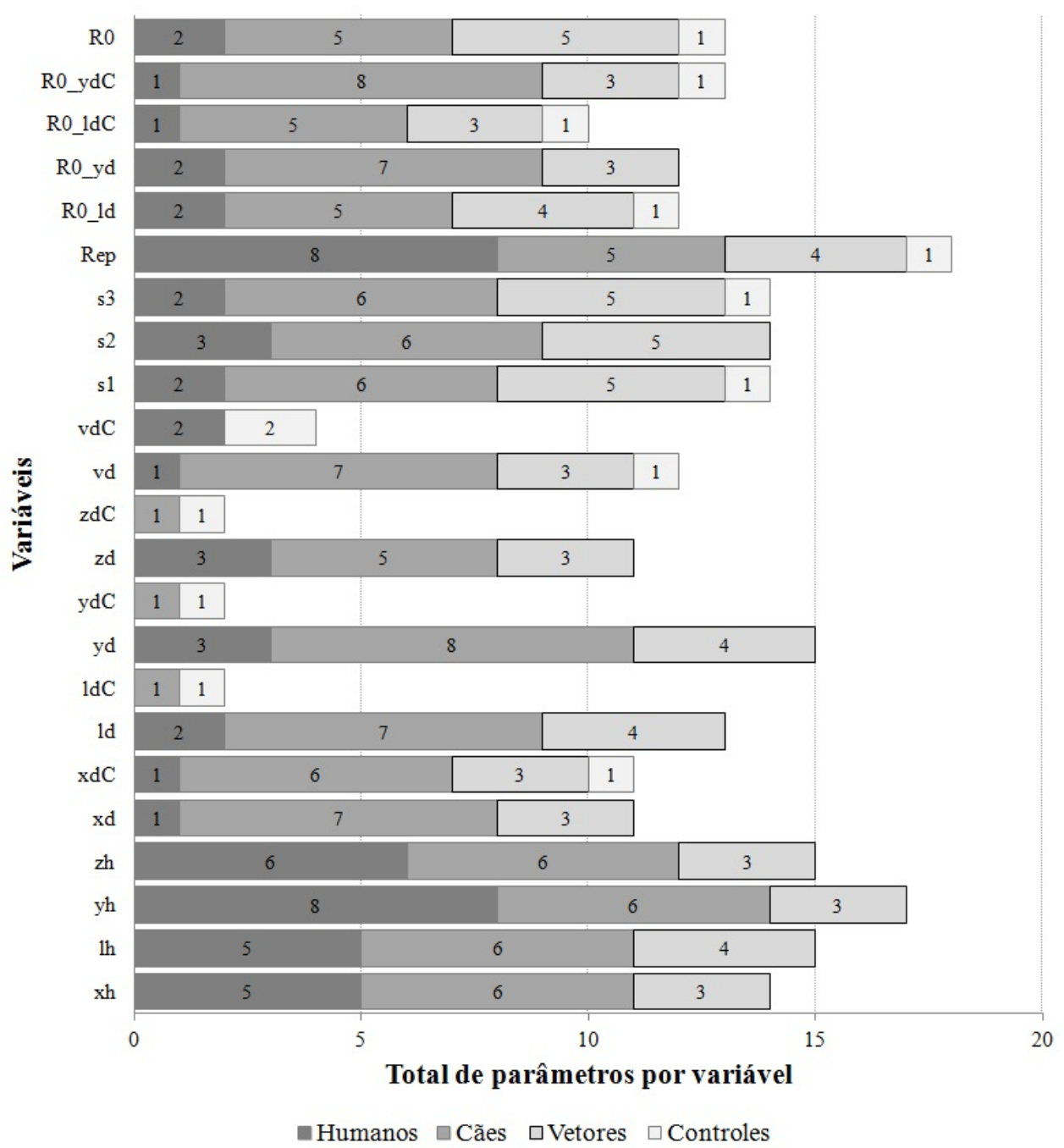

Figura 15 - Contagem do número de parâmetros que foram identificados como sensíveis para cada variável. Na legenda da figura, foram discriminados o número de parâmtros referentes à população de humanos, cães, mosquitos e aqueles que representam as estratégias de controle.

vetor se tornar infectado é maior ao picar um cão latente $\left(c_{l}=0,93\right)$ do que um clinicamente doente $\left.\left(c_{y}=0,67\right)\right)^{80}$. Já o parâmetro $\gamma_{d}$ contribui na remoção de cães da categoria de recuperados para o de suscetíveis $\left(\left(x_{d}\right.\right.$ e $\left.\left.x_{d}^{C}\right)\right)$. Portanto, esses três parâmetros justificam sua indicação como sensíveis por interferirem diretamente em pontos importantes na instalação da doença no sistema.

\subsection{A estabilidade do modelo nos estados de equilíbrio}




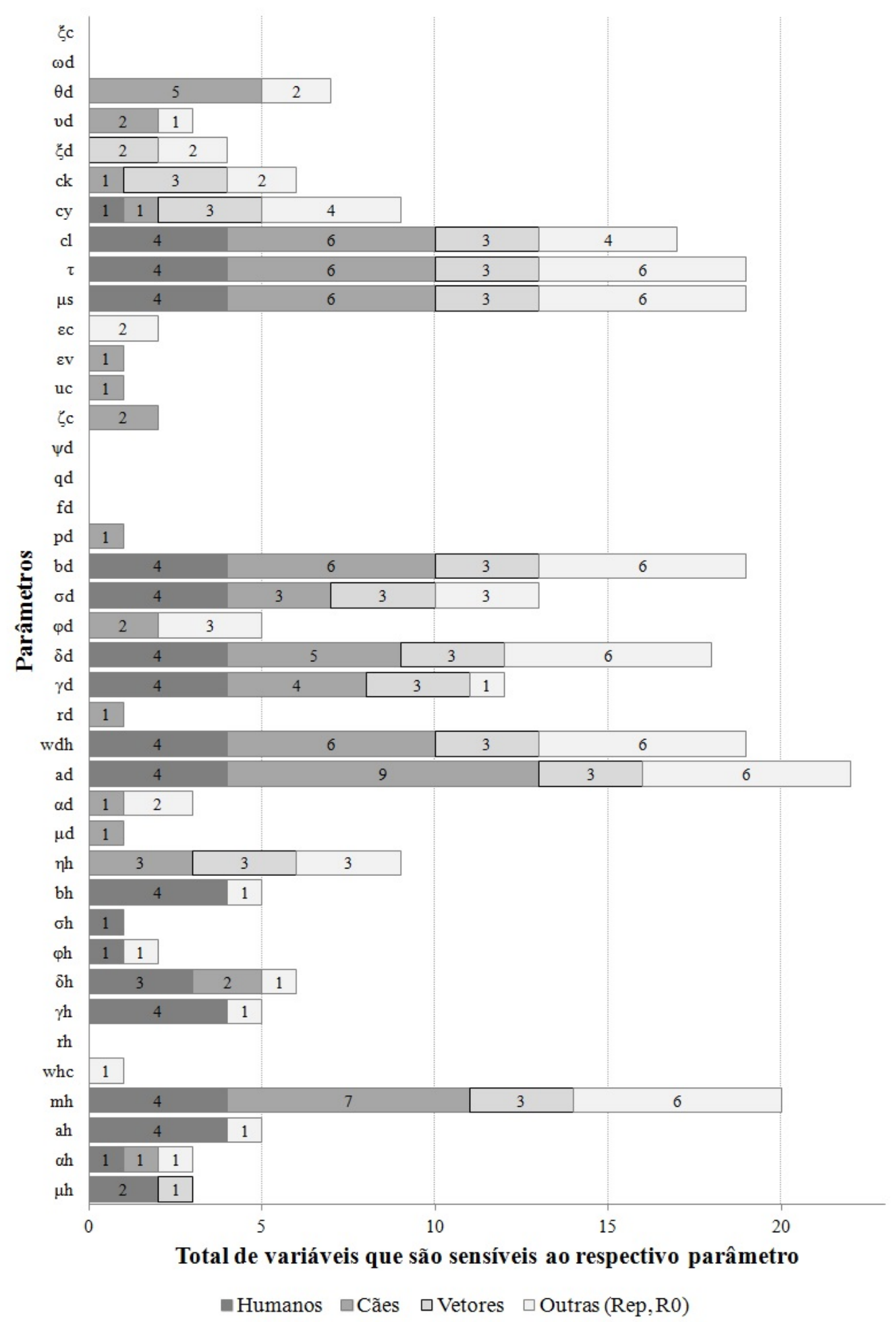

Figura 16 - Contagem do número de variáveis que foram identificados como sensíveis para o respectivo parâmetro. Na legenda da figura, foram discriminados o número de variáveis referentes à população de humanos, cães, mosquitos e outros índices estimados neste estudo.

O modelo matemático deste estudo apresenta dois estados de equilíbrio. Em um deles, temos o estado de equilíbrio livre da doença (que basicamente seriam os estados 
de equilíbrio triviais, onde há apenas indivíduos suscetíveis nas três populações). O outro seria o estado de equilíbrio endêmico, que corresponde ao estado de equilíbrio quando a doença se instala na população (que para o caso deste modelo são os valores densidades das categorias representadas na Tabela 9).

Para a estudo da estabilidade, é necessário calcular duas Jacobianas, conforme apresentado na secção 3.5. Devido ao fato do modelo ser extenso, não apresentaremos aqui todos os detalhes do cálculo, porém, deixaremos indicado como procedê-las.

Primeiramente, a Jacobiana usual em relação às variáveis instantâneas (isto é, sem argumentos com atraso), é calculada por (Eq. (84)):

$$
J_{0}=\left[\begin{array}{ccccc}
\frac{\partial \dot{x_{h}}}{\partial x_{h}} & \cdots & \frac{\partial \dot{x_{h}}}{\partial x_{d}} & \cdots & \frac{\partial \dot{x_{h}}}{\partial s_{3}} \\
\vdots & & \ddots & & \vdots \\
\frac{\partial \dot{x_{d}}}{\partial x_{h}} & \cdots & \frac{\partial \dot{x_{d}}}{\partial x_{d}} & \cdots & \frac{\partial \dot{x_{d}}}{\partial s_{3}} \\
\vdots & & \ddots & & \vdots \\
\frac{\partial \dot{s_{3}}}{\partial x_{h}} & \cdots & \frac{\partial \dot{s_{3}}}{\partial x_{d}} & \cdots & \frac{\partial \dot{s_{3}}}{\partial s_{3}}
\end{array}\right]
$$

e também calculamos o Jacobiano em relação às variáveis com argumentos com atraso (Eq. (85)):

$$
J_{\tau}=\left[\begin{array}{ccccc}
\frac{\partial \dot{x_{h}}}{\partial x_{h \tau}} & \ldots & \frac{\partial \dot{x_{h}}}{\partial x_{d \tau}} & \ldots & \frac{\partial \dot{x_{h}}}{\partial s_{3 \tau}} \\
\vdots & & \ddots & & \vdots \\
\frac{\partial \dot{x_{d}}}{\partial x_{h \tau}} & \cdots & \frac{\partial \dot{x_{d}}}{\partial x_{d \tau}} & \cdots & \frac{\partial \dot{x_{d}}}{\partial s_{3 \tau}} \\
\vdots & & \ddots & & \vdots \\
\frac{\partial \dot{s_{3}}}{\partial x_{h \tau}} & \cdots & \frac{\partial \dot{s_{3}}}{\partial x_{d \tau}} & \cdots & \frac{\partial \dot{s_{3}}}{\partial s_{3 \tau}}
\end{array}\right]
$$

Não foi possível estabelecer um resultado analítico para a resolução desta análise, pois os cálculos são extensos e complexos. Porém, apresentaremos os resultados numéricos. Estes resultados numéricos representam os resultados dos autovalores relativos a cada um dos estados de equilíbrio. 


\subsubsection{Estabilidade para o estado de equilíbrio livre da doença}

Inicialmente, para o estado de equilíbrio livre da doença, temos que as densidades de equilíbrio triviais são dadas por $\mathbf{x}_{\mathbf{h}}=\mathbf{x}_{\mathbf{d}}=\mathbf{s}_{\mathbf{1}}=1$, com todas as outras categorias iguais a zero.

Calculando os Jacobianos (Eq. (84) e (85)) com relação a este estado de equilíbrio livre da doença, e aplicando a Eq. (53), resta-nos determinar as raízes dessa equação, que corresponderiam aos autovalores para este estado de equilíbrio.

Não apresentaremos os cálculos da resolução do cálculo dos autovalores relativos ao estado de equilíbrio livre da doença. Porém, a informação importante com relação a este procedimento é relativo ao conjunto de autovalores calculados: $(-0,0157 ;-0,0122$; $-0,0169 ;-0,0219 ;-0,0240 ;-0,0120 ;-0,0073 ;-0,0006 ;-0,0010 ;-0,0030 ;-0,0030$; $0,0 ; 0,0 ;-0,0500)$. Para este conjunto de autovalores, concluímos que o ponto de equilíbrio livre da doença é não-assintoticamente estável ${ }^{82,83,95}$.

\subsubsection{Estabilidade para o estado de equilíbrio endêmico}

Seguindo o mesmo procedimento para o caso do estado de equilíbrio livre da doença, temos que as densidades de equilíbrio não-triviais são dadas pelos valores de densidade das categorias apresentados na Tabela 9.

Calculando os Jacobianos (Eq. (84) e (85)) com relação a este estado de equilíbrio endêmico, e aplicando a Eq. (53), novamente resta-nos determinar as raízes dessa equação, que corresponderiam aos autovalores para este estado de equilíbrio. Assim, o conjunto de autovalores calculados foram: $(-0,0156 ;-0,0129 ;-0,0172 ;-0,0218 ;-0,0240$; $\left.-0,0030 ;-0,0015 ;-1,53 \times 10^{-13} ;-0,0015 ;-0,0074 ;-0,0120\right)$. Para este conjunto de autovalores, concluímos que o ponto de equilíbrio livre da doença é assintoticamente estável $^{82,83}$.

\subsection{Qual a estratégia ótima de controle?}


Neste modelo nós incluimos cinco estratégias de controle preventivo: (1) eliminação de cães positivos, (2) controle vetorial, (3) uso de coleiras impregnadas com deltametrina 4\%, (4) vacinação de cães e (5) tratamento canino. Entretanto, o Ministério da Saúde adota apenas a elminação de cães positivos e o controle vetorial como métodos de controle oficiais $^{8,73}$.

A fim de checar a eficácia das estratégias de controle alternativos, nós simulamos o modelo numericamente considerando cada estratégia, que foi avaliada sistematicamente para uma mesma faixa de valores.

Para uma análise comparativa, nós observamos o efeito das taxas das estratégias sobre a taxa diária de casos humanos notificados (Figura 17).

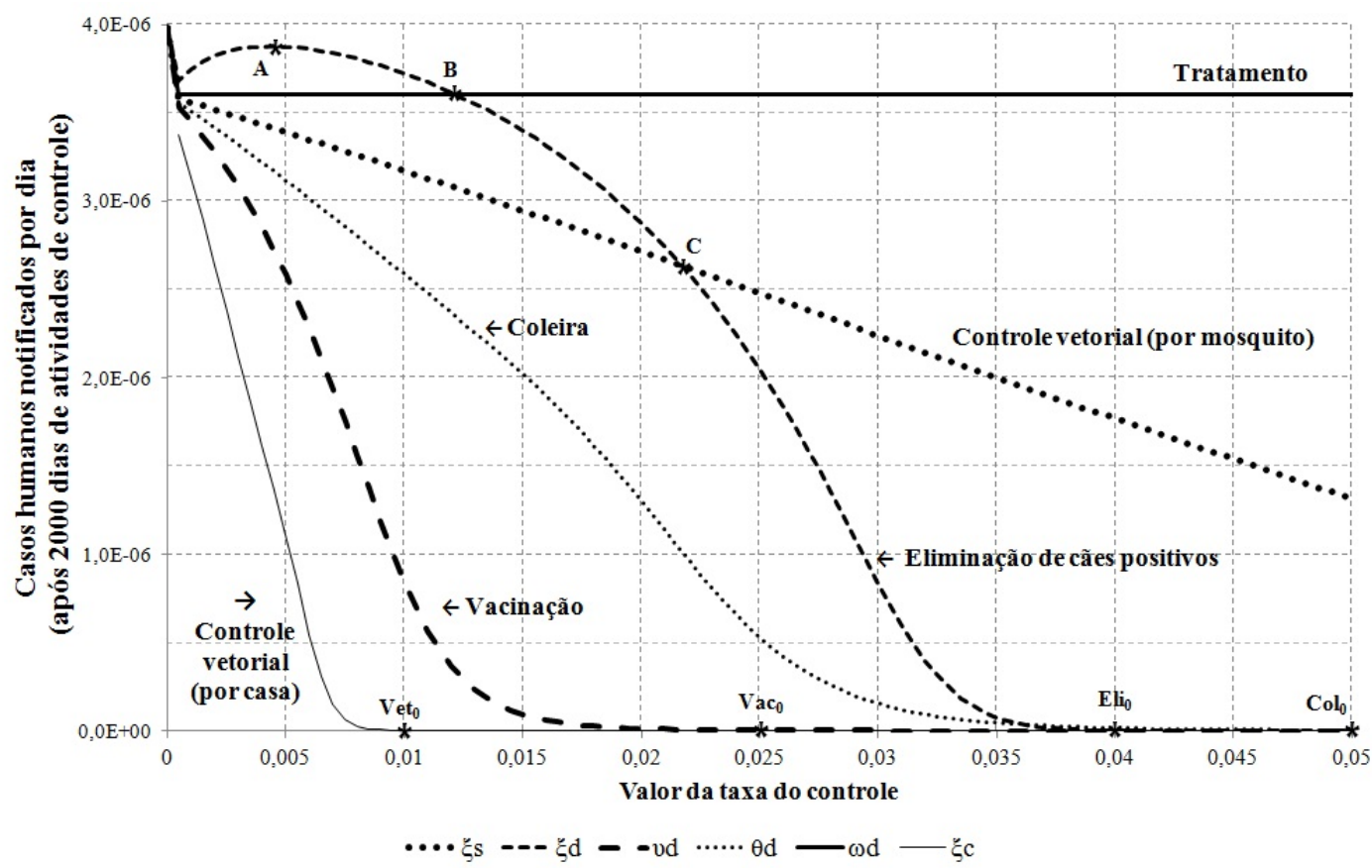

Figura 17 - Relação entre o número de casos humanos notificados por dia e os valores das taxas de controle, após 2000 dias. A: $\left(0,0045 ; 3,88 \times 10^{-6}\right)$; B: $\left(0,0120 ; 3,61 \times 10^{-6}\right) ; \mathrm{C}:\left(0,0215 ; 2,66 \times 10^{-6}\right) ;$ Vet $_{0}:(0,01$; $\left.1,05 \times 10^{-9}\right) ; \operatorname{Vac}_{0}:\left(0,025 ; 2,81 \times 10^{-9}\right) ;$ Eli $_{0}:\left(0,04 ; 2,36 \times 10^{-9}\right) ; \operatorname{Col}_{0}:\left(0,05 ; 3,07 \times 10^{-9}\right)$.

Ribas et al. ${ }^{10}$ também publicaram um modelo matemático para a dinâmica da leishmaniose visceral zoonótica e este modelo foi baseado no trabalho previamente publicado por Burattini et al. ${ }^{9}$. Neste modelo publicado em 2013, Ribas et al. ${ }^{10}$ apresentaram uma discussão sobre a estratégia de controle ótima entre essas mesmas 5 estratégias que consideramos aqui. Porém, em nosso modelo, nós podemos observar (1) a dinâmica e o 
movimento da população de cães entre os compartimentos "sem coleira" $\left(x_{d}, l_{d}, y_{d}, z_{d}\right)$ e "com coleira" $\left(x_{d}^{C}, l_{d}^{C}, y_{d}^{C}, z_{d}^{C}\right)$, e (2) entre os "vacinados" $\left(v_{d}\right)$ e "não vacinados" $\left(x_{d}\right)$ (Figura 9). No caso do tratamento canino, nós incluímos um termo para estimar a proporção de cães que se tornariam livres do status de fonte de infecção para os mosquitos $\left(1-c_{k}\right)$. Finalmente, sendo que a sorologia (ELISA e Imunofluorescência Indireta - RIFI) ${ }^{8}$ é o método de diagnóstico canino oficial adotada pelo Ministério da Saúde e, considerando que este método não é capaz de diferenciar se o anticorpo é vacinal ou se foi originado do processo infeccioso, nós assumimos que qualquer cão que tenha tido prévio contato com os parasitas (antígenos) está sujeito a ser eliminado ${ }^{91,96}$.

Os resultados obtidos neste trabalho são diferentes dos obtidos por Burattini et al. ${ }^{9}$ e Ribas et al. ${ }^{10}$. Embora esses trabalhos tenham apresentado conclusões sobre os resultados relacionados à prevalência humana, o controle vetorial foi considerado a estratégia de controle mais eficiente. Entretanto, nós ressaltamos que nosso modelo apresentou modificações e que alguns parâmetros foram atualizados.

Considerando a população de mosquitos, nós assumimos que esta população é restrategista e, assim, a permanência de mosquitos em uma determinada área dependeria do poder de sua capacidade de reprodução. Classicamente, os indivíduos r-estrategistas são indivíduos de porte (isto é, tamanho) pequeno, com curta expectativa de vida, maturidade rapidamente alcançada, alta taxa de mortalidade e curtos ciclos reprodutivos ${ }^{97}$. Assim, nós simulamos o controle da população de vetores por meio da adição de um termo extra para a taxa de mortalidade $\left(\xi_{s}\right)$.

Se considerarmos apenas os valores de taxas e ignorar os custos, a Figura 17 apresenta que o controle vetorial (determinado por número de casas) seria a estratégia mais eficiente. Em seguida, temos a vacinação, uso da coleira e eliminação de cães positivos. O tratamento de cães infectados praticamente não causaria impacto sobre o número de casos humanos notificados.

Entretanto, pela Figura 17, observa-se que, um cão causa mais impacto do que um mosquito. Isso pode ser observado pela comparação das curvas geradas por $\xi_{c}$ e $\xi_{s}$ (controle vetorial por casa e por mosquito, respectivamente). Para um mesmo valor de 
taxa, é intuitivo que o controle aplicado em uma casa seja mais impactante do que em um mosquito, visto que, em média, a densidade de mosquito por casa é em torno de $w_{h c} \times m_{h}=$ 10, 86 mosquitos/casa. Além disso, pela Figura 17, vacinar ou aplicar a coleira inseticida em um cão é mais impactante sobre o número de casos notificados do que eliminar um mosquito. Neste caso, o argumento é o mesmo que o levantado para a comparação entre o controle vetorial sobre casas e sobre mosquitos. Ao vacinar um cão suscetível, estamos prevenindo que ele tenha contato com pelo menos $w_{d h} \times m_{h}=20,11$ mosquitos. O mesmo ocorre quando aplicamos a coleira inseticida. Portanto, cada cão protegido pela vacina ou pela coleira poderia evitar a progressão do ciclo da doença em aproximadamente 20 mosquitos (seja no caso do mosquito se infectar ou no caso do mosquito infectar um cão).

Ainda com relação à Figura 17, fazemos uma observação importante ao ponto C. Observe que para valores $\xi_{d}<0,0215 /$ dia, a eliminação de um mosquito apresentaria impacto mais favorável do que a eliminação de um cão positivo. A compreensão deste fenômeno é complexa e multifatorial. Primeiramente, lembramos que neste modelo estamos considerando que qualquer cão que tenha tido contato prévio com o parasita (antígeno) seria considerado elegível para ser eliminado. Portanto, a eliminação de cães positivos não selecionaria apenas as categorias de cães latentes $\left(l_{d}, l_{d}^{C}\right)$ ou clinicamente doentes $\left(y_{d}, y_{d}^{C}\right)$ (mas também os cães resistentes $\left(z_{d}, z_{d}^{C}\right)$, bem como os vacinados $\left.v_{d}, v_{d}^{C}\right)$. Assim, para que a eliminação de um cão seja mais eficiente que a de um mosquito, devemos adotar uma taxa de eliminação de cães positivos $\xi_{d} \geq 0,0215 /$ dia. Para taxas acima deste valor, haveria redução significativa da fonte de infecção (categoria de cães latentes e clinicamente doentes), de forma a diminuir o desenvolvimento de mosquitos infectivos $\left(s_{3}\right)$.

Ressaltamos também que eliminar cães positivos a uma taxa $\xi_{d} \leq 0,0215 /$ dia possibilitaria a renovação de cães suscetíveis sem diminuir significativamente a proporção de cães latentes e clinicamente doentes. Portanto, manteríamos o as fontes de infecção $\left(l_{d}\right.$, $l_{d}^{C}, y_{d}, y_{d}^{C}$ ) no sistema e ainda aumentaríamos a proporção de cães suscetíveis (pois haveria a reposição de cães eliminados das categorias $y_{d}, y_{d}^{C}, v_{d}$ e $\left.v_{d}^{C}\right)$. Diante dessa argumentação, seria (em tese), mais eficiente eliminar um mosquito ao invés de um cão, caso se adote 
uma taxa de estratégia abaixo de 0,0215/dia.

Finalmente, nós temos o tratamento de cães, o qual seria a estratégia de controle menos efetiva. Embora nós tenhamos assumido o uso de um protocolo de tratamento que resulte na eliminação da parasitemia ${ }^{29}$, nossa hipótese é que o cão tratado ou retornaria à categoria de cães suscetíveis $\left(x_{d}, x_{d}^{C}\right)$ ou retornaria à categoria de cães latentes $\left(l_{d}, l_{d}^{C}\right)$, dependendo da probabilidade do cão tratado continuar sendo fonte de infecção para os mosquitos $\left(1-c_{k}\right)$. Portanto, o tratamento canino não evitaria que o cão se torne infectado novamente e, consequentemente, fonte de infecção.

\subsection{Qual estratégia apresenta melhor desempenho econômico?}

A análise do controle ótimo foi desenvolvida por meio de duas abordagens: (1) o custo total investido em cada estratégia e (2) o custo gasto com pacientes humanos ao longo de 2000 dias de atividades.

\subsection{1 $O$ custo total investido em cada estratégia}

A Figura 18 relaciona o custo total de cada estratégia de controle em função do respectivo valor da taxa. Observando esta figura, temos uma avaliação diferente em relação ao que foi comentado a respeito da Figura 17. No total, foram realizadas 200 valores de taxas $\times 5$ estratégias de controle $=1000$ simulações (conforme apresentado na secção 3.8). Para cada simulação, estimamos o valor total investido em cada estratégia, em correspondência a um dado valor de taxa. Os custos de cada estratégia estão resumidamente apresentados na Tabela 6.

Os pontos $\mathrm{Vac}_{0}, \mathrm{Eli}_{0}$ e $\mathrm{Col}_{0}$ são os pontos que apresentariam significante redução (100 vezes menor) do número de casos humanos notificados. Observe que o ponto Eli que corresponde à eliminação de cães positivos, é o ponto que indicaria o menor custo para se alcançar a redução em 1/100 do número de casos humanos notificados. Pelo controle vetorial também seria possível obter redução do número de casos humanos notificados, 
porém este ponto não está representado no gráfico (o custo do investimento é da ordem de USD $\left.10^{11}\right)$.

Mais uma observação deve ser comentada a respeito da Figura 18. Todas as estratégias de controle teriam maior custo conforme se aumenta o valor da taxa. No caso do controle vetorial $\left(\xi_{c}\right)$, da vacinação $\left(v_{d}\right)$ e da aplicação de coleira $\left(\theta_{d}\right)$, essa relação diretamente proporcional acontece, pois essas estratégias seriam atribuídas a todos os indivíduos de suas respectivas populações. Assim, todos os mosquitos seriam afetados pela borrifação e manejo ambiental; todos os cães estariam aptos a utilizar coleira; e todos os cães receberiam vacina. No caso do tratamento, foi observado pela Figura 17 que esta estratégia pouco interfere na dinâmica da doença. Portanto, a categoria de cães clinicamente doente $\left(y_{d}\right.$ e $\left.y_{d}^{C}\right)$ permaneceria constante. Logo, por mais que se aumente a taxa de tratamento canino $\left(\omega_{d}\right)$, pouquíssima alteração seria notada na dinâmica da doença. Por isso, quanto maior a taxa de tratamento canino, maior seria o custo envolvido.

Contudo, uma ressalva deve ser feita à elimnação de cães positivos. Conforme aumentamos a taxa de eliminação, observamos que a curva toma a forma de um "sino", com o pico obtido pelo ponto II da Figura 18. Porém devemos ficar atentos ao fato de que embora tenhamos um alto investimento para este ponto II, a taxa de $\xi_{d}=0,0125 /$ dia não seria suficiente para reduzir o número de casos humanos notificados a 1/100. Portanto, mantendo a eliminação de cães positivos a esta taxa de $\xi_{d}=0,0125 /$ dia, na prática, estaríamos removendo diariamente um número de cães insuficiente para a redução do número de casos humanos diários. Como consequência, teríamos um custo alto pela eliminação de cães sem ter a esperada redução da incidência humana.

Ainda, os pontos I e Eli $i_{0}$ estão praticamente no mesmo patamar do eixo "Custo (USD) acumulado". Entretanto, correspondem a valores diferentes de taxa. Para argumentarmos sobre este fenômeno, devemos lembrar que a eliminação de cães positivos seria uma estratégia seletiva (bem como o próprio nome sugere). Portanto, se iniciarmos a estratégia com uma taxa alta (digamos, aquela correspondente ao ponto $E l i_{0}, \xi_{d}=0,04$ ), estaríamos introduzindo uma alta pressão de eliminação sobre os cães positivos e, com o tempo, a proporção de cães positivos diminuiria. Em contrapartida, se introduzirmos uma 
taxa baixa (como aquela indicada pelo ponto I, $\xi_{d}=0,001$ ), a pressão de eliminação seria pequena e insuficiente para mudar a dinâmica da doença. Logo, teríamos o mesmo custo total que aquele apresentado pelo ponto Eli , porém, haveria pouca variação na quantidade diária de cães eliminados ao longo dos 2000 dias de atividades.

Para simplificar o pensamento a respeito do comportamento da curva que representa a eliminação de cães positivos na Figura 18, devemos imaginar a seguinte situação:

Há disponível um montante $X$ a ser investido na eliminação de cães positivos. Como deveríamos investir este montante? Eliminaríamos o máximo de cães possíveis no início da estratégia? Ou manteríamos a taxa de eliminação a níveis constantes, mantendo a atividade de controle "viva" até o final do planejamento da estratégia?

O ideal é se esforçar para eliminar o máximo de cães positivos o mais breve possivel.

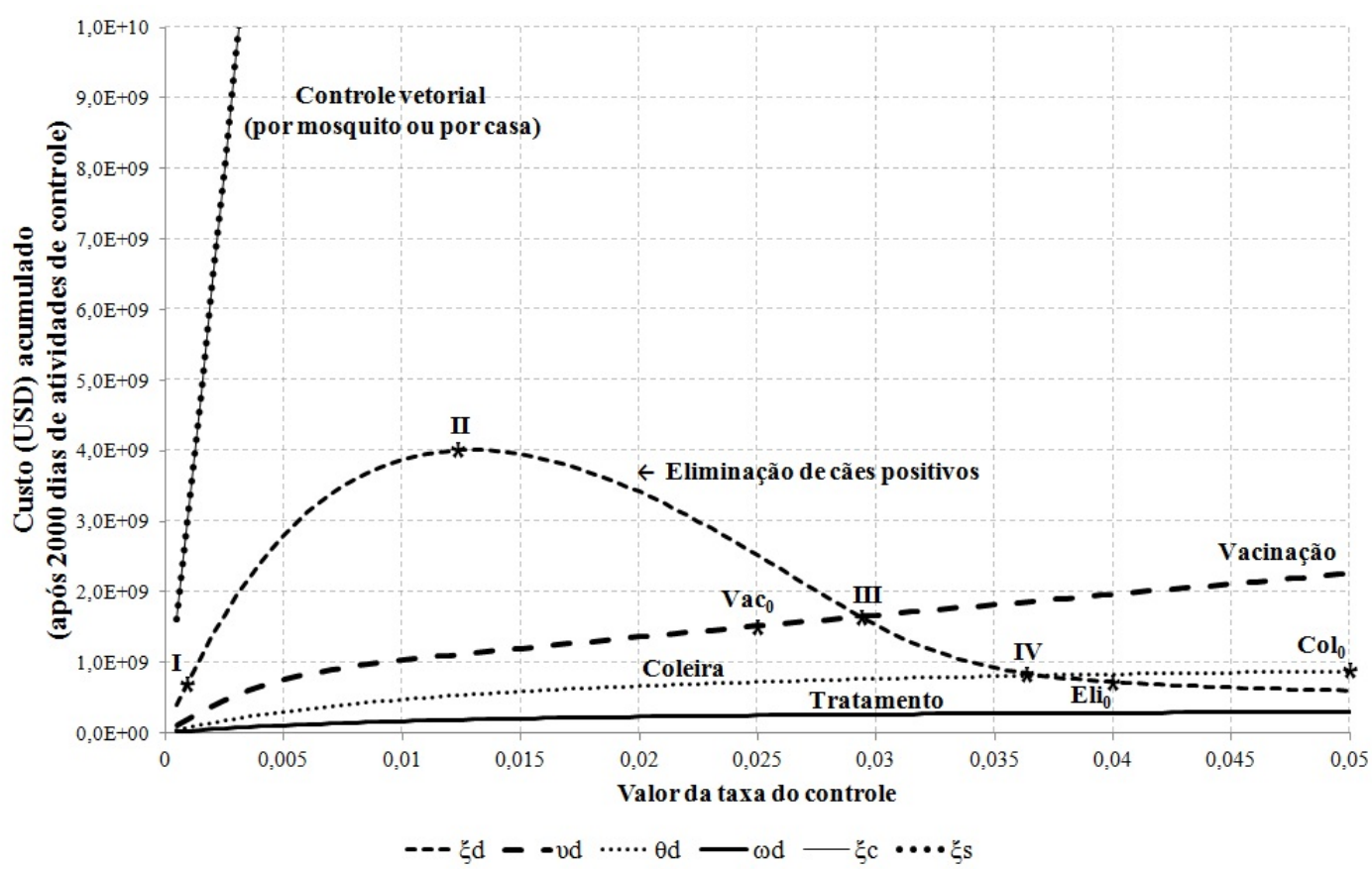

Figura 18 - Relação entre o custo total investido em cada estratégia de controle e sua respectiva taxa. $I:\left(0,001 ; 7,50 \times 10^{8}\right), I I:\left(0,0125 ; 4,01 \times 10^{9}\right) ; I I I:\left(0,0295 ; 1,65 \times 10^{9}\right) ; I V:\left(0,0365 ; 8,13 \times 10^{8}\right) ; V_{a c}$ : $\left(0,0250 ; 1,52 \times 10^{9}\right) ;$ Eli $_{0}:\left(0,04 ; 7,23 \times 10^{8}\right) ;$ Col $_{0}:\left(0,05 ; 8,77 \times 10^{8}\right)$.

\subsubsection{O custo total com pacientes humanos}


De forma similar ao que foi desenvolvido na secção 4.6.1, também é possível estimar como o custo total com pacientes humanos variaria conforme a estratégia de controle. A Figura 19 apresenta o resultado desta relação.

Com exceção do tratamento canino $\left(\omega_{d}\right)$, observa-se pela Figura 19 que todas as outras estratégias diminuiriam os custos médico-hospitalares, devido à tendência de queda do número diário de casos humanos (Figura 17). Observe que os pontos Vet $_{0}$, $V a c_{0}, E l i_{0}$ e $\operatorname{Col}_{0}$ correspondem às taxas mínimas de cada estratégia onde obteríamos o número diário de casos humanos notificados reduzidos em 100 vezes. Assim, entre esses quatro cenários possíveis, teríamos que o controle vetorial desenvolvido por residência $\left(\xi_{c}\right)$ traria a menor redução dos custos médicos hospitalares, seguido pela eliminação de cães positivos $\left(\xi_{d}\right)$, uso de coleira impregnada com deltametrina $4 \%\left(\theta_{d}\right)$ e vacinação canina $\left(v_{d}\right)$. Entretanto, embora o controle vetorial resulte na diminuição mais acentuada nos custos médico-hospitalares, esta estratégia seria a de maior custo (Figura 18).

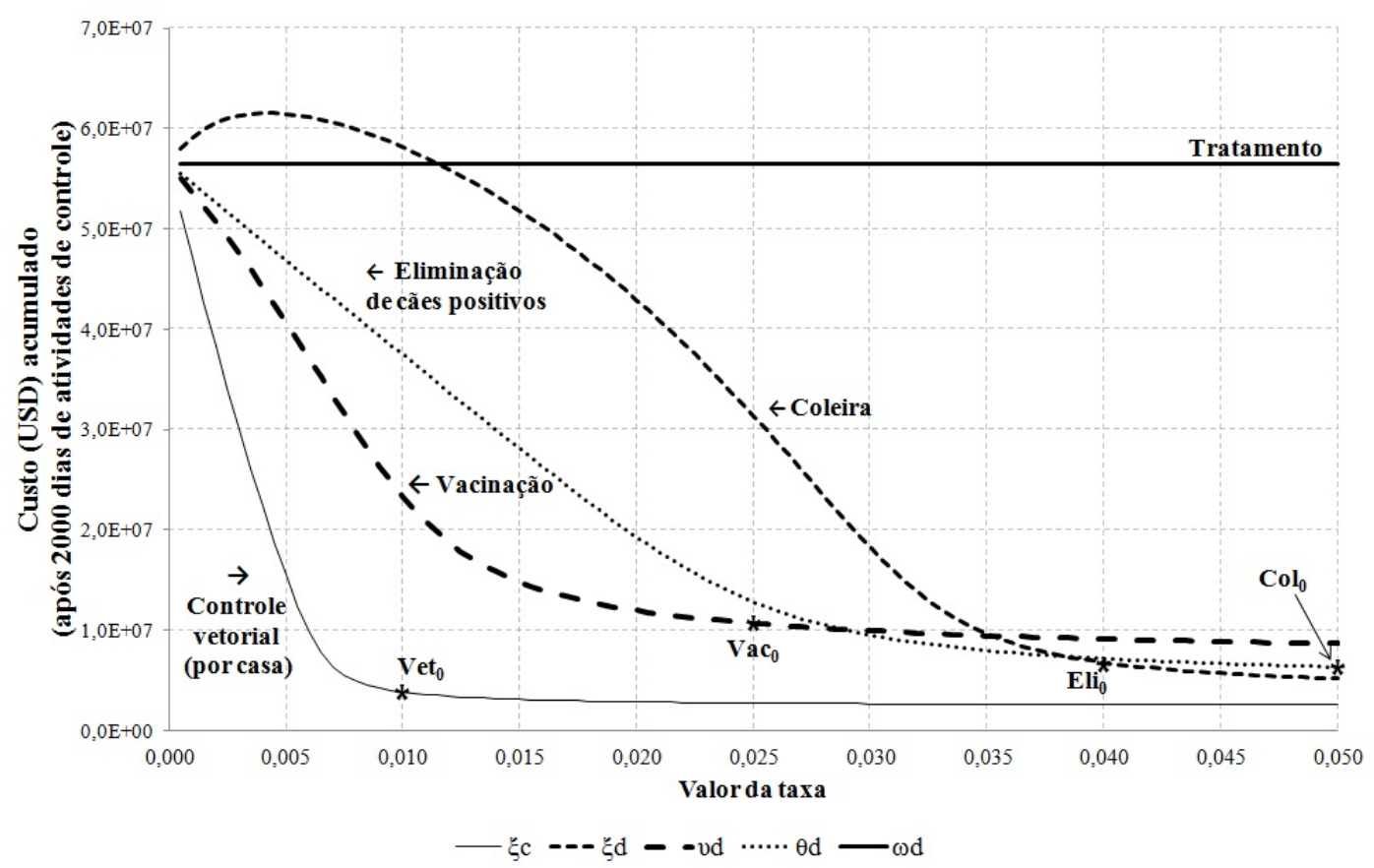

Figura 19 - Relação entre o valor da taxa de cada estratégia de controle e o valor gasto com tratamento médico-hospitalar após 2000 dias de atividades. Vet 0 : $\left(0,01 ; 3,85 \times 10^{6}\right) ;$ Vac $_{0}:\left(0,0250 ; 1,07 \times 10^{7}\right)$; Eli $_{0}:\left(0,04 ; 6,79 \times 10^{6}\right) ;$ Col $_{0}:\left(0,05 ; 6,34 \times 10^{6}\right)$.

4.6.3 Custos totais entre a estratégia de controle e o tratamento médico hospitalar 


\section{por valor de taxa de controle}

As Figuras 20 a 23 são gráficos relacionados aos custos envolvidos em cada estratégia de controle. Cada gráfico apresenta de forma conjunta a variação do custo da estratégia e do tratamento médico hospitalar, em correspondência com o valor da taxa. É apresentado em cada figura o valor mínimo total (a soma do custo da estratégia e o do tratamento médico-hospitalar) e o correspondente valor para o número diário de casos humanos notificados $(R)$.

\section{Controle vetorial}

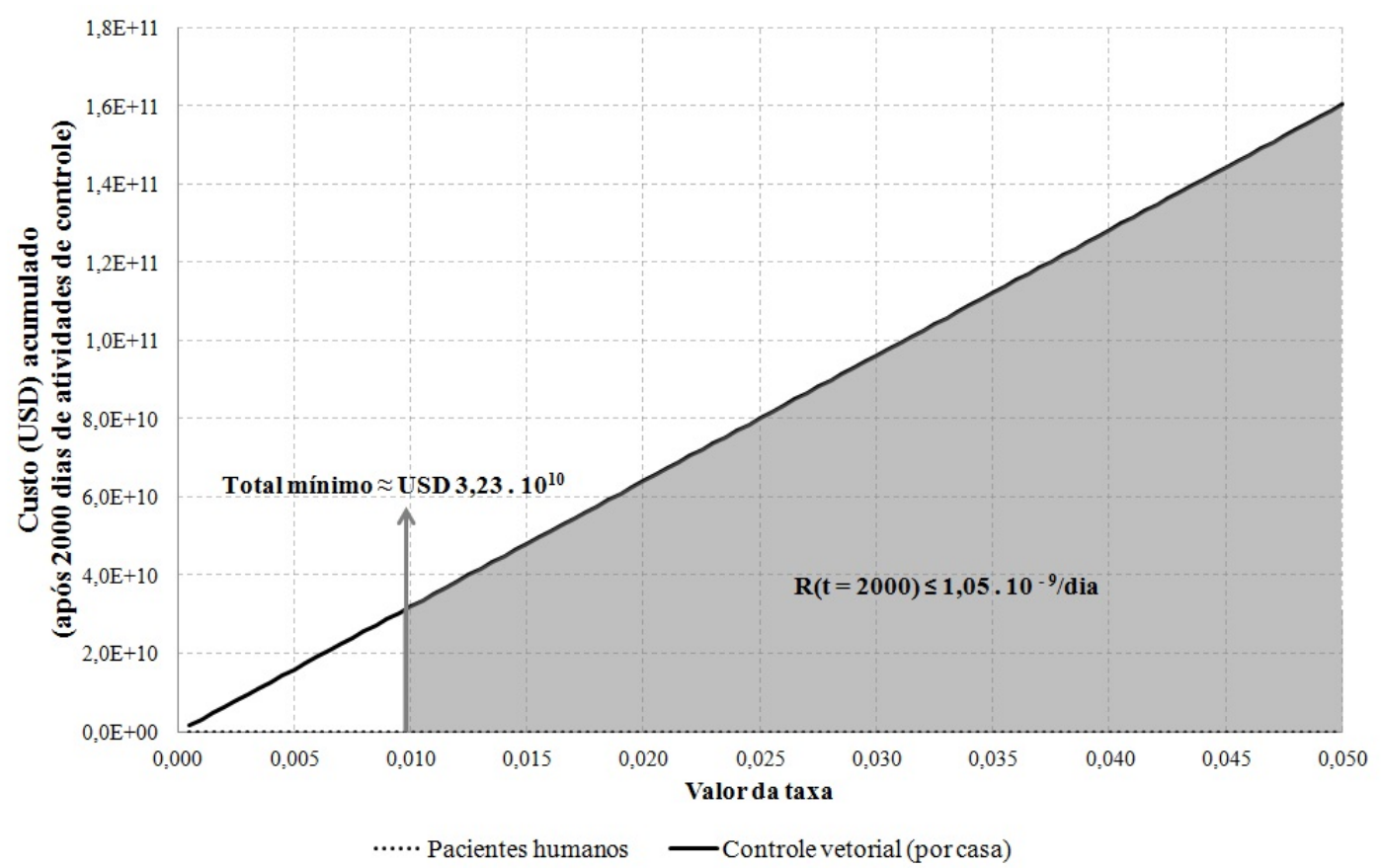

Figura 20 - Relação entre o custo total investido no controle vetorial e no tratamento médico-hospitalar de pacientes humanos e a respectiva taxa da estratégia. Em destaque, o custo mínimo e o correspondente número de casos notificados por dia $(R)$. A área em cinza corresponde à região do gráfico onde obteríamos valores menores que o $R$ indicado. 


\section{Vacinação de cães}

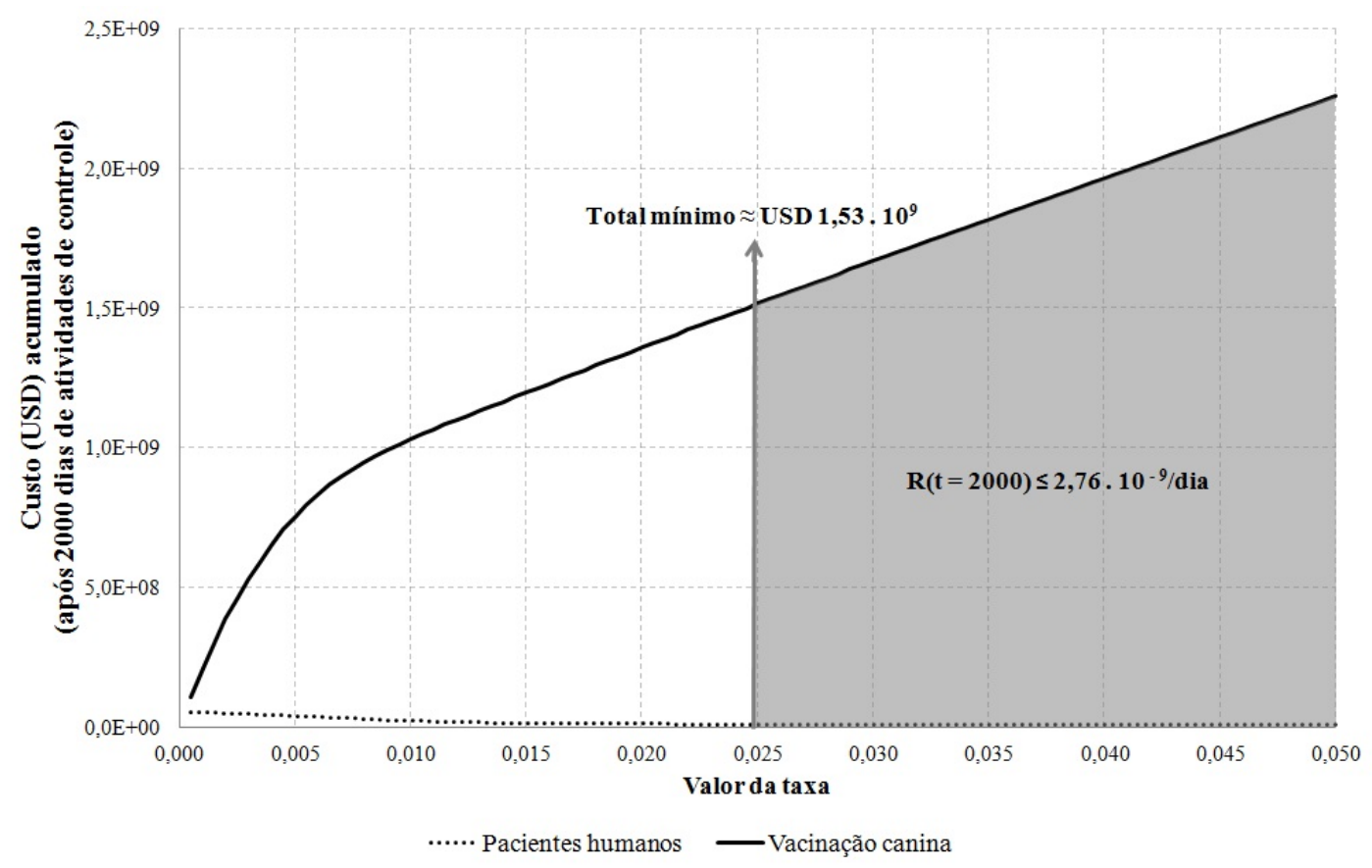

Figura 21 - Relação entre o custo total investido na vacinação de cães e no tratamento médico-hospitalar de pacientes humanos e a respectiva taxa da estratégia. Em destaque, o custo mínimo e o correspondente número de casos notificados por dia $(R)$. A área em cinza corresponde à região do gráfico onde obteríamos valores menores que o $R$ indicado. 


\section{Eliminação de cães positivos}

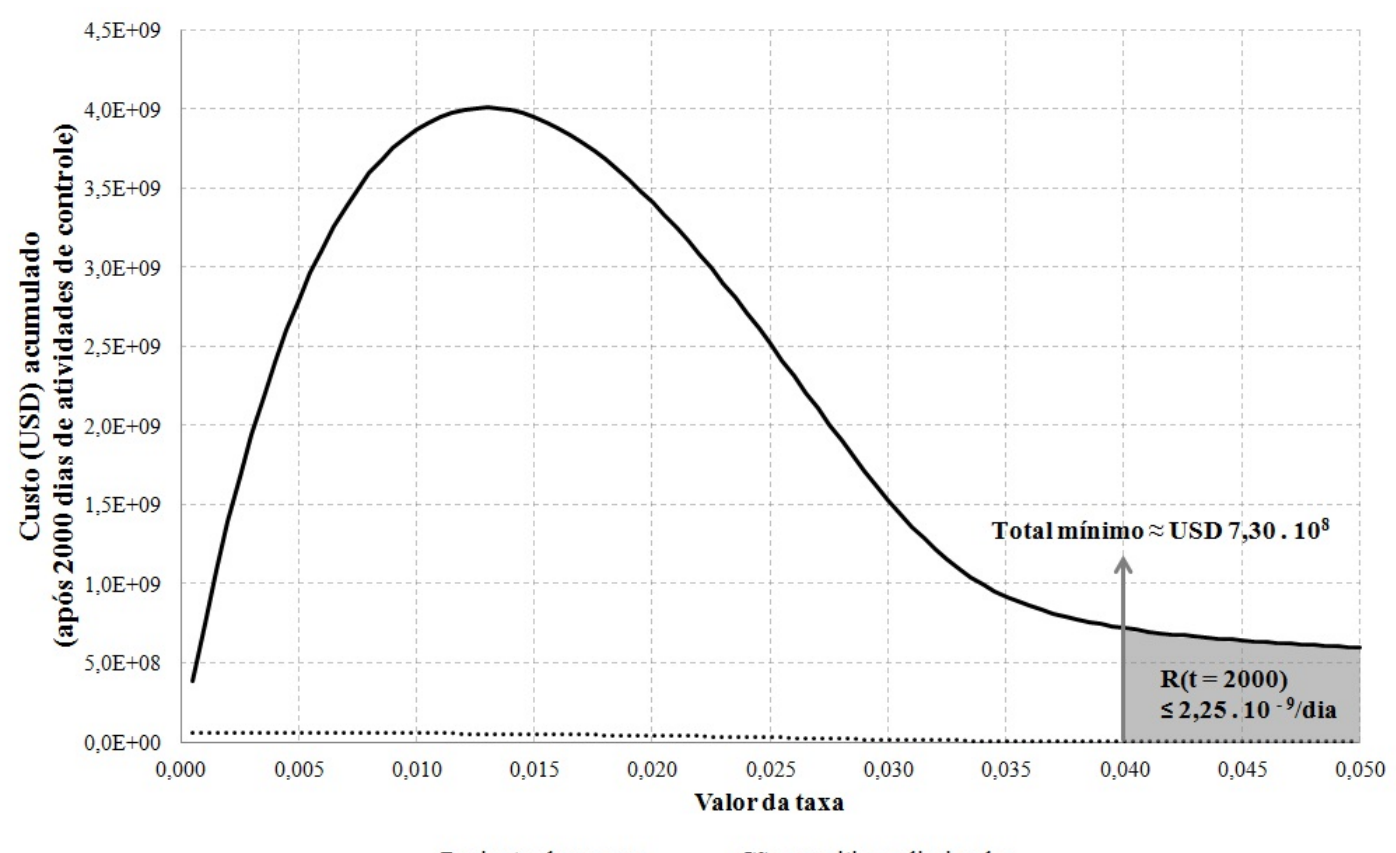

Figura 22 - Relação entre o custo total investido na eliminação de cães positivos e no tratamento médicohospitalar de pacientes humanos e a respectiva taxa da estratégia. Em destaque, o custo mínimo e o correspondente número de casos notificados por dia $(R)$. A área em cinza corresponde à região do gráfico onde obteríamos valores menores que o $R$ indicado. 


\section{Coleira impregnada com deltametrina $4 \%$}

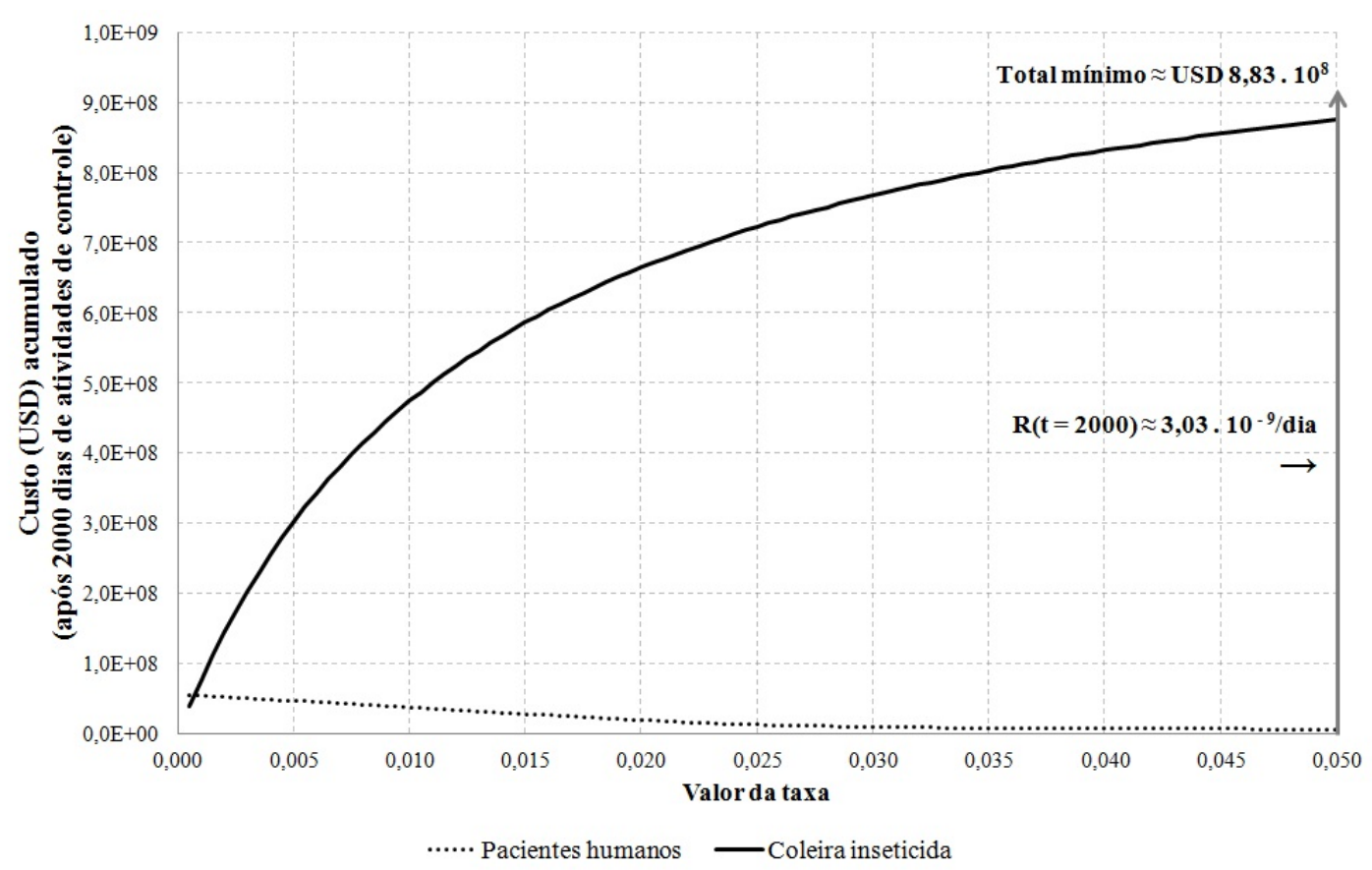

Figura 23 - Relação entre o custo total investido na distribuição de coleiras impregnadas com inseticidas aos cães e no tratamento médico-hospitalar de pacientes humanos e a respectiva taxa da estratégia. Em destaque, o custo mínimo e o correspondente número de casos notificados por dia $(R)$.

Na próxima secção exemplificaremos o efeito da ação destas quatro estratégias de controle (controle vetorial, eliminação de cães positivos, vacinação canina e uso da coleira impregnada com deltametrina 4\%), para os valores mínimos de taxa apontados neste estudo $\left(\xi_{c}=0,01 / \mathrm{dia}, \xi_{d}=0,04 / \mathrm{dia}, v_{d}=0,025 / \mathrm{dia}\right.$ e $\left.\theta_{d}=0,05 / \mathrm{dia}\right)$.

\subsection{Simulações numéricas para a intervenção de algumas estratégias}

A título de ilustração, exemplificaremos como seria a dinâmica do controle da doença, considerando a aplicação de uma dada estratégia de controle.

Em todos os exemplos, estamos supondo a doença se instalando na população entre os dias 0 a 2000 e a estratégia sendo introduzida a partir do dia 2000. Além disso, em todos os gráficos é possível observar a projeção das curvas das categorias $x_{h}, l_{h}, y_{h}$, 
$z_{h}, x_{d}, l_{d}, y_{d}, z_{d}, s_{1}, s_{2}$ e $s_{3}$ em tons de cinza. Esta projeção auxilia na visualização sobre como a dinâmica da doença se alteraria com a introdução da estratégia de controle.

\subsubsection{Eliminação de cães positivos}

As Figuras 24 a 26 representam a dinâmica do controle da leishmaniose visceral considerando a eliminação de cães positivos a uma taxa de $\xi_{d}=0,04 /$ dia.

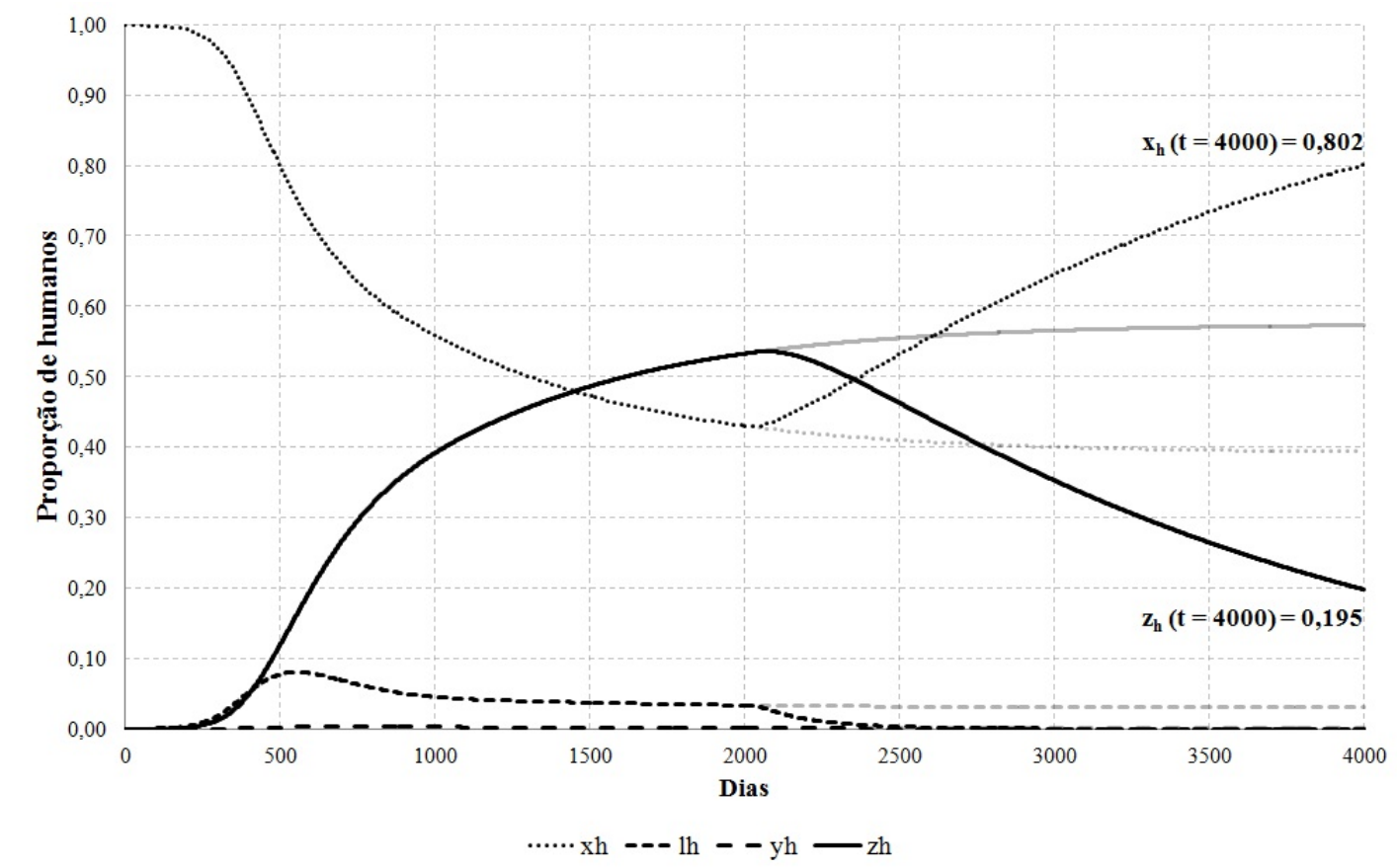

Figura 24 - Simulação numérica da dinâmica sobre a população de humanos, considerando a introdução da estratégia de eliminar cães positivos $\left(\xi_{d}=0,04 /\right.$ dia $)$ a partir do dia 2000. As curvas em tons de cinza representam a projeção das curvas caso não houvesse a introdução das estratégias de controle. 


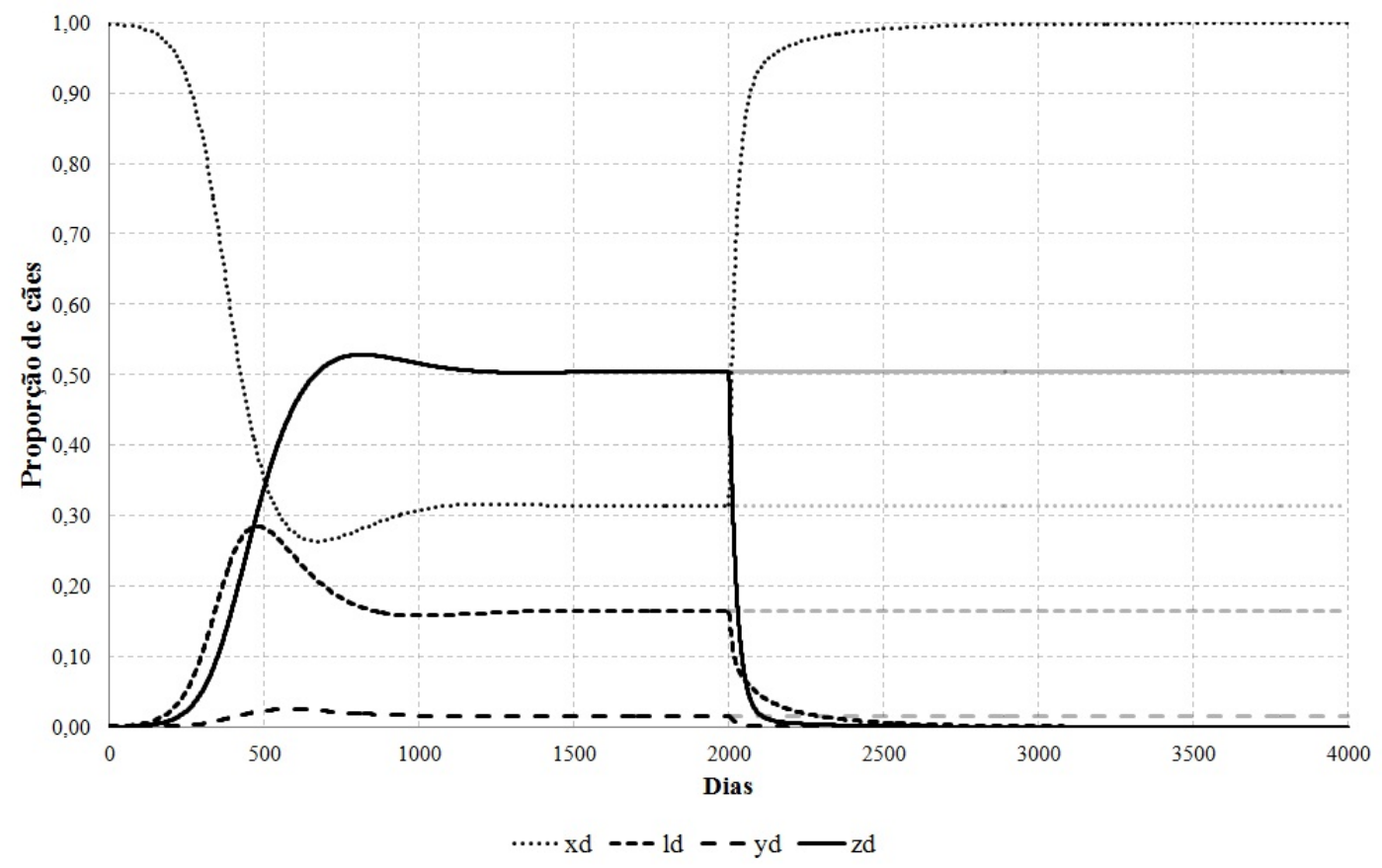

Figura 25 - Simulação numérica da dinâmica sobre a população de cães, considerando a introdução da estratégia de eliminar cães positivos $\left(\xi_{d}=0,04 /\right.$ dia $)$ a partir do dia 2000. As curvas em tons de cinza representam a projeção das curvas caso não houvesse a introdução das estratégias de controle.

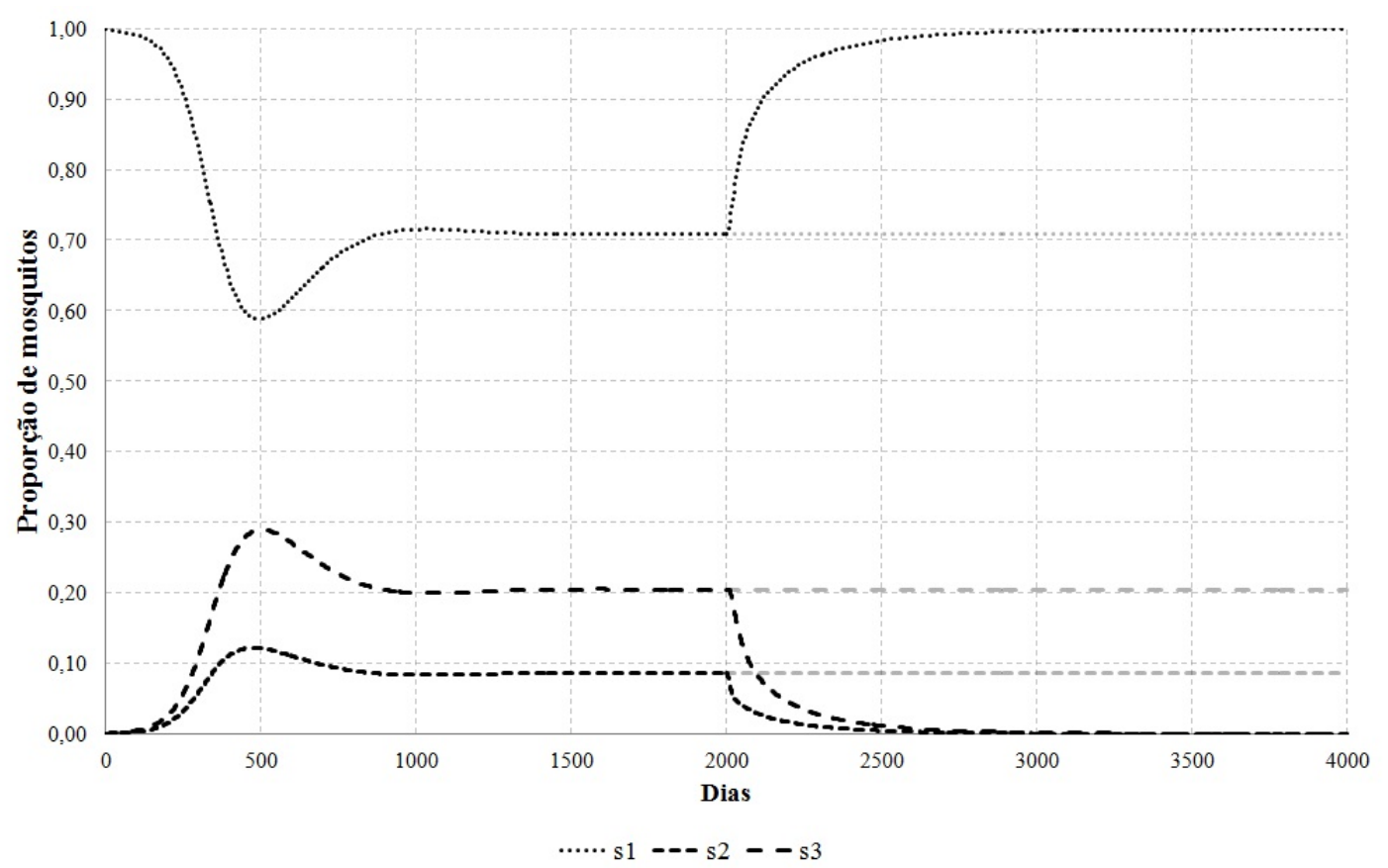

Figura 26 - Simulação numérica da dinâmica sobre a população de mosquitos, considerando a introdução da estratégia de eliminar cães positivos $\left(\xi_{d}=0,04 /\right.$ dia $)$ a partir do dia 2000 . As curvas em tons de cinza representam a projeção das curvas caso não houvesse a introdução das estratégias de controle. 


\subsubsection{Vacinação}

As Figuras 27 a 29 representam a dinâmica do controle da leishmaniose visceral considerando a vacinação de cães a uma taxa de $v_{d}=0,025 /$ dia.

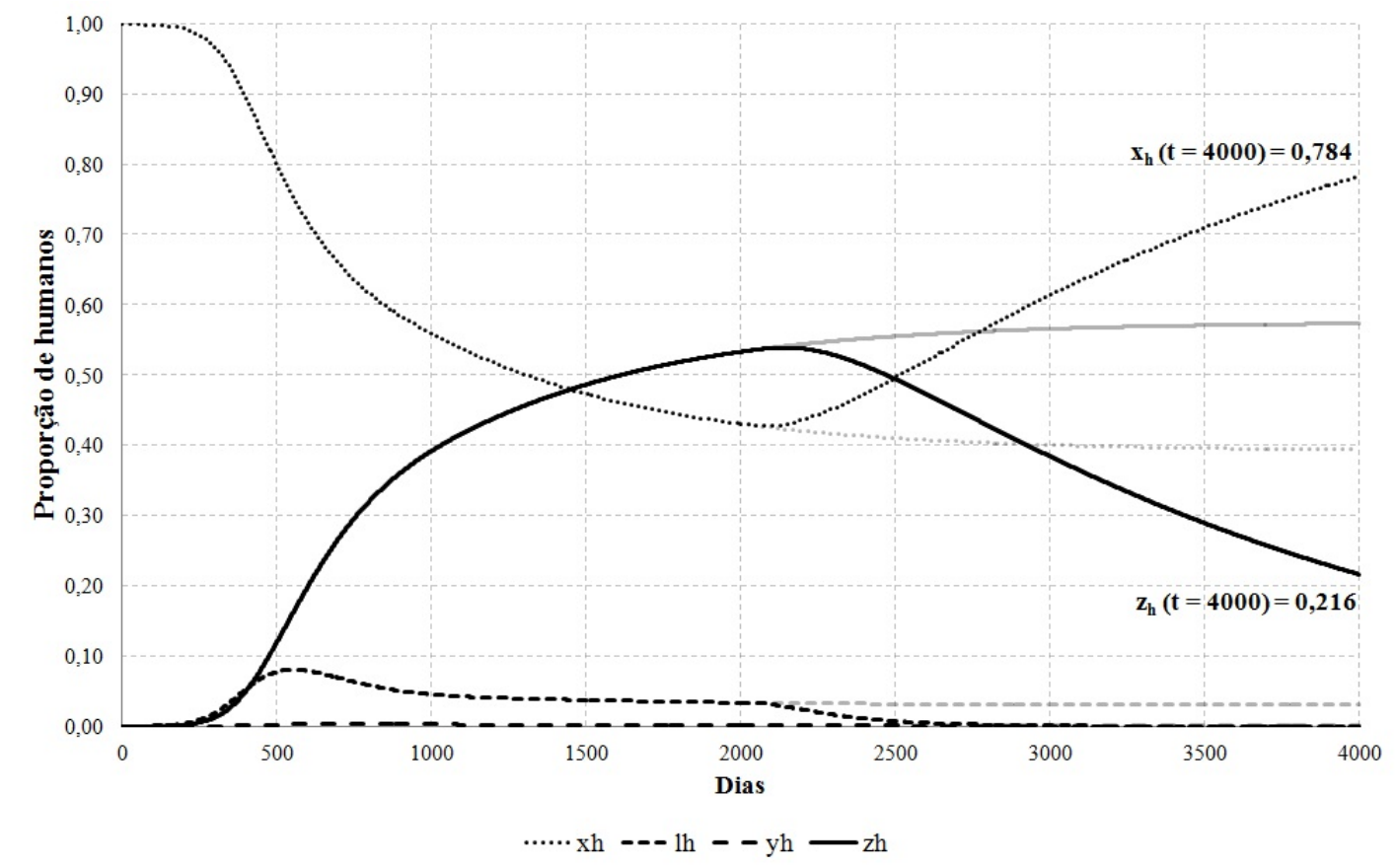

Figura 27 - Simulação numérica da dinâmica sobre a população de humanos, considerando a introdução da estratégia de vacinação canina $\left(v_{d}=0,025 /\right.$ dia $)$ a partir do dia 2000. As curvas em tons de cinza representam a projeção das curvas caso não houvesse a introdução das estratégias de controle. 


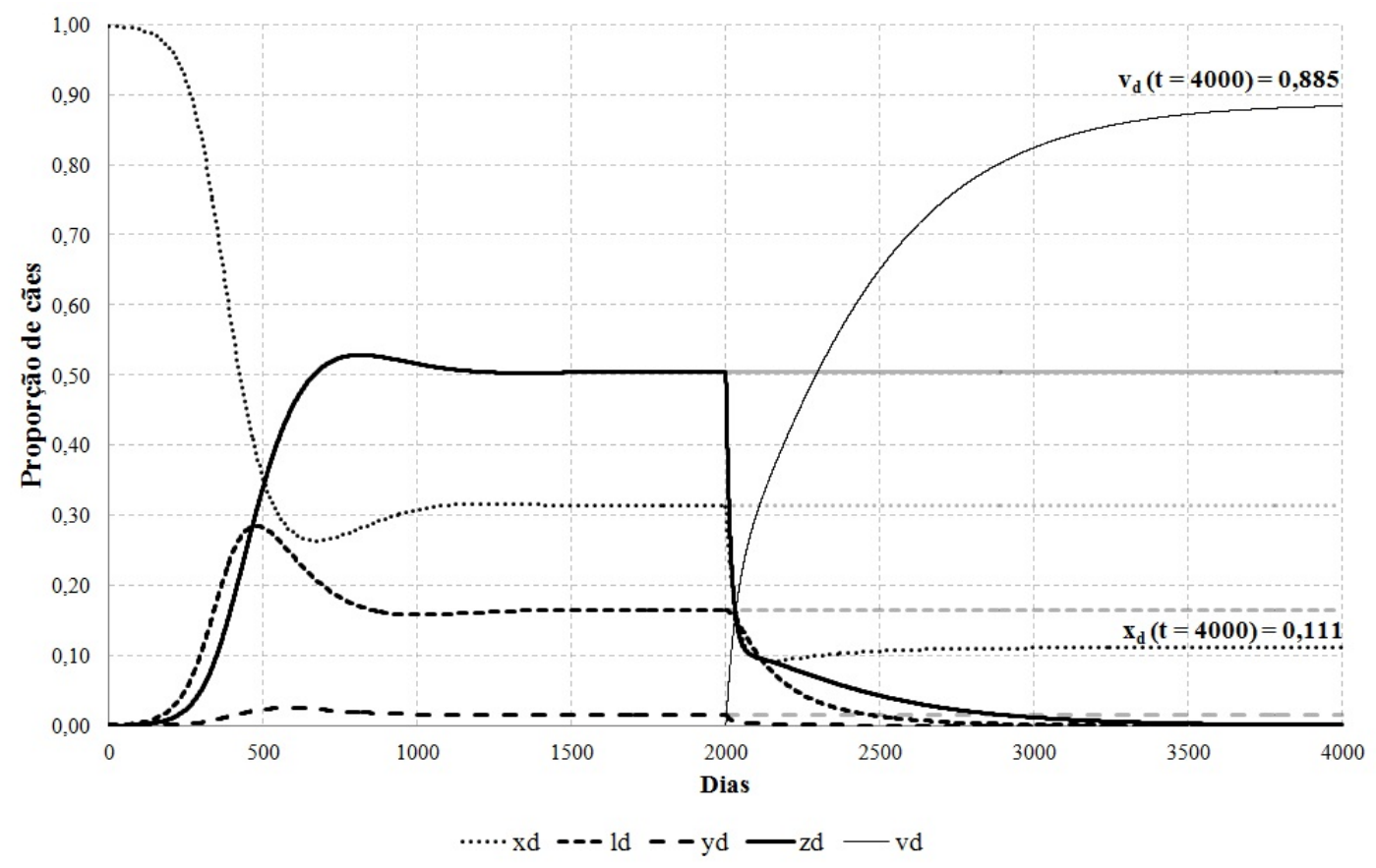

Figura 28 - Simulação numérica da dinâmica sobre a população de cães, considerando a introdução da estratégia de vacinação canina $\left(v_{d}=0,025 /\right.$ dia $)$ a partir do dia 2000 . As curvas em tons de cinza representam a projeção das curvas caso não houvesse a introdução das estratégias de controle.

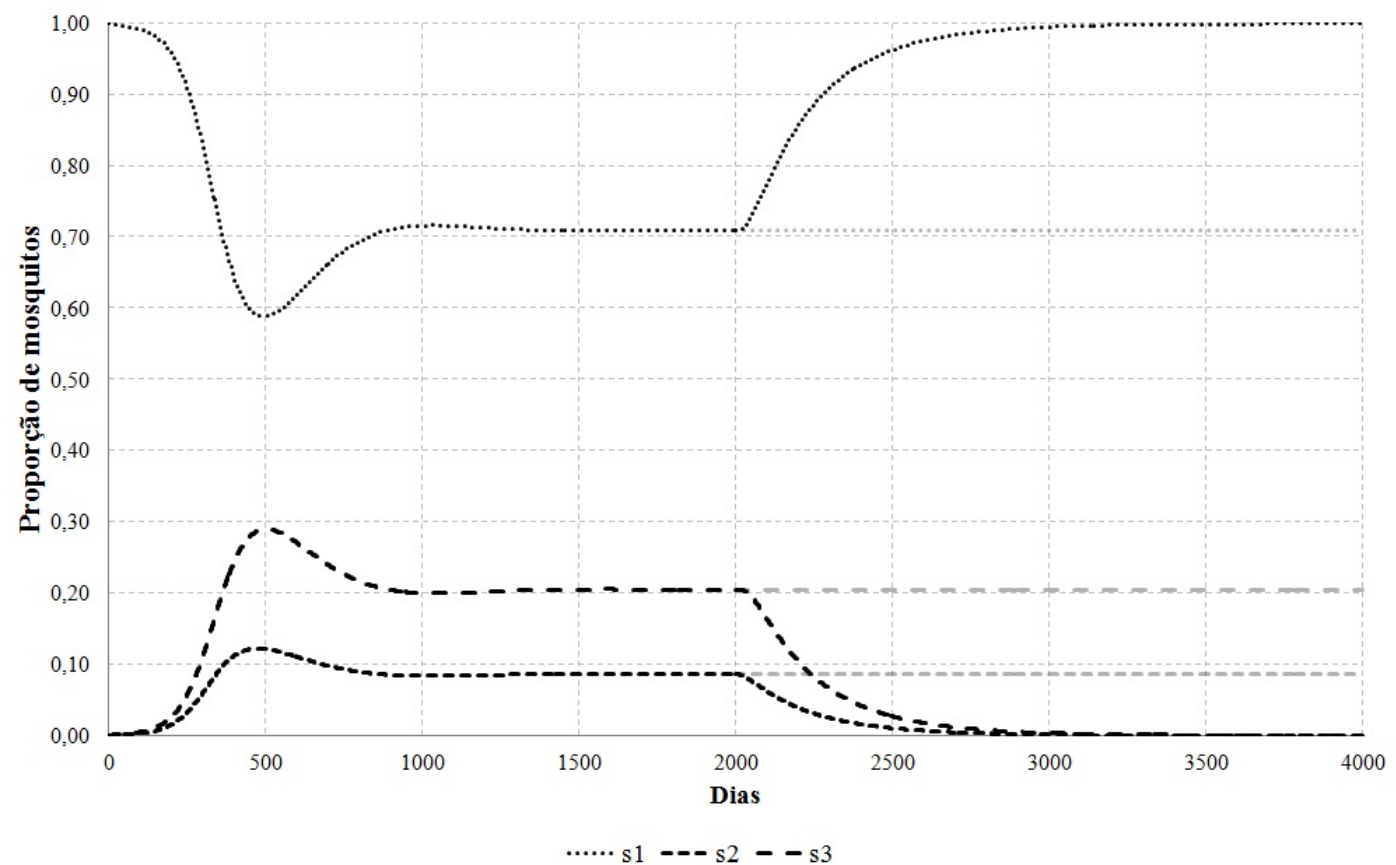

Figura 29 - Simulação numérica da dinâmica sobre a população de mosquitos, considerando a introdução da estratégia de vacinação canina $\left(v_{d}=0,025 /\right.$ dia $)$ a partir do dia 2000. As curvas em tons de cinza representam a projeção das curvas caso não houvesse a introdução das estratégias de controle. 


\subsubsection{Coleira impregnada com deltametrina $4 \%$}

As Figuras 30 a 32 representam a dinâmica do controle da leishmaniose visceral considerando a aplicação de coleiras impregnadas com deltametrina $4 \%$ a uma taxa de $\theta_{d}=0,05 /$ dia

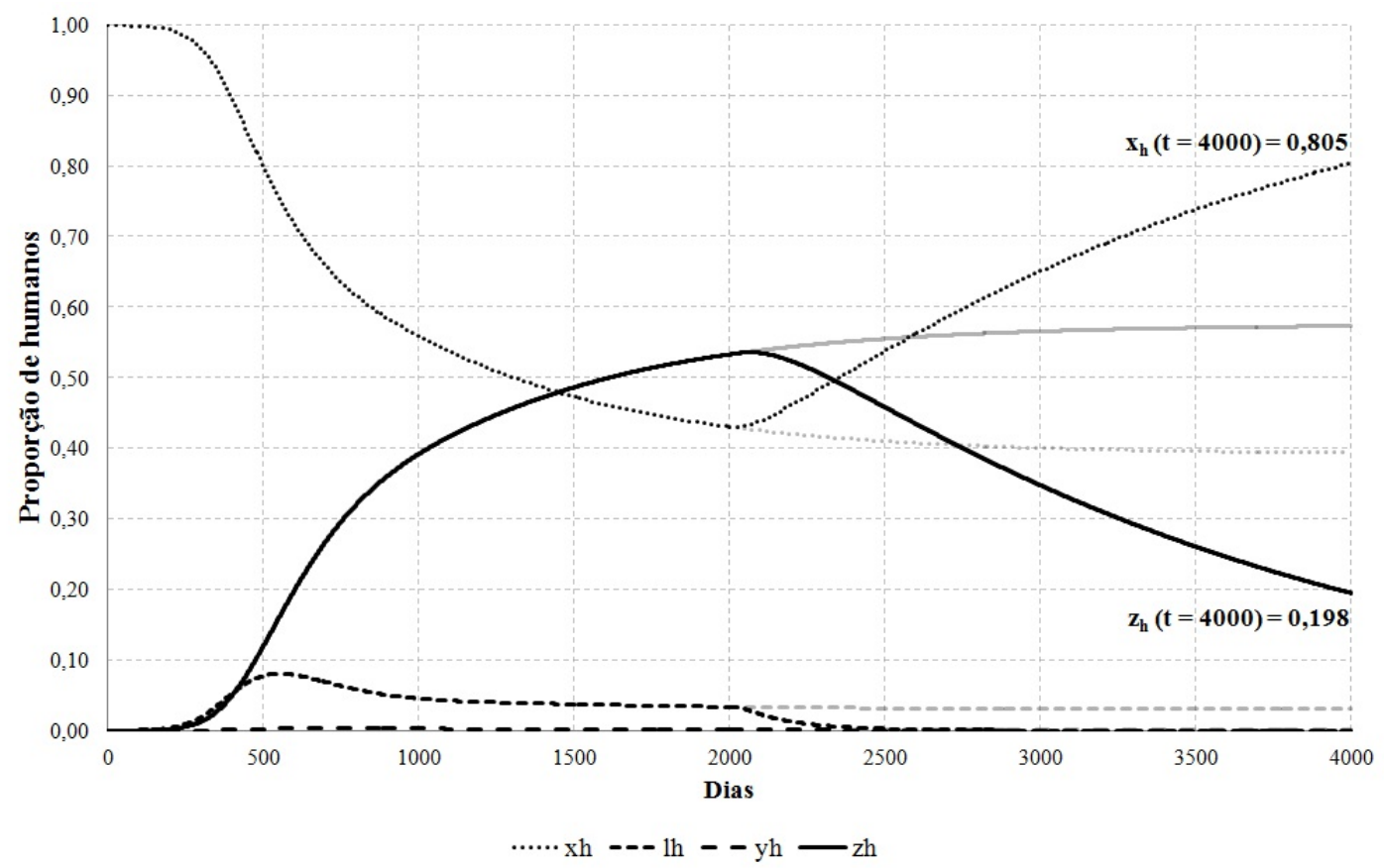

Figura 30 - Simulação numérica da dinâmica sobre a população de humanos, considerando a introdução da estratégia de distribuição de coleiras impregnadas com deltametrina $4 \%\left(\theta_{d}=0,05 /\right.$ dia $)$ a partir do dia 2000. As curvas em tons de cinza representam a projeção das curvas caso não houvesse a introdução das estratégias de controle. 


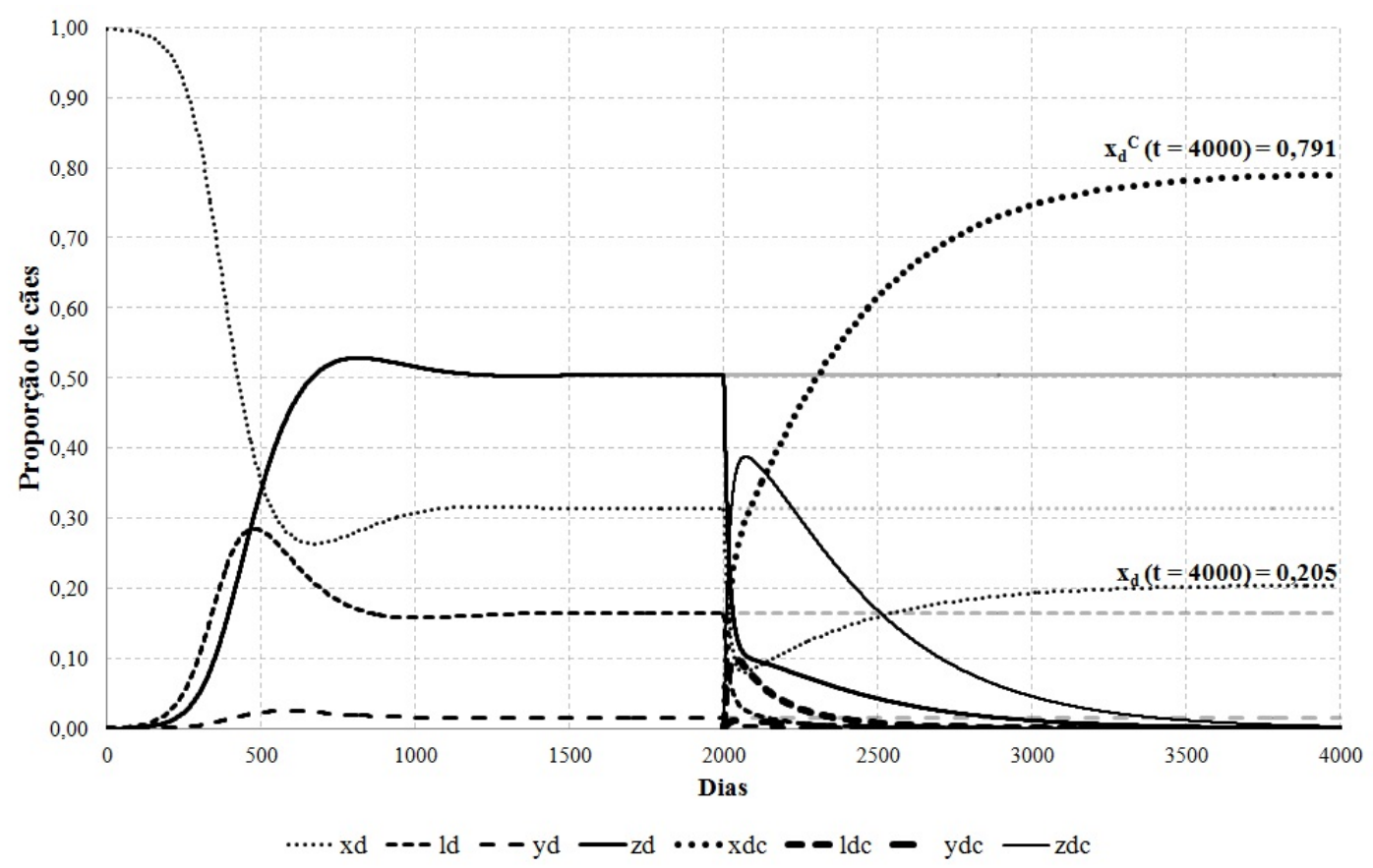

Figura 31 - Simulação numérica da dinâmica sobre a população de cães, considerando a introdução da estratégia de distribuição de coleiras impregnadas com deltametrina $4 \%\left(\theta_{d}=0,05 /\right.$ dia) a partir do dia 2000. As curvas em tons de cinza representam a projeção das curvas caso não houvesse a introdução das estratégias de controle.

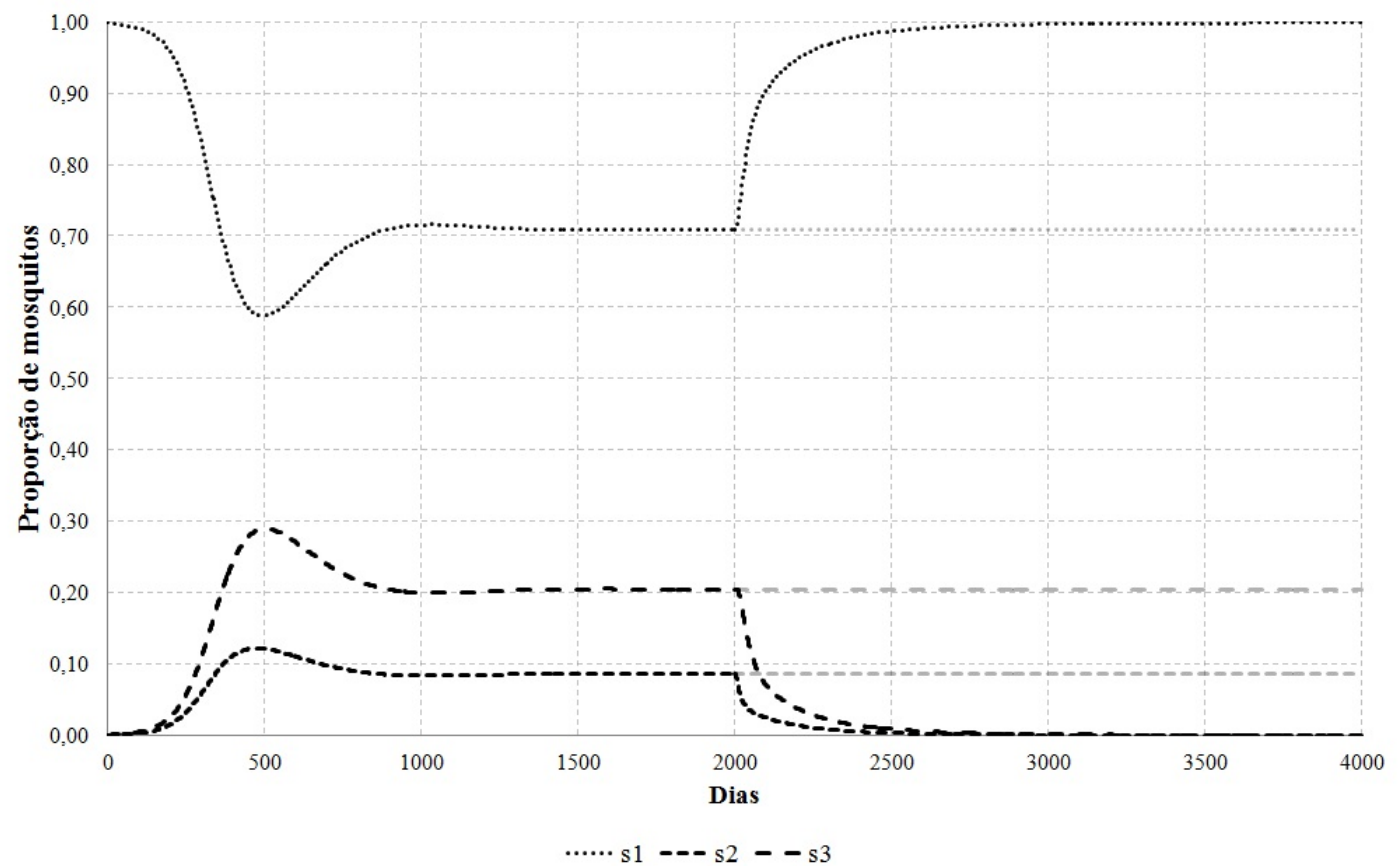

Figura 32 - Simulação numérica da dinâmica sobre a população de mosquitos, considerando a introdução da estratégia de distribuição de coleiras impregnadas com deltametrina $4 \%\left(\theta_{d}=0,05 /\right.$ dia $)$ a partir do dia 2000. As curvas em tons de cinza representam a projeção das curvas caso não houvesse a introdução das estratégias de controle. 


\subsubsection{Controle vetorial}

As Figuras 33 a 35 representam a dinâmica do controle da leishmaniose visceral considerando o controle vetorial (por meio do tratamento de casas) a uma taxa de $\xi_{c}=$ $0,01 /$ dia.

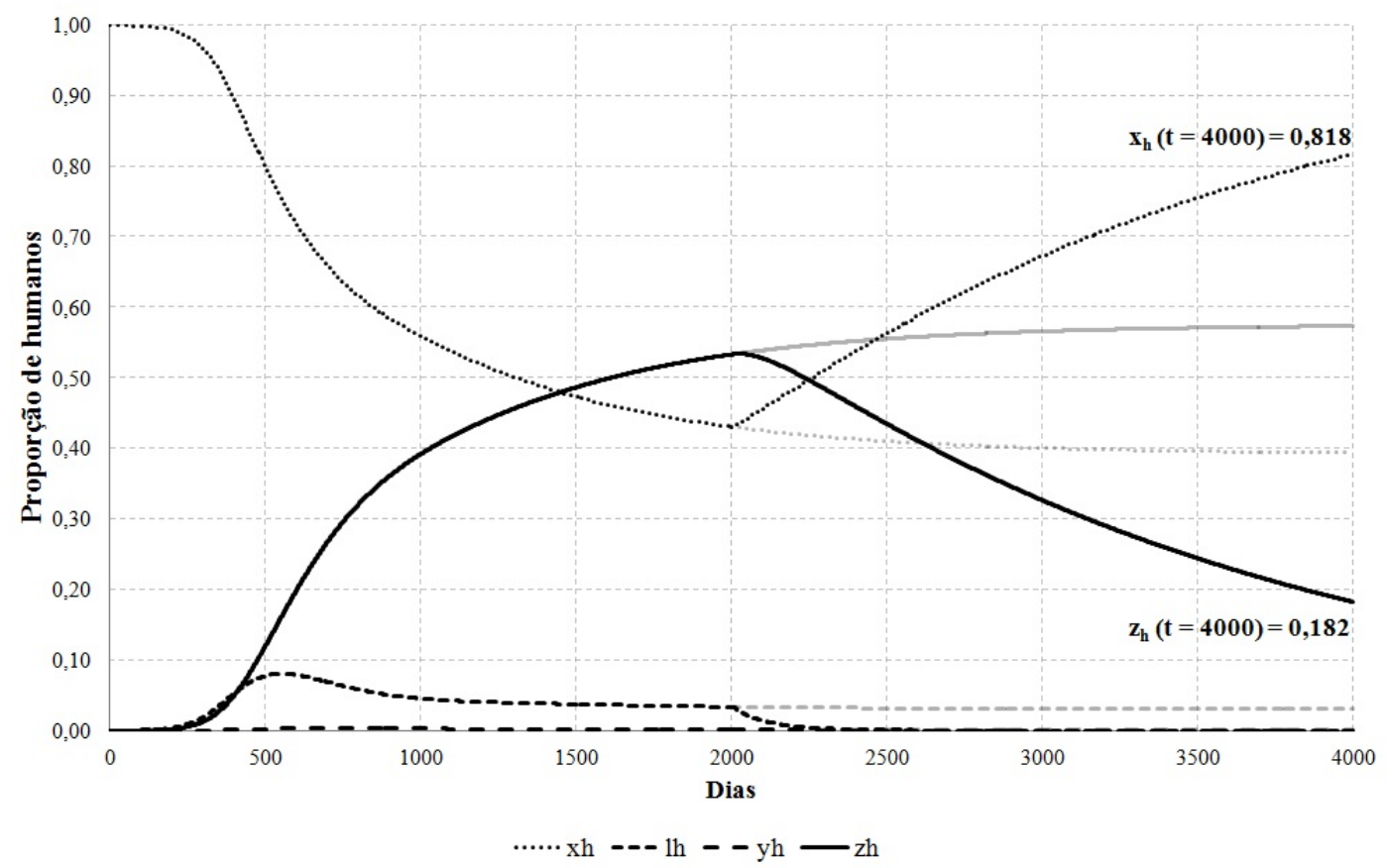

Figura 33 - Simulação numérica da dinâmica sobre a população de humanos, considerando a introdução da estratégia de controle vetorial $\left(\xi_{c}=0,01 /\right.$ dia) a partir do dia 2000. As curvas em tons de cinza representam a projeção das curvas caso não houvesse a introdução das estratégias de controle. 


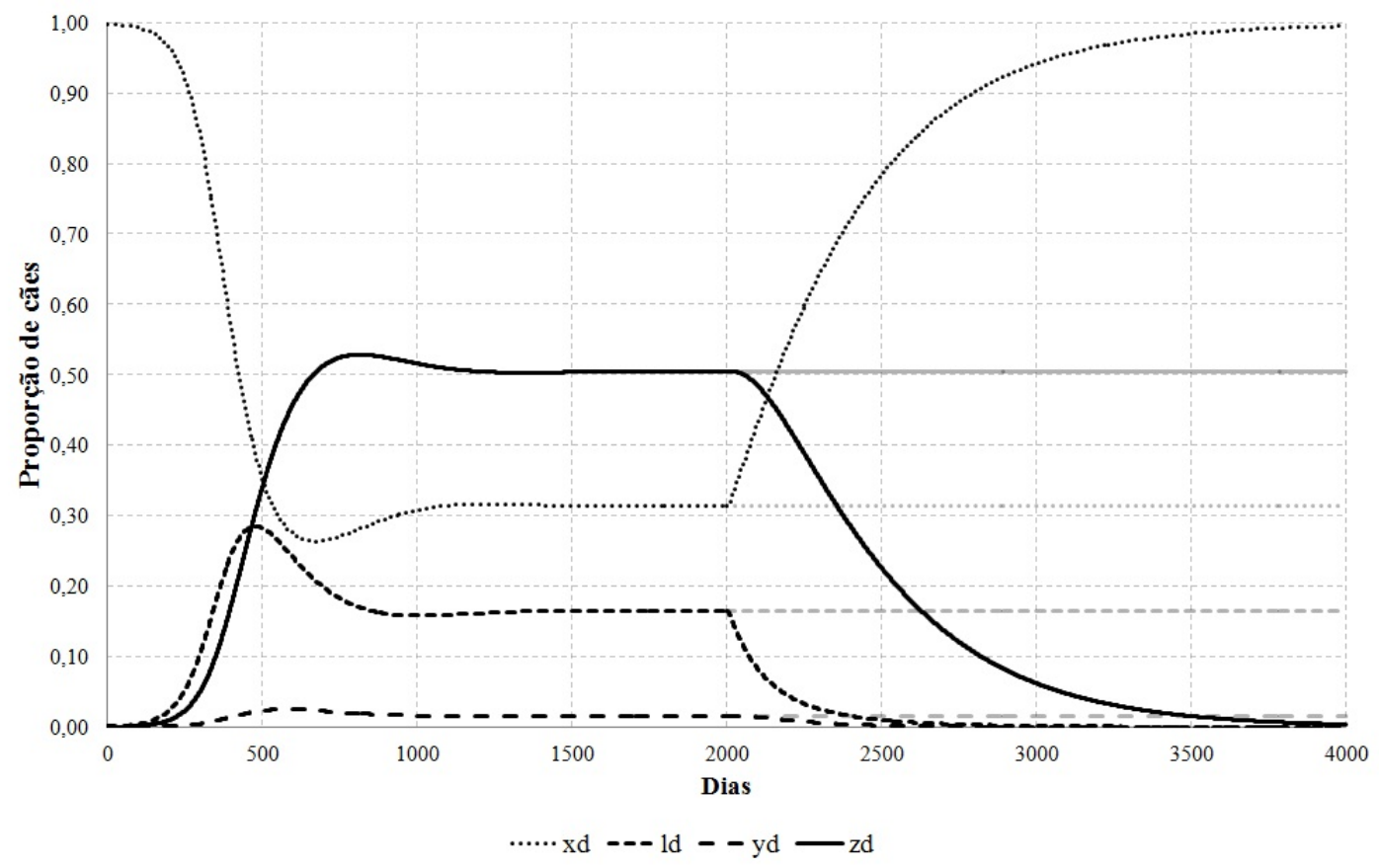

Figura 34 - Simulação numérica da dinâmica sobre a população de cães, considerando a introdução da estratégia de distribuição de controle vetorial $\left(\xi_{c}=0,01 /\right.$ dia $)$ a partir do dia 2000. As curvas em tons de cinza representam a projeção das curvas caso não houvesse a introdução das estratégias de controle.

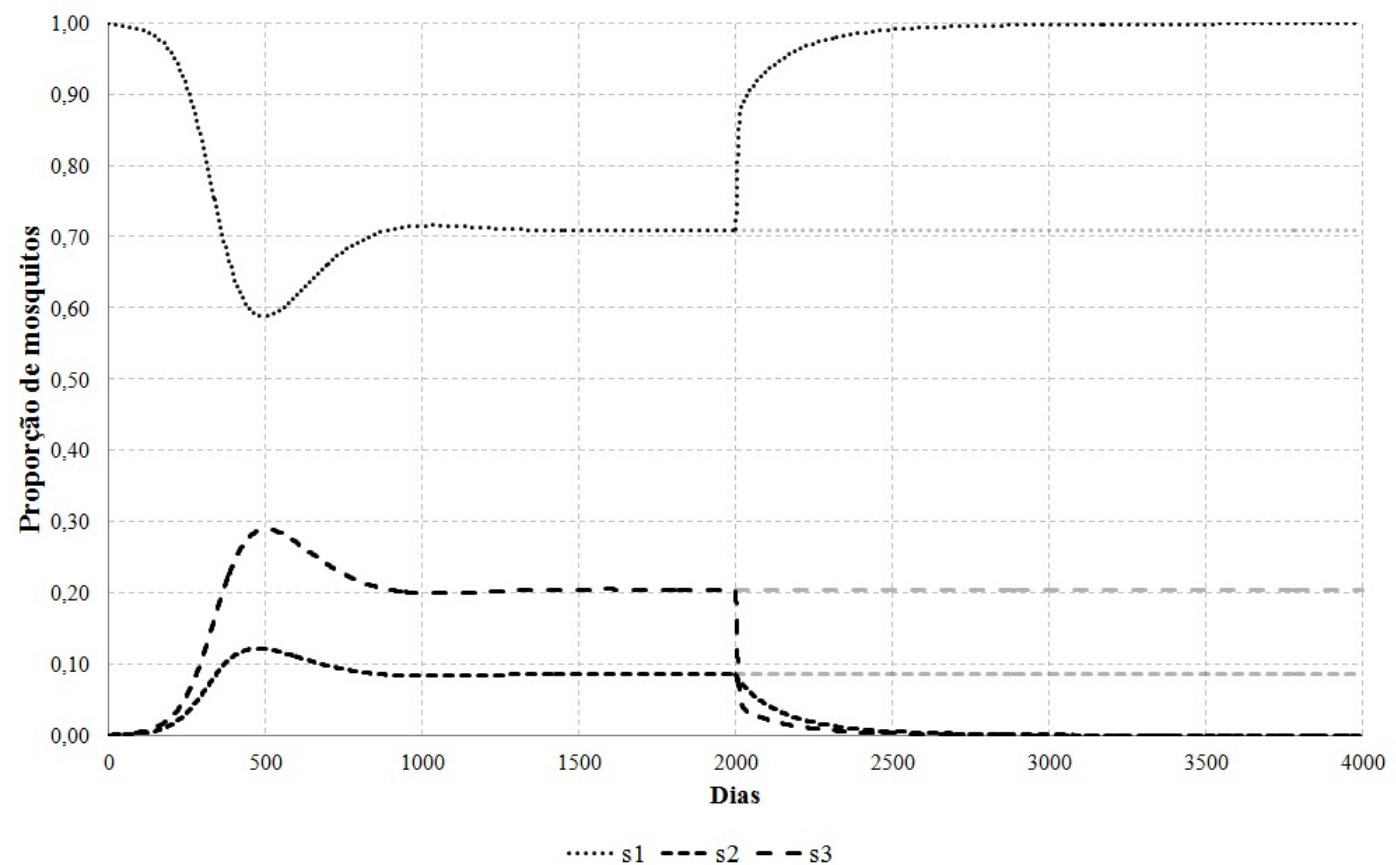

Figura 35 - Simulação numérica da dinâmica sobre a população de mosquitos, considerando a introdução da estratégia de controle vetorial ( $\left.\xi_{c}=0,01 / \mathrm{dia}\right)$ a partir do dia 2000. As curvas em tons de cinza representam a projeção das curvas caso não houvesse a introdução das estratégias de controle. 


\subsubsection{Casos humanos notificados por dia}

A Figura 36 representa a dinâmica do número de casos humanos notificados por dia. Nesta figura foram inclusas as 4 curvas referentes à ação das quatro estratégias de controle (controle vetorial, eliminação de cães positivos, vacinação canina, uso de coleiras impregnadas com deltametrina 4\%).

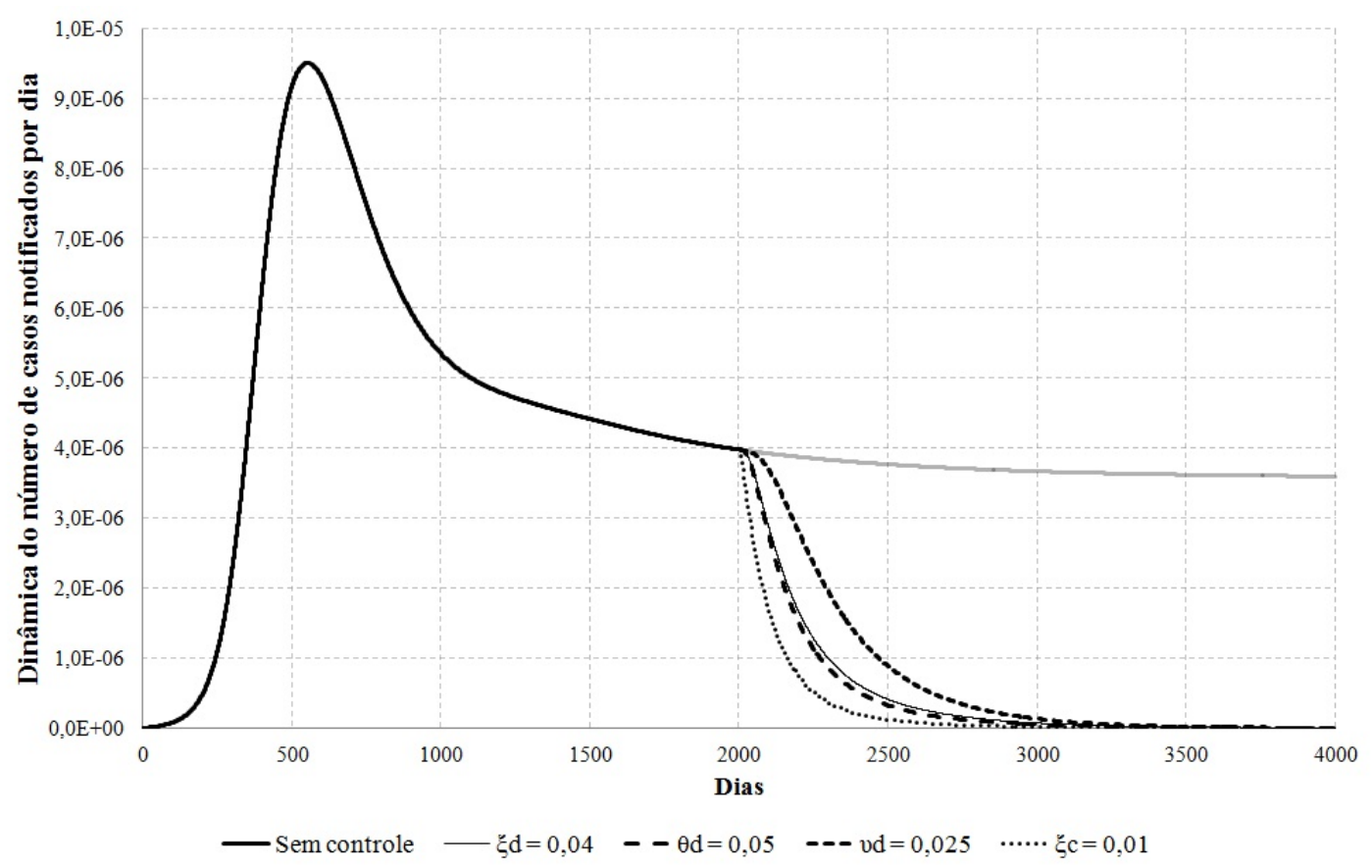

Figura 36 - Simulação numérica da dinâmica sobre a quantidade de casos humanos notificados por dia. A partir do dia 2000 temos as curvas que representam cada estratégia de controle. As curvas em tons de cinza representam a projeção das curvas caso não houvesse a intervenção.

A modificação da dinâmica da doença sobre a população humana (conforme apresentado nas Figuras 24, 27, 30 e 33) produziria o mesmo comportamento, independente da estratégia adotada. A diferença é observada com relação ao momento em que se obtém o aumento na proporção de humanos sucetíveis $x_{h}$. Comparando-se as quatro figuras, observa-se que para o controle vetorial teríamos a proporção de $x_{h}=0,818$ no instante $t=4000$ dias, a maior entre as quatro estratégias neste mesmo instante de tempo. Neste mesmo quesito, a estratégia de vacinação seria a mais baixa, atingindo a proporção de $x_{h}=0,784$ no instante $t=4000$ dias. 
Este fenômeno encontrado na dinâmica da doença em humanos é reflexo das alterações que ocorreriam no número de casos humanos notificados por dia. Assim, pela Figura 36, o controle vetorial é a estratégia que reduziria mais rapidamente o número diário de casos humanos notificados, seguido pelo uso de coleiras impregnadas com deltametrina $4 \%$, pela eliminação de cães positivos e pela vacinação canina.

Quando realizamos o controle vetorial, estamos acelerando a reposição de novos indivíduos na população de $\operatorname{mosquitos}^{9}$, levando ao aumento da proporção de mosquitos $s_{1}$ (mosquito não-infectado). Além disso, sendo a força de infecção caracterizada pela Eq. $(86)^{43}$ (onde $i=h, d$, no caso de humanos ou cães, e $S_{3}$, o valor absoluto desta categoria), a redução de $s_{3}$ evitaria o desenvolvimento tanto de novos casos humanos quanto de novas fontes de infecção. Por essa razão, o controle vetorial é considerado uma das estratégias mais eficazes ${ }^{9,10}$ (devido a esta sinergia presente na dinâmica desta estratégia).

$$
\begin{array}{r}
\lambda_{i}=m_{i} a_{i} b_{i} S_{3}(t) \\
i=h, d
\end{array}
$$

Por outro lado, no caso da vacinação canina, embora estejamos assumindo que todos os cães seriam vacinados, os efeitos protetores da vacina apareceriam apenas nos cães suscetíveis. Portanto, conforme o plano de vacinação seja executado, cães latentes $\left(l_{d}\right.$ e clinicamente doentes $\left(y_{d}\right)$ permaneceriam na população até que fossem naturalmente eliminados. Por essa razão, a vacinação é a estratégia mais lenta com relação ao crescimento da proporção de humanos suscetíveis $x_{d}$.

Sendo que as estratégias de controle têm suas ações focadas sobre as populações de cães e de mosquitos, temos que elas causariam impacto considerável na dinâmica da doença nessas duas populações. Note que a remoção de cães positivos (Figura 25) é a que elevaria mais rapidamente a proporção de cães suscetíveis $x_{d}$, visto que esta estratégia agiria diretamente sobre as fontes de infecção, eliminando-as da população. No caso do controle vetorial (Figura 34), a tendência seria similar ao caso da eliminação de cães positivos, porém seria um processo mais lento. Neste caso, pela diminuição da proporção 
de mosquitos infectivos, teríamos a inibição do desenvolvimento de novos cães latentes e a diminuição natural da proporção de cães clinicamente doentes e latentes. O efeito da vacinação de cães sobre a dinâmica da doença nesta população seria similar ao que foi comentado sobre o seu efeito sobre a dinâmica da doença na população humana (Figura 28). A diferença é que a própria população de cães receberia a vacina, enquanto que os efeitos apresentados pela população de humanos seriam o reflexo do que ocorre com a população de cães. Por fim, a dinâmica impulsionada pelo uso da coleira impregnada com deltametrina 4\% (Figura 31) seria, a princípio, semelhante à eliminação de cães positivos (embora as curvas da correspondente figura façam a distinção entre as categorias com e sem a coleira). Quando as coleiras são distribuídas aos cães, estaríamos diminuindo o acesso (isto é, a probabilidade de picada) do mosquito ao cão. Portanto, ao distribuir a coleira para cães latentes $\left(l_{d}\right)$ e clinicamente doentes $\left(y_{d}\right)$ seria como se estivéssemos eliminando estas categorias da população.

Por fim, o impacto das estratégias de controle sobre a dinâmica da doença na população de mosquito são semelhantes entre si. Em linhas gerais, todas elas (Figuras 26, 29, 32 e 35) atuariam renovando a população, eliminando os mosquitos infectados e repondo mosquitos não-infectados. A título de observação, no caso do controle vetorial, conforme representado pela Figura 35, ocorreria a eliminação direta dos mosquitos devido ao aumento da taxa de mortalidade e sua reposição por indivíduos não-infectados. Consequentemente, temos a aceleração do "turnover"da reposição de indivíduos da população, o que diminuiria a probabilidade do mosquito infectivo $\left(s_{3}\right)$ entrar em contato com cães $\left(x_{d}\right)$ e humanos suscetíveis $\left(x_{h}\right)$ ou do mosquito não-infectado $\left(s_{1}\right)$ entrar em contato com cães ou humanos latentes $\left(l_{d}, l_{h}\right)$ ou clinicamente doentes $\left(y_{h}, y_{d}\right)$. Por outro lado, as outras três estratégias (eliminação de cães positivos, vacinação canina e uso de coleiras impregnadas com deltametrina 4\%), não diminuiriam de imediato a proporção de mosquitos infectivos $s_{3}$. Assim, essas outras três estratégias, diminuiriam o desenvolvimento de novos mosquitos infectados e a diminuição dos mosquitos infectivos ocorreria naturalmente (conforme pode ser visto nas Figuras 26, 29 e 32). 


\section{o orgulho ferido}

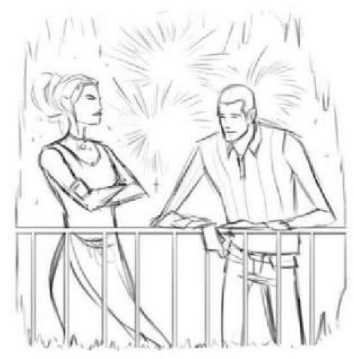

Um homem que trabalhava em um escritório ficou chocado quando um colega que secretamente desprezava foi promovido em seu lugar. Quando se encontraram, deu-thes tapinhas nos ombro e congratulações, engolindo a decepção e fazendo esforço para agir como se nada tivesse acontecido.

Todos que haviam sido passados para trás se reuniram depois do trabalho para comemorar a promoção do colega, como se fosse a coisa mais natural do mundo. Um não queria que o outro soubesse quanto ressentimento esse golpe provocara. $O$ homem não ousa admitir a humilhação nem para si mesmo e controla suas emoções. Ḧá certa tristeza no preço a pagar pelo ego ferido.

Depois da festa, cansado, o homem se viu adiante de uma dificuldade ainda maior Quando chegou em casa a esposa estava à sua espera.

"Pelo que vejo, foi beber de novo." "Fui. Um colega foi promovido."

"E vocês fizeram uma festa para ele?", a esposa pressionou pedindo detalhes. Depoís exclamou: "Você está calmo demais para afguém que acaba de perder uma promoção!".

"Noão dá para promover todo mundo ao mesmo tempo. Alguém tem de ser o primeiro."

"Então devia ter sido você."

"Noão, ele é o homem certo para o posto. Bem, acho que vou tomar um Ganho e deitar."

"Você não tem um pingo de orgulho, não é?".

A mulher não fazia a menor ideia de que ele estava com o orgulho ferido e de quanto custava fingir indiferença diante de sua dor intima. Ela também nem tentou se pôr no lugar dele. Uma esposa sábia teria entendido o que se passava sem que ele precisasse dizer e não tocaria no assunto. Uma esposa insensivel não percebe os verdadeiros sentimentos do marido numa situação como essa, e o pressiona impiedosamente.

Ninguém tem o direito de humilhar ou menosprezar o sentimento de seu companheiro. 


\section{DISCUSSÃO}

\subsection{As contribuições deste estudo}

O modelo apresentado neste estudo proporcionou uma nova e interessante visão sobre a dinâmica da transmissão da leishmaniose visceral entre humanos, cães e mosquitos (flebotomíneos). Além disso, desenvolvemos uma análise matemática e simulação computacional do impacto das estratégias de controle neste sistema. Por fim, nós estimamos a estratégia ótima ao compararmos os seus resultados entre si. Para avaliarmos essa eficácia, tomamos como referência a estimativa da redução do número diário de casos humanos notificados e dos custos envolvidos nas atividades de controle e no tratamento médico-hospitalar para pacientes humanos.

As pesquisas referentes às estratégias de controle da leishmaniose visceral raramente propõem a otimização de estratégias em uma abordagem geral. Em outras palavras, é muito usual encontrarmos resultados de caráter mais empírico do que analítico. Assim, qualquer extrapolação das conclusões desses resultados empíricos para outros cenários deve ser realizada com cautela. Ainda, com o crescimento do número de casos de leishmaniose visceral em países endêmicos (como o Brasil) e o aumento da propagação da transmissão para áreas sem registro de casos, surgem dúvidas sobre o impacto das medidas contínuas de controle ${ }^{98}$. Ademais, tais estudos têm analisado a eficácia das estratégias de controle individualmente e, ao compararem os estudos com outras estratégias, suas discussões se baseiam em resultados de estudos desenvolvidos em diferentes cenários ${ }^{99-103}$. Novamente, esta abordagem dificulta uma análise prática, visto que as discussões apresentadas são referentes a desenhos experimentais nem sempre similares e às áreas de estudo distintas. Por último, a definição de um grupo controle em estudos dessa natureza 
é controversa devido a questões éticas ${ }^{98}$.

A revisão escrita por Romero e Boelaert ${ }^{98}$ sobre o controle da leishmaniose visceral na América Latina revelou que muito trabalho ainda deve ser realizado para esclarecer a dinâmica da transmissão na população de humanos, cães e vetores. No modelo apresentado neste trabalho, foi possível desenvolver uma simulação que prediz o que poderia acontecer se as estratégias de controle ocorrerem. Assim, nosso estudo teórico apresentou uma clara aplicação prática e ainda apresenta a vantagem de não entrar em conflito com procedimentos éticos (justamente por ser um trabalho teórico, não envolve experimentação com seres vivos). Por outro lado, embora seja possível desenvolver um estudo de otimização por meio de um estudo de campo, nós precisaríamos organizar equipes de apoio e obter recursos materiais e financeiros. Outro detalhe importante é que nós obteríamos os resultados desses estudos a médio e a longo prazo. Entretanto, deve ser ressaltado que ensaios experimentais desse tipo não seriam tão simples nem diretos, visto que (possivelmente) os projetos necessitariam ser submetidos ao tramite burocrático para receber o aval de execução da parte de todas as entidades e instituições envolvidas. Logo, é possível supor um alto investimento de recursos e de tempo, visto que teríamos que desenvolver vários ensaios/experimentos/estudos de campo, até alcançarmos a intensidade correta (ótima) para se investir na estratégia de controle.

Como exemplo, nós podemos mencionar alguns estudos de campo relativos ao controle da leishmaniose visceral. Magalhães et al. ${ }^{104}$ publicaram um trabalho sobre o impacto de ações combinadas, que consistiam no (i) tratamento de casos humanos, na (ii) eliminação de cães positivos e no (iii) controle vetorial. Como resultado, os casos humanos foram controlados em 15 anos de aplicação dessas estratégias. Moreira Junior et al. ${ }^{105}$ registraram a taxa de incidência de leishmaniose canina em uma coorte de cães submetidos a uma estratégia de eliminação otimizada, que considera (i) o monitoramento de amostras de soro por meio do teste de ELISA; (ii) a diminuição do intervalo de tempo entre o resultado do sorodiagnóstico e a eliminação dos cães positivos; e (iii) a intensificação da vigilância sobre a população canina. Nesse ensaio, foi observado que, durante a aplicação dessas atividades de controle, a incidência da infecção canina perma- 
neceu estável por 2,5 anos. Porém, não houve um controle para comparação. Costa et al. ${ }^{106}$ compararam o efeito de quatro estratégias sobre controle da leishmaniose visceral em humanos. As quatro estratégias consideradas foram: (i) pulverização de casas e currais com insceticida piretróide; (ii) pulverização de casas e eliminação de cães positivos; (iii) combinação de pulverização de casas e de currais, mais a eliminação de cães positivos; e (iv) pulverização de casas (apenas como referência para comparação). Os resultados desse estudo indicaram um efeito positivo da eliminação de cães sobre a incidência em humanos, mas a combinação entre a eliminação de cães e a pulverização de abrigos de animais em peridomicílio não apresentou efeito significativo. Souza et al. ${ }^{107}$ compararam o efeito (i) da pulverização do inseticida piretróide; e (ii) da pulverização do inseticica piretróide e a eliminação de cães positivos, ambos com o cenário sem intervenção. As intervenções foram mantidas por dois anos e os resultados foram registrados ano a ano, com a pulverização do inseticida sendo desenvolvida a cada seis meses. Como resultado desse trabalho, a menor incidência foi observada nos grupos submetidos às intervenções, sendo que o impacto foi mais evidenciado no segundo ano do estudo. Embora todos esses estudos tenham apresentado excelentes resultados, é necessário termos em mente que eles foram alcançados mediante condições e cenários experimentais distintos. Além disso, todos foram desenvolvidos a médio e a longo prazo, o que reforça a ideia do investimento e esforço realizado na execução desses trabalhos.

Em nosso modelo, foi possível estimar a proporção de indivíduos em cada categoria da população e como elas variaram ao longo do tempo. Este tipo de estimativa é muito interessante, visto que é algo difícil de ser avaliado em estudos de campo (principalmente a categoria de indivíduos latentes, tanto para humanos quanto para cães). Foi possível estimar também o número diário de casos humanos notificados (veja a Figura 14 , onde o valor obtido no estado de equilíbrio foi de $3.58 \times 10^{-6}$ dia). Killick-Kendrick ${ }^{2}$ ressalta que a chave para se alcançar o controle da leishmaniose visceral é a educação. O efeito do impacto educativo não foi avaliada em nosso modelo, mas sabe-se que a educação sanitária e vigilância epidemiológica estão muito próximas e trabalham juntas. Como exemplo, caso as pessoas infectadas tenham pouco conhecimento sobre a leishma- 
niose visceral (e não procurem os serviços de saúde, por ignorarem os sinais e sintomas clínicos da doença) pode haver casos sub-notificados da doença. Como consequência, poucos casos seriam relatados e o planejamento de programas de controle tornar-seia insuficientemente organizado (pois todo o planejamento é baseado em dados epidemiológicos). Assim, ao obtermos a estimativa da proporção de casos sub-notificados, podemos avaliar a eficácia do serviço de vigilância. A eficácia desse serviço, por sua vez, pode influenciar os programas de controle, pois o sistema de vigilância bem estruturado é fundamental para evitar a sub-notificação de casos humanos e para acompanhar a dinâmica da infecção tanto em cães quanto na população humana. A vigilância fortalecida certamente contribuirá para melhorar a qualidade dos dados epidemiológicos e, consequentemente, para a tomada de decisões neste cenário complexo ${ }^{70,98}$.

\subsection{Interpretação dos resultados}

Os resultados obtidos neste trabalho podem ser analisados por duas abordagens. Inicialmente, podemos avaliar o impacto das estratégias de controle sem considerar as limitações econômicas. Em seguida, podemos interpretar os resultados dentro da ótica do custo-benefício. Para facilitar o raciocínio, apresentaremos a discussão por partes.

\subsubsection{As características e os resultados do modelo}

Diferente do que foi adotado no modelo matemático apresentado por Burattini et al. ${ }^{9}$, em nosso estudo apenas os cães são considerados fontes de infecção para leishmaniose visceral. Portanto, é natural que o número de reprodutibilidade basal estimado $\left(\mathscr{R}_{0}\right)$ seja dependente apenas das categorias de populações de cães (em particular, os cães latentes $\left(l_{d}\right.$ e $\left.l_{d}^{C}\right)$ e os clinicamente doentes $\left(y_{d}\right.$ e $\left.\left.y_{d}^{C}\right)\right)$. Ainda, de forma similar ao resultado apresentado por Burattini et al. ${ }^{9}$, a contribuição dos cães clinicamente doentes para o $\mathscr{R}_{0}\left(\mathscr{R}_{0,\left(y_{d}\right)}=0,30\right)$ foi numericamente menor do que a contribuição dos cães latentes $\left(\mathscr{R}_{0,\left(l_{d}\right)}=4,50\right)$. Porém, observe que a contribuição devido aos cães clinicamente doentes 
foi estimada como $\mathscr{R}_{0,\left(y_{d}\right)} \leq 1$. Este resultado foi obtido devido às premissas do modelo e, em especial, devido aos parâmetros utilizados (a fração de vetores que adquirem a infecção após picar um cão clinicamente doente foi assumida como $c_{y}=0,67$, enquanto que para o caso de picar um cão latente, foi de $\left.c_{l}=0,93\right)^{80}$. Este resultado aponta a imporância dos cães latentes na manutenção e instalação da leishmaniose visceral na população. Ainda, considerando o fato de os cães latentes serem visualmente sadios e devido ao período de incubação variável ${ }^{8}$, torna-se ainda mais difícil detectá-los. Assim, esses cães permaneceriam livres para atuar como fonte de infecção durante o tempo em estiverem incubando a doença.

Neste trabalho, a análise se concentrou em estratégias de controle de caráter preventivo. Logo, o objetivo esperado é evitar a ocorrência de novos casos humanos. Para tanto, focamos o estudo no impacto de estratégias que se aplicam sobre a população de cães (cujos indivíduos infectados são considerados as fontes de infecção da leishmaniose visceral) e na população de vetores (que são efetivamente os transmissores clássicos desta doença). A atenção sobre estratégias de controle se justifica também pelos resultados apresentados na análise de sensibilidade (secção 4.3). Pela análise de sensibilidade, os parâmetros considerados mais dominantes (por serem apontados como responsáveis pela sensibilidade de pelo menos 10 variáveis, conforme a Figura 16) estão diretamente relacionados à manutenção da leishmaniose visceral no sistema. Neste modelo, esses parâmetros são responsáveis por determinar as proporções de cães suscetíveis $\left(x_{d}\right)$, latentes $\left(l_{d}\right)$, clinicamente doentes $\left(y_{d}\right)$ e os hábitos alimentares e de sobrevivência dos mosquitos. Portanto, as estratégias de controle preventivo consideradas neste trabalho atuam diretamente na contenção e no avanço da doença sobre esses pontos cruciais. A eliminação de cães positivos $\left(\xi_{d}\right)$ e o controle vetorial $\left(\xi_{c}\right)$ atuam eliminando as fontes de infecção (no caso, os cães positivos, principalmente os cães da categoria $l_{d}, l_{d}^{C}, y_{d}$ e $y_{d}^{C}$ ) e aumentando a taxa de mortalidade de vetores, respectivamente. A vacinação canina $\left(v_{d}\right)$ atua diminuindo a proporção de cães suscetíveis $\left(x_{d}\right.$ e $\left.x_{d}^{C}\right)$. A coleira impregnada com inseticida $\left(\theta_{d}\right)$ age diminuindo o contato do cão (com particular interesse sobre os da categoria $x_{d}, x_{d}^{C}, l_{d}, l_{d}^{C}, y_{d}$ e $\left.y_{d}^{C}\right)$ com os vetores. E, embora o tratamento canino $\left(\omega_{d}\right)$ tenha se 
mostrado ineficiente, ele teria por objetivo remover os cães da categoria de clinicamente doentes $\left(y_{d}\right.$ e $\left.y_{d}^{C}\right)$ para o de suscetíveis $\left(x_{d}\right.$ e $\left.x_{d}^{C}\right)$.

A simulação desenvolvida neste trabalho apresentou resultados muito interessantes, mesmo quando a estratégia de eliminação de cães positivos não foi aplicada. Na literatura científica, há alguns autores que enfatizam a importância do desenvolvimento e da utilização de vacinas caninas, a fim de reduzir a fonte de infecção (categorias de cães latentes $l_{d}$ e clinicamente doentes $y_{d}$ ). Por conseguinte, isto poderia interromper o ciclo de transmissão de parasitas de Leishmania para os mosquitos (e indiretamente aos seres humanos) e poderia se tornar um método alternativo ao sacrifício de cães positivos ${ }^{3,5}$. Outros autores enfatizam o uso de coleiras impregnadas com inseticida ${ }^{23,99,100}$. Assim, podemos compreender que o controle da leishmaniose visceral pode ser alcançado sob restrições éticas. Além disso, há algumas pesquisas que destacam a eficácia do controle da população de flebotomíneos, quando comparado com a eliminação de cães infecta$\operatorname{dos}^{9,10,22,98}$. Portanto, se tomarmos como referência o número diário de casos humanos notificados (independente dos custos envolvidos), pela Figura 36, o controle vetorial $\left(\xi_{s}\right)$ (considerando como referência a quantidade de casas trabalhadas) seria a estratégia mais eficiente, seguida pelo uso da coleira impregnada com inseticida $\left(\theta_{d}\right)$, eliminação de cães positivos $\left(\xi_{d}\right)$ e vacinação canina $\left(v_{d}\right)$. Dessa forma, a evidência de um controle mais humano e ético deveria atrair a atenção dos serviços de vigilância epidemiológica para a possibilidade de estratégias alternativas à eliminação de cães positivos.

Embora nosso modelo tenha apontado a ineficácia do tratamento canino para o controle da leishmaniose visceral e apesar de encontrarmos estudos que não recomendam esta conduta ${ }^{108-110}$ (visto que há controvérsias sobre a obtenção da cura parasitológica), nosso modelo indicou que seria possível obter o controle da leishmaniose visceral sem a necessidade de eliminar cães positivos. Assim, se um controle humano e ético pode ser utilizado (isto é, reduzir o sacrifício de cães), poderíamos supor que o tratamento de cães infectados seria aceitável. Supondo que um cão infectado seja domiciliado (portanto, tenha um proprietário responsável) e que os outros métodos de controle preventivo sejam aplicados, o proprietário poderia ter liberdade para tratar seu próprio cão. 


\subsubsection{Os custos das estratégias apresentados por este estudo}

Apesar da simplicidade na análise econômica abordada neste trabalho, podese dizer que ela traz o ineditismo de apresentá-la por meio de um modelo matemático dinâmico. No modelo utilizado, nos concentramos sobre as vias de transmissão clássicas, bem como os hospedeiros, vetores e fontes de infecção preponderantes. Portanto, as estimativas de custo ótimo são uma diretriz muito interessante para avaliar a estratégia de controle mais eficaz.

Em relação ao controle da leishmaniose visceral, poucos trabalhos desenvolveram algum estudo econômico sobre as estratégias de controle preventivo ${ }^{19}$. Muitos apresentaram a análise econômica referente ao tratamento e diagnóstico de casos huma-

nos ${ }^{19,59,60}$ e, dentro dessa visão, uma das conclusões é a vantagem econômica em se investir em atividades preventivas ${ }^{55,56,59}$.

Inicialmente, desenvolvemos uma análise similar a uma "triagem", onde apenas avaliamos o impacto epidemiológico das estratégias, sem considerar os potenciais custos (conforme apresentado na secção 3.8). Com exceção do tratamento canino $\left(\omega_{d}\right)$, todas as outras quatro estratégias foram capazes de reduzir a taxa de casos humanos notificados $(R)$ (Figura 17). E, entre essas quatro estratégias, aquelas que reduziram a taxa de casos humanos notificados com menor custo foram a eliminação de cães positivos $\left(\xi_{d}\right)$, uso da coleira impregnada com inseticida $\left(\theta_{d}\right)$ e a vacinação canina $\left(v_{d}\right)$.

Segundo os resultados obtidos por Camargo-Neves ${ }^{57}$ (entre 1999 a 2001) para o município de Araçatuba/SP, o controle vetorial $\left(\xi_{c}\right)$ foi considerado uma estratégia de alto custo (USD 11.186, 17 para o controle químico e USD 4.815, 38 para o manejo ambiental), quando comparada com a eliminação de cães positivos $\left(\xi_{d}\right)$ (que variou entre USD 3.045, 07 a USD 3.572, 82). Segundo os resultados do nosso modelo, o custo mínimo total estimado para a eliminação de cães positivos em 2000 dias de atividade seria de USD $7,23 \times 10^{8}$, enquanto que para o controle vetorial, teríamos USD $3,23 \times 10^{10}$. Portanto, os nossos resultados também concordam com o que foi concluído por Camargo-Neves ${ }^{57}$, 
apesar da diferença em ordem de grandeza dos valores.

Uma possível justificativa deste resultado foi comentado anteriormente na secção 4.6. Um cão tende a viver mais que um flebotomíneo. Portanto, se investirmos apenas no controle vetorial (que foi um dos cenários simulados neste trabalho), deveremos manter a taxa de eliminação de mosquitos $\left(\xi_{c}\right)$ até que a densidade de cães latentes $\left(l_{d}\right.$ e $\left.l_{d}^{C}\right)$ e clinicamente doentes $\left(y_{d}\right.$ e $\left.y_{d}^{C}\right)$ diminuam de tal forma a refletir na diminuição do número de casos humanos notificados $(R)$ (isto é, ao mesmo tempo que mosquitos seriam eliminados, também deveríamos aguardar pela morte natural dos cães). Logo, deve-se investir continuamente na remoção de vetores, o que significa que este controle atuaria de forma constante ao longo do tempo. Consequentemente, teríamos um custo fixo (por exemplo, diário), visto que teríamos que estar sempre removendo fleobotomíneos da população. Por outro lado, um cão latente ou clinicamente doente eliminado tenderia a deixar de ser alvo de $m_{d}=w_{d h} \times m_{h}=20,11$ mosquitos. Assim, seguindo este raciocínio e observando a dinâmica apontada pelo modelo, a redução da densidade de cães latentes e clinicamente doentes, bem como de humanos infectados, tenderia a ser mais intensa. Com o tempo, o número de cães infectados tenderia a diminuir e, consequentemente, o número de cães eliminados. Logo, o investimento na eliminação de cães diminuiria com o tempo. Contudo, Das et al. ${ }^{56}$ referem em seu trabalho que o controle vetorial pode ser uma alternativa de alto custo-efetividade, dependendo dos fatores sociais e econômicos específicos do local.

Ainda em um segundo estudo desenvolvido por Camargo-Neves et al. ${ }^{23,58}$, no município de Andradina/SP, foi comparado o impacto do uso de coleiras impregnadas com inseticida $\left(\theta_{d}\right)$ com o controle vetorial $\left(\xi_{c}\right)$, sendo ambos associados com a eliminação de cães positivos $\left(\xi_{d}\right)$. Neste trabalho, conduzido entre 2002 a 2005, concluiu-se que o custo da associação entre o uso de coleiras com a eliminação de cães foi economicamente mais favorável do que a associação entre o controle vetorial e a eliminação de cães positivos. Este fato também foi observado pelo modelo matemático desenvolvido neste trabalho. Uma possível justificativa para este fenômeno é muito similar ao que foi comentado para a comparação entre controle vetorial e eliminação de cães positivos, no parágrafo anterior. Porém, em termos de dinâmica de transmissão da doença, o uso da coleira apresenta 
um detalhe adicional, devido ao seu fator de repelência, pois diminui a probabilidade de contato entre os mosquitos e os cães. Assim, o uso da coleira protege tanto o cão suscetível de se infectar pela picada de mosquitos infectivos $s_{3}$, quanto o mosquito nãoinfectado de se infectar por meio do repasto sanguíneo sobre cães latentes $\left(l_{d}\right.$ e $\left.l_{d}^{C}\right)$ e/ou clinicamente doentes $\left(y_{d}\right.$ e $\left.y_{d}^{C}\right)$.

Não foram encontrados estudos com abordagem econômica sobre a vacinação canina. Entretanto, o estudo de Lee et al. ${ }^{54}$ apresenta uma análise econômica a respeito de vacinação humana para a prevenção de leishmaniose visceral. Apesar deste estudo usar como referência o Estado de Bihar (Índia) e, portanto, considerar dinâmicas distintas daquelas conhecidas no Brasil (por exemplo, neste trabalho de Lee et al. ${ }^{54}$, humanos também são fonte de infecção), foi demonstrado por meio de simulações computacionais que a vacinação é altamente custo-benéfica e é também capaz de proporcionar uma grande economia de custos. Esse resultado traz alguma semelhança ao encontrado em nossa simulação. A vacinação canina também foi considerada uma das que apresenta menor custo (foi a terceira (USD $1,52 \times 10^{9}$ ), atrás do custo total estimado da eliminação canina (USD 7,23 $\times 10^{8}$ ), e do uso da coleira (USD 8,77 $\times 10^{8}$ )). A provável justificativa da vacinação canina ocupar o terceiro posto seria o fato de estarmos considerando que (1) todos os cães seriam vacinados (não apenas os sucetíveis) e que (2) há um período de defasagem para que o impacto da vacina sobre o número de casos humanos notificados $(R)$ apareça. Em outras palavras, para se obter a mesma redução que aquela desempenhada pela eliminação de cães $\left(\xi_{d}\right)$ e pelo uso da coleira $\left(\theta_{d}\right)$, seria necessário aguardar a eliminação "natural"das fontes de infecção (cães latentes e clinicamente doentes), enquanto que os cães suscetíveis remanescentes se tornariam protegidos pela vacina. Portanto, seria um processo mais lento, já que não selecionaria os indivíduos a serem vacinados e dependeria da eliminação natural. Este fato poderia justificar, em parte, a argumentação de que a vacina canina seria "custo-limitante"e que necessitaria de mais estudos sobre sua eficácia a campo ${ }^{27}$.

Assim, até este ponto, nosso modelo aponta que a estratégia que apresentou menor custo foi a eliminação de cães positivos $\left(\xi_{d}\right)$. Entretanto, esta estratégia não foi a que 
reduziu mais rapidamente o número diário de casos humanos notificados $(R)$. Neste caso, o controle vetorial $\left(\xi_{c}\right)$ foi estratégia mais eficaz neste sentido (Figura 36). Consequentemente, o controle vetorial, entre todas as estratégias, foi (1) a estratégia capaz de reduzir os custos hospitalares aos menores valores e (2) a que diminuiu esses custos de forma mais rápida (Figura 19). Estas duas consequências se destacam, visto que assumimos em nosso modelo que a taxa de casos humanos notificados equivale à taxa de pacientes que são submetidos ao tratamento. Logo, se o controle vetorial é o que possibilita a menor e a mais rápida redução dessa taxa $R$, consequentemente teremos a menor soma de pacientes tratados ao longo dos 2000 dias.

Diante dos resultados apresentados, embora todas as estratégias de controle tenham como objetivo comum a redução de casos humanos, cada uma delas atua em pontos distintos dentro da cadeia epidemiológica. Portanto, a atuação conjunta (isto é, o controle integrado) entre elas não só potencializará os resultados positivos do controle, como também resultará em uma otimização ainda maior dos custos ${ }^{54,57}$. Embora não tenhamos tratado da questão relativa a este tipo de cenário, a atuação simultânea de diferentes estratégias de controle torna-se uma motivação para prosseguirmos no estudo do controle da leishmaniose-visceral.

\subsection{Limitações do estudo}

Apesar de todas as contribuições e resultados interessantes obtidos neste estudo, ainda assim, devemos estar atentos com relação às limitações.

A modelagem matemática é uma forma muito prática de avaliar a dinâmica de um fenômeno (em particular, a dinâmica da leishmaniose visceral). Entretanto, o modelo matemático é uma representação simplificada da realidade ${ }^{54,81}$. Assim, o modelo apresentado neste trabalho, apesar da sofisticação matemática e das hipóteses adotadas, ainda assim é considerado uma simplificação.

Devido a esta simplificação, alguns fatores que atualmente têm ganho importância na dinâmica da leishmaniose visceral não foram levados em consideração. Recentemente, 
casos de transmissão vertical do parasita entre cães infectados têm sido relatados ${ }^{111}$. Outro ponto a ser ressaltado é o fato deste modelo não considerar o impacto gerado pelas mudanças climáticas sobre a dinâmica da doença. Tais alterações climáticas refletem o aspecto sazonal da população de vetor ${ }^{8}$. Para este estudo, preferimos apenas manter as vias clássicas de transmissão da doença e a hipótese simples de que as três populações são constantes ao longo do tempo. Assim, a inclusão desses novos fatores torna-se um ponto de motivação para estudos futuros sobre a dinâmica da leishmaniose visceral.

Limitações também devem ser ressaltadas com relação à modelagem das estratégias de controle. No caso do controle vetorial $\left(\xi_{c}\right)$, assumimos que o único efeito gerado por este controle é o aumento da mortalidade dos mosquitos. Entretanto, visto que o controle vetorial é baseado na borrifação das residências com inseticida e no manejo ambiental, não apenas ocorre o aumento da mortalidade, mas também a diminuição da população. Ao executar o controle químico baseado na borrifação, devem ser respeitados os períodos residuais do produto químico utilizado ${ }^{8,112}$. A princípio, durante o período residual haveria ação do produto químico impregnado nas superfícies borrifadas, impedindo a presença do mosquito próximo a estas superfícies. Além disso, o manejo ambiental (que se baseia na limpeza de terrenos e na alteração das condições ambientais propícias para o desenvolvimento do mosquito $)^{8}$ também refletiria na diminuição da população de vetores. Portanto, apesar de nossa simplificação a respeito do controle vetorial, devemos ressaltar que o impacto dela vai além do aumento da taxa de mortalidade dos mosquitos.

No caso da vacinação de cães $\left(v_{d}\right)$, da coleira impregnada com inseticida $\left(\theta_{d}\right)$ e da eliminação de cães positivos $\left(\xi_{d}\right)$, devemos fazer uma ressalva com relação aos custos por cão. Todas essas três estratégias, em algum momento de seus desenvolvimentos, envolveriam todos os cães da população. Assim, adotamos a hipótese de que todos os cães seriam aptos para receber a vacina ou a coleira. Entretanto, a vacina só teria efeito sobre os cães suscetíveis $\left(x_{d}\right.$ e $\left.x_{d}^{C}\right)$. De forma similar, o real interesse sobre a aplicação das coleiras recai nos cães suscetíveis $\left(x_{d}\right)$, latentes $\left(l_{d}\right)$ e clinicamente doentes $\left(y_{d}\right)$. No caso da eliminação de cães positivos, devemos notar que a decisão para eliminar um cão depende do resultado do diagnóstico sorológico. Dentro deste cenário hipotético, a aplicação do diagnóstico fa- 
ria parte da atividade de vigilância epidemiológica sobre a população de cães. Portanto, o custo da eliminação de cães envolveria a soma do custo total do número de diagnósticos e do total de animais sacrificados (que não necessariamente corresponderia ao número de cães submetidos ao diagnóstico). Portanto, os custos dessas três estratégias deveriam ser corrigidas (Eq. (87), (88) e (89)).

$$
\begin{aligned}
& \mathscr{C}_{v_{d}}^{\text {cor }}=\frac{N_{d}}{x_{d}(t)+x_{d}^{C}(t)} v_{d} \mathscr{C}_{v_{d}} \\
& \mathscr{C}_{\theta_{d}}^{\text {cor }}=\frac{x_{d}(t)+l_{d}(t)+y_{d}(t)+z_{d}(t)+v_{d}(t)}{x_{d}(t)+l_{d}(t)+y_{d}(t)} \theta_{d} \mathscr{C}_{\theta_{d}} \\
& \mathscr{C}_{\xi_{d}}^{\text {cor }}=\left(\frac{1-x_{d}(t)-x_{d}^{C}(t)}{l_{d}(t)+l_{d}^{C}(t)+y_{d}(t)+y_{d}^{C}(t)}\right) \xi_{d}\left(\frac{1}{1-x_{d}(t)-x_{d}^{C}(t)} \mathscr{C}_{\text {diag }}+\mathscr{C}_{\text {sac }}\right)
\end{aligned}
$$

Na Eq. (87), o termo $N_{d} /\left(x_{d}(t)+x_{d}^{C}(t)\right)$ representa a "concentração"do custo investido na distribuição de vacinas por toda população canina entre apenas aqueles que realmente seriam os indivíduos de eleição para a vacinação. Já a Eq. (88), o termo $\left(x_{d}(t)+l_{d}(t)+y_{d}(t)+z_{d}(t)+v_{d}(t)\right) /\left(x_{d}(t)+l_{d}(t)+y_{d}(t)\right)$ representa a mesma idéia para o caso da coleira, em que o custo investido na sua distribuição seria "concentrado"entre apenas aqueles que seriam os indivíduos de eleição para o uso da coleira. Finalmente, na Eq. (89) (onde $\mathscr{C}_{\text {diag }}$ representa o custo do diagnóstico por cão e $\mathscr{C}_{\text {sac }}$ o custo do sacrifício por cão), o termo $1 /\left(1-x_{d}(t)-x_{d}^{C}(t)\right)$ "concentra"o custo de todos os diagnósticos realizados entre aqueles que realmente seriam sacrificados e o termo $\left(1-x_{d}(t)-x_{d}^{C}(t)\right) /\left(l_{d}(t)+l_{d}^{C}(t)+\right.$ $\left.y_{d}(t)+y_{d}^{C}(t)\right)$ "concentra"o custo total da eliminação de todos os cães entre apenas aqueles que realmente contribuiriam para a manutenção da doença na população.

Apesar destas correções, para este trabalho foi dada a preferência de considerar uma situação idealizada (conforme apresentado na secção 3.9) e esses ajustes sobre o custos não foram adotados. Dado que as proporções das categorias populacionais são apenas estimativas, há uma margem de erro inerente a elas. Portanto, a estimativa de custos totais apresentada neste estudo pela Figura 18 (que foram baseadas neste cenário idealizado) já embute uma margem de erro, que se ajustada conforme as Eq. (87), (88) e 
(89), poderia agregar uma margem de erro ainda maior ${ }^{85}$.

Uma outra simplificação que merece ressalva é com relação à dinâmica imuológica do cão. Observe pela Tabela 2 que os parâmetros $f_{d}$ e $q_{d}$ (respectivamente taxa de recuperação de clinicamente doentes para latentes e Taxa de perda de imunidade (recuperados para latentes)) foram assumidos como nulos. Na realidade, esta informação é difícil de ser interpretada nos trabalhos que abordam o tema ${ }^{113}$. No momento, decidimos assumir a situação mais simples, que foi $f_{d}=q_{d}=0$.

Por fim, um último aspecto deve ser comentado. Em uma situação de campo, nada impediria que mais de uma estratégia de controle fosse aplicada ao mesmo tempo. Inclusive, considerar a avaliação de intervenções combinadas poderia melhorar a avaliação econômica ${ }^{19}$. Dois estudos de autoria de Camargo-Neves ${ }^{23,57}$ apresentaram o impacto (em diferentes protocolos experimentais) da aplicação simultânea do controle vetorial, eliminação de cães positivos e da distribuição de coleiras impregnadas com deltametrina 4\%. Embora existam na literatura métodos de otimização mais robustos e específicos para sistemas de equações diferenciais ${ }^{114-116}$, optamos por um procedimento mais simples que propõe a avaliação do método ótimo. O desenvolvimento de um modelo de otimização mais robusto, que leve em conta a ação simultânea de todas as estratégias de controle, seria o próximo passo a ser proposto no progresso desta pesquisa. 


\section{o segredo da felicidade doméstica}

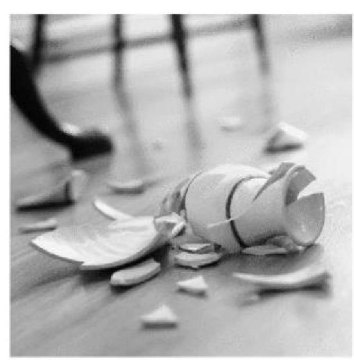

Uma familia que vivia sempre em atrito era vizinha de uma familia harmoniosa e que construira um lar tranquilo. O chefe da familia briguenta ficava perplexo ao constatar como todo mundo se dava bem na casa vizinha. Finalmente, um dia, ele foi procurar o vizinho e disse consternado: "Como você deve saber, nossa familia está sempre brigando e não sei mais o que fazer. $\mathcal{N a}$ sua familia, vejo que todos se dão muito bem. Por favor, me diga qual é o seu segredo".

o vizinho respondeu: "Não há nada de especial. Provavelmente, em sua família, todos estão sempre certos. Aqui em casa, nós todos estamos sempre errados, então nunca discutimos. $\mathcal{\mathcal { E }}$ só isso".

Certo de que estava sendo ridicularizado, o visitante estava a ponto de explodir de raiva quando ouviu um alto ruido vindo de dentro da casa. Parecia que algum objeto de cerâmica tinha caido no chão.

Ouviu-se a voz de uma moca penitente: "Desculpe-me. NNão olhei por onde andava e derrubei aquele vaso que era tão importante para a senfiora. A culpa é minha, por favor, me desculpe".

"Bobagem", disse a sogra. "NNão é culpa sua não. $\mathcal{E} u$ estava sempre pensando em guardar esse vaso, mas acabei não fazendo isso. $\mathcal{E} u$ é que não devia de ter deixado o vaso no caminho Sou eu quem deve pedir desculpas".

Então, o visitante pensou assim: "Entendi. Todo mundo nessa familia está sempre errado e admite isso. Por isso não há Grigas".

$\mathcal{N} a ̃ o$ posso condenar nínguém por maiores que sejam os seus defeitos, porque eles não são quase nada se forem aos meus comparados. 


\section{CONCLUSÕES}

O modelo de otimização apresentado teve um resultado muito positivo na compreensão do impacto das estratégias de controle preventivo e nas modificações que elas causariam sobre a dinâmica da leishmaniose visceral. Além disso, diante dos resultados relativos à análise econômica e verificando estudos similares, o investimento em atividades preventivas tende a envolver custos menores, se comparado com os custos de atividades curativas.

E, em correspondência com os objetivos específicos, considerando as estratégias que foram capazes de diminuir o número diário de casos humanos notificados $(R)$ (lembramos que a estratégia de tratar cães doentes não gerou impacto na diminuição de $R$ ), temos que:

1. O controle vetorial (aplicado por residência) $\left(\xi_{c}\right)$ mostrou ser a estratégia que causaria a diminuição mais rápida em $R$ e, consequentemente, foi também a que mais reduz os custos médico-hospitalares. Entretanto, foi a estratégia de maior custo;

2. Segundo o modelo utilizado, os custos mínimos para se obter a redução do número diário de casos notificados a 1/100 seriam de:

(1) USD 7,30 × $10^{8}$ para a eliminação de cães positivos a uma taxa de $\xi_{d}=0,04 / \mathrm{dia}$

(2) USD $8,83 \times 10^{8}$ para o uso de coleiras impregnadas com inseticida a uma taxa de $\theta_{d}=0,05 /$ dia;

(3) USD $1,53 \times 10^{9}$ para a vacinação canina a uma taxa $v_{d}=0,025 /$ dia;

(4) USD $3,23 \times 10^{10}$ para o controle vetorial $\xi_{c}=0,01 / \mathrm{dia}$;

3. A estratégia de eliminar cães positivos foi a que apresentou o menor 
custo. 


\section{REFERÊNCIAS}

[1] Acha PN, Szyfres B. Zoonosis y enfermedades transmisibles comunes al hombre y a los animales. 2nd ed. Organización Panamericana de la Salud; 1986.

[2] Killick-Kendrick R. Education is key to controlling visceral leishmaniasis. Bulletin of the World Health Organization. 2010;88(1):11-2.

[3] Duthie MS, Raman VS, Piazza FM, Reed SG. The development and clinical evaluation of second-generation leishmaniasis vaccines. Vaccine. 2012;30(2):134-41.

[4] Brasil. Registro dos casos humanos de leishmaniose visceral; 2013 [Acesso em 11 de maio 2015]. Disponível em http://dtr2004.saude.gov.br/sinanweb/ . Sistema de Informação de Agravos de Notificação, Ministério da Saúde.

[5] de Sousa CBP, Day MJ. One Health: The global challenge of epidemic and endemic leishmaniasis. Parasites \& Vectors. 2011;4:10.

[6] Vieira JBF, Coelho GE. Visceral leishmaniasis or kala-azar: the epidemiological and control aspects. Rev Soc Bras Med Trop. 1998;2(31):85-9.

[7] Dye C. The logic of visceral leishmaniasis control. Am J Trop Med. $1996 ; 55(2): 125-30$.

[8] Brasil. Manual de Vigilância e Controle da Leishmaniose Visceral; 2006 [citado em 23 abril 2015]. Disponível em http://bvsms.saude.gov.br/bvs/publicacoes/manual_ vigilancia_controle_leishmaniose_visceral.pdf. Ministério da Saúde.

[9] Burattini MN, Coutinho FAB, Lopez LF, Massad E. Modelling the dynamics of leishmaniasis considering human, animal host and vector populations. J Biol Syst. 1998;6(4):337-56. 
[10] Ribas LM, Zaher VL, Shimozako HJ, Massad E. Estimating the Optimal Control of Zoonotic Visceral Leishmaniasis by the Use of a Mathematical Model. The Scientific World Journal. 2013; .

[11] Duarte MIS, da S Badaró R. Leishmaniose Visceral (Calazar). In: Foccacia R, Diament D, Ferreira MS, Siciliano RF, editors. Tratado de Infectologia. 4th ed. São Paulo: Editora Atheneu; 2009. .

[12] Brasil. Leishmaniose Visceral; 2015 [citado em 23 abril 2015]. Disponível em http://portalsaude.saude.gov.br/index.php/o-ministerio/principal/secretarias/svs/ leishmaniose-visceral-lv. Ministério da Saúde.

[13] São Paulo (Estado). Secretaria do Estado da Saúde de São Paulo. II Informe Técnico. Leishmaniose Visceral Americana; 2003 [citado em 23 abril 2015]. Disponível em: ftp://ftp.cve.saude.sp.gov.br/doc_tec/zoo/if_2lva0409.pdf.

[14] São Paulo (Estado). Secretaria de Estado da Saúde de São Paulo, Superintendência de Controle de Endemias - SUCEN e Coordenadoria de Controle de Doenças - CCD. Manual de Vigilância e Controle da Leishmaniose Visceral Americana do Estado de São Paulo; 2006 [citado em 17 nov. 2010]. Disponível em: ftp://ftp.cve.saude.sp.gov.br/doc_tec/zoo/lva06_manual.pdf.

[15] Baneth G, Solano-Gallego L. 73. Leishmaniasis. In: CE G, editor. Infectious Diseases of the Dog and Cat. St. Louis, Missouri: Elsevier Saunders; 2011. .

[16] Pinelli E, Gonzalo RM, Boog CJP, Rutten VPMG, Gebhard D, del Real G, et al. Leishmania infantum-sepecific $\mathrm{T}$ cell lines derived from asymptomatic dogs that lyse infected macrophages in a major histocompatibiligy complex-restricted manner. Eur J Immunol. 1995;25(6):1594-600.

[17] Cabral M, O’Grady JE, Gomes S, Sousa JC, Thompson H, Alexander J. The immunology of canine leishmaniosis: strong evidence for a developing disease spectrum from asymptomatic dogs. Vet Parasitol. 1998;76(3):173-80. 
[18] Santos-Gomes GM, Campino L, Abranches P. Canine Experimental Infection: Intradermal Inoculation of Leishmania infantum Promastigotes. Mem Inst Oswaldo Cruz. 2000;95(2):193-8.

[19] Marinho DS, Casas CNPR, de a Pereira CC, Leite IC. Health economic evaluations of visceral leishmaniasis treatments: a systematic review. PLoS Negl Trop Dis. $2015 ; 9(2)$.

[20] Maia-Elkhoury ANS, Alves WA, Souza-Gomes ML, Sena JM, Luna EA. Visceral leishmaniasis in Brazil: trends and challenges. Cad Saúde Pública. 2008;24(12):2941-7.

[21] Halbig P, Hodjati MH, Mazloumi-Gavgani AS, Mohite H, Davies CR. Further evidence that deltamethrin-impregnated collars protect domestic dogs from sandfly bites. Med Vet Entomol. 2000;14(2):223-6.

[22] Reithinger R, Coleman PG, Alexander B, Vieira EP, Assis G, Davies CR. Are insecticide-impregnated dog collars a feasible alternative to dog culling as a strategy for controlling canine visceral leishmaniasis in Brazil? Int J Parasitol. 2004;34(1):55-62.

[23] de Camargo-Neves VLF, Rodas LAC, Junior CP. Avaliação da Efetividade da Utilização de Coleiras Impregnadas com Deltametrina a 4\% para o Controle da Leishmaniose Visceral Americana no Estado de São Paulo: Resultados Preliminares. Boletim Epidemiológico Paulista. 2004;1(12 [citado em 16 abril 2015]). Disponível em http://www.cve.saude.sp.gov.br/agencia/bepa12_lva.htm.

[24] Scalibor website; 2014 [citado em 15 out 2014]. Disponível em: http://www.medicanimal.com/Scalibor-Collar/p/I0000475.

[25] Saraiva EM, Barbosa AD, Santos FN, Borja-Cabrera GP, Nico D, Souza LOP, et al. The FML-vaccine (Leishmune $($ ) against canine visceral leishmaniasis: A transmission blocking vaccine. Vaccine. 2006;24(13):2423-31. 
[26] Fernandes CB, Junior JTM, de Jesus C, da Silva Souza BMP, Larangeira DF, Fraga DBM, et al. Comparison of two commercial vaccines against visceral leishmaniasis in dogs from endemic areas: $\operatorname{IgG}$, and subclasses, parasitism, and parasite transmission by xenodiagnosis. Vaccine. 2014;32(11):1287-95.

[27] Otranto D, Dantas-Torres F. The prevention of canine leishmaniasis and its impact on public health. Trends Parasitol. 2013;29(7).

[28] Brasil. Ministério da Agrigultura, Pecuária e Abastecimento. Secretaria de Defesa Agropecuária. Departamento de Fiscalização de Insumos Pecuários; 2014. Nota Técnica No. 038/2014/DFIP/SDA.

[29] Miro G, Galvez R, Fraile C, Descalzo MA, Molina R. Infectivity to Phlebotomus perniciosus of dogs naturally parasitized with Leishmania infantum after different treatments. Parasites \& Vectors. 2011;4:7.

[30] Roura X. Treatment of Canine Leishmaniosis. In: Proceedings 2nd International Congress on Canine Leishmaniasis. Pisa, Italia; 2010. p. 77-93.

[31] Solano-Gallego L, Miró G, Koutinas A, Cardoso L, Pennisi MG, Ferrer L, et al. LeishVet guidelines for the practical management of canine leishmaniosis. Parasites \& Vectors. 2011;4.

[32] Travi BL. Ethical and epidemiological dilemmas in the treatment of dogs forvisceral leishmaniasis in Latin America. Biomédica. 2014;43:7-12.

[33] Murray JD. Mathematical Biology. I. An Introduction. New York: Springer-Verlag; 2002.

[34] Feynman RP, Leighton RB, Sands M. The Feynman Lectures on Physics. Volume 1. New York: Basic Books; 2010.

[35] Silveira PSP. 4. Genética quantitativa: regras simples, complexidade e a variabilidade humana. In: Massad E, Menezes RX, Silveira PSP, Ortega NRS, editors. Métodos Quantitativos em Medicina. Barueri: Manole; 2004. . 
[36] Massad E. 1. Introdução. In: Massad E, Menezes RX, Silveira PSP, Ortega NRS, editors. Métodos Quantitativos em Medicina. Barueri: Manole; 2004. .

[37] Coutinho FAB. 3. A matemática das epidemias. In: Massad E, Menezes RX, Silveira PSP, Ortega NRS, editors. Métodos Quantitativos em Medicina. Barueri: Manole; 2004. .

[38] Anderson RM, May RM. Infectious diseases of humans: dynamics and control. New York: Oxford University Press; 2010.

[39] Otto SP, Day T. A Biologist's Guide to Mathematical Modeling in Ecology and Evolution. Princeton University Press; 2007.

[40] Jeraj R. Future of physics in medicine and biology. Acta Oncol. 2009;48(2):17884.

[41] Daley DJ, Gani MJ. Epidemic modelling: an introduction. New York, USA: Cambridge University Press; 1999.

[42] Diekmann O, Heesterbeek JAP. Mathematical epidemiology of infectious diseases: model building, analysis and interpretation. New York, USA: John Wiley \& Sons, LTD; 2000.

[43] Massad E, Behrens RH, Burattini MN, Coutinho FAB. Modelling the risk of malaria for travellers to areas with stable maralria transmission. Malaria Journal. $2009 ; 8$.

[44] Raimundo SM, Amaku M, Massad E. Equilibrium Analysis of a Yellow Fever Dynamical Model with Vaccination. Computational and Mathematical Methods in Medicine. 2015;

[45] Qesmi R, Heffernan JM, Wu J. An immuno-epidemiological model with threshold delay: a study of the effects of multiple exposures to a pathogen. J Math Biol. 2015;70(1-2):343-66. 
[46] Xiao Y, Tang S, Wu J. Media impact switching surface during an infectious disease outbreak. Sci Rep. 2015;5.

[47] World Health Organization (Organização Mundial da Saúde). Neglected tropical disease (NTD) research; 2012 [citado em 14 dez. 2012]. Disponível em http://www.who.int/tdr/research/ntd/en/.

[48] Antonialli SAC, Torres TG, Paranhos-Filho AC, Tolezano JE. Spatial analysis of American Visceral Leishmaniasis in Mato Grosso do Sul State, Central Brazil. Journal of Infection. 2007;54:509-14.

[49] Secretaria de Vigilância em Saúde. Situação epidemiológica das zoonoses de interesse para a saúde pública; 2010. Ministério da Saúde, Boletim Eletrônico Epidemiológico.

[50] Instituto Brasileiro de Geografia e Estatística (IBGE). Economia da Saúde. Uma perspectiva macroeconômica 2000 - 2005; 2008 [citado em 14 dez. 2012]. Disponível em http://www.ibge.gov.br/home/estatistica/economia/economia_saude/ economia_saude.pdf. Instituto Brasileiro de Geografia e Estatística.

[51] Haycox A. What is Health Economics?; 2009 [citado em 14 dez. 2012]. Disponível em http://www.medicine.ox.ac.uk/bandolier/painres/download/whatis /what_is_health_econ.pdf.

[52] Andrade EIG, de Assis Acúrcio F, Cherchiglia ML, Belisário SA, Júnior AAG, Szuster DAC, et al. Pesquisa e produção científica em economia da saúde no Brasil. Revista de Administração Pública. 2007;41(4):211-35.

[53] Akhavan D. Análise de custo-efetividade do componente de leishmaniose no projeto de controle de doenças endêmicas no nordeste do Brasil. Rev Pat Trop. 1996;25(2):203-52.

[54] Lee BY, Bacon KM, Shah M, Kitchen SB, Connor DL, Slayton RB. The economic 
value of a visceral leishmaniasis vaccine in Bihar State, India. Am J Trop Med Hyg. 2012;86(3):417-25.

[55] Adhikari SR, Supakankunti S. A cost benefit analysis of elimination of kala-azar in Indian subcontinent: an example of Nepal. J Vector Borne. 2010;47:127-39.

[56] Das M, Banjara M, Chowdhury R, Kumar V, Rijal S, Joshi A, et al. Visceral leishmaniasis on the Indian sub-continent: a multi-centre study of the costs of three interventions for the control of the sandfly vector, Phlebotomus argentipes. Ann Trop Med Parasitol. 2008;108(8):729-41.

[57] de Camargo-Neves VLF. Aspectos epidemiológicos e avaliação das medidas de controle da leishmaniose visceral americana no Estado de São Paulo, Brasil. Faculdade de Saúde Pública, Universidade de São Paulo.. São Paulo; 2004.

[58] de Camargo-Neves VLF. Avaliação do emprego das coleiras impregnadas com deltametrina $4 \%$ associada às medidas tradicionais de controle da leishmaniose visceral no estado de São Paulo, Brasil. Conectfarma Publicações Científicas Ltda. 2011 [citado em 16 abril 2015];Disponível em http://www.nossamatilha.com.br/anuncie/novidades-dos-parceiros/conhecaestudo-realizado-no-estado-de-sao-paulo-sobre-controle-de-leishmaniosevisceral-utilizando-coleiras-impregnadas-com-4-90460n.aspx.

[59] Anoopa-Sharma D, Bern C, Varghese B, Chowdhury R, Haque R, Ali M, et al. The economic impact of visceral leishmaniasis on households in Bangladesh. Trop Med Int Health. 2006;11(5):757-64.

[60] Boelaert M, Lynen L, Desjeux P, der Stuyft PV. Cost-effectiveness of competing diagnostic therapeutic strategies for visceral leishmaniasis. Bull World Health Organ. 1999;77(8):667-74.

[61] Scarpin CT, Steiner MTA, Dias GJC, Steiner-Neto PJ. Otimização no serviço de 
saúde no estado do Paraná: fluxo de pacientes e novas configurações hierárquicas. Gest Prod. 2008;15(2):275-90.

[62] Das VN, Siddiqui NA, Verma RB, Topno RK, Singh D, Das S, et al. Asymptomatic infection of visceral leishmaniasis in hyperendemic areas of Vaishali district, Bihar, India: a challenge to kala-azar elimination programmes. Transactions of the Royal Society of Tropical Medidine and Hygiene. 2011;105:661-6.

[63] Yaesoubi R, Cohen T. Generalized Markov models of infectious disease spread: A novel framework of developing dynamic health polices. European Journal of Operational Research. 2011;215:679-87.

[64] Edmunds J, Postma M. Cost-effectiveness of Vaccination Programmes: issues, solutions and examples. European Journal of Public Health. 2007;17(2):120-2.

[65] Chaiyakunapruk N, Somkrua R, Hutubessy R, Henao AM, Hombach J, Melegaro A, et al. Cost Effectiveness of pediatric pneumococcal conjugate vaccines: a comparative assessment of decision-making tools. BMC Medicine. 2011;9(53).

[66] Instituto Brasileiro de Geografia e Estatística (IBGE). In 2012, life expectancy at birth was 74.6 years (em português);. Disponível em: http://saladeimprensa. ibge.gov.br/noticias? view $=$ noticia $\&$ id $=1 \&$ busca $=1 \&$ idnoticia $=2528 . \quad$ Instituto Brasileiro de Geografia e Estatística.

[67] Pearson RD, Souza AQ. Leishmania species: visceral (kala-azar), cutaneous and mucosal leishmaniasis. In: Mandell GL, Douglas-Junior RG, Bennett JE, editors. Principles and Practice of Infectious Diseases. New York: Churchill Livingstone Inc.; 1990. p. 2066-77.

[68] Forattini OP. Entomologia Medica. São Paulo: EDUSP; 1974.

[69] Instituto Brasileiro de Geografia e Estatística (IBGE). São Paulo, Araçatuba;. Instituto Brasileiro de Geografia e Estatística. 
[70] da Silva Badaró RJ, Jones TC, Carvalho EM, Sampaio DBP, Reed SG, Barral A, et al. New perspectivees on a subclinical form of visceral leishmaniasis. J Infect Dis. 1986;154(6):1003-11.

[71] Kault DA, Marsh LM. Modeling AIDS as a function of other sexually transmitted disease. Math Biosc. 1991;103(1):17-31.

[72] Molineaux L, Gramiccia G. The Garki Project. Geneva: World Health Organization; 1990.

[73] Maia-Elkhoury ANS, Carmo EH, Sousa-Gomes ML, Mota E. Analysis of visceral leishmaniasis reports by the capture-recapture method. Rev Saúde Pública. $2007 ; 41(6)$.

[74] Selman C, Nussey DH, Monaghan P. Ageing: it's a dog's life. Curr Biol. 2013;23(10):R451-3.

[75] Lanotte G, Rioux JA, Perieres J, Vollhardt Y. [Ecology of leishmaniasis in the south of France. 10. Developmental stages and clinical characterization of canine leishmaniasis in relation to epidemiology. (tradução do autor)]. Ann Parasitol Hum Comp. 1979;54(3):277-95.

[76] Andrade AM, Queiroz LH, Perri SHV, Nunes CM. Estudo descritivo da estrutura populacional canina da área urbana de Araçatuba, São Paulo, Brasil, no período de 1994 a 2004. Cad Saúde Pública. 2008;24(4):927-32.

[77] Zoetis Brasil website (em português); 2015 [citado em 15 jan 2015]. Disponível em: https://www.zoetis.com.br/node/19883.

[78] de Lima Moreira M. Duração da imunidade vacinal na Leishmaniose visceral canina: Perfil fenotípico e funcional da atividade fagocítica anti-Leishmania chagasi; 2013.

[79] Neva F, Sacks D. Leishmaniasis. In: Warren KS, Mahmoud AAF, editors. Tropical and Geographical Medicine. 2nd ed. New York: McGraw-Hill; 1990. p. 296-308. 
[80] Rossi CN. Avaliação da imunidade celular na pele de cães naturalmente infectados com Leishmania (Leishmania) infantum chagasi e sua correlação com transmissibilidade ao vetor. Universidade de São Paulo, Faculdade de Medicina Veterinária e Zootecnia; 2013.

[81] Struchiner CJ, Massad E, de Azevedo Neto RS. Introdução à dinâmica populacional das doenças transmissíveis : Dinâmica de processos infecciosos. Rio de Janeiro: LNCC; 2000. Escola de Verão Metodos Computacionais em Biologia (2000, Petropolis, Rio de Janeiro).

[82] Roussel MR. Delay-differential equations; 2005 [citado em 23 abril 2015]. Disponível em http://people.uleth.ca/ roussel/nld/delay.pdf.

[83] do Prado CPC, Fidler-Ferrara N. Caos - Uma Introdução. São Paulo, SP: Editora Edgard Blücher LTDA; 1995.

[84] van den Driessche P, Watmough J. Reproduction numbers and sub-threshold endemic equilibria for compartmental models of disease transmission. Mathematical Biosciences. 2002;180:29-48.

[85] Vuolo JH. Fundamentos da teoria dos erros. 2nd ed. Editora Blucher; 1996.

[86] Marino S, Hogue IB, Ray CJ, Kirschner DE. A methodology for performing global uncertainty and sensitivity analysis in systems biology. J Theor Biol. 2008;254(1):178-96.

[87] Milone G. Estatística Geral e Aplicada. Thomson Learning; 2006.

[88] de Camargo-Neves VLF, Rodas LAC, Calemes E, Junior CP, da Silva LJ. Cost effectiveness of deltamethrin impregnated collars (Scalibor $®)$ for the control of visceral leishmaniasis in human and canine populations in Brazil. In: Proceedings 2nd International Congress on Canine Leishmaniasis. Pisa, Italia; 2010. p. 118-20.

[89] Antimionato de meglumina; 2014 [Citado em 11 de novembro de 2014]. Brasmed (Disponível em http://www.maispreco.com/preco/antimoniato-de-meglumina). 
[90] Alopurinol; 2014 [Citado em 11 de novembro de 2014]. Brasmed (Disponível em http://www.maispreco.com/comprar/alopurinol-300-mg-30-cprs-medley).

[91] Barichello FFG. Avaliação da resposta imunológica de cães vacinados com a vacina FML (Leishmune $囚)$ e cães naturalmente infectados com leishmaniose visceral canina por meio de dois métodos sorológicos : ELISA e RIFI; 2010.

[92] Faustino M. Ministério proibe fabricação de vacina de leishmaniose e gera polêmica. Campo Grande News. 2014 [citado em 23 abril 2015];;

[93] Hertape. Leish-Tec®; 2015 [citado em 23 abril 2015]. Disponível em http://www.hertape.com.br/produtos/detalhes.php?produto=NjQ\%3D\&cat=6\&sub $=4 \&$ site $=1 \&$ secao=3. Hertape Saúde e Bem-estar Animal (Hertape Calier Saúde Animal S.A.).

[94] Massad E, Coutinho FAB, Lopez LF, da Silva DR. Modeling the impact of global warming on vector-borne infections. Physics of Life Reviews;8:169 - 99.

[95] Lebovitz N. Chapter 8: Stability I: Equilibrium Points; 2015 [citado em 13 maio 2015]. Disponível em http://people.cs.uchicago.edu/ lebovitz/eodesnotes.html. Textbook for Mathematics 27300.

[96] Brasil. Guia de Vigilância Epidemiológica; 1998.

[97] Forattini OP. Ecologia, Epidemiologia e Sociedade. 2nd ed. Artes Medicas; 2004.

[98] Romero GAS, Boelaert M. Control of Visceral Leishmaniasis in Latin America A Systematic Review. Plos Neglected Tropical Diseases. 2010;4(1):17.

[99] Maroli M, Mizzoni V, Siragusa C, D’Orazi A, Gradoni L. Evidence for an impact on the incidence of canine leishmaniasis by the mass use of deltamethrinimpregnated dog collars in southern Italy. Medical and Veterinary Entomology. 2001;15(4):358-63. 
[100] Gavgani AS, Hodjati MH, Mohite H, Davies CR. Effect of insecticide-impregnated dog collars on incidence of zoonotic visceral leishmaniasis in Iranian children: a matched-cluster randomised trial. Lancet. 2002;360(9330):374-9.

[101] Nunes CM, de Lima VMF, de Paula HB, Perri SHV, de Andrade AM, Dias FEF, et al. Dog culling and replacement in an area endemic for visceral leishmaniasis in Brazil. Veterinary Parasitology. 2008;153.

[102] Fernandes AP, Costa MMS, Coelho EAF, Michalick MSM, de Freitas E, Melo $\mathrm{MN}$, et al. Protective immunity against challenge with Leishmania (Leishmania) chagasi in beagle dogs vaccinated with recombinant A2 protein. Vaccine. 2008;26(46):5888-95.

[103] de Amorim IFG, Freitas E, Alves CF, Tafuri WL, Melo MN, Michalick MSM, et al.

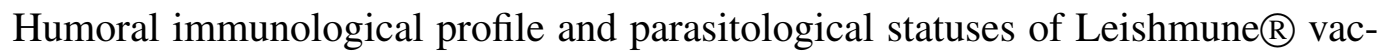
cinated and visceral leishmaniasis infected dogs from an endemic area. Veterinary Parasitology. 2010;173(1-2):55-63.

[104] Magalhães PA, Mayrink W, da Costa CA, Melo MN, Dias M, Batista S, et al. Kalaazar in Rio Doce, Minas Gerais, Brazil. Results of a prophylactic campaign. Inst Med Trop S Paulo. 1980;22(4).

[105] Moreira-Junior ED, de Souza VMM, Sreenivasan M, Nascimento EG, de Carvalho LP. Assessment of an optimized dog-culling program in the dynamics of canine Leishmania transmission. Veterinary Parasitology. 2004;122(4):245-52.

[106] Costa CHN, Tapety CMM, Werneck GL. Control of visceral leishmaniasis in urban areas: randomized factorial intervention trial. Revista da Sociedade Brasileira de Medicina Tropical. 2007;40(4):415-19.

[107] de Souza VMM, da Silva Julião F, Neves RCS, Magalhães PB, Bisinotto TV, de Souza Lima A, et al. Communitary Assay for Assessment of Effectiveness of Strategies for Prevention and Control of Human Visceral Leishmaniasis in The 
Municipality of Feira de Santana, State of Bahia, Brazil. Epidemiol Serv Saúde,. 2008;17(2):97-106.

[108] Athanasiou LV, Saridomichelakis MN, Kontos VI, Spanakos G, Rallis TS. Treatment of canine leishmaniosis with aminosidine at an optimized dosage regimen: A pilot open clinical trial. Veterinary Parasitology. 2013;192(1-3):91-7.

[109] Andrade HM, Toledo V, Pinheiro MB, Guimarães TM, Oliveira NG, Castro JA, et al. Evaluation of miltefosine for the treatment of dogs naturally infected with L. infantum (=L. chagasi) in Brazil. Veterinary Parasitology. 2011;181(2-4):83-90.

[110] Rougier S, Hasseine L, Delaunay P, Michel G, Marty P. One-year clinical and parasitological follow-up of dogs treated with marbofloxacin for canine leishmaniosis. Veterinary Parasitology. 2012;186(3-4):245-53.

[111] Naucke TJ, Lorentz S. First report of venereal and vertical transmission of canine leishmaniasis from naturally infected dogs in Germany. Parasites \& Vectors. 2012;5:67.

[112] Falcão AL, Falcão AR, Pinto CT, Gontijo CMF, Falqueto A. Effect of deltamethrin spraying on the sandfly populations in a focus of american cutaneous leishmaniasis. Mem Inst Oswaldo Cruz. 1991;86(4):399-404.

[113] Costa FAL. The dog as a risk factor in transmission of visceral leishmaniasis: A Review. Advances in Infectious Diseases. 2012;2(2):37-47.

[114] Lenhart S, Workman JT. Optimal Control Applied to Biological Models. London, UK: Chapman \& Hall/CRC, Taylor \& Francis Group; 2007.

[115] Göllmann L, Kern D, Maurer H. Optimal control problems with delays in state and control variables subject to mixed control-state constraints. Optim Control Appl Meth. 2008; 
[116] Hattaf K, Yousfi N. Optimal control of a delayed HIV infection model with immune response using an efficient numerical method. ISRN Biomathematics. 2012;Article ID 215124.

[117] Marcondes M, de Lima VMF, de Fátima Lereno de Araújo M, Hiramoto RM, Tolezano JE, da Costa Vieira RF, et al. Longitudinal analysis of serological tests officially adopted by the Brazilian Ministry of Health for the diagnosis of canine visceral leishmaniasis in dogs vaccinated with Leishmune $囚$. Veterinary Parasitology. 2013;197(3-4):649-52. 


\section{Quem se deita com cão acorda com pulgas}

\section{Gamou Ujisato, que dispensou um fomem frifhante}

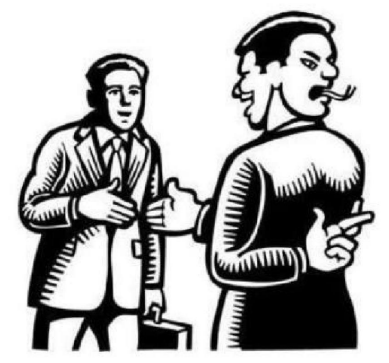

- Conheço um sujeito excelente, que the seria de grande valor.

Assim foi recomendado Tama gawa Souma, pessoa de grande reputação e talento, a Gamou Ujisato (1556 - 1595), Corde do castelo de Aizu Wakamatsu.

Porém, em pouco mais de uma semana, Ujisato entregou uma soma em dinheiro a Souma e o dispensou, sem motivo aparente. Seus subordinados não compreenderam a decisão.

- Senhor, por que demitiu um homem tão genial? Achávamos inclusive que, no futuro, ele seria nomeado oficial do estado-maior.

- № día em que conheci Souma, ele nada fez além de me cobrir de elogios excessivos, usando todos os recursos da sua retórica: um bajulador. $\mathcal{N} o$ encontro seguinte, maldisse os colegas e os superiores: um caluniador, $e$ caluniadores destroem qualquer organização. Como se não bastasse, vangloriava-se de possuir pessoas maravifhosas em seu circulo de amizades: um egocêntrico. Homens assim, por mais brithantes que sejam, são indignos de confiança. Por isso, não hesitei em dispensá-fo - respondeu Ujisato.

Depois de deixar os dominios de Ujisato, Tamagawa Souma foi servir a outro daimiô, que ficara exultante por dispor de homem de tantos tafentos. Passaram-se os anos, e Souma acabou expulsando o vassalo mais antigo do clâ além de invejar todos aqueles próximos ao seu senhor. Sempre que possivel, ostentava suas próprias qualidades. Dessa forma, acabou desfazendo os laços que uniam os integrantes do feudo Quando o daimiô caiu em si e dispensou Souma, seu clã já entrara em colapso.

Bajuladores, egocêntricos e caluniadores são indignos de confiança, pois contaminam todos que os cercam. Como diz o ditado: "Quem se deita com cão acorda com pulgas". Pessoas como Souma são corrosivas, o melhor é manter distância.

Aproxime-se de pessoas esforçadas e dignas de confiança. Assim, você assegurará um futuro promissor. 


\section{Apêndice}

Os apêndices a seguir são informações complementares ao trabalho desenvolvido, que não foram incorporados ao longo do texto para não haver prejuízo de objetividade e clareza. 


\section{Apêndice A - Resumo em chinês}

\section{摘要:}

圣保罗 HJ 利什曼病控制的最优化模型：流行性疾病和其经济性分析[论文]“圣保 罗大学医学院”; 2015

人畜共患的内脏利什曼病 $(\mathrm{ZVL})$ 是最重要的新型寄生虫疾病之一。特别的，巴 西是这类疾病最为流行的国家之一。尽管内脏利什曼病控制指导方针的出版和在 公众卫生和控制和预防活动的投资，城市的下水管道和水库区域仍然是这些控制 措施的主要挑战。这是因为：(1) 需要更好地理解城市环境的媒介传播行为 ; (2) 在执行过程中的操作很难达到理想的效果；(3) 控制活动的高额费用。本文的主 要研究目的是阐述利什曼病控制的优化模型。这个模型是基于 5 个与下面策略对 应的控制参数：（一）载体人口数量控制，（二）消灭阳性狗，（三）使用狗项圈,

（四）对狗注射育苗，（五）对狗进行治疗。这个模型是有十七个微分方程构成的 一个方程系统。其中四个方程代表人类的发病规律 (易感人群 $\left(x_{h}\right)$, 潜在人群 $\left(l_{h}\right)$, 感 染人群 $\left(y_{h}\right)$ 和康复人群 $\left.\left(z_{h}\right)\right), 10$ 个方程代表狗 (易感狗群 $\left(x_{d}\right.$ 和 $\left.x_{d}{ }^{C}\right)$,潜在狗群 $\left(l_{d}\right.$ 和 $\left.l_{d}{ }^{C}\right)$, 感染狗群 $\left(y_{d}\right.$ 和 $\left.y_{d}{ }^{C}\right)$, 康复狗群 $\left(z_{d}\right.$ 和 $\left.z_{d}{ }^{C}\right)$ ) 和接种育苗狗群 $\left(v_{d}\right.$ 和 $\left.v_{d}{ }^{C}\right)$

（C 代表使用这种狗项圈的狗群）最后 3 个媒介群体（没有感染群体 $\left(s_{I}\right)$, 感染但 不没有传染性的群体 $\left(s_{2}\right)$, 易感染并具有传染性的群体 $\left.\left(s_{3}\right)\right)$ 。由对这些控制策略的 经济化分析, 我们预估了每一只狗的费用（在传播群体研究中, 估计了每个个体 治疗)。关于没有控制策略的数值模拟, 地方病平衡密度 : $\mathbf{x}_{\mathbf{h}} *=0.394, \mathbf{l}_{\mathbf{h}} *=0.0305$, $\mathbf{y}_{\mathbf{h}} *=0.00167, \mathbf{z}_{\mathbf{h}} *=0.574, \mathbf{x}_{\mathbf{d}} *=0.314, \mathbf{l}_{\mathbf{d}} *=0.165, \mathbf{y}_{\mathbf{d}} *=0.0163, \mathbf{z}_{\mathbf{d}} *=0.505, \mathbf{s}_{\mathbf{1}} *=$ $0.709, \mathbf{s}_{\mathbf{2}} *=0.0858, \mathbf{s}_{\mathbf{3}} *=0.205$ 。在这个流行性病平衡状态中，基本繁殖数和每天人 的感染速度估计如下: $\mathcal{R}_{0}=4.50$ 和 $R=3.58 \times 10^{-6} /$ 天。考虑到控制策略的影响估 计, 媒介群体控制是能够使每人感染人群速率下降, 并且极大的减少媒体和医院 花费的策略。另一方面，对媒介群体控制的花费是最高的。因为在流行病传播链 中控制操作的不同点，考虑到这些策略活动的同步性，控制计划不仅仅到这一个 非常有趣的控制策略，而且提高了对内脏利什曼病的投入的优化程度。

关键词：人畜共患的内脏利什曼病; 数学建模; 疾病控制策略; 流行病学; 经济 分析；成本估计。 


\section{Apêndice A - Descrição das equações do modelo (sem as estratégias de controle)}

Explicaremos sobre a estrutura do modelo esquematizado pela Figura 8 e das respectivas equações, observando as categorias individualmente.

Começaremos pelas equações referentes à dinâmica da leishmaniose visceral sobre a população humana.

\section{Humanos suscetíveis $\left(x_{h}(t)\right)$}

O princípio básico para a elaboração das equações é a mesma para todas elas. Assim, iremos explicar com detalhes a respeito da dinâmica sobre a categoria de humanos suscetíveis, a fim de facilitar a compreensão da lógica inserida sobre as demais categorias.

Podemos considerar que o início da dinâmica da LVZ sobre a população humana se inicia a partir do momento em que ocorre a transmissão do parasita $L$. $d$. chagasi ao humano suscetível. Em epidemiologia matemática, esta taxa de transmissão da doença é indicada pela letra grega $\beta$. No caso da LVZ, tal transmissão é realizada pelo contato (picada) de um mosquito. Porém, sabemos que nem todos os mosquitos são infectivos e, portanto, uma proporção deles $\left(s_{3}(t)\right)$ é a que consideramos como infectivos. Assim, podemos imaginar que a taxa de transmissão diária seja diretamente proporcional ao total de picadas diárias $a_{h}$ geradas pelos mosquitos infectivos. Porém, apenas uma fração $b_{h}$ dessas picadas tornam o humano suscetível em latente (Eq. (90)).

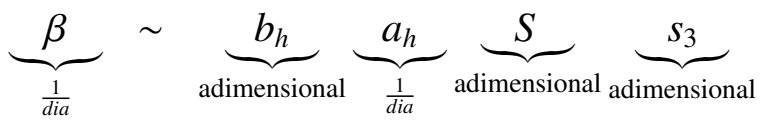

Portanto, a quantidade de humanos suscetíveis que se infectam (ou seja, que se tornam latentes) em um intervalo de tempo $d t$ é $b_{h} a_{h} S(t) s_{3}(t) x_{h} d t$. Somado a este termo, temos também o decréscimo devido à mortalidade natural dos indivíduos desta categoria. Logo, para o mesmo intervalo de tempo $d t$, a categoria de humanos suscetíveis 
decresce proporcionalmente à taxa de mortalidade $\mu_{h}$, ou seja, $\mu_{h} X_{h}(t) d t,\left(X_{h}\right.$ sendo o número absoluto de humanos suscetíveis). Em outras palavras, a categoria de humanos suscetíveis apresenta um decréscimo de $\left(b_{h} a_{h} S(t) s_{3}(t) x_{h}+\mu_{h} X_{h}(t)\right) d t$ a cada intervalo de tempo $d t$.

Por outro lado, a categoria $x_{h}(t)$ também apresenta elementos de acréscimo. A partir da categoria de humanos latentes $l_{h}(t)$, há um fluxo diário de indivíduos que é proporcional à taxa de recuperação espontânea $\left(r_{h} L_{h}(t)\right.$, onde $L_{h}$ é o número absoluto de humanos latentes - "L"maiúsculo). Ideia semelhante ocorre com os humanos imunes que revertem sua condição de recuperados proporcionalmente à taxa de perda de imunidade $\left(\gamma_{d} Z_{h}(t)\right.$, com $Z_{h}$ o número absoluto de humanos imunes).

Por fim, há também o fluxo diário de entrada a este sistema. Biologicamente, este fluxo representa o termo de entrada devido à natalidade e, basicamente, ele repõe as perdas devido à mortalidade natural e à letalidade calazar específica. Assim, consideramos que este fluxo diário de entrada é proporcional à taxa de mortalidade natural $\left(\mu_{h} \mathscr{N}_{h}(t)\right.$, onde $\mathscr{N}_{h}$ é o total absoluto de humanos na população) e à taxa de letalidade calazar específica ( $\alpha_{h} Y_{h}(t)$, onde $Y_{h}$ é o total absoluto de humanos clinicamente doentes na população).

Ao final, em um intervalo de tempo $d t$, o acréscimo é dado por $\left(\mu_{h} \mathscr{N}_{h}(t)+r_{h} L_{h}(t)+\right.$ $\left.\alpha_{h} Y_{h}(t)+\gamma_{d} Z_{h}(t)\right) d t$. Isso significa que a cada intervalo de tempo $d t$, a categoria de humanos suscetíveis aumenta desta quantidade.

Finalmente, para um dado intervalo de tempo $d t$, a variação da categoria de sucetíveis $d X_{h}$ ( $X_{h}$ sendo o número absoluto de humanos suscetíveis) será:

$$
\begin{aligned}
d X_{h}= & \left(\mu_{h} \mathscr{N}_{h}(t)+r_{h} L_{h}(t)+\alpha_{h} Y_{h}(t)+\gamma_{d} Z_{h}(t)\right) d t \\
& -\left(b_{h} a_{h} S(t) s_{3}(t) x_{h}+\mu_{h} X_{h}(t)\right) d t
\end{aligned}
$$

Dividindo a Eq. (91) por $\mathscr{N}_{h} d t$ e nomeando $S(t) / \mathscr{N}_{h}(t)=m_{h}$ obtemos a Eq. (1). Ressaltamos que ao dividirmos os valores absolutos das respectivas categorias pelo total da população de humanos, nós obtemos as respectivas categorias em termos de proporção (isto é, normalizados). Assim, quando utilizamos letras maíusculas " $X$ ", " $L "$, " $Y$ "e "Z", 
estamos nos referindo a valores absolutos, e quando utilizamos letras minúsculas, " $x$ ", "l", "y"e "z", estamos nos referindo à respectiva proporção dessas categorias na população. Este esclarecimento também é válido para as populações de cães e de mosquitos, que explicaremos a seguir.

\section{Humanos latentes $\left(l_{h}(t)\right)$}

O crescimento diário da categoria de humanos latentes é modulado pela transmissão do parasita aos humanos suscetíveis $\left(b_{h} a_{h} S(t) s_{3}(t) x_{h}\right)$, conforme descrito anteriormente. Porém, a diminuição desta categoria é modulada por quatro taxas. Em primeiro lugar, há uma saída de indivíduos desta categoria que é proporcional à taxa de mortalidade natural $\left(\mu_{h} L_{h}(t)\right)$. Além disso, os humanos latentes podem seguir por três caminhos diferentes: (1) eles pode retornar ao estado de humano suscetível $x_{h}$ e, neste caso, o fluxo é proporcional à taxa de recuperação espontânea $\left(r_{h} L_{h}(t)\right)$; (2) eles podem sofrer com a evolução da doença, passando a apresentar sinais e sintomas clínicos (categoria de humanos clinicamente doentes $y_{h}$ ), sendo o fluxo proporcional ao inverso do período de incubação $\left(\varphi_{h} L_{h}(t)\right)$; (3) eles podem evoluir para estado de humano recuperado (imune) $z_{h}$ e, neste caso, o fluxo é proporcional à taxa de recuperação dos latentes para imunes $\left(\delta_{h} L_{h}(t)\right)$

Portanto, para um dado intervalo de tempo $d t$, a variação da categoria de latentes $d L_{h}$ ( $L_{h}$ sendo o número absoluto de humanos suscetíveis) será:

$$
d L_{h}=b_{h} a_{h} S(t) s_{3}(t) x_{h} d t-\left(\mu_{h}+r_{h}+\varphi_{h}+\delta_{h}\right) L_{h}(t) d t
$$

Dividindo a Eq. 92 por $\mathscr{N}_{h}(t) d t$ e nomeando $S(t) / \mathscr{N}_{h}(t)=m_{h}$ obtemos a Eq. (2).

\section{Humanos clinicamente doentes $\left(y_{h}(t)\right)$}


A categoria de humanos clinicamente doentes contém os humanos que sofreram pela progressão clínica da doença. Assim, o fluxo diário de entrada é proporcional ao termo $\varphi_{h} L_{h}(t)$, conforme descrito anteriormente. Porém, o fluxo de saída é modulado por três taxas. Em primeiro lugar, temos a saída de indivíduos devido à mortalidade natural (cujo princípio é o mesmo para as categorias de humanos suscetíveis e de latentes): $\mu_{h} Y_{h}(t)$. A outra saída é decorrente da letalidade calazar específica (isto é, a morte devido à doença) e é proporcional à taxa de letalidade para esta doença, $\alpha_{h} Y_{h}(t)$. Por fim, os indivíduos desta categoria podem se recuperar e se tornar imunes, fluxo que é proporcional à taxa de recuperação dos clinicamente doentes para imunes, $\sigma_{h} Y_{h}(t)$.

Logo, para um dado intervalo de tempo $d t$, a variação da categoria de latentes $d Y_{h}\left(Y_{h}\right.$ sendo o número absoluto de humanos suscetíveis) será:

$$
d Y_{h}=\varphi_{h} L_{h}(t) d t-\left(\mu_{h}+\alpha_{h}+\sigma_{h}\right) Y_{h}(t) d t
$$

Dividindo a Eq. (93) por $\mathscr{N}_{h}(t) d t$, obtemos a Eq. (3).

\section{Humanos recuperados (imunes) $\left(z_{h}(t)\right)$}

A última categoria dentro desta sequência relativa à dinâmica da LVZ sobre a população humana é a categoria de humanos recuperados (imunes). O humano infectado pode se tornar imune a partir de sua condição de latente, $\delta_{h} L_{h}(t)$, ou de clinicamente doente, $\sigma_{h} Y_{h}(t)$, conforme os fluxos diários provenientes das categorias comentadas anteriormente.

Já o fluxo diário de saída é dada pela reversão da condição de imune para suscetível, e este fluxo é proporcional à taxa de perda de imunidade, $\gamma_{h} Z_{h}(t)$. Ainda, há também as perdas devido à mortalidade natural dos indivíduos, $\mu_{h} Z_{h}(t)$.

Assim, para um dado intervalo de tempo $d t$, a variação da categoria de latentes $d Z_{h}\left(Z_{h}\right.$ sendo o número absoluto de humanos suscetíveis) será: 


$$
d Z_{h}=\left(\delta_{h} L_{h}(t)+\sigma_{h} Y_{h}(t)\right) d t-\left(\mu_{h}+\gamma_{h}\right) Z_{h}(t) d t
$$

Dividindo a Eq. (94) por $\mathscr{N}_{h} d t$, obtemos a Eq. (4).

A seguir, comentaremos sobre as equações referentes à dinâmica da leishmaniose visceral sobre a população canina.

\section{Cães suscetíveis $\left(x_{d}(t)\right)$}

A dinâmica da LVZ sobre a população de cães é muito similar àquela apresentada para a população de humanos. Apenas alguns detalhes são acrescidos.

Em particular, no caso da categoria de cães suscetíveis, o princípio básico para descrever a dinâmica desta categoria é a mesma utilizada para o equivalente em humanos. Portanto, podemos resumir dizendo que a mesma equação para a dinâmica da categoria de humanos suscetíveis pode ser utilizada para os cães suscetíveis, com a diferença de que devemos utilizar as taxas referentes à população de cães.

Assim, como resultado, obtemos a Eq. (5).

\section{Cães latentes $\left(l_{d}(t)\right)$}

Seguindo o curso natural da doença, temos a categoria de cães latentes $l_{d}(t)$. A dinâmica que envolve esta categoria é muito próxima ao equivalente em humanos. Porém, há o acréscimo de dois fluxos diários em relação ao similar em humanos.

O fluxo de entrada é basicamente o mesmo que o descrito para humanos. Contudo há o acréscimo de um fluxo originário da categoria de cães clinicamente doentes $y_{d}(t)$ que se recuperam, mas que mantém o status de fonte de infecção $l_{d}(t)$. Este fluxo 
é proporcional à taxa de recuperação de clinicamente doentes para latentes $f_{d}$, portanto $f_{d} Y_{d}(t)$. Ainda, há também um fluxo originário da categoria de cães imunes $z_{d}(t)$, que perdem o status de imune e passam a se tornar fontes de infecção. Neste caso, o fluxo é proporcional à taxa de perda de imunidade (de imunes para latentes) $q_{d}$, logo $q_{d} Z_{d}(t)$. Já o fluxo de saída se mantém basicamente o mesmo ao equivalente dos humanos latentes Como resultado, obtemos a Eq. (6).

\section{Cães clinicamente doentes $\left(y_{d}(t)\right)$}

A diferença entre esta categoria e a equivalente em humanos é a adição de um fluxo de saída. Este fluxo (comentado anteriormente) representa a recuperação de cães clinicamente doentes $y_{d}(t)$, mas que mantém o status de fonte de infecção $l_{d}(t)$ (ou seja $\left.f_{d} Y_{d}(t)\right)$.

Como resultado, obtemos a Eq. (7).

\section{Cães recuperados (imunes) $\left(z_{d}(t)\right)$}

Por fim, em relação ao seu equivalente humano $z_{h}(t)$, a categoria de cães imunes $z_{d}$ difere em sua dinâmica pelo acréscimo de um fluxo de saída. Este fluxo (explicado anteriormente) se refere à perda do status de imune $z_{d}(t)$, passando para o status de cães latentes $l_{d}(t)$, portanto, $q_{d} Z_{d}(t)$.

Assim, obtemos a Eq. (8).

Finalmente, comentaremos sobre a dinâmica da leishmaniose visceral sobre a população de vetores.

Mosquito não-infectado $\left(s_{1}(t)\right)$ 
Esta categoria da população de mosquitos se equivale a categoria de suscetíveis das populações de humanos e de cães. Porém, há algumas diferenças em termos estruturais sobre o desenvolvimento dos termos que modulam a sua dinâmica.

O fluxo diário de entrada contém o mesmo princípio daquele aplicado para as categorias de sucetíveis. Basicamente, o fluxo de entrada tem por finalidade repor os indivíduos nesta população. Assim, dado que a população é constante, as entradas são numericamente equivalentes às saídas. Por essa ótica, as saídas desse sistema são proporcionais à taxa de mortalidade natural $\mu_{s}$ (ou seja, $\mu_{s} \mathscr{N}_{s}$, onde $\mathscr{N}_{s}$ é o total absoluto de mosquitos na população).

Por outro lado, o fluxo diário de saída é composto por duas vias. Uma delas é a mortalidade natural. Matematicamente, este fluxo é proporcional à taxa de mortalidade natural, $\mu_{s} S_{1}(t)$.

A outra via de saída representa a infecção do mosquito pelo parasita. Essa infecção ocorre no momento da picada de um mosquito não-infectado $s_{1}(t)$ sobre cães latentes $l_{d}(t)$ ou clinicamente doentes $y_{d}(t)$. Se considerarmos que a frequência de picadas diárias é dada por $a_{d}$ e que apenas uma proporção de picadas efetivamente levam ao estado de mosquito infectado ( $c_{l}$, para o caso do contato com cães latentes, e $c_{y}$, para o caso dos cães clinicamente doentes), então o fluxo de saída devido ao processo de infecção do mosquito é dado por $a_{d}\left(c_{l} l_{d}(t)+c_{y} y_{d}(t)\right) S_{1}(t)$.

Assim, para um dado intervalo de tempo $d t$, a variação da categoria de mosquitos não infectados $d S_{1}\left(S_{1}(t)\right.$ sendo o número absoluto de mosquitos não-infectados) será:

$$
d S_{1}=\mu_{h} \mathscr{N}_{s}(t) d t-\left(\mu_{s}+a_{d}\left(c_{l} l_{d}(t)+c_{y} y_{d}(t)\right)\right) S_{1}(t) d t
$$

Dividindo a Eq. (95) por $\mathscr{N}_{s} d t$, obtemos a Eq. (9).

\section{Mosquito infectado, porém não-infectivo $\left(s_{2}(t)\right)$}


Seguindo o curso natural da doença, ao ser infectado, o mosquito passa a um estágio de latência antes de se tornar infectivo (isto é, transmissor do parasita).

Nesta categoria, o fluxo diário de entrada é representado pela via de saída dada pela infecção dos mosquitos não-infectados $s_{1}$, ou seja $a_{d}\left(c_{l} l_{d}(t)+c_{y} y_{d}(t)\right) S_{1}(t)$.

O fluxo diário de saída é dado por duas vias. Uma delas é a mortalidade natural, da mesma forma que ocorre para a categoria dos mosquitos não-infectados $s_{1}$. Matematicamente, este fluxo é dado por $\mu_{s} S_{2}(t)$.

A outra via é dada pela progressão dos mosquitos desta categoria para o estágio de infectivos. Entretanto, na dinâmica desta categoria, há o envolvimento do termo $\tau$ (período de incubação extrínseco), que numericamente equivale a cerca da metade da expectativa de vida das mosquitos. Biologicamente, este termo significa que somente após $\tau$ dias a partir do contato do mosquito não-infectado com o cão latente ou clincamente doente é que o mosquito passará a ser infectivo (isto é, transmissor). Assim, para traduzirmos este efeito biológico em termos matemáticos, incorporamos o efeito da defasagem nas variáveis envolvidas (termos com atraso, isto é, aqueles com o argumento $(t-\tau)$ ). Como resultado final, o termo de saída desta via é o mesmo termo de entrada, porém referente a $\tau$ dias atrás. Logo, obtemos $a_{d}\left(c_{l} l_{d}(t-\tau)+c_{y} y_{d}(t-\tau)\right) S_{1}(t-\tau)$.

Um último detalhe deve ser ressaltado. Por hipótese, a partir do instante em que o mosquito se infecta, há uma probabilidade de que ele sobreviva até se tornar infectivo. Em outras palavras, a presença de um período de incubação extrínseco do parasita no vetor implica em um termo de exponencial negativo na transição de infectado para infectivo. Este termo exponencial $\left(e^{-\mu_{s} \tau}\right)$ representa esta probabilidade de um mosquito infectado sobreviver até se tornar infectivo ${ }^{9}$. Portanto, o fluxo de mosquitos que efetivamente se tornam infectivos é representado por $a_{d}\left(c_{l} l_{d}(t-\tau)+c_{y} y_{d}(t-\tau)\right) S_{1}(t-\tau) e^{-\mu_{s} \tau}$.

Logo, para um dado intervalo de tempo $d t$, a variação da categoria de mosquitos infectados $d S_{2}\left(S_{2}(t)\right.$ sendo o número absoluto de mosquitos infectados) será:

$$
\begin{aligned}
d S_{2}= & a_{d}\left(c_{l} l_{d}(t)+c_{y} y_{d}(t)\right) S_{1}(t) d t-\mu_{s} S_{2}(t) d t \\
& -a_{d}\left(c_{l} l_{d}(t-\tau)+c_{y} y_{d}(t-\tau)\right) S_{1}(t-\tau) e^{-\mu_{s} \tau} d t
\end{aligned}
$$


Dividindo a Eq. (96) por $\mathscr{N}_{s} d t$, obtemos a Eq. (10).

\section{Mosquito infectado, porém infectivo $\left(s_{3}(t)\right)$}

O último estágio da dinâmica da infecção sobre os mosquitos ocorre a partir do momento em que eles se tornam infectivos $s_{3}(t)$. A dinâmica desta categoria é modulada pelo fluxo de entrada (referente a saída da categoria $\left.s_{2}(t)\right), a_{d}\left(c_{l} l_{d}(t-\tau)+c_{y} y_{d}(t-\tau)\right) S_{1}(t-$ $\tau) e^{-\mu_{s} \tau}$, enquanto que o de saída é dada pela mortalidade natural aplicada a esta categoria, $\mu_{s} S_{3}(t)$.

Considerando um dado intervalo de tempo $d t$, a variação da categoria de mosquitos infectivos $d S_{3}\left(S_{3}(t)\right.$ sendo o número absoluto de mosquitos infectados) será:

$$
d S_{3}=a_{d}\left(c_{l} l_{d}(t-\tau)+c_{y} y_{d}(t-\tau)\right) S_{1}(t-\tau) e^{-\mu_{s} \tau} d t-\mu_{s} S_{3}(t) d t
$$

Dividindo a Eq. (97) por $\mathscr{N}_{s} d t$, obtemos a Eq. (11). 


\section{Apêndice B - Descrição das equações do modelo (com as estratégias de controle)}

Descreveremos a seguir a dinâmica envolvida em cada categoria considerando a inclusão das estratégias de controle.

\section{Modificações sobre a população de cães}

\section{Cães suscetíveis sem coleira $\left(x_{d}(t)\right)$}

Com a adição das estratégias de controle, a categoria de cães suscetíveis passa a sofrer alterações no fluxo de saída e de entrada.

Em relação ao modelo com as estratégias de controle, além do fluxo de saída devido à transmissão do parasita aos sucetíveis $\left(b_{d} a_{d} m_{d} s_{3}(t) x_{d}(t)\right)$, agora temos também o fluxo diário de aplicação de coleiras e de vacinas. Estes dois fluxos são proporcionais às respectivas taxas de encoleiramento $\theta_{d}$ e de vacinação $v_{d}$ (lembrando que apenas uma proporção $\varepsilon_{v}$ de cães vacinados efetivamente adquire imunidade). Portanto, o novo fluxo de saída passa a ser $\left(b_{d} a_{d} m_{d} s_{3}(t)+\theta_{d}+\varepsilon_{v} v_{d}\right) x_{d}(t)$.

Por outro lado, o fluxo de entrada também passa por algumas modificações. $\mathrm{O}$ princípio da reposição de cães por recrutamento devido à (1) mortalidade natural e (2) letalidade calazar específica permanece o mesmo. Entretanto, no caso da letalidade calazar específica, a reposição passa a ser proporcional também à categoria de cães clinicamente doentes encoleirados $y_{d}^{C}(t)$. Ainda com relação à reposição por recrutamento, também consideramos a reposição devido aos cães eliminados por serem positivos para a LVZ. Esta reposição é proporcional à taxa de eliminação de cães $\xi_{d}$ e está vinculada a todos as categorias soropositivas para o parasita (neste caso, as únicas categorias que não consideramos soropositivas são a de suscetíveis $x_{d}(t)$ e $\left.x_{d}^{C}(t)\right)$. Portanto, o fluxo de entrada devido ao recrutamento é definido por $\mu_{d}\left(1-x_{d}(t)\right)+\xi_{d}\left(1-x_{d}(t)-x_{d}^{C}(t)\right)+\alpha_{d}\left(y_{d}(t)+y_{d}^{C}(t)\right)$. 
Além do fluxo de entrada por recrutamento, há também novos fluxos a serem considerados. Primeiramente, há o fluxo devido ao tratamento de cães clinicamente doentes (sem coleira), que eliminam a parasitemia e se tornam suscetíveis. Este fluxo é proporcional à taxa de tratamento $\omega_{d}$. Porém, este fluxo está sujeito à proporção de cães que não desiste do tratamento $\psi_{d}$ e da proporção de cães que consegue eliminar a parasitemia $1-c_{k}$. Portanto, este fluxo é dado por $\left(1-c_{k}\right) \psi_{d} \omega_{d} y_{d}(t)$.

Há também o fluxo de entrada devido à perda de efetividade da coleira e da vacina. No caso da perda da efetividade da coleira, isso ocorre devido a duas taxas: a perda física da coleira $\zeta_{c}$ e ao decaimento natural devido à perda de atividade da deltametrina $u_{c}$. Portanto, este fluxo é proporcional a essas duas taxas e envolve a categoria de cães suscetíveis e encoleirados $x_{d}^{C}(t)$. Já no caso da perda da efetividade da vacina, o princípio é basicamente o mesmo, sendo que neste caso consideramos o decaimento natural devido à perda da atividade, $p_{d}$. Assim, este fluxo é proporcional à taxa $p_{d}$ e está relacionado à categoria de cães vacinados $v_{d}$. Logo, o fluxo de entrada devido à perda de efetividade dessas duas estratégias é dada por $\left(\zeta_{c}+u_{c}\right) x_{d}^{C}(t)+p_{d} v_{d}(t)$.

Logo, a Eq. (5) passa a ser modificada para (12).

\section{Cães suscetíveis com coleira $\left(x_{d}^{C}(t)\right)$}

A categoria de cães suscetíveis com coleira é uma espécie de categoria similar a de cães suscetíveis sem coleira. Porém, ela apresenta algumas diferenças no seus fluxos de entrada e de saída.

Um dos fluxos de entrada é proporcional à taxa de aplicação de coleiras em cães suscetíveis e está relacionado a esta categoria. Portanto, este fluxo é dado por $\theta_{d} x_{d}(t)$. As outras vias de entrada estão relacionadas a fluxos originários de outras categorias encoleiradas. Assim, há a recuperação de cães latentes encoleirados para suscetíveis $r_{d} l_{d}(t)$ e a perda de imunidade de cães recuperados encoleirados para suscetíveis $\gamma_{d} z_{d}(t)$. Há também o fluxo de cães clinicamente doentes, porém encoleirados, que são tratados e que 
eliminam a parasitemia, portanto $\left(1-c_{k}\right) \psi_{d} \omega_{d} y_{d}^{C}(t)$. Finalmente, temos também os cães encoleirados que também optam por ser vacinados, mas que passam pelo decaimento do efeito da vacinação $p_{d}$, tornando-se cães suscetíveis encoleirados $p_{d} v_{d}^{C}(t)$.

Por outro lado, o fluxo de saída apresenta algumas diferenças em relação a sua categoria similar sem coleira. Primeiramente, observamos a saída de indivíduos devido à mortalidade natural, $\mu_{d} x_{d}^{C}(t)$. Em seguida, cães suscetíveis encoleirados podem optar por uma proteção adicional, como a vacinação. Neste caso, a saída desta categoria para a categoria de vacinados com coleira $v_{d}^{C}(t)$ é proporcional à taxa de vacinação, à proporção de cães que efetivametne adquirem a imunidade e à categoria de cães suscetíveis, mas encoleirados, $\varepsilon_{v} v_{d} x_{d}^{C}(t)$. Há também a saída de indivíduos devido à perda física da coleira e ao decaimento do efeito da deltametrina impregnada na coleira, portanto $\left(u_{c}+\zeta_{c}\right) x_{d}^{C}(t)$. Finalmente, apesar dos cães suscetíveis estarem encoleirados, a coleira não oferece proteção $100 \%$ eficaz. Portanto, uma parcela dos cães encoleirados $\left(1-\varepsilon_{c}\right)$ ainda permanece exposta à picada do mosquito e pode se tornar latente. Esse mecanismo pode ser traduzido para o nosso modelo pelo mesmo termo utilizado para representar o processo de transmissão do parasita aos sucetíveis $\left(1-\varepsilon_{c}\right) b_{d} a_{d} m_{d} s_{3}(t) x_{d}^{C}(t)$.

Logo, temos que a dinâmica desta categoria de cães suscetíveis e encoleirados é dada pela Eq. (13).

\section{Cães latentes sem coleira $\left(l_{d}(t)\right)$}

A dinâmica dos cães latentes sem coleira sofre algumas modificações ao incorporar o efeito das estratégias de controle.

Uma das vias de entrada se mantém a mesma, isto é, $b_{d} a_{d} m_{d} s_{3}(t) x_{d}(t)$. Há também, uma via correspondente àquela devido à perda da atividade da coleira (similar ao que foi comentado para o caso da categoria de cães suscetíveis sem a coleira $\left.x_{d}^{C}(t)\right)$. Portanto, o fluxo de entrada devido a esta perda da atividade é proporcional à taxa de perda física $\zeta_{c}$ e à taxa de decaimento da efetividade da coleira $u_{c}$, além de depender também 
da categoria de cães latentes, porém encoleirados, $\left(\zeta_{c}+u_{c}\right) l_{d}^{C}(t)$. Por fim, há também uma via de entrada nova devido ao tratamento de cães clinicamente doentes que não elimina a parasitemia, $c_{k} \psi_{d} \omega_{d} y_{d}(t)$. Também devem ser considerados (1) o fluxo de entrada devido a cães clinicamente doentes que se recuperam espontâneamente para latentes $f_{d} y_{d}(t)$ e (2) os cães imunes que perdem a imunidade para a categoria de latentes $q_{d} z_{d}(t)$. Logo, o fluxo de entrada para esta categoria é dada por $b_{d} a_{d} m_{d} s_{3}(t) x_{d}(t)+\left(\zeta_{c}+u_{c}\right) l_{d}^{C}(t)+\left(f_{d}+\right.$ $\left.c_{k} \psi_{d} \omega_{d}\right) y_{d}(t)+q_{d} z_{d}(t)$.

Já o fluxo de saída é basicamente o mesmo que aquele considerado para o caso sem as estratégias de controle. Neste caso, há a adição da aplicação do encoleiramento e da eliminação dos cães positivos. Assim, o fluxo de saída é dada por $\left(\mu_{d}+r_{d}+\delta_{d}+\varphi_{d}+\right.$ $\left.\xi_{d}+\theta_{d}\right) l_{d}(t)$

Logo, temos que a dinâmica desta categoria de cães latentes sem coleira passa a ser modificada da Eq. (6) para (14).

\section{Cães latentes com coleira $\left(l_{d}^{C}(t)\right)$}

No caso dos cães latentes com coleira, a dinâmica é composta por quatro vias de entrada. Uma delas corresponde à aplicação da coleira sobre os cães latentes, $\theta_{d} l_{d}(t)$. As outras são originadas de categorias em que os cães já estão com a coleira. Assim, há aqueles animais suscetíveis que, mesmo usando a coleira, acabam se infectando pela picada do mosquito, $\left(1-\varepsilon_{c}\right) b_{d} a_{d} m_{d} s_{3}(t) x_{d}^{C}(t)$. Da categoria de cães clinicamente doentes que usam a coleira, os animais ou podem ser tratados, sem se livrar da parasitemia, $c_{k} \psi_{d} \omega_{d} y_{d}(t)$, ou podem se recuperar espontaneamente, passando para a categoria de latentes, $f_{d} y_{d}(t)$. Finalmente, os cães imunes que utilizam coleira podem perder a imunidade e migrar para a categoria de cães latentes, $q_{d} z_{d}(t)$. Portanto, o fluxo de entrada para esta categoria é dada por $\theta_{d} l_{d}(t)+\left(1-\varepsilon_{c}\right) b_{d} a_{d} m_{d} s_{3}(t) x_{d}^{C}(t)+\left(f_{d}+c_{k} \psi_{d} \omega_{d}\right) y_{d}(t)+q_{d} z_{d}(t)$.

Com relação às saídas, são basicamente as mesmas do fluxo de saída da categoria de cães latentes $l_{d}(t)$ (Eq. (6)). Entretanto, para esta categoria de cães latentes com coleira, 
há três fluxos de saída adicionais: (1) eliminação de cães positivos, (2) perda física da coleira e (3) decaimento da eficácia da coleira. Portanto, o fluxo de saída desta categoria é dada por $\left(\xi_{d}+\mu_{d}+\zeta_{c}+u_{c}+r_{d}+\delta_{d}+\varphi_{d}\right) l_{d}^{C}(t)$.

Logo, a dinâmica da categoria de cães latentes com coleira é determinada pela Eq. (15).

\section{Cães clinicamente doentes sem coleira $\left(y_{d}(t)\right)$}

Seguindo a evolução da dinâmica, a categoria de cães clinicamente doentes apresenta uma dinâmica muito próxima da apresentada pela Eq. (7).

Neste caso, o fluxo de entrada apresenta dois fluxos adicionais. Estes dois fluxos adicionais se referem à inatividade da coleira dos cães clinicamente doentes que a utilizam. Logo, este fluxo é proporcional à perda física da coleira e à perda da atividade da deltametrina, $\left(\zeta_{c}+u_{c}\right) y_{d}^{C}(t)$. Portanto, o fluxo de entrada para esta categoria se torna $\varphi_{d} l_{d}(t)+\left(\zeta_{c}+u_{c}\right) y_{d}^{C}(t)$

Já o fluxo de saída ganha o acréscimo de três vias novas: (1) o animal clinicamente doente pode ser sacrificado $\left(\xi_{d} y_{d}(t)\right)$, (2) pode adquirir a coleira $\left(\theta_{d} y_{d}(t)\right)$, ou (3) pode ser tratado $\left(\psi_{d} \omega_{d} y_{d}(t)\right)$. Contudo, o animal desta categoria quando é tratado, ele pode ou não eliminar a parasitemia. Portanto, o fluxo de saída é dado por $\left(f_{d}+\mu_{d}+\alpha+\sigma_{d}+\theta_{d}+\xi_{d}+\psi_{d} \omega_{d}\right) y_{d}(t)$

Logo, a dinâmica da categoria de cães clinicamente doentes sem coleira é alterada da Eq. (7) para (16).

\section{Cães clinicamente doentes com coleira $\left(y_{d}^{C}(t)\right)$}

A dinâmica desta categoria é muito similar à de cães clinicamente doentes sem coleira $y_{d}(t)$. Entretanto, há uma pequena diferença nos fluxos de entrada e de saída.

Comparando com a categoria de cães clinicamente doentes sem coleira $y_{d}(t)$, há 
uma troca de posição entre duas vias de fluxo. Enquanto a aplicação de coleira é uma via de saída para $y_{d}(t)$, esta passa a ser a via de entrada para a categoria de cães clinicamente doentes com coleira $y_{d}^{C}(t)$. Por outro lado, a perda de atividade da coleira é uma via de entrada para $y_{d}(t)$, ao passo que ela é uma via de saída para $y_{d}^{C}(t)$. O restante das vias de fluxo permanecem as mesmas.

Assim, a dinâmica da categoria de cães clinicamente doentes com coleira é determinada pela Eq. (17).

\section{Cães recuperados (imunes) sem coleira $\left(z_{d}(t)\right)$}

A dinâmica da categoria de cães recuperados é dependente da entrada de indivíduos infectados de outras categorias ou que perdem a coleira, e da saída de indivíduos que perdem a imunidade ou que adquirem a coleira.

O fluxo de entrada é dependente de quatro vias. Duas delas são relativas à aquisição da imunidade pelo cão infectado. Assim, cães latentes $l_{d}(t)$ e cães clinicamente doentes $y_{d}(t)$ adquirem imunidade proporcionalmente a uma taxa de recuperação espontânea, $\delta_{d}$ e $\sigma_{d}$, respectivamente. Além disso, há também os cães imunes que perdem a coleira ou que a coleira perde a eficiência. Portanto, os cães imunes com a coleira $z_{d}^{C}(t)$ passam a migrar para a categoria de imunes sem a coleira $z_{d}(t)$ proporcionalmente à taxa $\zeta_{c}$ (perda física da coleira) e à taxa $u_{c}$ (decaimento da atividade da deltametrina). Logo, o fluxo de entrada é dado por $\delta_{d} l_{d}(t)+\sigma_{d} y_{d}(t)+\left(\zeta_{c}+u_{c}\right) z_{d}^{C}(t)$.

Em contrapartida, o fluxo de saída é similar ao apresentado para a Eq. (8). Entretanto, há o acréscimo de duas vias adicionais. Os cães imunes também estariam sujeitos a serem eliminados, pois seriam soropositivos aos testes de diagonósticos oficiais. Além disso, os cães imunes desta categoria também estariam sujeitos ao uso da coleira. Logo, o fluxo de saída é dado por $\left(q_{d}+\mu_{d}+\gamma_{d}+\theta_{d}+\xi_{d}\right) z_{d}(t)$.

Por fim, temos que a dinâmica da categoria de cães imunes sem coleira é modificada da Eq. (8) para (18). 


\section{Cães recuperados (imunes) com coleira $\left(z_{d}^{C}(t)\right)$}

A dinâmica relacionada aos cães imunes com coleira $y_{d}^{C}(t)$ é bastante similar a categoria análoga sem a coleira $y_{d}(t)$.

Ao passo que os cães imunes sem coleira passam a ser encoleirados, este processo se torna um dos componentes do fluxo de entrada para a categoria de cães imunes com coleira $y_{d}^{C}(t)$. Portanto, o fluxo de entrada se modifica para $\delta_{d} l_{d}^{C}(t)+\sigma_{d} y_{d}^{C}(t)+\theta_{d} z_{d}(t)$.

E, de forma oposta, dois componentes do fluxo de entrada da categoria de cães imunes sem coleira $\left(\left(\zeta_{c}+u_{c}\right) z_{d}^{C}(t)\right)$ é uma das vias de saída da categoria de cães imunes com coleira. Logo, temos que o fluxo de saída total se torna $\left(q_{d}+\mu_{d}+\gamma_{d}+\zeta+u_{c}+\xi_{d}\right) z_{d}^{C}(t)$.

Assim, a dinâmica da categoria de cães imunes com coleira é determinada pela Eq. (19).

\section{Cães vacinados sem coleira $\left(v_{d}(t)\right)$}

A categoria de cães vacinados $v_{d}(t)$ é uma categoria nova que está sendo inclusa em nosso modelo a partir de agora. Estrategicamente, esta categoria tem por finalidade diminuir a quantidade de cães suscetíveis expostos à picada do mosquito infectivo e que possam se tornar latentes.

O fluxo de entrada para esta categoria é composta por duas vias. Uma delas diz respeito à vacinação de cães suscetíveis sem coleira $\left(x_{d}(t)\right)$, sendo proporcional à taxa de vacinação e à fração de cães que se tornam efetivamente imunes $\left(\varepsilon_{v} v_{d} x_{d}(t)\right)$. A outra via de entrada está relacionada aos cães vacinados e que também estão encoleirados $\left(v_{d}^{C}(t)\right)$, mas que passam a perder a atividade da coleira, $\left(\zeta_{c}+u_{c}\right) v_{d}^{C}(t)$. Assim, o fluxo de entrada é dado por $\varepsilon_{v} v_{d} x_{d}(t)+\left(\zeta_{c}+u_{c}\right) v_{d}^{C}(t)$.

E, no caso do fluxo de saída, temos quatro fatores envolvidos. Uma vez vacinado e imune, o cão pode emigrar desta categoria devido à (1) mortalidade natural, (2) perda 
da eficácia da vacinação, (3) aplicação de coleira e (4) ao sacrifício. Lembramos que os cães vacinados também são passíveis de serem eliminados, pois estamos assumindo que os métodos de diagnóstico não são capazes de diferenciar o anticorpo de cães infectados daqueles vacinados ${ }^{117}$. Portanto, o fluxo de saída é dado por $\left(p_{d}+\mu_{d}+\theta_{d}+\xi_{d}\right) v_{d}(t)$

Assim, a dinâmica da categoria de cães vacinados sem coleira é determinada pela Eq. (20).

\section{Cães vacinados com coleira $\left(v_{d}^{C}(t)\right)$}

A dinâmica da categoria de cães vacinados com coleira $v_{d}^{C}(t)$ é parecida com a dos vacinados sem coleira $v_{d}(t)$.

O fluxo de entrada é semelhante, porém, com algumas diferenças. Os cães vacinados que pertencem a esta categoria podem ser provenientes da categoria de cães suscetíveis com coleira $x_{c}^{C}(t)$, que foram vacinados, ou dos cães vacinados $v_{d}(t)$, que receberam coleira. Portanto, o fluxo de entrada é dado por $\varepsilon_{v} v_{d} x_{d}^{C}(t)+\theta_{d} v_{d}(t)$.

Já o fluxo de saída é composto pelos mesmos componentes do análogo sem a coleira. Porém, enquanto na categoria de cães vacinados sem a coleira, uma das vias de saída é devido à aplicação da coleira, no caso dos cães vacinados com coleira, há uma via de saída devido à perda da atividade da coleira. Portanto, o fluxo de saída é dado por $\left(p_{d}+\mu_{d}+\zeta_{c}+u_{c}+\xi_{d}\right) v_{d}^{C}(t)$.

Logo, a dinâmica da categoria de cães vacinados com coleira é determinada pela Eq. (21).

\section{Modificações sobre a população de mosquitos}

As modificações relativas a esta população são simples e descreveremos em poucas palavas.

Das cinco estratégias de controle, uma age sobre a população de mosquitos: o 
controle da população de vetores $\left(\xi_{s}\right)$. Em nosso modelo, a premissa adotada é que o controle da população de vetores é baseada no aumento da taxa de mortalidade. O aumento da mortalidade é consequência das ações de saneamento ambiental e do controle químico (por exemplo, por meio da aspersão do inseticida nas áreas infestadas pelos mosquitos). Por fim, este acréscimo à taxa de mortalidade natural é representada por $\xi_{s}$, sendo que a taxa de mortalidade total nesta população passa a ser $\mu_{s}+\xi_{s}$.

Outra observação importante é a respeito da presença de novas fontes de infecção. Dado que o colar não é $100 \%$ eficaz, temos que tanto cães latentes e clinicamente doentes que usam a coleira ainda continuam expostos (embora em menor grau) à ação do mosquito. Assim, a contribuição dessas duas novas categorias (isto é, $\left(1-\varepsilon_{c}\right)\left(c_{l} l_{d}^{C}(t)+\right.$ $\left.\left.c_{y} y_{d}^{C}(t)\right)\right)$ devem ser somadas àquelas já descritas e que não utilizam a coleira. Logo, $c_{l} l_{d}(t)+c_{y} y_{d}(t)+\left(1-\varepsilon_{c}\right)\left(c_{l} l_{d}^{C}(t)+c_{y} y_{d}^{C}(t)\right)$. 


\section{Apêndice C - Descrição do cálculo dos pontos de equilíbrio}

Pelo aspecto biológico do sistema, temos que a população de humanos apenas adquire o parasita leishmania. Já a população de cães tanto adquire quanto transmite o parasita para a população de flebotomíneos. Por fim, a população de mosquitos adquire o parasita apenas pela população de cães (fonte de infecção), mas transmite para cães e humanos. Portanto, observamos que as densidades de equilíbrio da população de humanos depende diretamente dos equilíbrios da população de mosquitos. Sendo assim, nosso cálculo dos pontos de equilíbrio se inicia considerando as populações de cães e de mosquitos.

Devemos fazer aqui uma breve observação é com relação aos termos com atraso. Quando o sistema entra em estado de equilíbrio, o valor numérico de uma determinada categoria (por exemplo, $\left.l_{d}(t)\right) \tau$ dias atrás (em relação a um instante de tempo $t$ ) será o mesmo que o do próprio instante de tempo $t$. Assim, adotamos para o cálculo dos pontos de equilíbrio que $f(t-\tau)=f(t)$.

Uma segunda observação importante é que a dinâmica da doença na população de cães depende da categoria $s_{3}(t)$, que é a categoria dos mosquitos que transmite o parasita para esta população. Por outro lado, a dinâmica sobre a população de mosquitos depende da presença das fontes de infecção, em particular, das categorias $l_{d}(t), l_{d}^{C}(t), y_{d}(t)$ e $y_{d}^{C}(t)$. Portanto, para que possamos obter um único sistema composto por categorias de uma única população, devemos (1) descrever os pontos de equilíbrio das categorias $l_{d}(t), l_{d}^{C}(t)$, $y_{d}(t)$ e $y_{d}^{C}(t)$ em termos de $s_{3}(t)$, ou (2) obter os pontos de equilíbrio de $s_{3}(t)$ em termos de $l_{d}(t), l_{d}^{C}(t), y_{d}(t)$ e $y_{d}^{C}(t)$. Por uma mera questão de conveniência, optamos pelo primeiro método.

Assim, iniciaremos pela população de cães.

Pontos de equilíbrio referentes à população canina 
A população de cães é composta por 10 categorias (Eq. (12) a (21)). Porém, para determinar os pontos de equilíbrio não triviais devemos substituir uma das 10 equações pela condição:

$$
1=\mathbf{x}_{\mathbf{d}}+\mathbf{x}_{\mathbf{d}}^{\mathbf{C}}+\mathbf{l}_{\mathbf{d}}+\mathbf{l}_{\mathbf{d}}^{\mathrm{C}}+\mathbf{y}_{\mathbf{d}}+\mathbf{y}_{\mathbf{d}}^{\mathrm{C}}+\mathbf{z}_{\mathbf{d}}+\mathbf{z}_{\mathbf{d}}^{\mathrm{C}}+\mathbf{v}_{\mathbf{d}}+\mathbf{v}_{\mathbf{d}}^{\mathrm{C}}
$$

A Eq. (98) deve substituir qualquer uma das Eq. (12) a (21). Aqui, substituiremos a Eq. (12), por ser considerada a mais complexa entre as 10 equações.

A fim de simplificar os cálculos, vamos adotar que:

$$
\begin{aligned}
& a_{1}=\xi_{d}+\theta_{d}+r_{d}+\delta_{d}+\mu_{d}+\varphi_{d} \\
& a_{2}=f_{d}+c_{k} \psi_{d} \omega_{d} \\
& a_{3}=\xi_{d}+\zeta_{c}+u_{c}+\mu_{d}+r_{d}+\delta_{d}+\varphi_{d} \\
& a_{4}=\zeta_{c}+u_{c} \\
& a_{5}=f_{d}+\sigma_{d}+\alpha_{d}+\mu_{d}+\theta_{d}+\xi_{d}+\psi_{d} \omega_{d} \\
& a_{6}=f_{d}+\sigma_{d}+\alpha_{d}+\mu_{d}+\zeta_{c}+u_{c}+\xi_{d}+\psi_{d} \omega_{d} \\
& a_{7}=q_{d}+\gamma_{d}+\mu_{d}+\theta_{d}+\xi_{d} \\
& a_{8}=q_{d}+\gamma_{d}+\mu_{d}+\zeta_{c}+u c+\xi_{d} \\
& a_{9}=p_{d}+\mu_{d}+\xi_{d}+\theta_{d} \\
& a_{10}=p_{d}+\mu_{d}+u_{c}+\zeta_{c}+\xi_{d} \\
& a_{11}=\xi_{d}+\mu_{d} \\
& a_{12}=\left(1-c_{k}\right) \psi_{d} \omega_{d}
\end{aligned}
$$

Inicialmente, podemos determinar os pontos de equilíbrio $\mathbf{l}_{\mathbf{d}}, \mathbf{l}_{\mathbf{d}}^{\mathbf{C}}$ e $\mathbf{v}_{\mathbf{d}}$ diretamente das Eq. (16), (17) e (20). 


$$
\begin{aligned}
& \mathbf{l}_{\mathbf{d}}=\frac{a_{5} \mathbf{y}_{\mathbf{d}}-a_{4} \mathbf{y}_{\mathbf{d}}^{\mathbf{C}}}{\varphi_{d}} \\
& \mathbf{l}_{\mathbf{d}}^{\mathbf{C}}=\frac{a_{6} \mathbf{y}_{\mathbf{d}}^{\mathbf{C}}-\theta_{d} \mathbf{y}_{\mathbf{d}}}{\varphi_{d}} \\
& \mathbf{v}_{\mathbf{d}}=\frac{a_{4} \mathbf{v}_{\mathbf{d}}^{\mathbf{C}}+\varepsilon_{v} v_{d} \mathbf{x}_{\mathbf{d}}}{a_{9}}
\end{aligned}
$$

Substituindo Eq. (111), (112) e (113) sobre as demais equações, temos:

$$
\begin{aligned}
b_{1}= & f_{d}+\sigma_{d}+\alpha_{d}+\mu_{d}+\xi_{d}+\psi_{d} \omega_{d} \\
1= & \left(1+\frac{\varepsilon_{v} v_{d}}{a_{9}}\right) \mathbf{x}_{\mathbf{d}}+\mathbf{x}_{\mathbf{d}}^{\mathbf{C}}+\left(1+\frac{b_{1}}{\varphi_{d}}\right)\left(\mathbf{y}_{\mathbf{d}}+\mathbf{y}_{\mathbf{d}}^{\mathbf{C}}\right)+\mathbf{z}_{\mathbf{d}}+\mathbf{z}_{\mathbf{d}}^{\mathbf{C}}+\left(1+\frac{a_{4}}{a_{9}}\right) \mathbf{v}_{\mathbf{d}}^{\mathbf{C}} \\
0= & \theta_{d} \mathbf{x}_{\mathbf{d}}-\left(\left(1-\varepsilon_{c}\right) b_{d} a_{d} m_{d} \mathbf{s}_{\mathbf{3}}+\varepsilon_{v} v_{d}+a_{4}+\mu_{d}\right) \mathbf{x}_{\mathbf{d}}^{\mathbf{C}}-\frac{r_{d} \theta_{d}}{\varphi_{d}} \mathbf{y}_{\mathbf{d}} \\
& +\left(a_{12}+\frac{r_{d} a_{6}}{\varphi_{d}}\right) \mathbf{y}_{\mathbf{d}}^{\mathbf{C}}+\gamma_{d} \mathbf{z}_{\mathbf{d}}^{\mathbf{C}}+p_{d} \mathbf{v}_{\mathbf{d}}^{\mathbf{C}} \\
0= & b_{d} a_{d} m_{d} \mathbf{s}_{\mathbf{3}} \mathbf{x}_{\mathbf{d}}+\left(a_{2}-\frac{a_{5} a_{1}}{\varphi_{d}}-\frac{a_{4} \theta_{d}}{\varphi_{d}}\right) \mathbf{y}_{\mathbf{d}}+\left(\frac{a_{1} a_{4}}{\varphi_{d}}+\frac{a_{6} a_{4}}{\varphi_{d}}\right) \mathbf{y}_{\mathbf{d}}^{\mathbf{C}}+q_{d} \mathbf{z}_{\mathbf{d}} \\
0= & \left(1-\varepsilon_{c}\right) b_{d} a_{d} m_{d} \mathbf{s}_{\mathbf{3}} \mathbf{x}_{\mathbf{d}}^{\mathbf{C}}+\left(\frac{a_{5} \theta_{d}}{\varphi_{d}}+\frac{a_{3} \theta_{d}}{\varphi_{d}}\right) \mathbf{y}_{\mathbf{d}}+\left(a_{2}-\frac{a_{4} \theta_{d}}{\varphi_{d}}-\frac{a_{3} a_{6}}{\varphi_{d}}\right) \mathbf{y}_{\mathbf{d}}^{\mathbf{C}} \\
& +q_{d} \mathbf{z}_{\mathbf{d}}^{\mathbf{C}} \\
0= & \frac{\theta_{d} \varepsilon_{v} v_{d}}{a_{9}} \mathbf{x}_{\mathbf{d}}+\varepsilon_{v} v_{d} \mathbf{x}_{\mathbf{d}}^{\mathbf{C}}+\left(\frac{\theta_{d} a_{4}}{a_{9}}-a_{10}\right) \mathbf{v}_{\mathbf{d}}^{\mathbf{C}} \\
0= & \left(\frac{\delta_{d} a_{5}}{\varphi_{d}}+\sigma_{d}\right) \mathbf{y}_{\mathbf{d}}-\frac{\delta_{d} a_{4}}{\varphi_{d}} \mathbf{y}_{\mathbf{d}}^{\mathbf{C}}-a_{7} \mathbf{z}_{\mathbf{d}}+a_{4} \mathbf{z}_{\mathbf{d}}^{\mathbf{C}} \\
0 & \left(\frac{\delta_{d} a_{6}}{\varphi_{d}}+\sigma_{d}\right) \mathbf{y}_{\mathbf{d}}^{\mathbf{C}}-\frac{\delta_{d} \theta_{d}}{\varphi_{d}} \mathbf{y}_{\mathbf{d}}+\theta_{d} \mathbf{z}_{\mathbf{d}}-a_{8} \mathbf{z}_{\mathbf{d}}^{\mathbf{C}} \\
0 & \\
0 & \\
0 &
\end{aligned}
$$

Agora, com algumas manipulações algébricas, podemos isolar $\mathbf{z}_{\mathbf{d}}^{\mathbf{C}}$ e $\mathbf{v}_{\mathbf{d}}^{\mathbf{C}}$ das Eq. 
(120) e (121), respectivamente.

$$
\begin{aligned}
& \mathbf{v}_{\mathbf{d}}^{\mathbf{C}}=\frac{\varepsilon_{v} v_{d}\left(\theta_{d} \mathbf{x}_{\mathbf{d}}+\left(a_{11}+p_{d}+\theta_{d}\right) \mathbf{x}_{\mathbf{d}}^{\mathbf{C}}\right)}{\left(p_{d}+a_{11}\right)\left(a_{10}+\theta_{d}\right)} \\
& \mathbf{z}_{\mathbf{d}}^{\mathbf{C}}=\frac{\left(\delta_{d} a_{6}+\varphi_{d} \sigma_{d}\right) \mathbf{y}_{\mathbf{d}}^{\mathbf{C}}-\theta_{d} \delta_{d} \mathbf{y}_{\mathbf{d}}+\varphi_{d} \theta_{d} \mathbf{z}_{\mathbf{d}}}{\varphi_{d} a_{8}}
\end{aligned}
$$

Então, substituindo Eq. (122) e (123) nas Eq. (115) a (119), temos:

$$
\begin{aligned}
1= & \left(\frac{a_{9}+\varepsilon_{v} v_{d}}{a_{9}}+\frac{\left(a_{9}+\varepsilon_{v} v_{d}\right) \varepsilon_{v} v_{d} \theta_{d}}{a_{9}\left(p_{d}+a_{11}\right)\left(a_{10}+\theta_{d}\right)}\right) \mathbf{x}_{\mathbf{d}}+\frac{p_{d}+a_{1} 1+\varepsilon_{v} v_{d}}{p_{d}+a_{1} 1} \mathbf{x}_{\mathbf{d}}^{\mathbf{C}} \\
& +\left(\frac{\varphi_{d}+b_{1}}{\varphi_{d}}+\frac{\theta_{d} \delta_{d}}{\varphi_{d} a_{8}}\right) \mathbf{y}_{\mathbf{d}}+\left(\frac{\varphi_{d}+b_{1}}{\varphi_{d}}\right) \mathbf{y}_{\mathbf{d}}^{\mathbf{C}}+\left(\frac{a_{6} \delta_{d}+\varphi_{d} \sigma_{d}}{\varphi_{d} a_{8}}\right) \mathbf{y}_{\mathbf{d}}^{\mathbf{C}}+\left(\frac{a_{8}+\theta_{d}}{a_{8}}\right) \mathbf{z}_{\mathbf{d}} \\
0= & \frac{\theta_{d}\left(\left(p_{d}+a_{11}\right)\left(a_{10}+\theta_{d}\right)+p_{d} \varepsilon_{v} v_{d}\right)}{\left(p_{d}+a_{11}\right)\left(a_{10}+\theta_{d}\right)} \mathbf{x}_{\mathbf{d}}+\frac{p_{d} \varepsilon_{v} v_{d} a_{9}}{\left(p_{d}+a_{11}\right)\left(a_{10}+\theta_{d}\right)} \mathbf{x}_{\mathbf{d}}^{\mathbf{C}} \\
& -\left(\left(1-\varepsilon_{c}\right) b_{d} a_{d} m_{d} \mathbf{s}_{\mathbf{3}}+\varepsilon_{v} v_{d}+\mu_{d}+a_{4}\right) \mathbf{x}_{\mathbf{d}}^{\mathbf{C}}-\frac{\theta_{d}\left(a_{8} r_{d}+\gamma_{d} \delta_{d}\right)}{\varphi_{d} a_{8}} \mathbf{y}_{\mathbf{d}} \\
& +\left(\frac{\gamma_{d}\left(a_{6} \delta_{d}+\varphi_{d} \sigma_{d}\right)}{\varphi_{d} a_{8}}+\frac{a_{1} 2 \varphi_{d}+r d a_{6}}{\varphi_{d}}\right) \mathbf{y}_{\mathbf{d}}^{\mathbf{C}}+\frac{\gamma_{d} \varphi_{d} \theta_{d}}{\varphi_{d} a_{8}} \mathbf{z}_{\mathbf{d}} \\
0 & b_{d} a_{d} m_{d} \mathbf{s}_{\mathbf{3}} \mathbf{x}_{\mathbf{d}}+\left(a_{2}-\frac{\left(a_{5} a_{1}-a_{4} \theta_{d}\right)}{\varphi_{d}}\right) \mathbf{y}_{\mathbf{d}}+\frac{a_{4}\left(a_{6}+a_{1}\right)}{\varphi_{d}} \mathbf{y}_{\mathbf{d}}^{\mathbf{C}}+q_{d} \mathbf{z}_{\mathbf{d}} \\
0= & \left(1-\varepsilon_{c}\right) b_{d} a_{d} m_{d} \mathbf{s}_{\mathbf{3}} \mathbf{x}_{\mathbf{d}}^{\mathbf{C}}+\left(\frac{\left(a_{6}+a_{1}\right) \theta_{d}}{\varphi_{d}}-\frac{q_{d} \delta_{d} \theta_{d}}{\varphi_{d} a_{8}}\right) \mathbf{y}_{\mathbf{d}} \\
& +\left(a_{2} y_{d}^{C}-\frac{a_{4} \theta_{d}}{\varphi_{d}}-\frac{a_{3} a_{6}}{\varphi_{d}}+\frac{\left(a_{6} \delta_{d}+\varphi_{d} \sigma_{d}\right) q_{d}}{\varphi_{d} a_{8}}\right) \mathbf{y}_{\mathbf{d}}^{\mathbf{C}}+\frac{q_{d} \theta_{d}}{a_{8}} \mathbf{z}_{\mathbf{d}} \\
0= & \left(\frac{\delta_{d} a_{5}+\varphi_{d} \sigma_{d}}{\varphi_{d}}-\frac{a_{4} \theta_{d} \delta_{d}}{\varphi_{d} a_{8}}\right) \mathbf{y}_{\mathbf{d}}+\frac{\left(c_{1} \delta_{d}+\varphi_{d} \sigma_{d}\right) a_{4}}{\varphi_{d} a_{8}} \mathbf{y}_{\mathbf{d}}^{\mathbf{C}}+\left(\frac{a_{4} \theta_{d}}{a_{8}}-a_{7}\right) \mathbf{z}_{\mathbf{d}} \\
0 & (128)) \\
0 & \\
0 &
\end{aligned}
$$

A partir da Eq. (128), podemos isolar $\mathbf{z}_{\mathbf{d}}$.

$$
\begin{aligned}
& c_{1}=f_{d}+\sigma_{d}+\alpha_{d}+\psi_{d} \omega_{d}-q_{d}-\gamma_{d} \\
& \mathbf{z}_{\mathbf{d}}=\frac{\left(\delta_{d} a_{5}+\varphi_{d} \sigma_{d}\right) a_{8}-a_{4} \theta_{d} \delta_{d}}{\left(a_{7} a_{8}-a_{4} \theta_{d}\right) \varphi_{d}} \mathbf{y}_{\mathbf{d}}+\frac{\left(c_{1} \delta_{d}+\varphi_{d} \sigma_{d}\right) a_{4}}{\left(a_{7} a_{8}-a_{4} \theta_{d}\right) \varphi_{d}} \mathbf{y}_{\mathbf{d}}^{\mathbf{C}}
\end{aligned}
$$


Antes de prosseguirmos, vamos renomear os termos:

$$
\begin{aligned}
& d_{1}=\left(\left(a_{6}+a_{1}\right) a_{8}-q_{d} \delta_{d}+\frac{q_{d}\left(\left(\delta_{d} a_{5}+\varphi_{d} \sigma_{d}\right) a_{8}-a_{4} \theta_{d} \delta_{d}\right)}{a_{7} a_{8}-a_{4} \theta_{d}}\right)\left(\frac{\theta_{d}}{\varphi_{d} a_{8}}\right) \\
& d_{2}=\left(a_{2} \varphi_{d}-a_{4} \theta_{d}-a_{3} a_{6}\right) a_{8}+\left(a_{6} \delta_{d}+\varphi_{d} \sigma_{d}\right) q_{d} \varphi_{d} a_{8} \\
& +\frac{q_{d} \theta_{d}\left(c_{1} \delta_{d}+\varphi_{d} \sigma_{d}\right) a_{4}}{a_{8}\left(a_{7} a_{8}-a_{4} \theta_{d}\right) \varphi_{d}} \\
& d_{3}=\frac{a_{9}+\varepsilon_{v} v_{d}}{a_{9}}+\frac{\left(a_{9}+\varepsilon_{v} v_{d}\right) \varepsilon_{v} v_{d} \theta_{d}}{a_{9}\left(p_{d}+a_{11}\right)\left(a_{10}+\theta_{d}\right)} \\
& d_{4}=\frac{p_{d}+a_{11}+\varepsilon_{v} v_{d}}{p_{d}+a_{11}} \\
& d_{5}=\frac{\varphi_{d}+b_{1}}{\varphi_{d}}+\frac{\theta_{d} \delta_{d}}{\varphi_{d} a_{8}}+\frac{\left(a_{8}+\theta_{d}\right)\left(\delta_{d} a_{5}+\varphi_{d} \sigma_{d}\right)}{\varphi_{d}\left(a_{7} a_{8}-a_{4} \theta_{d}\right)} \\
& -\frac{\left(\zeta_{c}+u_{c}\right) \theta_{d} \delta_{d}\left(a_{8}+\theta_{d}\right)}{\varphi_{d} a_{8}\left(a_{7} a_{8}-\left(\zeta_{c}+u c\right) \theta_{d}\right)} \\
& d_{6}=\frac{\left(\varphi_{d}+b_{1}\right) a_{8}}{\varphi_{d} a_{8}}+\frac{a_{6} \delta_{d}+\varphi_{d} \sigma_{d}}{\varphi_{d} a_{8}}+\frac{\left(a_{8}+\theta_{d}\right) a_{4}\left(c_{1} \delta_{d}+\varphi_{d} \sigma_{d}\right)}{a_{8}\left(a_{7} a_{8}-a_{4} \theta_{d}\right) \varphi_{d}} \\
& d_{7}=\frac{\theta_{d}\left(\left(p_{d}+a_{11}\right)\left(a_{10}+\theta_{d}\right)+p_{d} \varepsilon_{v} v_{d}\right)}{\left(p_{d}+a_{11}\right)\left(a_{1} 0+\theta_{d}\right)} \\
& d_{8}=\frac{p_{d} \varepsilon_{v} v_{d} a_{9}}{\left(p_{d}+a_{11}\right)\left(a_{10}+\theta_{d}\right)}-\varepsilon_{v} v_{d}-a_{4}-\mu_{d} \\
& d_{9}=\frac{\gamma_{d} \theta_{d}\left(\delta_{d} a_{5}+\varphi_{d} \sigma_{d}\right)}{\left(a_{7} a_{8}-a_{4} \theta_{d}\right) \varphi_{d}}-\frac{\gamma_{d} \theta_{d}\left(\zeta_{c}+u_{c}\right) \theta_{d} \delta_{d}}{a_{8}\left(a_{7} a_{8}-a_{4} \theta_{d}\right) \varphi_{d}}-\frac{\theta_{d}\left(a_{8} r_{d}+\gamma_{d} \delta_{d}\right)}{\varphi_{d} a_{8}} \\
& d_{10}=\frac{\gamma_{d}\left(a_{6} \delta_{d}+\varphi_{d} \sigma_{d}\right)}{\varphi_{d} a_{8}}+\frac{\left(1-c_{k}\right) \psi_{d} \omega_{d} \varphi_{d}+r d a_{6}}{\varphi_{d}} \\
& +\frac{\gamma_{d} \theta_{d}\left(c_{1} \delta_{d}+\varphi_{d} \sigma_{d}\right)\left(\zeta_{c}+u c\right)}{a_{8}\left(a_{7} a_{8}-a_{4} \theta_{d}\right) \varphi_{d}} \\
& d_{11}=a_{2}-\frac{a_{5} a_{1}}{\varphi_{d}}-\frac{a_{4} \theta_{d}}{\varphi_{d}}+\frac{q_{d}\left(\delta_{d} a_{5}+\varphi_{d} \sigma_{d}\right) a_{8}}{\left(a_{7}-a_{4} \theta_{d}\right) \varphi_{d}}-\frac{q_{d} a_{4} \theta_{d} \delta_{d}}{\left(a_{7}-a_{4} \theta_{d}\right) \varphi_{d}} \\
& d_{12}=\frac{\left(a_{6}+a_{1}\right) a_{4}}{\varphi_{d}}+\frac{q_{d}\left(c_{1} \delta_{d}+\varphi_{d} \sigma_{d}\right) a_{4}}{\left(a_{7} a_{8}-a_{4} \theta_{d}\right) \varphi_{d}}
\end{aligned}
$$


Substituindo Eq. (130) nas Eq. (124), (125), (126) e (127), temos:

$$
\begin{aligned}
& 1=d_{3} \mathbf{x}_{\mathbf{d}}+d_{4} \mathbf{x}_{\mathbf{d}}^{\mathbf{C}}+d_{5} \mathbf{y}_{\mathbf{d}}+d_{6} \mathbf{y}_{\mathbf{d}}^{\mathbf{C}} \\
& 0=d_{7} \mathbf{x}_{\mathbf{d}}+\left(d_{8}-\left(1-\varepsilon_{c}\right) b_{d} a_{d} m_{d} s_{3}\right) \mathbf{x}_{\mathbf{d}}^{\mathbf{C}}+d_{9} \mathbf{y}_{\mathbf{d}}+d_{10} \mathbf{y}_{\mathbf{d}}^{\mathbf{C}} \\
& 0=b_{d} a_{d} m_{d} \mathbf{x}_{\mathbf{d}}+d_{11} \mathbf{y}_{\mathbf{d}}+d_{12} \mathbf{y}_{\mathbf{d}}^{\mathbf{C}} \\
& 0=\left(1-\varepsilon_{c}\right) b_{d} a_{d} m_{d} \mathbf{S}_{3} \mathbf{x}_{\mathbf{d}}^{\mathbf{C}}+d_{1} \mathbf{y}_{\mathbf{d}}+d_{2} \mathbf{y}_{\mathbf{d}}^{\mathbf{C}}
\end{aligned}
$$

A partir da Eq. (146), podemos obter $\mathbf{y}_{\mathbf{d}}^{\mathbf{c}}$ :

$$
\mathbf{y}_{\mathbf{d}}^{\mathbf{C}}=-\frac{\left(1-\varepsilon_{c}\right) b_{d} a_{d} m_{d} \mathbf{s}_{3} \mathbf{x}_{\mathbf{d}}^{\mathbf{C}}+d_{1} \mathbf{y}_{\mathbf{d}}}{d_{2}}
$$

Substituindo Eq. (147) nas Eq. (143), (144) e (145), temos:

$$
\begin{aligned}
& 1=d_{3} \mathbf{x}_{\mathbf{d}}+d_{4} \mathbf{x}_{\mathbf{d}}^{\mathbf{C}}+\left(d_{5}-\frac{d_{6} d_{1}}{d_{2}}\right) \mathbf{y}_{\mathbf{d}}-\frac{d_{6}\left(1-\varepsilon_{c}\right) b_{d} a_{d} m_{d} \mathbf{s}_{\mathbf{3}}}{d_{2}} \mathbf{x}_{\mathbf{d}}^{\mathbf{C}} \\
& 0=d_{7} \mathbf{x}_{\mathbf{d}}+\left(d_{8}-\left(1+\frac{d_{10}}{d_{2}}\right)\left(1-\varepsilon_{c}\right) b_{d} a_{d} m_{d} \mathbf{s}_{3}\right) \mathbf{x}_{\mathbf{d}}^{\mathbf{C}}+\left(d_{9}-\frac{d_{10} d_{1}}{d_{2}}\right) \mathbf{y}_{\mathbf{d}} \\
& 0=b_{d} a_{d} m_{d} \mathbf{s}_{3} \mathbf{x}_{\mathbf{d}}+\left(d_{11}-\frac{d_{12} d_{1}}{d_{2}}\right) \mathbf{y}_{\mathbf{d}}-\frac{d_{12}}{d_{2}}\left(1-\varepsilon_{c}\right) b_{d} a_{d} m_{d} \mathbf{s}_{\mathbf{3}} \mathbf{x}_{\mathbf{d}}^{\mathbf{C}}
\end{aligned}
$$

A partir da Eq. (150), obtemos $\mathbf{y}_{\mathbf{d}}$ :

$$
\mathbf{y}_{\mathbf{d}}=\frac{\left(d_{12}\left(1-\varepsilon_{c}\right) \mathbf{x}_{\mathbf{d}}^{\mathbf{C}}-d_{2} \mathbf{x}_{\mathbf{d}}\right) b_{d} a_{d} m_{d} \mathbf{s}_{\mathbf{3}}}{d_{11} d_{2}-d_{12} d_{1}}
$$

Novamente, simplificaremos os termos:

$$
\begin{aligned}
& f_{1}=\frac{d_{5} d_{2}-d_{6} d_{1}}{d_{11} d_{2}-d_{12} d_{1}} \\
& f_{2}=\frac{\left(d_{5} d_{2}-d_{6} d_{1}\right) d_{12}}{d_{2}\left(d_{11} d_{2}-d_{12} d_{1}\right)}-\frac{d_{6}}{d_{2}}
\end{aligned}
$$




$$
\begin{aligned}
& f_{3}=\frac{d_{9} d_{2}-d_{10} d_{1}}{d_{11} d_{2}-d_{12} d_{1}} \\
& f_{4}=\frac{\left(d_{9} d_{2}-d_{10} d_{1}\right) d_{12}}{d_{2}\left(d_{11} d_{2}-d_{12} d_{1}\right)}-1-\frac{d_{10}}{d_{2}}
\end{aligned}
$$

Portanto, substituindo Eq. (151) nas Eq. (148) e (149), obtemos:

$$
\begin{aligned}
& 1=\left(d_{3}-f_{1} b_{d} a_{d} m_{d} \mathbf{s}_{3}\right) \mathbf{x}_{\mathbf{d}}+\left(d_{4}+f_{2}\left(1-\varepsilon_{c}\right) b_{d} a_{d} m_{d} \mathbf{s}_{\mathbf{3}}\right) \mathbf{x}_{\mathbf{d}}^{\mathbf{C}} \\
& 0=\left(d_{7}-f_{3} b_{d} a_{d} m_{d} \mathbf{s}_{3}\right) \mathbf{x}_{\mathbf{d}}+\left(d_{8}+f_{4}\left(1-\varepsilon_{c}\right) b_{d} a_{d} m_{d} \mathbf{s}_{3}\right) \mathbf{x}_{\mathbf{d}}^{\mathbf{C}}
\end{aligned}
$$

A partir das Eq. (156) e (157), pode-se obter todos os pontos de equilíbrio das categorias da população de cães em termos dos parâmetros e do ponto de equilíbrio da categoria $\mathbf{s}_{\mathbf{3}}$. Portanto, obtemos (Eq. (30) e (31)):

$$
\begin{aligned}
& \mathbf{x}_{\mathbf{d}}^{\mathbf{C}}=\frac{d_{7}-f_{3} b_{d} a_{d} m_{d} \mathbf{s}_{\mathbf{3}}}{g_{1}\left(b_{d} a_{d} m_{d}\right)^{2} \mathbf{s}_{\mathbf{3}}^{2}+g_{2} b_{d} a_{d} m_{d} \mathbf{s}_{\mathbf{3}}+g_{3}} \\
& \mathbf{x}_{\mathbf{d}}=-\frac{d_{8}+f_{4}\left(1-\varepsilon_{c}\right) b_{d} a_{d} m_{d} \mathbf{s}_{\mathbf{3}}}{g_{1}\left(b_{d} a_{d} m_{d}\right)^{2} \mathbf{s}_{\mathbf{3}}{ }^{2}+g_{2} b_{d} a_{d} m_{d} \mathbf{s}_{\mathbf{3}}+g_{3}}
\end{aligned}
$$

onde:

$$
\begin{aligned}
& g_{1}=\left(f_{1} f_{4}-f_{2} f_{3}\right)\left(1-\varepsilon_{c}\right) \\
& g_{2}=\left(f_{2} d_{7}-d_{3} f_{4}\right)\left(1-\varepsilon_{c}\right)+f_{1} d_{8}-d_{4} f_{3} \\
& g_{3}=d_{4} d_{7}-d_{3} d_{8}
\end{aligned}
$$

As categorias $\mathbf{y}_{\mathbf{d}}$ e $\mathbf{y}_{\mathbf{d}}^{\mathbf{C}}$ passam a ser (Eq. (32) e (33)):

$$
\mathbf{y}_{\mathbf{d}}=\left(\frac{h_{1}+h_{2}\left(1-\varepsilon_{c}\right) b_{d} a_{d} m_{d} \mathbf{s}_{\mathbf{3}}}{h_{3}\left(g_{1}\left(b_{d} a_{d} m_{d}\right)^{2} \mathbf{s}_{\mathbf{3}}^{2}+g_{2} b_{d} a_{d} m_{d} \mathbf{s}_{\mathbf{3}}+g_{3}\right)}\right) b_{d} a_{d} m_{d} \mathbf{S}_{\mathbf{3}}
$$




$$
\mathbf{y}_{\mathbf{d}}^{\mathbf{C}}=-\left(\frac{d_{1} h_{1}+h_{3}\left(1-\varepsilon_{c}\right) d_{7}+\left(d_{1} h_{2}-h_{3} f_{3}\right)\left(1-\varepsilon_{c}\right) b_{d} a_{d} m_{d} \mathbf{s}_{\mathbf{3}}}{d_{2} h_{3}\left(g_{1}\left(b_{d} a_{d} m d\right)^{2} \mathbf{s}_{\mathbf{3}}^{2}+g_{2} b_{d} a_{d} m_{d} \mathbf{s}_{\mathbf{3}}+g_{3}\right)}\right) b_{d} a_{d} m_{d} \mathbf{s}_{\mathbf{3}}
$$

onde:

$$
\begin{aligned}
& h_{1}=d_{12} d_{7}\left(1-\varepsilon_{c}\right)+d_{8} d_{2} \\
& h_{2}=f_{4} d_{2}-f_{3} d_{12} \\
& h_{3}=d_{11} d_{2}-d_{12} d_{1}
\end{aligned}
$$

A categoria $\mathbf{z}_{\mathbf{d}}$ se torna (Eq. (34)):

$$
\mathbf{z}_{\mathbf{d}}=\left(\frac{j_{2}+j_{3}\left(1-\varepsilon_{c}\right) b_{d} a_{d} m_{d} \mathbf{s}_{\mathbf{3}}}{j_{1}\left(g_{1}\left(b_{d} a_{d} m_{d}\right)^{2} \mathbf{s}_{\mathbf{3}}^{2}+g_{2} b_{d} a_{d} m_{d} \mathbf{s}_{\mathbf{3}}+g_{3}\right)}\right) b_{d} a_{d} m d \mathbf{s}_{\mathbf{3}}
$$

onde:

$$
\begin{aligned}
j_{1}= & \left(a_{7} a_{8}-a_{4} \theta_{d}\right) v a r p h i_{d} d_{2} h_{3} \\
j_{2}= & \left(\left(\delta_{d} a_{5}+\varphi_{d} \sigma_{d}\right) a_{8}-a_{4} \theta_{d} \delta_{d}\right) d_{2} h_{1} \\
& -\left(c_{1} \delta_{d}+\varphi_{d} \sigma_{d}\right) a_{4}\left(d_{1} h_{1}+h_{3}\left(1-\varepsilon_{c}\right) d_{7}\right) \\
j_{3}= & \left(\left(\delta_{d} a_{5}+\varphi_{d} \sigma_{d}\right) a_{8}-a_{4} \theta_{d} \delta_{d}-\left(c_{1} \delta_{d}+\varphi_{d} \sigma_{d}\right) a_{4}\left(d_{1} h_{2}-h_{3} f_{3}\right)\right) d_{2} h_{2}
\end{aligned}
$$

$\operatorname{Para} \mathbf{z}_{\mathbf{d}}^{\mathbf{C}}$, temos (Eq. (35)):

$$
\mathbf{z}_{\mathbf{d}}^{\mathbf{C}}=\left(\frac{k_{2}+k_{3}\left(1-\varepsilon_{c}\right) b_{d} a_{d} m d \mathbf{s}_{\mathbf{3}}}{k_{1}\left(g_{1}\left(b_{d} a_{d} m_{d}\right)^{2} \mathbf{s}_{\mathbf{3}}^{2}+g_{2} b_{d} a_{d} m_{d} \mathbf{s}_{\mathbf{3}}+g_{3}\right)}\right) b_{d} a_{d} m d \mathbf{s}_{\mathbf{3}}
$$

onde:

$$
\begin{aligned}
& k_{1}=\varphi_{d} a_{8} d_{2} h_{3} j_{1} \\
& k_{2}=d_{2}\left(h_{3} \varphi_{d} \theta_{d} j_{2}-j_{1} \theta_{d} \delta_{d} h_{1}\right)-j_{1}\left(a_{6} \delta_{d}+\varphi_{d} \sigma_{d}\right)\left(d_{1} h_{1}+h_{3}\left(1-\varepsilon_{c}\right) d_{7}\right)
\end{aligned}
$$


$k_{3}=d_{2}\left(h_{3} \varphi_{d} \theta_{d} j_{3}-j_{1} \theta_{d} \delta_{d} h_{2}\right)-j_{1}\left(a_{6} \delta_{d}+\varphi_{d} \sigma_{d}\right)\left(d_{1} h_{2}-h_{3} f_{3}\right)$

A categoria $\mathbf{v}_{\mathbf{d}}^{\mathbf{C}}$ (Eq. (39)):

$$
\mathbf{v}_{\mathbf{d}}^{\mathbf{C}}=\frac{l_{2}-l_{3} b_{d} a_{d} m_{d} \mathbf{s}_{\mathbf{3}}}{l_{1}\left(g_{1}\left(b_{d} a_{d} m_{d}\right)^{2} \mathbf{s}_{\mathbf{3}}^{2}+g_{2} b_{d} a_{d} m_{d} \mathbf{s}_{\mathbf{3}}+g_{3}\right)}
$$

onde:

$$
\begin{aligned}
& l_{1}=\left(p_{d}+a_{11}\right)\left(a_{10}+\theta_{d}\right) \\
& l_{2}=\varepsilon_{v} v_{d}\left(\left(a_{11}+p_{d}+\theta_{d}\right) d_{7}-\theta_{d} d_{8}\right) \\
& l_{3}=\varepsilon_{v} v_{d}\left(\theta_{d} f_{4}\left(1-\varepsilon_{c}\right)+\left(a_{11}+p_{d}+\theta_{d}\right) f_{3}\right)
\end{aligned}
$$

Para $\mathbf{l}_{\mathbf{d}}$ (Eq. (37)):

$$
\mathbf{l}_{\mathbf{d}}=\left(\frac{m_{2}+m_{3}\left(1-\varepsilon_{c}\right) b_{d} a_{d} m_{d} \mathbf{s}_{\mathbf{3}}}{m_{1}\left(g_{1}\left(b_{d} a_{d} m_{d}\right)^{2} \mathbf{s}_{\mathbf{3}}^{2}+g_{2} b_{d} a_{d} m_{d} \mathbf{s}_{\mathbf{3}}+g_{3}\right)}\right) b_{d} a_{d} m_{d} \mathbf{s}_{\mathbf{3}}
$$

onde:

$$
\begin{aligned}
& m_{1}=\varphi_{d} d_{2} h_{3} \\
& m_{2}=a_{5} d_{2} h_{1}+a_{4}\left(d_{1} h_{1}+h_{3}\left(1-\varepsilon_{c}\right) d_{7}\right) \\
& m_{3}=a_{5} d_{2} h_{2}+a_{4}\left(d_{1} h_{2}-h_{3} f_{3}\right)
\end{aligned}
$$

Para $\mathbf{l}_{\mathbf{d}}^{\mathbf{C}}$, temos (Eq. (38)):

$$
\mathbf{I}_{\mathbf{d}}^{\mathbf{C}}=-\left(\frac{n_{2}+n_{3}\left(1-\varepsilon_{c}\right) b_{d} a_{d} m_{d} \mathbf{s}_{\mathbf{3}}}{n_{1}\left(g_{1}\left(b_{d} a_{d} m_{d}\right)^{2} \mathbf{s}_{\mathbf{3}}^{2}+g_{2} b_{d} a_{d} m_{d} \mathbf{s}_{\mathbf{3}}+g_{3}\right)}\right) b_{d} a_{d} m_{d} \mathbf{s}_{\mathbf{3}}
$$

onde: 


$$
\begin{aligned}
& n_{1}=\varphi_{d} d_{2} h_{3} \\
& n_{2}=a_{6}\left(d_{1} h_{1}+h_{3}\left(1-\varepsilon_{c}\right) d_{7}\right)+\theta_{d} d_{2} h_{1} \\
& n_{3}=a_{6}\left(d_{1} h_{2}-h_{3} f_{3}\right)+\theta_{d} d_{2} h_{2}
\end{aligned}
$$

Finalmente, para $\mathbf{v}_{\mathbf{d}}^{\mathbf{C}}$ (Eq. (39)):

$$
\mathbf{v}_{\mathbf{d}}^{\mathbf{C}}=\frac{a_{4} l_{2}-\varepsilon_{v} v_{d} l_{1} d_{8}-\left(a_{4} l_{3}+\varepsilon_{v} v_{d} l_{1} f_{4}\left(1-\varepsilon_{c}\right)\right) b_{d} a_{d} m_{d} \mathbf{s}_{\mathbf{3}}}{a_{9} l_{1}\left(g_{1}\left(b_{d} a_{d} m_{d}\right)^{2} \mathbf{s}_{\mathbf{3}}^{2}+g_{2} b_{d} a_{d} m_{d} \mathbf{s}_{\mathbf{3}}+g_{3}\right)}
$$

\section{Pontos de equilíbrio referentes à população de mosquitos}

A população de mosquitos é composta por três categorias, representadas pelas Eq. (23) a (25). Entretanto, para obtermos os pontos de equilíbrio não triviais, é necessário substituir uma dessas três equações pela condição:

$$
1=\mathbf{s}_{\mathbf{1}}+\mathbf{s}_{\mathbf{2}}+\mathbf{s}_{\mathbf{3}}
$$

A partir da Eq. (179), isolamos $\mathbf{S}_{\mathbf{2}}$ (Eq. (29)):

$$
\mathbf{s}_{\mathbf{2}}=1-\mathbf{s}_{\mathbf{1}}-\mathbf{s}_{\mathbf{3}}
$$

Substituindo $\mathbf{s}_{\mathbf{2}}$ presente nas Eq. (23) e (25) por (29), obtemos:

$$
\begin{aligned}
& 0=-a_{d}\left(c_{l} \mathbf{l}_{\mathbf{d}}+c_{y} \mathbf{y}_{\mathbf{d}}+\left(1-\varepsilon_{c}\right)\left(c_{l} \mathbf{l}_{\mathbf{d}}^{\mathbf{C}}+c_{y} \mathbf{y}_{\mathbf{d}}^{\mathbf{C}}\right)\right) \mathbf{s}_{\mathbf{1}}+\left(\mu_{s}+\xi_{s}\right)\left(1-\mathbf{s}_{\mathbf{1}}\right) \\
& 0=-\left(\mu_{s}+\xi_{s}\right) \mathbf{s}_{\mathbf{3}}+a_{d}\left(c_{l} \mathbf{l}_{\mathbf{d}}+c_{y} \mathbf{y}_{\mathbf{d}}+\left(1-\varepsilon_{c}\right)\left(c_{l} \mathbf{l}_{\mathbf{d}}^{\mathbf{C}}+c_{y} \mathbf{y}_{\mathbf{d}}^{\mathbf{C}}\right)\right) \mathbf{s}_{\mathbf{1}} e^{-\left(\mu_{s}+\xi_{s}\right) \tau}
\end{aligned}
$$

Note que as Eq. (180) e (181) estão desacopladas entre si. Assim podemos isolar $\mathbf{s}_{\mathbf{1}}$ e $\mathbf{s}_{\mathbf{3}}$ diretamente: 


$$
\begin{aligned}
& s_{1}=\frac{\mu_{s}+\xi_{s}}{a_{d}\left(c_{l} \mathbf{l}_{\mathbf{d}}+c_{y} \mathbf{y}_{\mathbf{d}}+\left(1-\varepsilon_{c}\right)\left(c_{l} \mathbf{l}_{\mathbf{d}}^{\mathbf{C}}+c_{y} \mathbf{y}_{\mathbf{d}}^{\mathbf{C}}\right)\right)+\mu_{s}+\xi_{s}} \\
& s_{3}=\frac{a_{d}\left(c_{l} \mathbf{l}_{\mathbf{d}}+c_{y} \mathbf{y}_{\mathbf{d}}+\left(1-\varepsilon_{c}\right)\left(c_{l} \mathbf{l}_{\mathbf{d}}^{\mathbf{C}}+c_{y} \mathbf{y}_{\mathbf{d}}^{\mathbf{C}}\right)\right) e^{-\left(\mu_{s}+\xi_{s}\right) \tau}}{a_{d}\left(c_{l} \mathbf{l}_{\mathbf{d}}+c_{y} \mathbf{y}_{\mathbf{d}}+\left(1-\varepsilon_{c}\right)\left(c_{l} \mathbf{l}_{\mathbf{d}}^{\mathbf{C}}+c_{y} \mathbf{y}_{\mathbf{d}}^{\mathbf{C}}\right)\right)+\mu_{s}+\xi_{s}}
\end{aligned}
$$

Porém, as Eq. (182) e (183) continuam vinculadas à população de cães por meio das categorias $l_{d}, y_{d}, l_{d}^{C}$ e $y_{d}^{C}$. Por outro lado (conforme já calculamos anteriormente) os pontos de equilíbrio dessas 4 categorias podem ser descritas em termos de $\mathbf{s}_{\mathbf{3}}$. Logo, adotando uma simplificação para os termos, obtemos:

$$
\begin{aligned}
p_{1}= & d_{2} h_{3} m_{1} n_{1} \\
p_{2}= & n_{1} d_{2}\left(c_{l} h_{3} m_{2}+c_{y} m_{1} h_{1}\right) \\
& -\left(1-\varepsilon_{c}\right) m_{1}\left(c_{l} d_{2} h_{3} n_{2}+c_{y} n_{1}\left(d_{1} h_{1}+h_{3}\left(1-\varepsilon_{c}\right) d_{7}\right)\right) \\
p_{3}= & \left(c_{l} h_{3} m_{3}+c_{y} m_{1} h_{2}\right) n_{1} d_{2}-\left(1-\varepsilon_{c}\right) m_{1}\left(c_{l} d_{2} h_{3} n_{3}+c_{y} n_{1}\left(d_{1} h_{2}-h_{3} f_{3}\right)\right) \\
c_{l} \mathbf{l}_{\mathbf{d}}+ & c_{y} \mathbf{y}_{\mathbf{d}}+\left(1-\varepsilon_{c}\right)\left(c_{l} \mathbf{l}_{\mathbf{d}}^{\mathbf{C}}+c_{y} \mathbf{y}_{\mathbf{d}}^{\mathbf{C}}\right)= \\
& \frac{\left(p_{2}+p_{3}\left(1-\varepsilon_{c}\right) b_{d} a_{d} m_{d} \mathbf{s}_{3}\right) b_{d} a_{d} m_{d} \mathbf{s}_{\mathbf{3}}}{p_{1}\left(g_{1}\left(b_{d} a_{d} m_{d}\right)^{2} \mathbf{s}_{3}^{2}+g_{2} b_{d} a_{d} m_{d} \mathbf{s}_{\mathbf{3}}+g_{3}\right)}
\end{aligned}
$$

Assim, reescrevendo as Eq. (182) e (183), obtemos (Eq. (28) e (188)):

$$
\begin{aligned}
\mathbf{s}_{\mathbf{1}}= & \frac{\left(\mu_{s}+\xi_{s}\right) p_{1}\left(g_{1}\left(b_{d} a_{d} m_{d}\right)^{2} \mathbf{s}_{\mathbf{3}}^{2}+g_{2} b_{d} a_{d} m_{d} \mathbf{s}_{\mathbf{3}}+g_{3}\right)}{q_{1} \mathbf{S}_{\mathbf{3}}^{2}+\left(p_{1}\left(\mu_{s}+\xi_{s}\right) g_{2}+a_{d} p_{2}\right) b_{d} a_{d} m_{d} \mathbf{s}_{\mathbf{3}}+p_{1}\left(\mu_{s}+\xi_{s}\right) g_{3}} \\
\mathbf{s}_{\mathbf{3}}= & \frac{a_{d}\left(\frac{\left(p_{2}+p_{3}\left(1-\varepsilon_{c}\right) b_{d} a_{d} m_{d} \mathbf{s}_{\mathbf{3}}\right) b_{d} a_{d} m_{d} \mathbf{s}_{\mathbf{3}}}{p_{1}\left(g_{1}\left(b_{d} a_{d} m_{d}\right)^{2} \mathbf{s}_{\mathbf{3}}^{2}+g_{2} b_{d} a_{d} m_{d} \mathbf{s}_{\mathbf{3}}+g_{3}\right)}\right) b_{d} a_{d} m_{d} \mathbf{s}_{\mathbf{3}} e^{-\left(\mu_{s}+\xi_{s}\right) \tau}}{a_{d}\left(\frac{\left(p_{2}+p_{3}\left(1-\varepsilon_{c}\right) b_{d} a_{d} m_{d} \mathbf{s}_{\mathbf{3}}\right) b_{d} a_{d} m_{d} \mathbf{s}_{\mathbf{3}}}{p_{1}\left(g_{1}\left(b_{d} a_{d} m_{d}\right)^{2} \mathbf{s}_{\mathbf{3}}{ }^{2}+g_{2} b_{d} a_{d} m_{d} \mathbf{s}_{\mathbf{3}}+g_{3}\right)}\right) b_{d} a_{d} m_{d} \mathbf{s}_{\mathbf{3}}+\left(\mu_{s}+\xi_{s}\right)}
\end{aligned}
$$

Finalmente, podemos calcular $\mathbf{s}_{\mathbf{3}}$ exclusivamente em termos dos parâmetros. Para tanto, para facilitar os cálculos, renomearemos os termos: 


$$
\begin{aligned}
& q_{1}=\left(a_{d} p_{3}\left(1-\varepsilon_{c}\right)+p_{1}\left(\mu_{s}+\xi_{s}\right) g_{1}\right)\left(b_{d} a_{d} m_{d}\right)^{2} \\
& q_{2}=\left(p_{1}\left(\mu_{s}+\xi_{s}\right) g_{2}+a_{d} p_{2}\right) b_{d} a_{d} m_{d}-a_{d} p_{3}\left(1-\varepsilon_{c}\right) e^{-\left(\mu_{s}+\xi_{s}\right) \tau}\left(b_{d} a_{d} m_{d}\right)^{2} \\
& q_{3}=p_{1}\left(\mu_{s}+\xi_{s}\right) g_{3}-p_{2} b_{d} a_{d}^{2} m_{d} e^{-\left(\mu_{s}+\xi_{s}\right) \tau}
\end{aligned}
$$

Assim, obtemos uma equação de segundo grau simples a partir da Eq. (188):

$$
0=q_{1} \mathbf{S}_{\mathbf{3}}^{2}+q_{2} \mathbf{S}_{\mathbf{3}}+q_{3}
$$

A raiz positiva da Eq. (192) equivale ao ponto de equilíbrio $\mathbf{s}_{\mathbf{3}}$ (Eq. (27)):

$$
\mathbf{s}_{\mathbf{3}}=\frac{-q_{2}-\sqrt{q_{2}^{2}-4 q_{1} q_{3}}}{2 q_{1}}
$$

Portanto, foram obtidas as expressões para o ponto fixo para as categorias das populações de cães e de mosquitos em termos dos parâmetros e de $\mathbf{s}_{3}$. Consequentemente, ao substituirmos o termo $\mathbf{s}_{\mathbf{3}}$ (nas Eq. (28) a (39)) pela expressão obtida na Eq. (27), obtemos todas os pontos fixos das respectivas categorias exclusivamente em termos dos parâmetros do modelo.

\section{Pontos de equilíbrio referentes à população humana}

Os pontos de equilíbrio das categorias referentes à população de humanos depende diretamente da população de mosquitos (em particular, $\mathbf{s}_{\mathbf{3}}$ ).

A dinâmica sobre a população de humanos é descrita pelas Eq. (1) a (4). Porém, para determinarmos os pontos de equilibrio não triviais, devemos substituir uma das 4 equações pela condição:

$$
1=\mathbf{x}_{\mathbf{h}}+\mathbf{y}_{\mathbf{h}}+\mathbf{l}_{\mathbf{h}}+\mathbf{z}_{\mathbf{h}}
$$


Por conveniência, substituiremos a Eq. (1) pela Eq. (193).

A partir da Eq. (3), podemos isolar $\mathbf{l}_{\mathbf{h}}$ (Eq. (43)):

$\mathbf{l}_{\mathbf{h}}=\frac{\left(\mu_{h}+\alpha_{h}+\sigma_{h}\right) \mathbf{y}_{\mathbf{h}}}{\varphi_{h}}$

Substituindo Eq. (43) em (2), (4) e (193), temos:

$$
\begin{aligned}
0 & =b_{h} a_{h} m_{h} \mathbf{s}_{\mathbf{3}} \mathbf{x}_{\mathbf{h}}-\frac{\left(\mu_{h}+r_{h}+\delta_{h}+\varphi_{h}\right)\left(\mu_{h}+\alpha_{h}+\sigma_{h}\right)}{\varphi_{h}} \mathbf{y}_{\mathbf{h}} \\
0 & =\left(\frac{\delta_{h}\left(\mu_{h}+\alpha_{h}+\sigma_{h}\right)+\varphi_{h} \sigma_{h}}{\varphi_{h}}\right) \mathbf{y}_{\mathbf{h}}-\left(\mu_{h}+\gamma_{h}\right) \mathbf{z}_{\mathbf{h}} \\
1 & =\mathbf{x}_{\mathbf{h}}+\left(\frac{\mu_{h}+\alpha_{h}+\sigma_{h}+\varphi_{h}}{\varphi_{h}}\right) \mathbf{y}_{\mathbf{h}}+\mathbf{z}_{\mathbf{h}}
\end{aligned}
$$

A partir da Eq. (195), determinamos $\mathbf{y}_{\mathbf{h}}$ (Eq. (42)):

$$
\mathbf{y}_{\mathbf{h}}=\frac{\varphi_{h}\left(\mu_{h}+\gamma_{h}\right)}{\left(\delta_{h}\left(\mu_{h}+\alpha_{h}+\sigma_{h}\right)+\varphi_{h} \sigma_{h}\right)} \mathbf{z}_{\mathbf{h}}
$$

E, substituindo Eq. (42) em (194) e (196), temos:

$$
\begin{aligned}
& 0=b_{h} a_{h} m_{h} \mathbf{s}_{3} \mathbf{x}_{\mathbf{h}}-\left(\frac{\left(\mu_{h}+r_{h}+\delta_{h}+\varphi_{h}\right)\left(\mu_{h}+\alpha_{h}+\sigma_{h}\right)\left(\mu_{h}+\gamma_{h}\right)}{\left(\delta_{h}\left(\mu_{h}+\alpha_{h}+\sigma_{h}\right)+\varphi_{h} \sigma_{h}\right)}\right) \mathbf{z}_{\mathbf{h}} \\
& 1=\mathbf{x}_{\mathbf{h}}+\left(\frac{\left(\mu_{h}+\alpha_{h}+\sigma_{h}+\varphi_{h}\right)\left(\mu_{h}+\gamma_{h}\right)}{\delta_{h}\left(\mu_{h}+\alpha_{h}+\sigma_{h}\right)+\varphi_{h} \sigma_{h}}+1\right) \mathbf{z}_{\mathbf{h}}
\end{aligned}
$$

A partir da Eq. (197), isolamos $\mathbf{z}_{\mathbf{h}}$ (Eq. (41)):

$$
\mathbf{z}_{\mathbf{h}}=\frac{\delta_{h}\left(\mu_{h}+\alpha_{h}+\sigma_{h}\right)+\varphi_{h} \sigma_{h}}{\left(\mu_{h}+r_{h}+\delta_{h}+\varphi_{h}\right)\left(\mu_{h}+\alpha_{h}+\sigma_{h}\right)\left(\mu_{h}+\gamma_{h}\right)} b_{h} a_{h} m_{h} \mathbf{s}_{3} \mathbf{x}_{\mathbf{h}}
$$

Simplificando o termo:

$$
r_{1}=\frac{\left(\mu_{h}+\alpha_{h}+\sigma_{h}+\varphi_{h}\right)\left(\mu_{h}+\gamma_{h}\right)+\delta_{h}\left(\mu_{h}+\alpha_{h}+\sigma_{h}\right)+\varphi_{h} \sigma_{h}}{\left(\mu_{h}+r_{h}+\delta_{h}+\varphi_{h}\right)\left(\mu_{h}+\alpha_{h}+\sigma_{h}\right)\left(\mu_{h}+\gamma_{h}\right)}
$$


Portanto, substituindo a Eq. (41) na Eq. (198), obtemos $\mathbf{x}_{\mathbf{h}}$ em termos de $\mathbf{x}_{\mathbf{3}}$ (Eq. (40)):

$$
\mathbf{x}_{\mathbf{h}}=\frac{1}{1+r_{1} b_{h} a_{h} m_{h} \mathbf{s}_{\mathbf{3}}}
$$

Conforme visto anteriormente, $\mathbf{s}_{\mathbf{3}}$ foi calculado explicitamente em termos dos parâmetros pela Eq. (27). Portanto, pela Eq. (40), $\mathbf{x}_{\mathbf{h}}$ também está determinado em termos dos parâmetros. Por consequência, as demais categorias da população humana $\left(\mathbf{l}_{\mathbf{h}}, \mathbf{y}_{\mathbf{h}}, \mathbf{z}_{\mathbf{h}}\right)$ também passam a estar determinados em termos dos parâmetros (isto é, substituindo o termo $\mathbf{s}_{\mathbf{3}}$ nas Eq. (40) a (43) pela Eq. (27)). 


\section{Apêndice D - Representação gráfica da análise de incerteza e sensibilidade}

Os gráficos a seguir representam os resultados das análises de incerteza e sensibilidade pelas técnicas LHS/PRCC e apresentam de forma mais detalhada os resultados sumarizados pela Tabela 9. Esta análise foi realizada considerando (1) os estados de equilíbrio das 17 variáveis de estado (na ausência das estratégias de controle, isto é, $\left.\xi_{d}=\theta_{d}=v_{d}=\omega_{d}=\xi_{d}=0\right),(2)$ a expressão do $\mathscr{R}_{0}$ e de suas componentes referentes à contribuição das categorias $l_{d}, y_{d}, l_{d}^{C}$ e $y_{d}^{C}$, e (3) a expressão referente ao número de casos humanos notificados por dia $(R)$. 


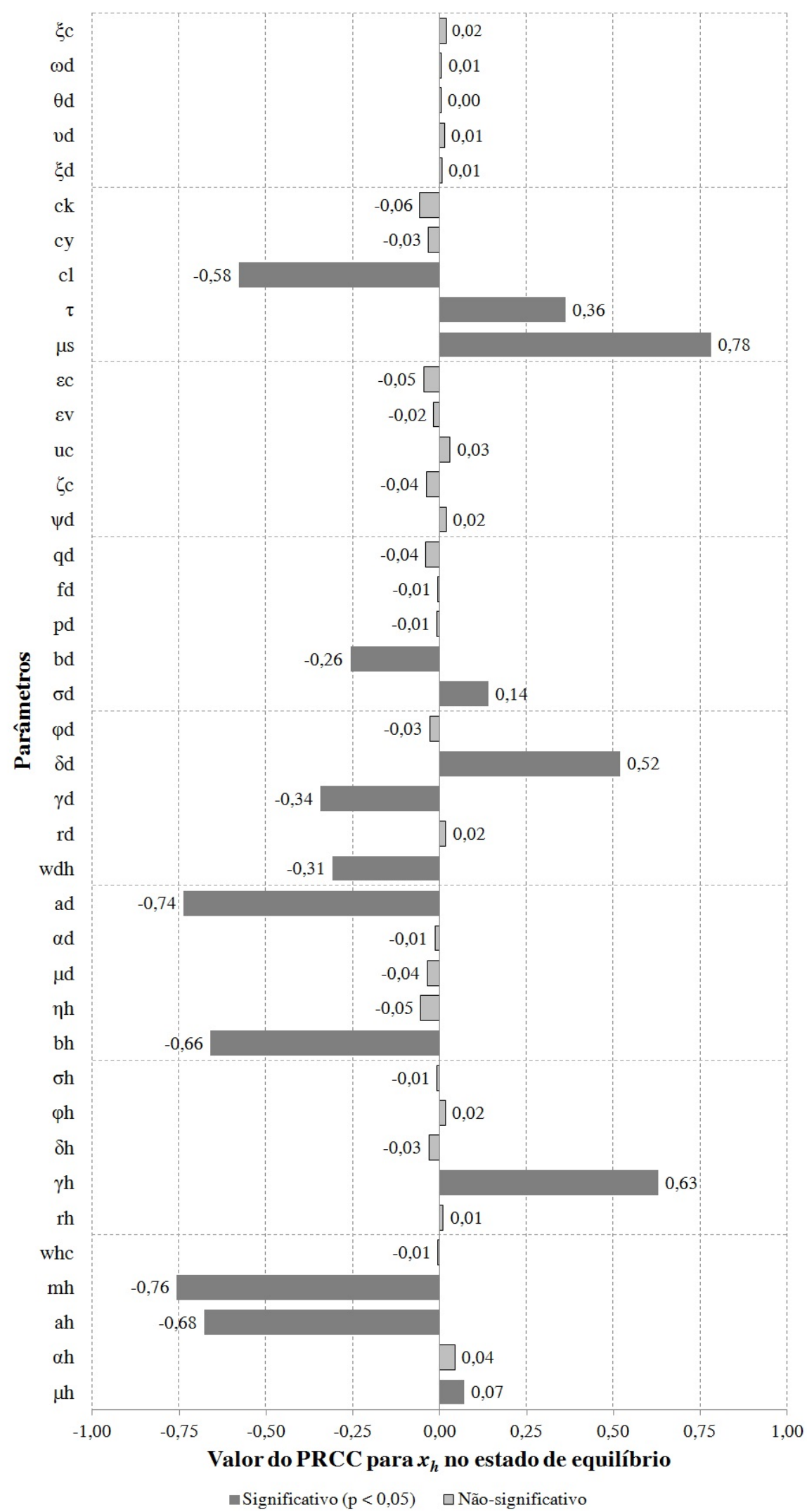

Figura 37 - Valores do PRCC para os parâmetros do modelo em relação à categoria $x_{h}$. Próximo de cada barra, há o valor de PRCC para os respectivos parâmetros. Os parâmetros significantes estão em cinza escuro. 


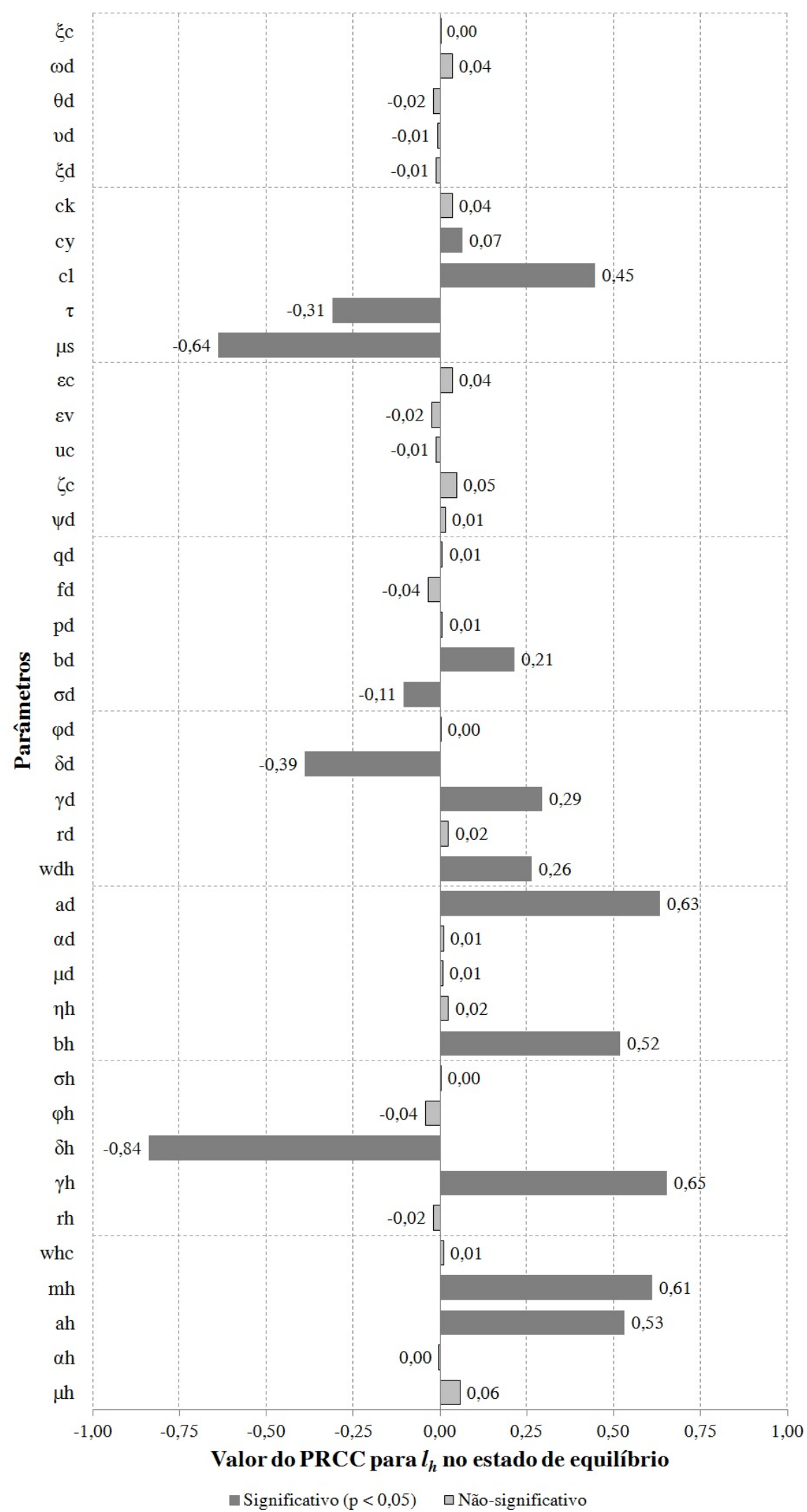

Figura 38 - Valores do PRCC para os parâmetros do modelo em relação à categoria $l_{h}$. Próximo de cada barra, há o valor de PRCC para os respectivos parâmetros. Os parâmetros significantes estão em cinza escuro. 


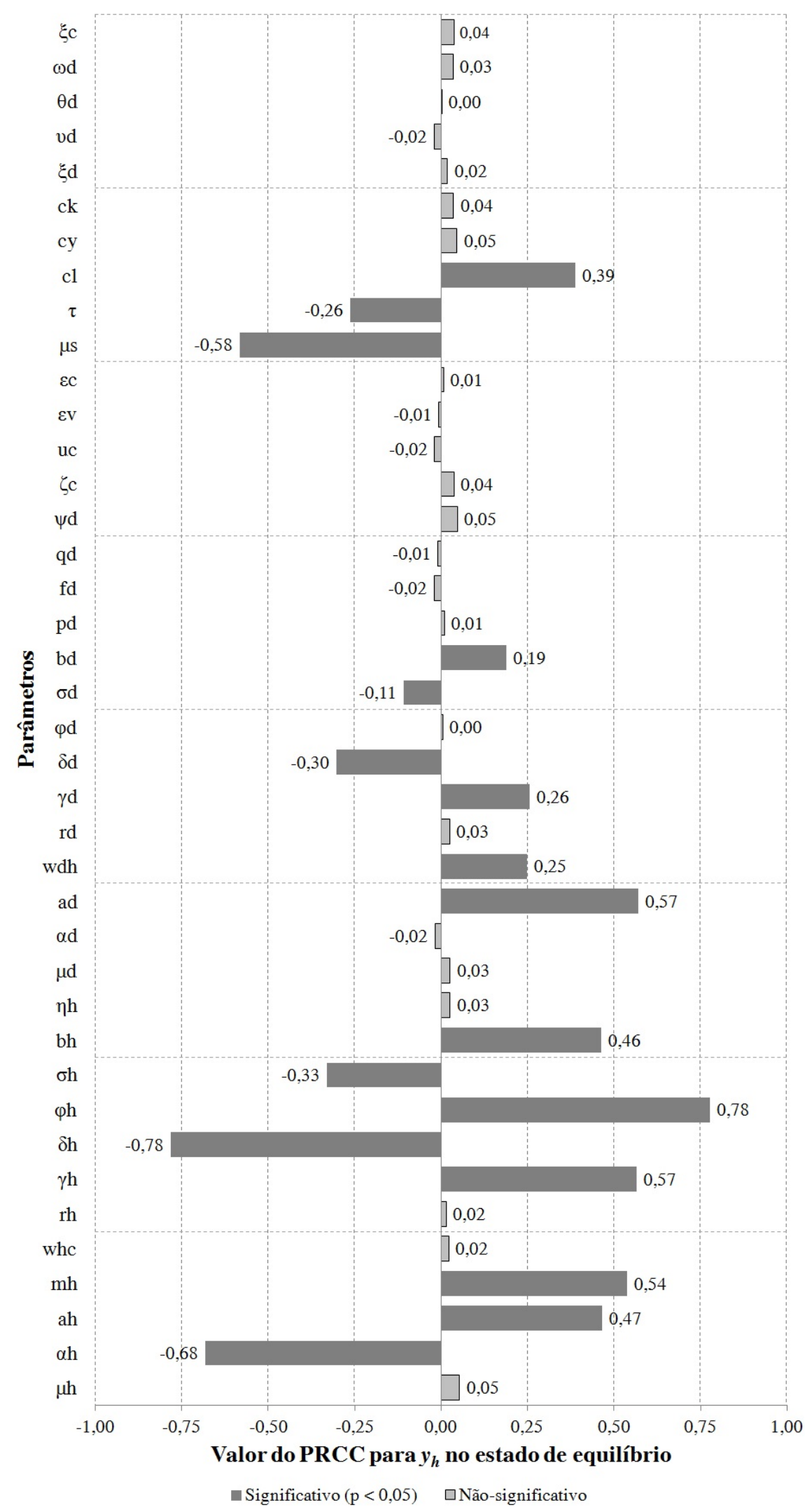

Figura 39 - Valores do PRCC para os parâmetros do modelo em relação à categoria $y_{h}$. Próximo de cada barra, há o valor de PRCC para os respectivos parâmetros. Os parâmetros significantes estão em cinza escuro. 


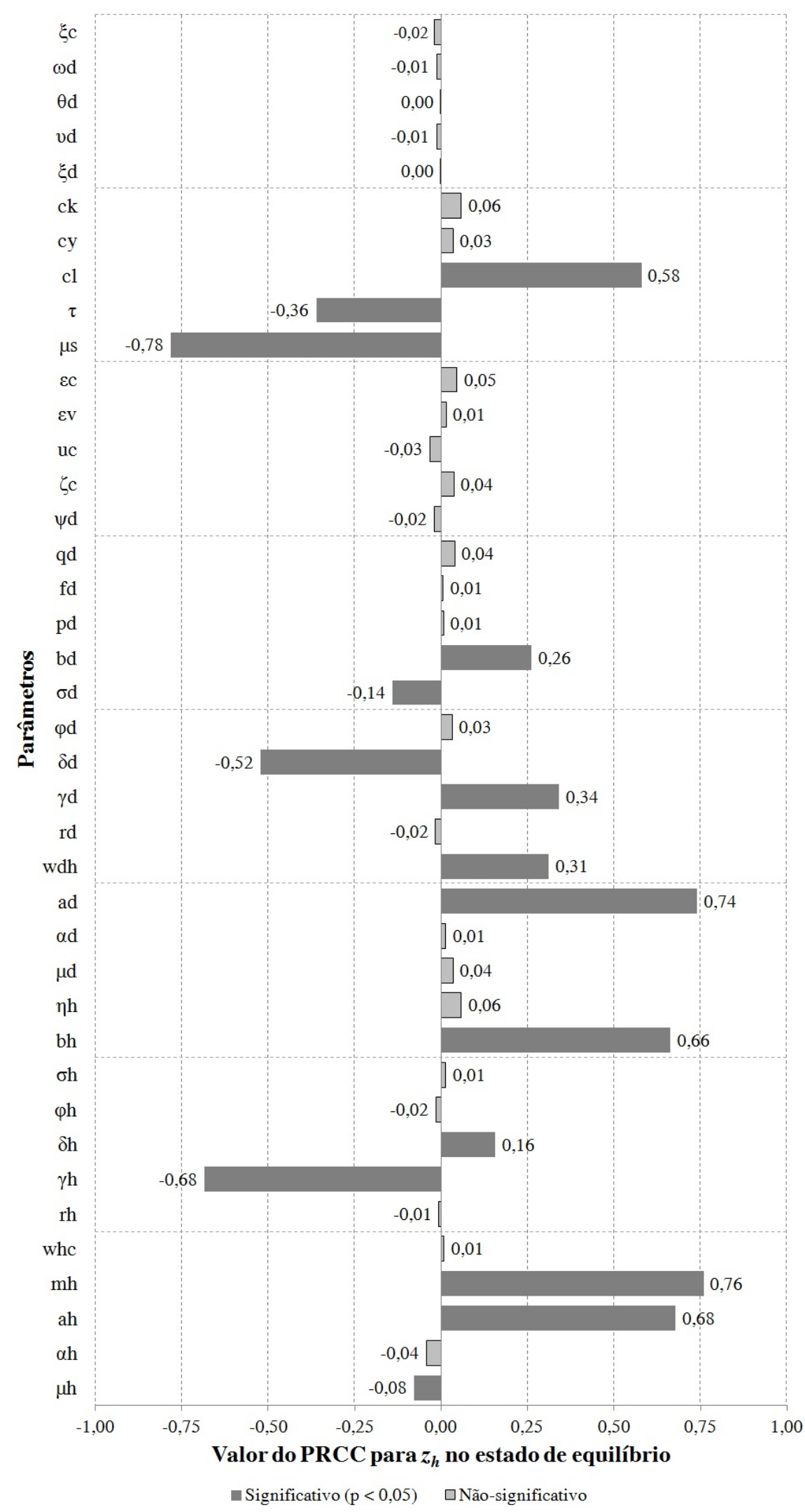

Figura 40 - Valores do PRCC para os parâmetros do modelo em relação à categoria $z_{h}$. Próximo de cada barra, há o valor de PRCC para os respectivos parâmetros. Os parâmetros significantes estão em cinza escuro. 


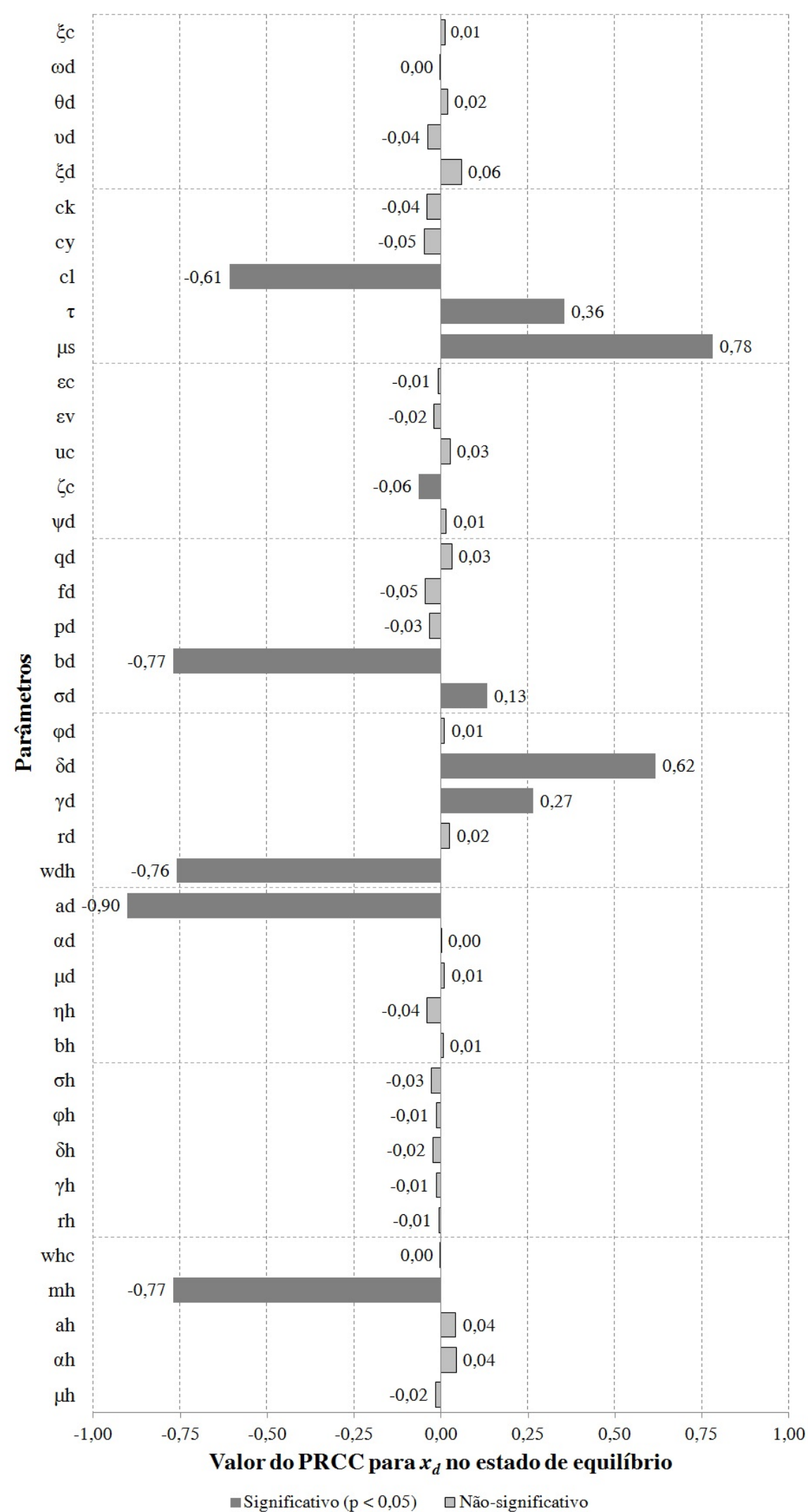

Figura 41 - Valores do PRCC para os parâmetros do modelo em relação à categoria $x_{d}$. Próximo de cada barra, há o valor de PRCC para os respectivos parâmetros. Os parâmetros significantes estão em cinza escuro. 


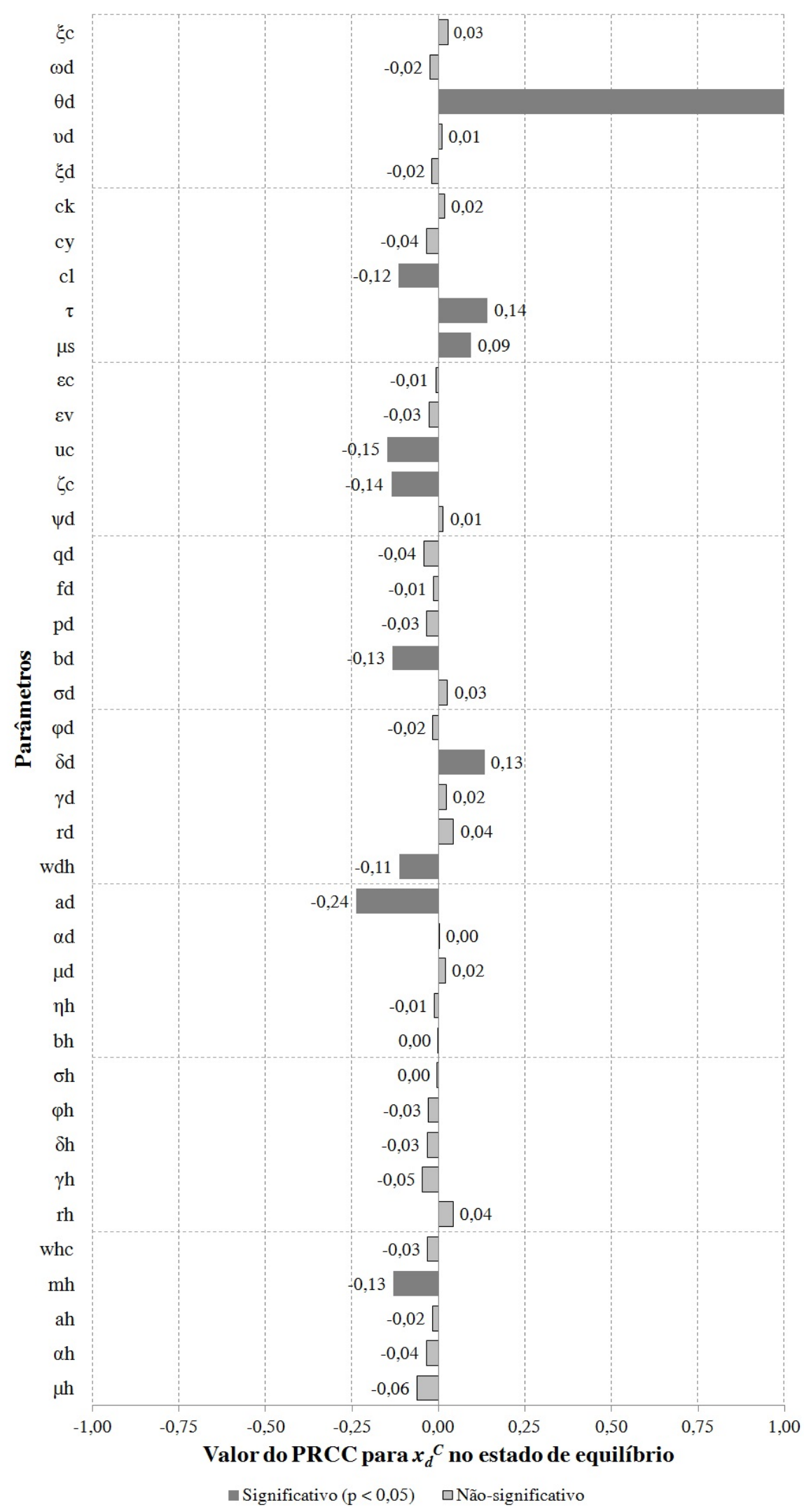

Figura 42 - Valores do PRCC para os parâmetros do modelo em relação à categoria $x_{d}^{C}$. Próximo de cada barra, há o valor de PRCC para os respectivos parâmetros. Os parâmetros significantes estão em cinza escuro. 


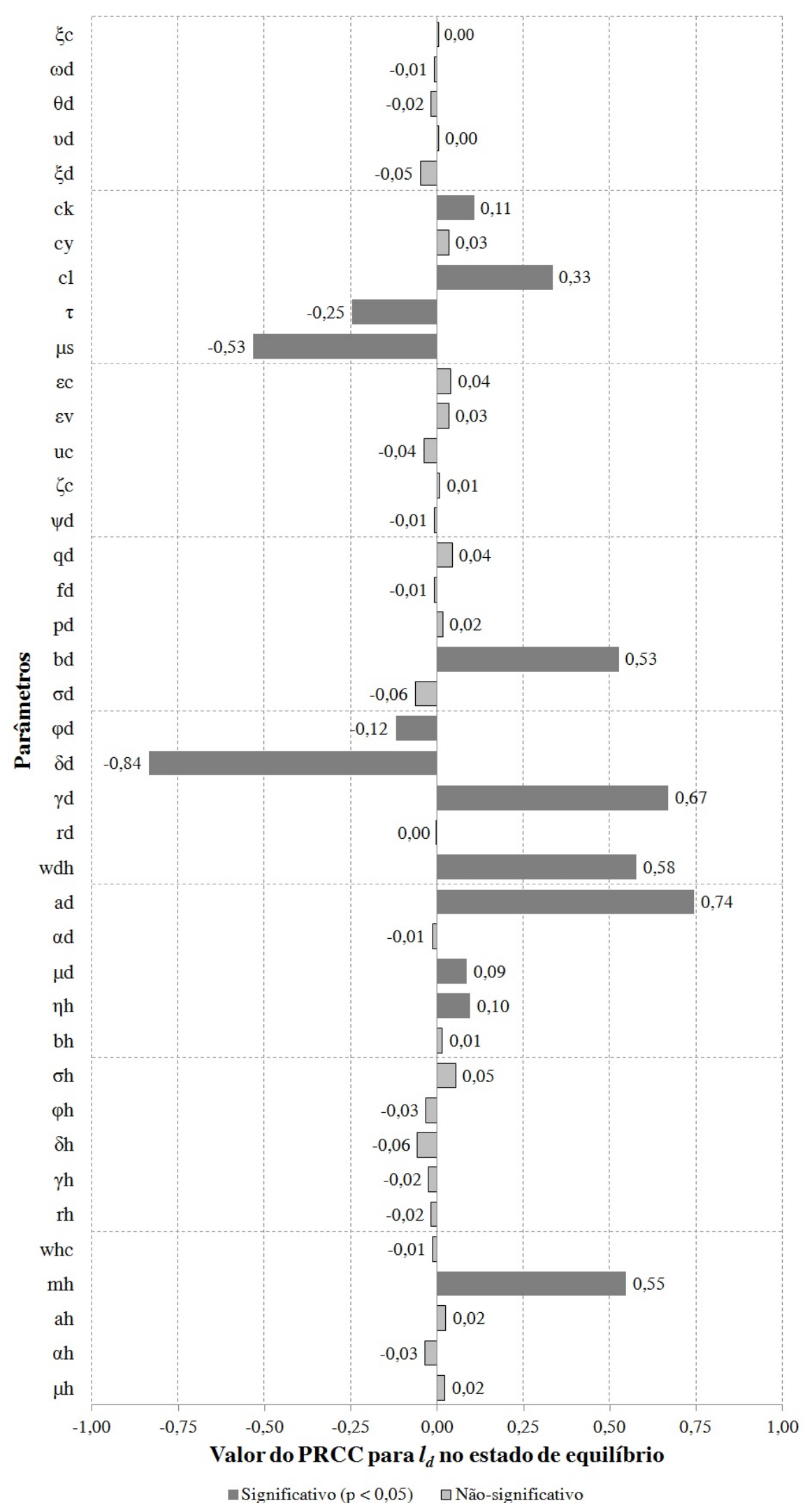

Figura 43 - Valores do PRCC para os parâmetros do modelo em relação à categoria $l_{d}$. Próximo de cada barra, há o valor de PRCC para os respectivos parâmetros. Os parâmetros significantes estão em cinza escuro. 


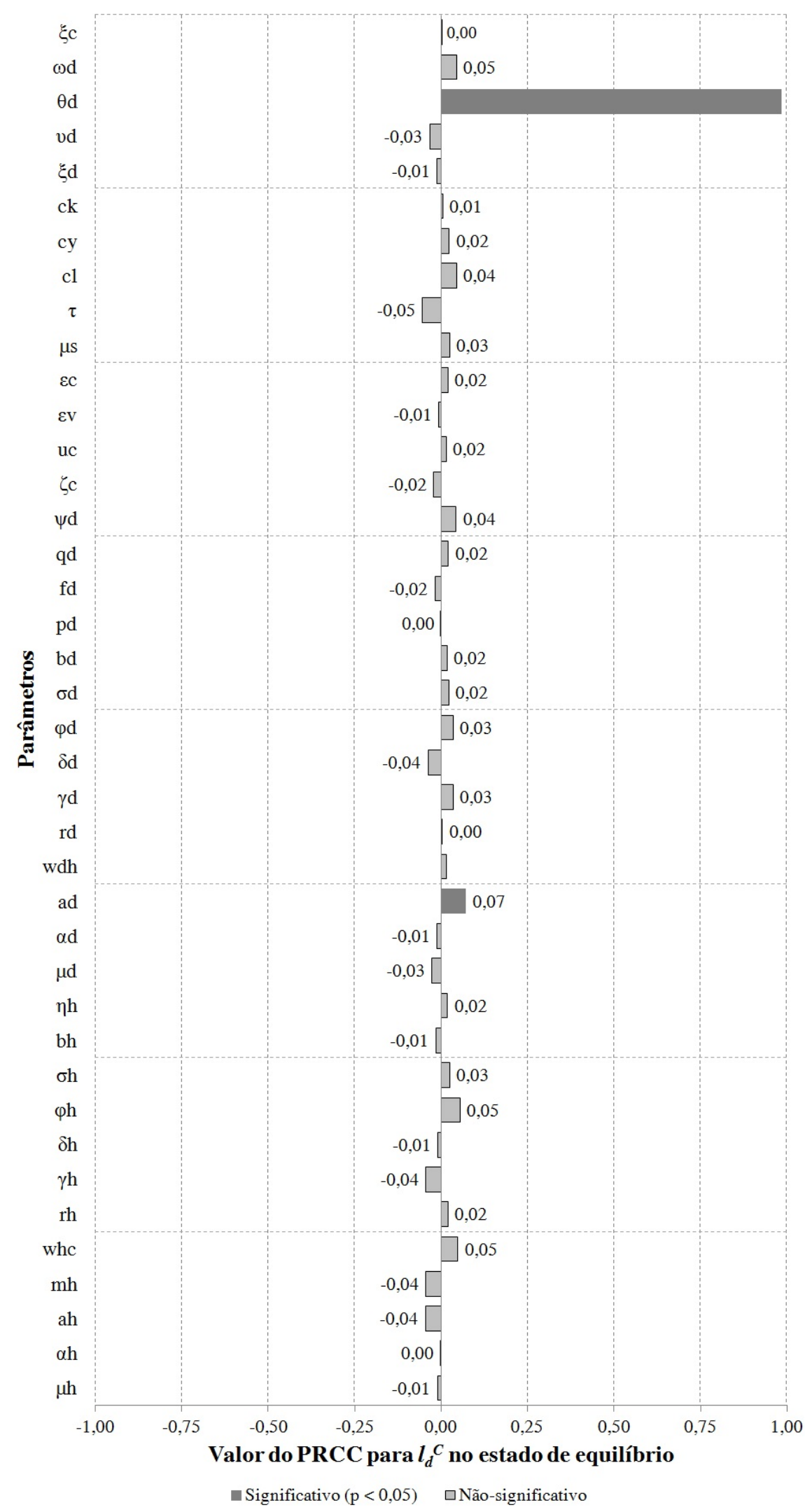

Figura 44 - Valores do PRCC para os parâmetros do modelo em relação à categoria $l_{d}^{C}$. Próximo de cada barra, há o valor de PRCC para os respectivos parâmetros. Os parâmetros significantes estão em cinza escuro. 


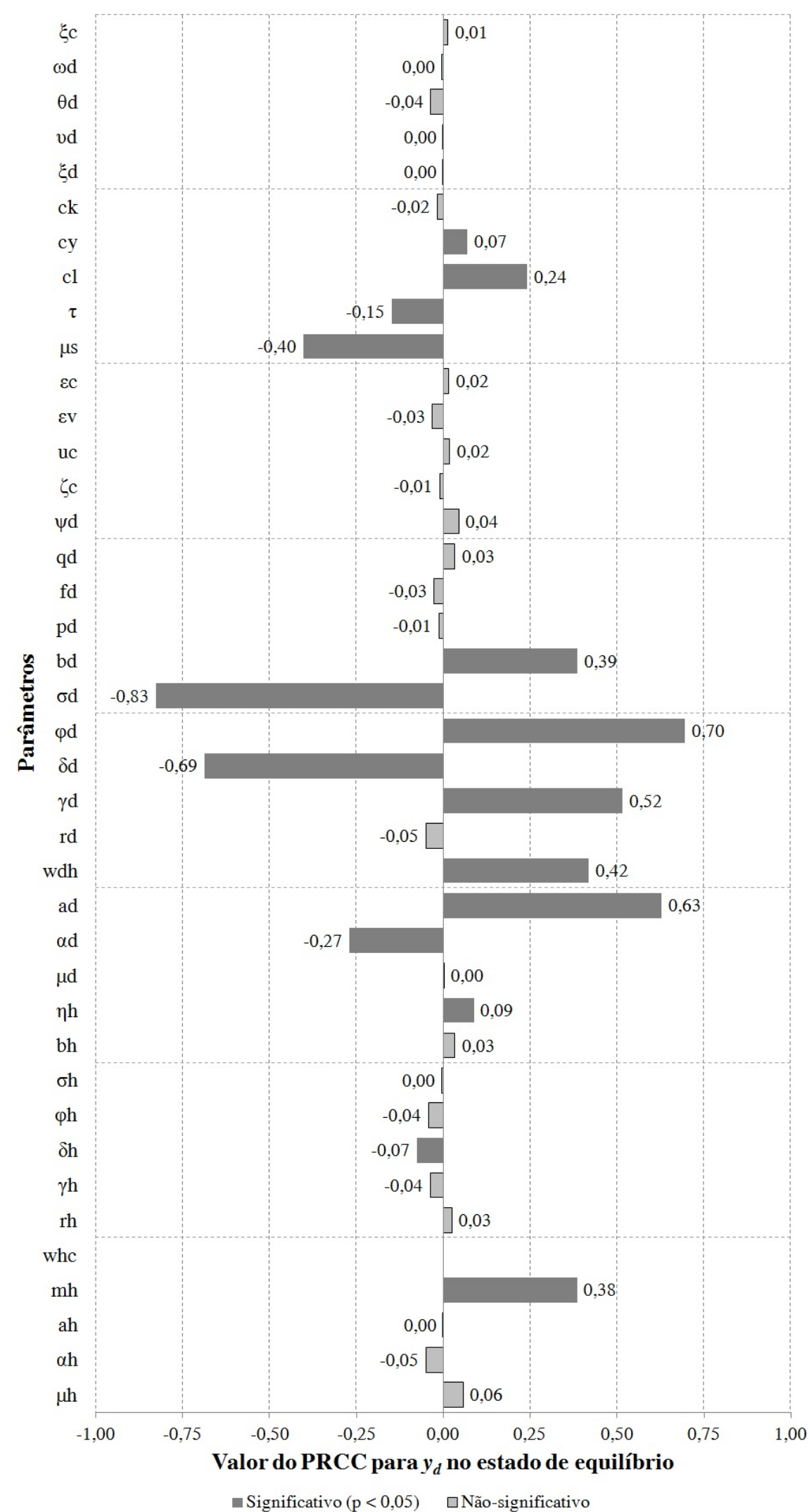

Figura 45 - Valores do PRCC para os parâmetros do modelo em relação à categoria $y_{d}$. Próximo de cada barra, há o valor de PRCC para os respectivos parâmetros. Os parâmetros significantes estão em cinza escuro. 


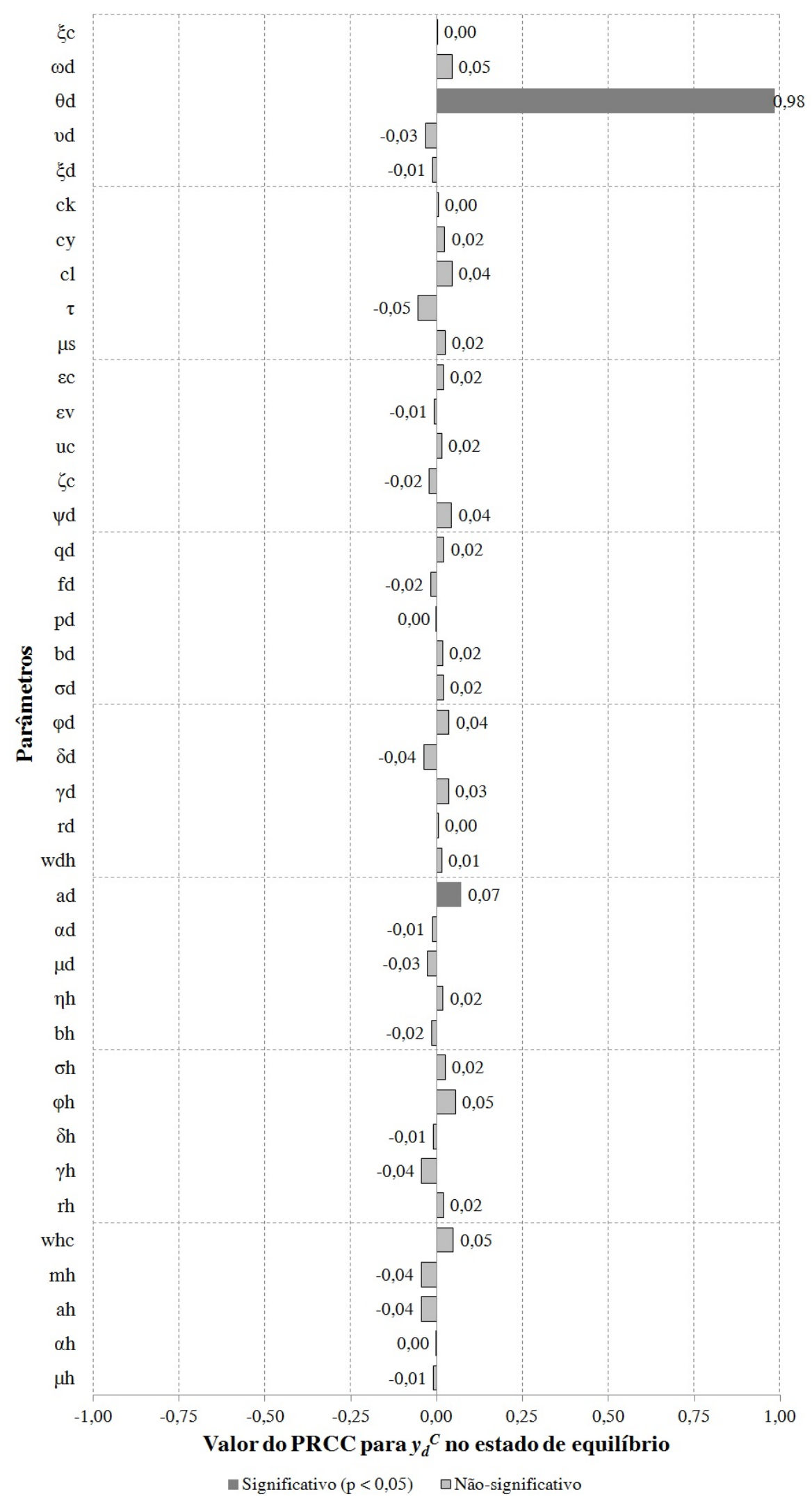

Figura 46 - Valores do PRCC para os parâmetros do modelo em relação à categoria $y_{d}^{C}$. Próximo de cada barra, há o valor de PRCC para os respectivos parâmetros. Os parâmetros significantes estão em cinza escuro. 


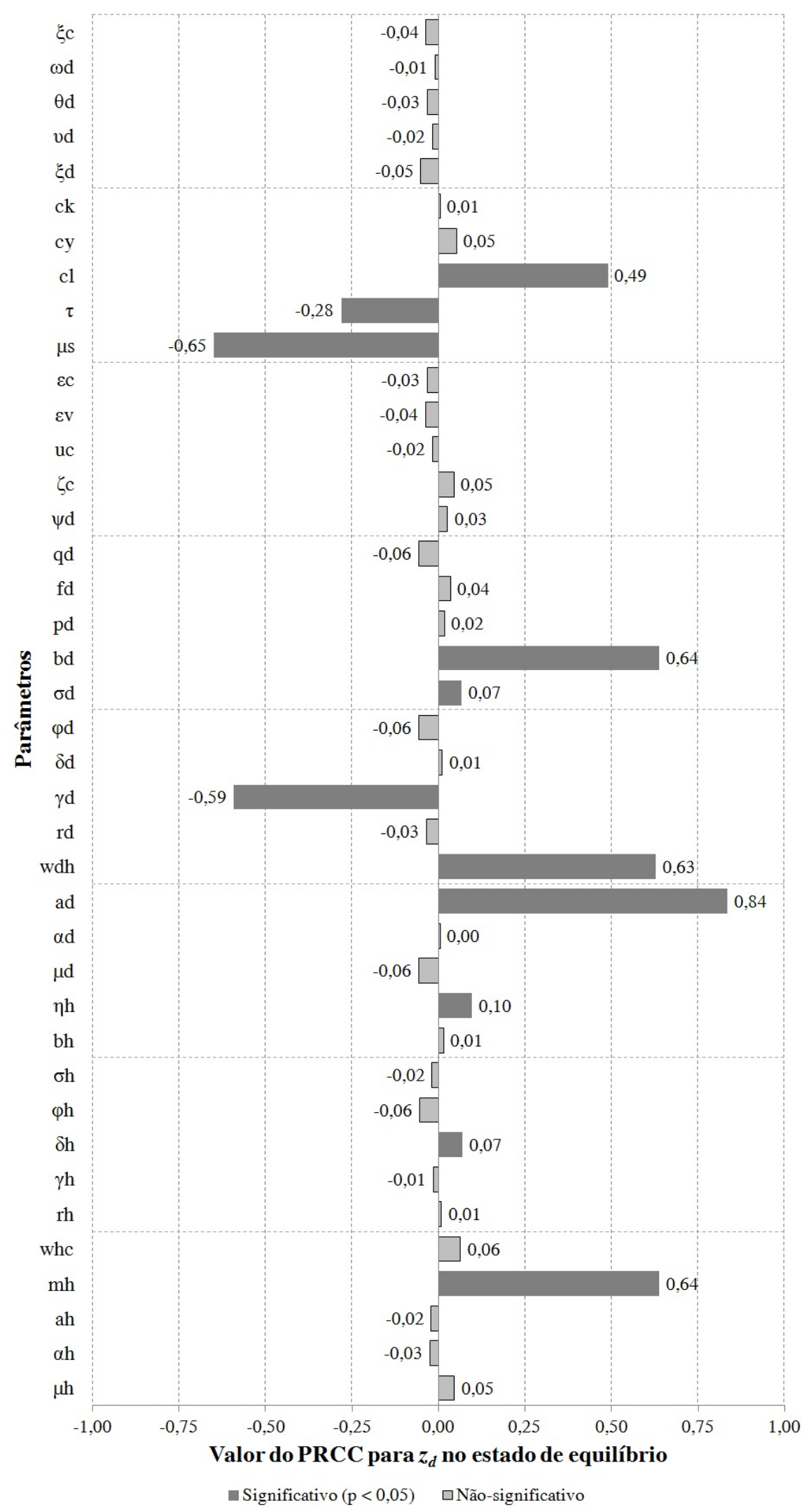

Figura 47 - Valores do PRCC para os parâmetros do modelo em relação à categoria $z_{d}$. Próximo de cada barra, há o valor de PRCC para os respectivos parâmetros. Os parâmetros significantes estão em cinza escuro. 


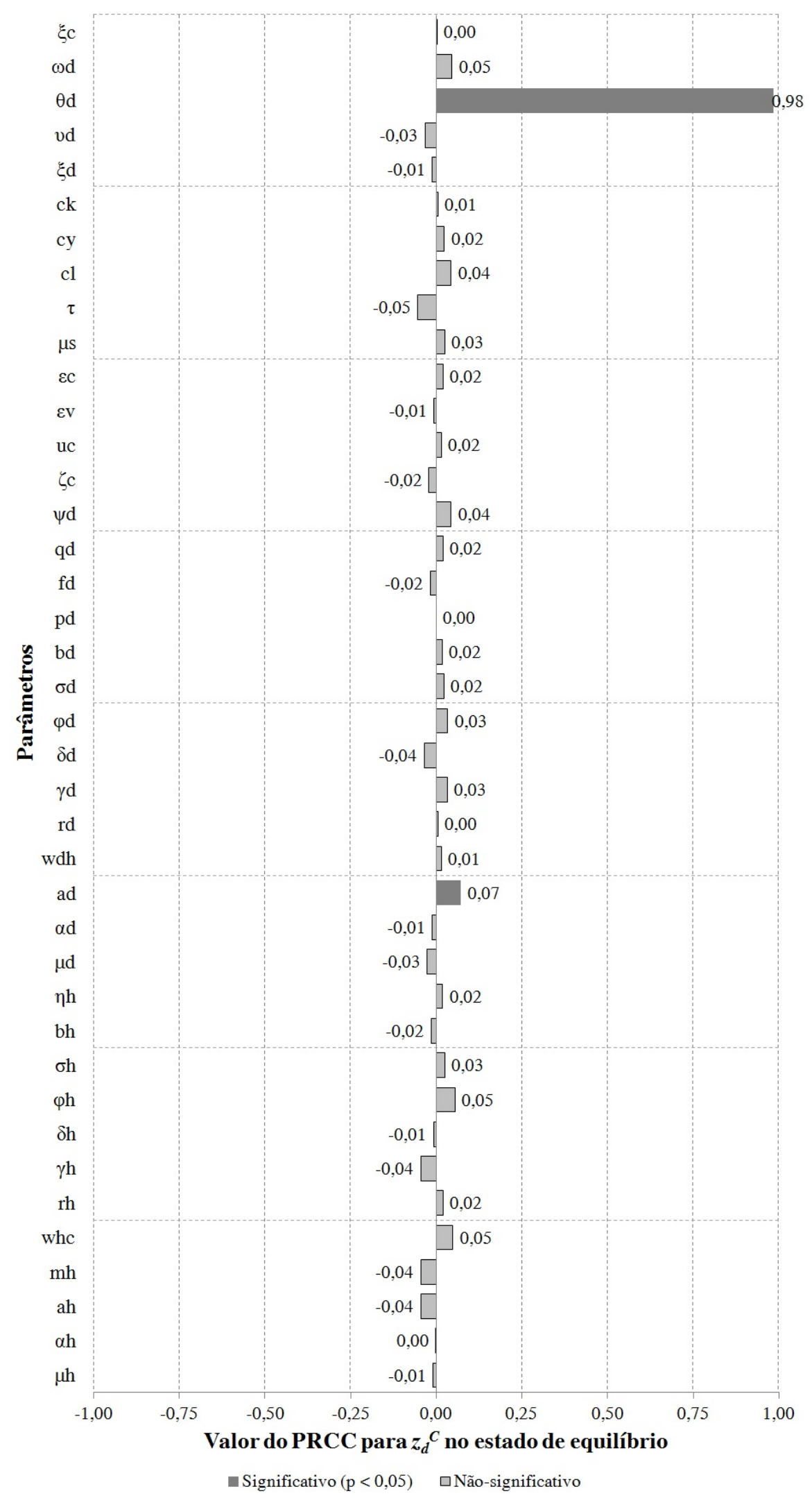

Figura 48 - Valores do PRCC para os parâmetros do modelo em relação à categoria $z_{d}^{C}$. Próximo de cada barra, há o valor de PRCC para os respectivos parâmetros. Os parâmetros significantes estão em cinza escuro. 


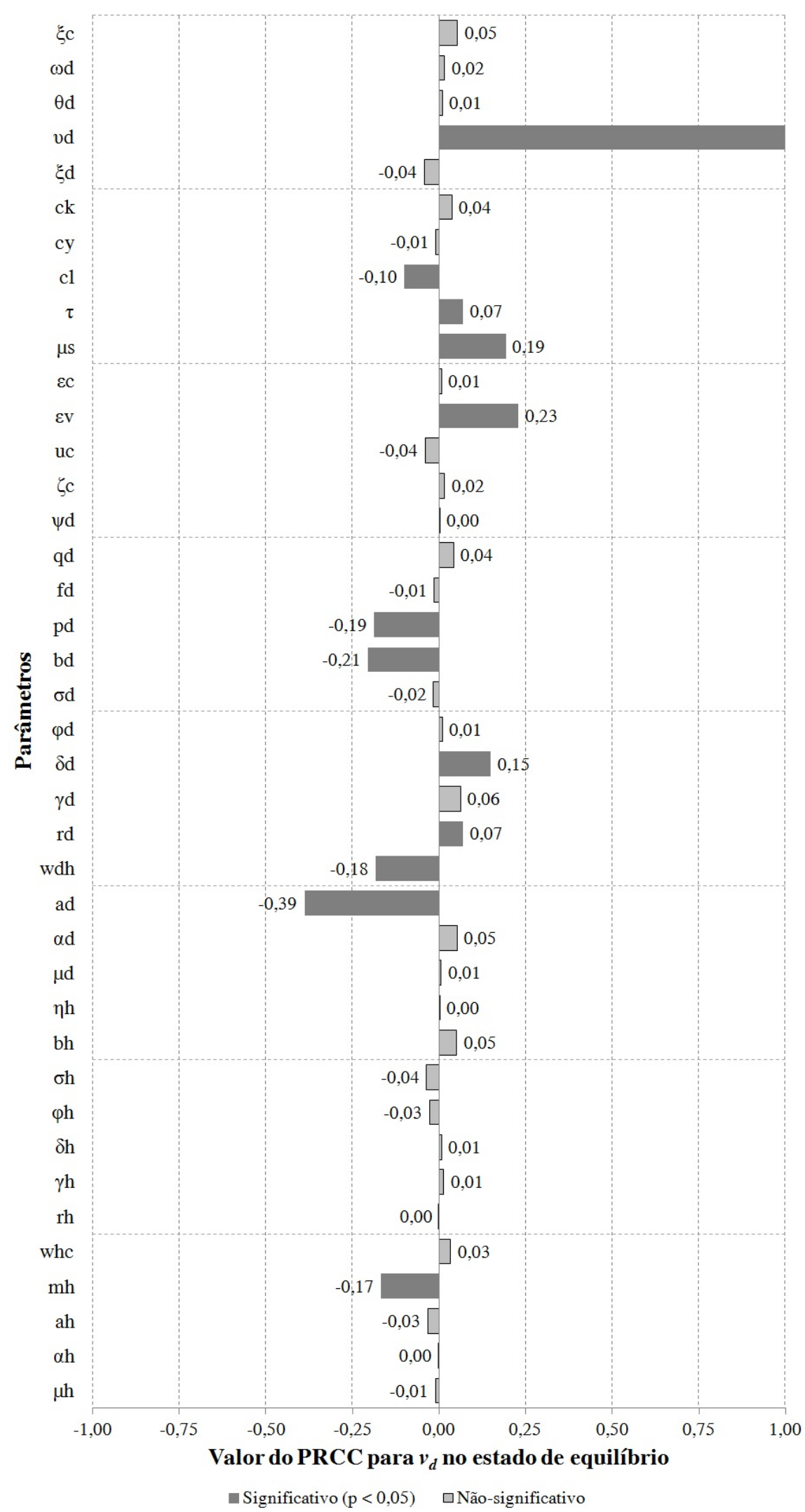

Figura 49 - Valores do PRCC para os parâmetros do modelo em relação à categoria $v_{d}$. Próximo de cada barra, há o valor de PRCC para os respectivos parâmetros. Os parâmetros significantes estão em cinza escuro. 


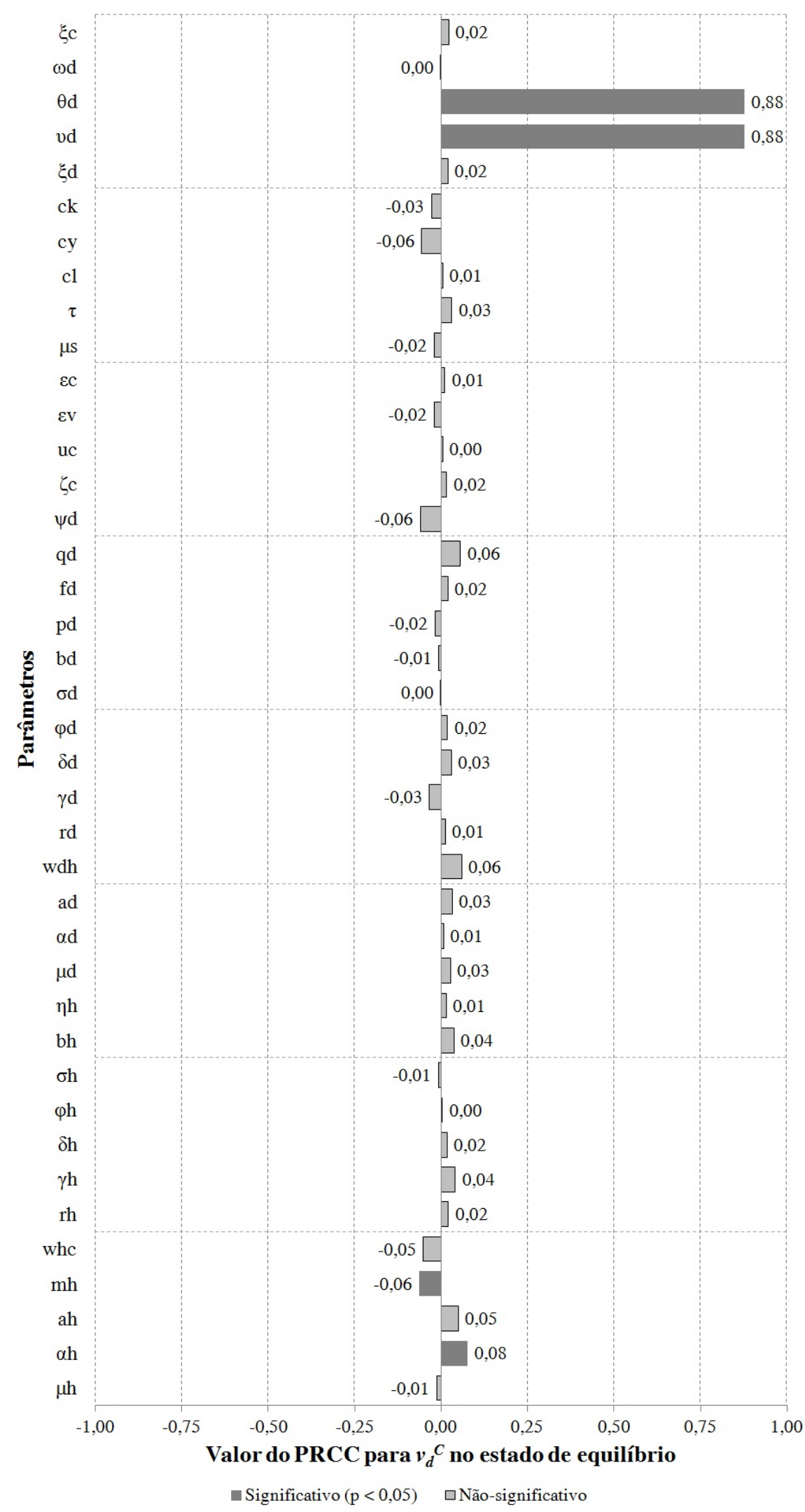

Figura 50 - Valores do PRCC para os parâmetros do modelo em relação à categoria $v_{d}^{C}$. Próximo de cada barra, há o valor de PRCC para os respectivos parâmetros. Os parâmetros significantes estão em cinza escuro. 


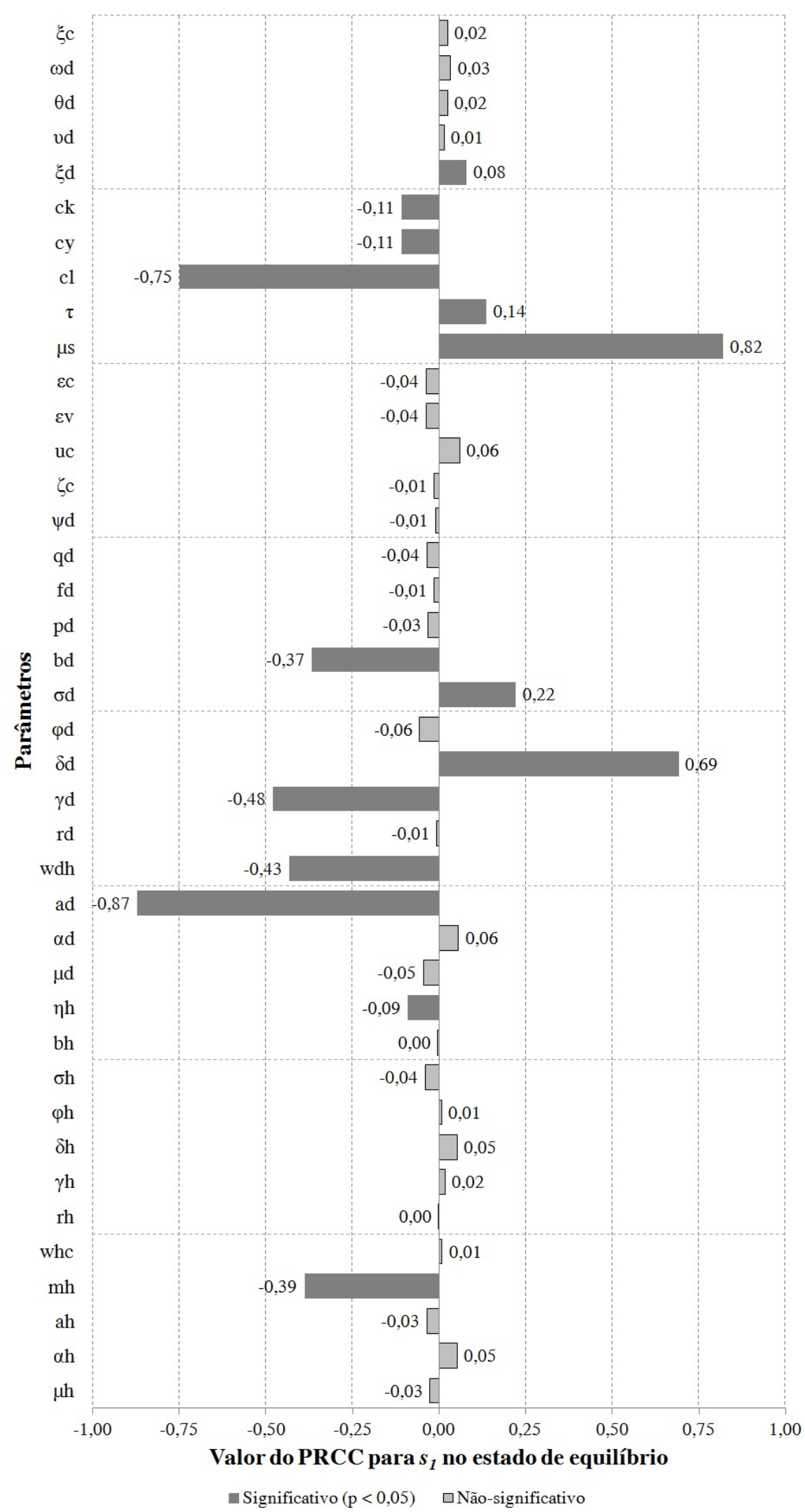

Figura 51 - Valores do PRCC para os parâmetros do modelo em relação à categoria $s_{1}$. Próximo de cada barra, há o valor de PRCC para os respectivos parâmetros. Os parâmetros significantes estão em cinza escuro. 


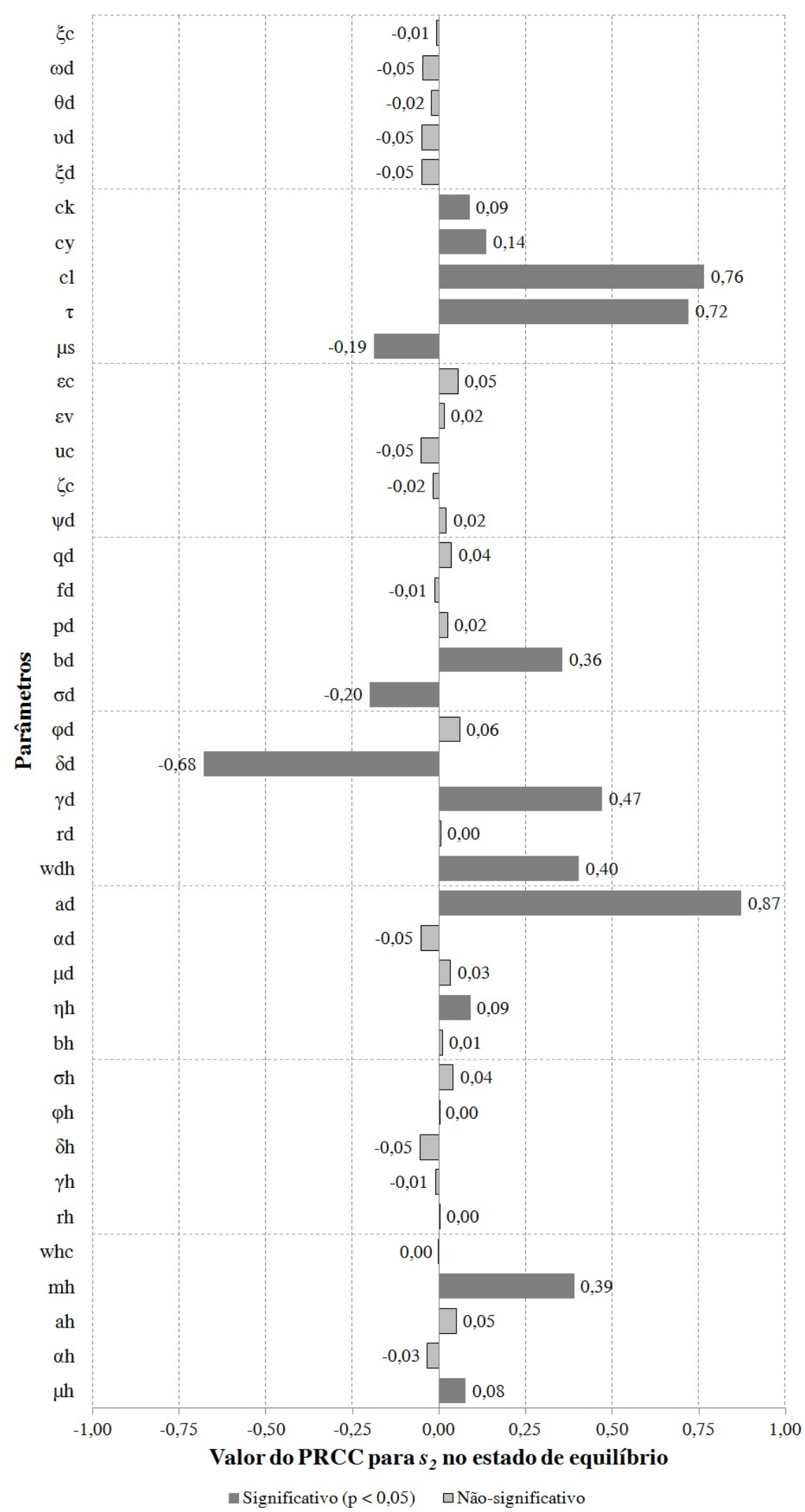

Figura 52 - Valores do PRCC para os parâmetros do modelo em relação à categoria $s_{2}$. Próximo de cada barra, há o valor de PRCC para os respectivos parâmetros. Os parâmetros significantes estão em cinza escuro. 


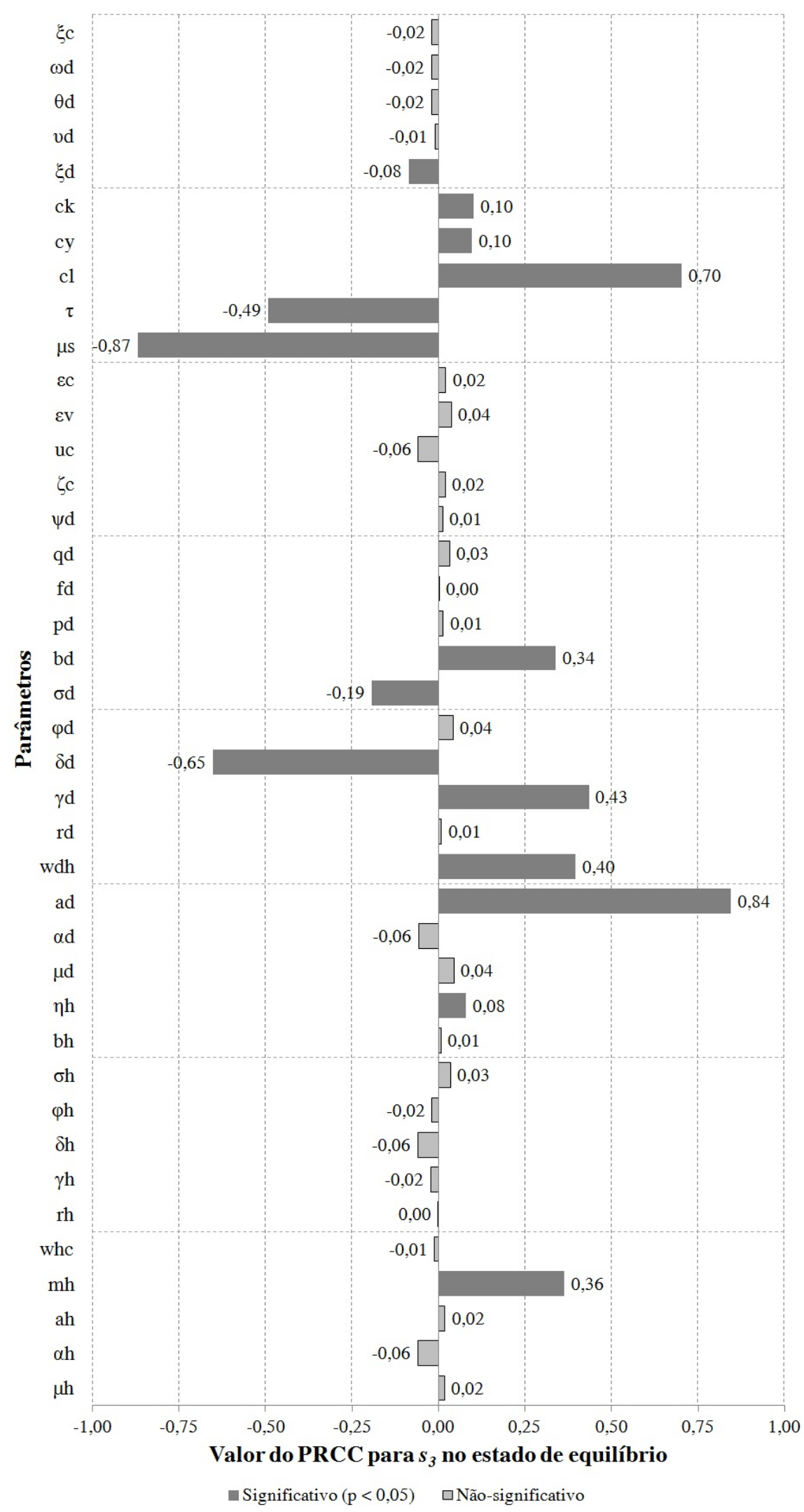

Figura 53 - Valores do PRCC para os parâmetros do modelo em relação à categoria $s_{3}$. Próximo de cada barra, há o valor de PRCC para os respectivos parâmetros. Os parâmetros significantes estão em cinza escuro. 


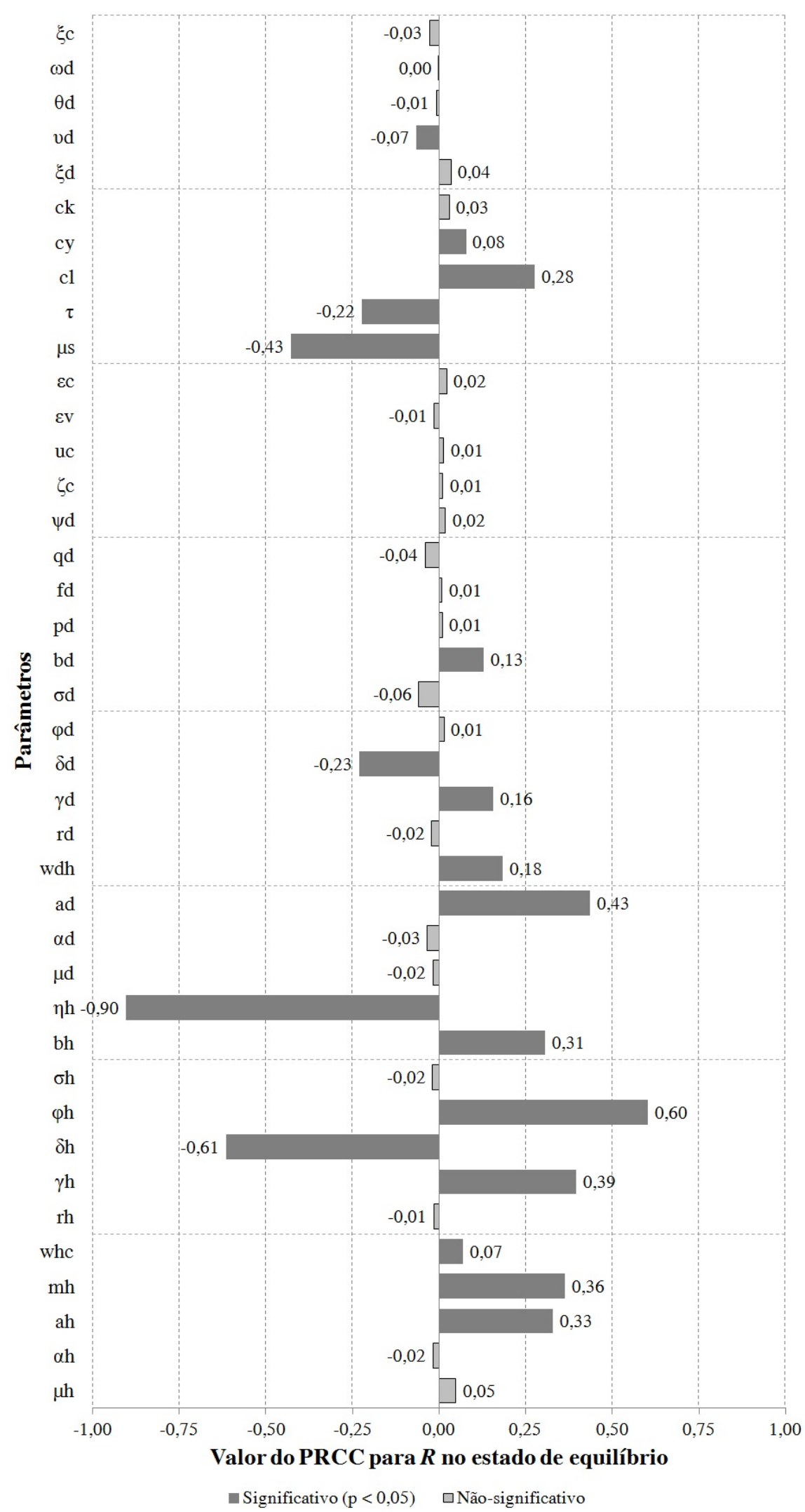

Figura 54 - Valores do PRCC para os parâmetros do modelo em relação ao número de casos notificados por dia $(R)$. Próximo de cada barra, há o valor de PRCC para os respectivos parâmetros. Os parâmetros significantes estão em cinza escuro. 


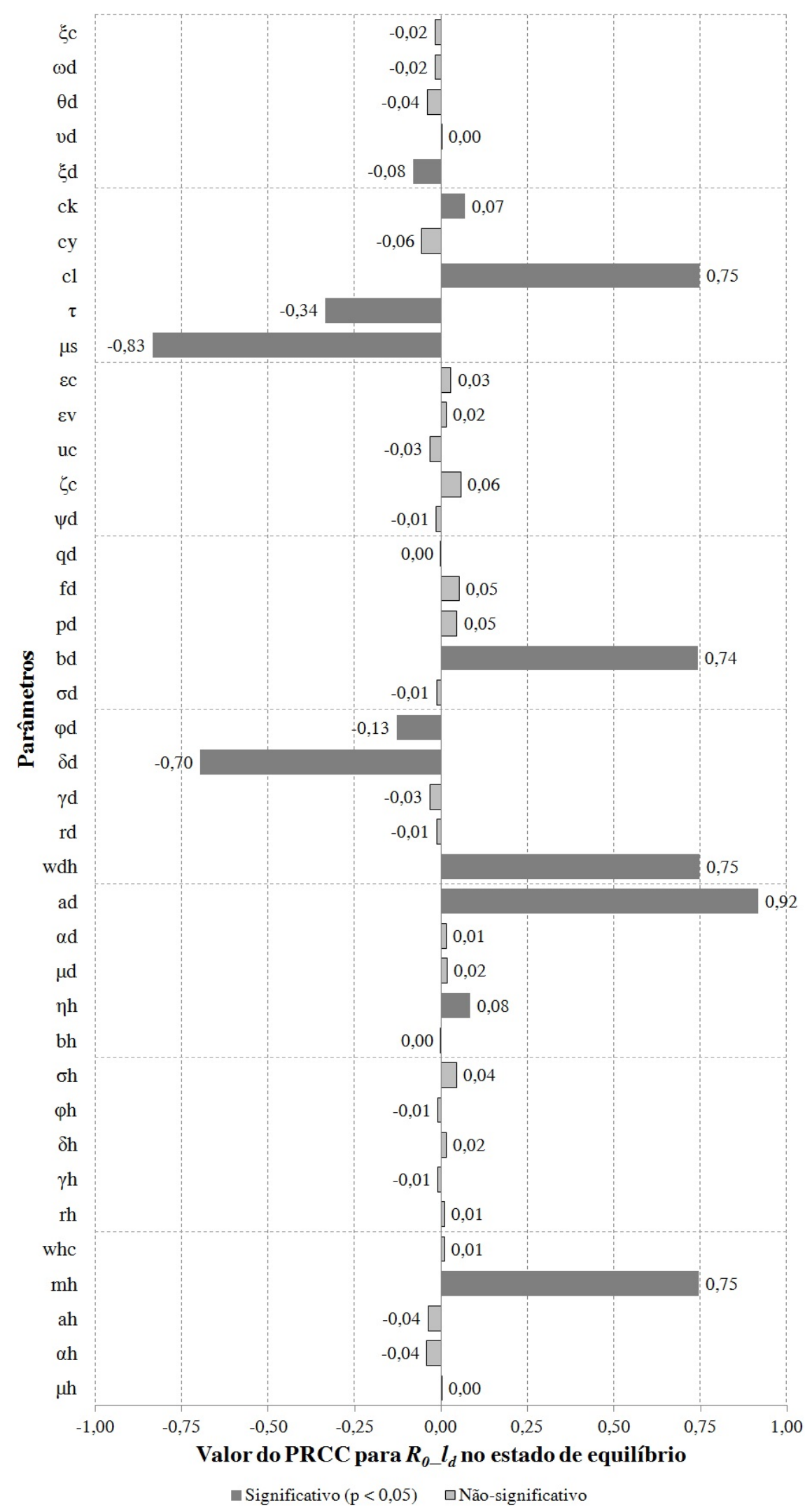

Figura 55 - Valores do PRCC para os parâmetros do modelo em relação à contribuição da categoria $l_{d}$ ao número de reprodutibilidade basal $\left(\mathscr{R}_{0}\right)$. Próximo de cada barra, há o valor de PRCC para os respectivos parâmetros. Os parâmetros significantes estão em cinza escuro. 


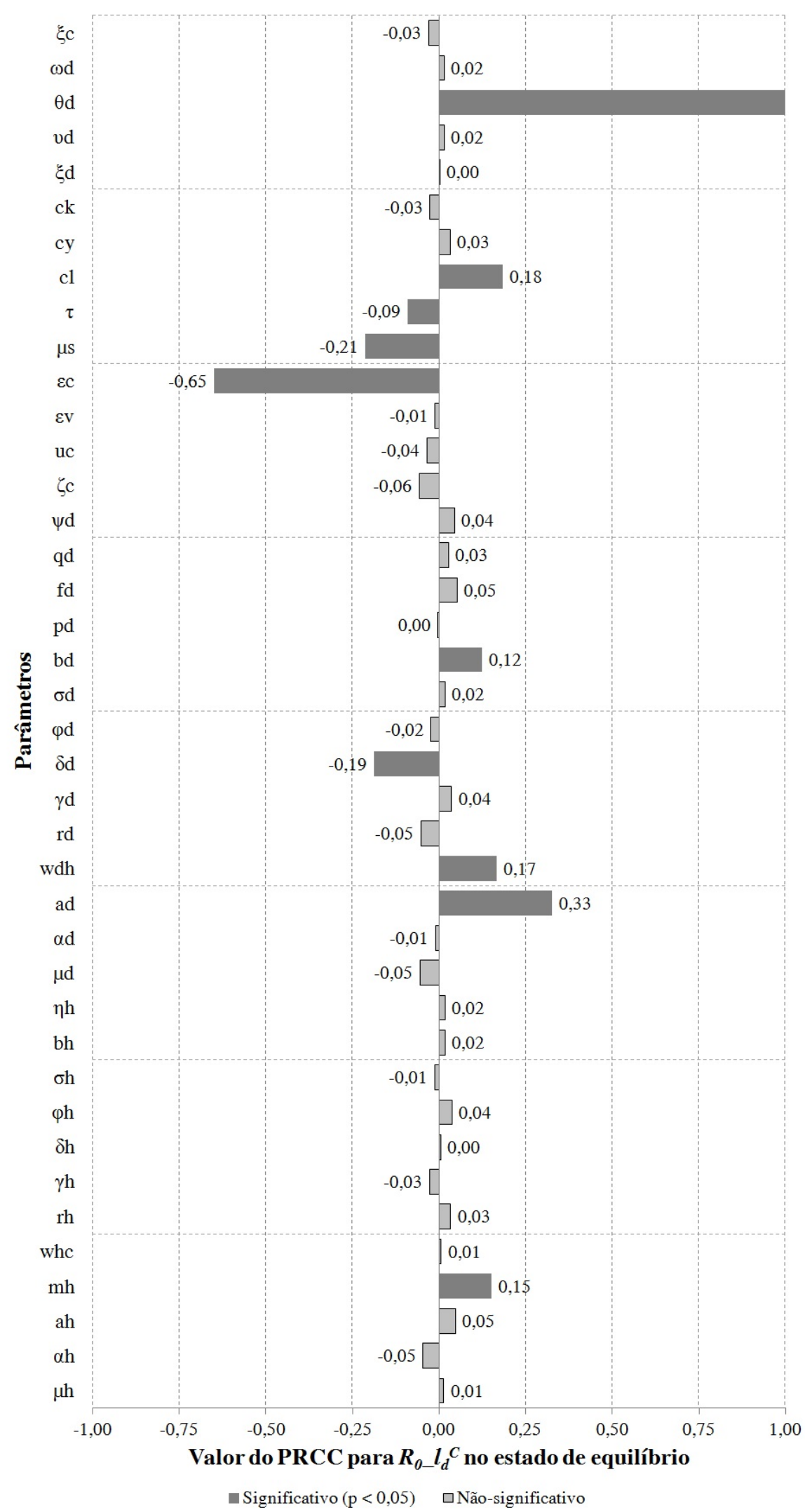

Figura 56 - Valores do PRCC para os parâmetros do modelo em relação à contribuição da categoria $l_{d}^{C}$ ao número de reprodutibilidade basal $\left(\mathscr{R}_{0}\right)$. Próximo de cada barra, há o valor de PRCC para os respectivos parâmetros. Os parâmetros significantes estão em cinza escuro. 


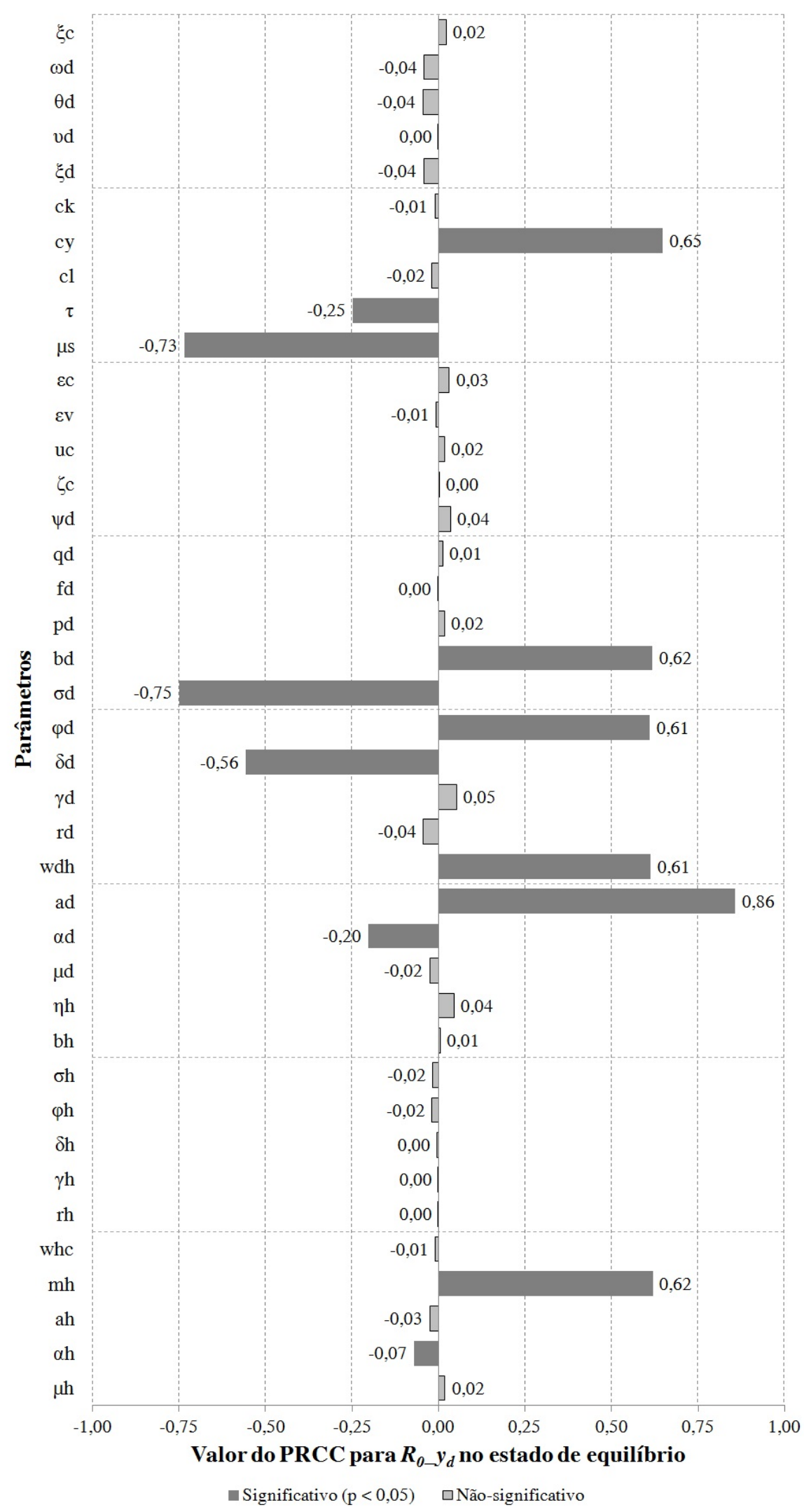

Figura 57 - Valores do PRCC para os parâmetros do modelo em relação à contribuição da categoria $y_{d}$ ao número de reprodutibilidade basal $\left(\mathscr{R}_{0}\right)$. Próximo de cada barra, há o valor de PRCC para os respectivos parâmetros. Os parâmetros significantes estão em cinza escuro. 


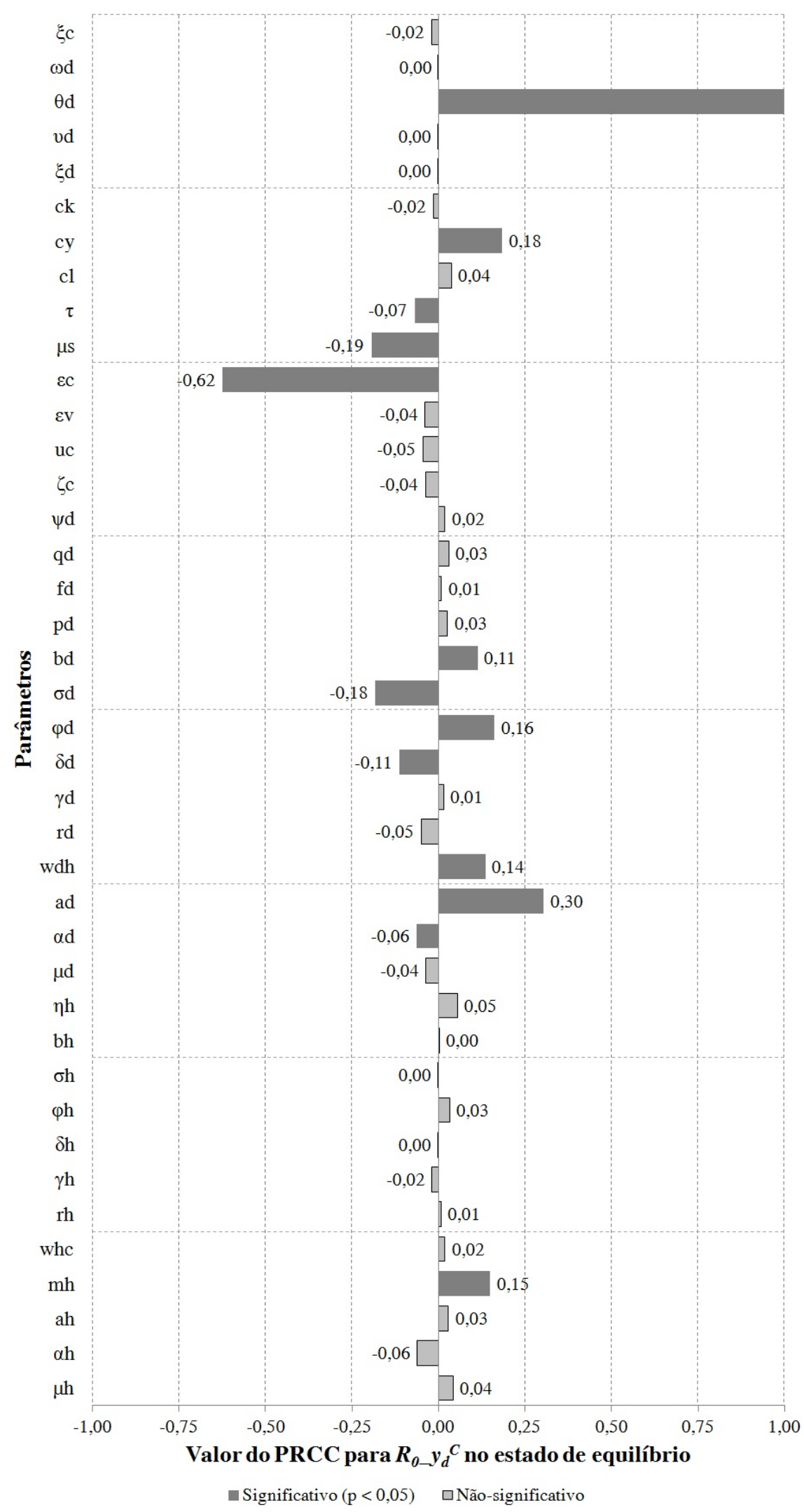

Figura 58 - Valores do PRCC para os parâmetros do modelo em relação à contribuição da categoria $y_{d}^{C}$ ao número de reprodutibilidade basal $\left(\mathscr{R}_{0}\right)$. Próximo de cada barra, há o valor de PRCC para os respectivos parâmetros. Os parâmetros significantes estão em cinza escuro. 


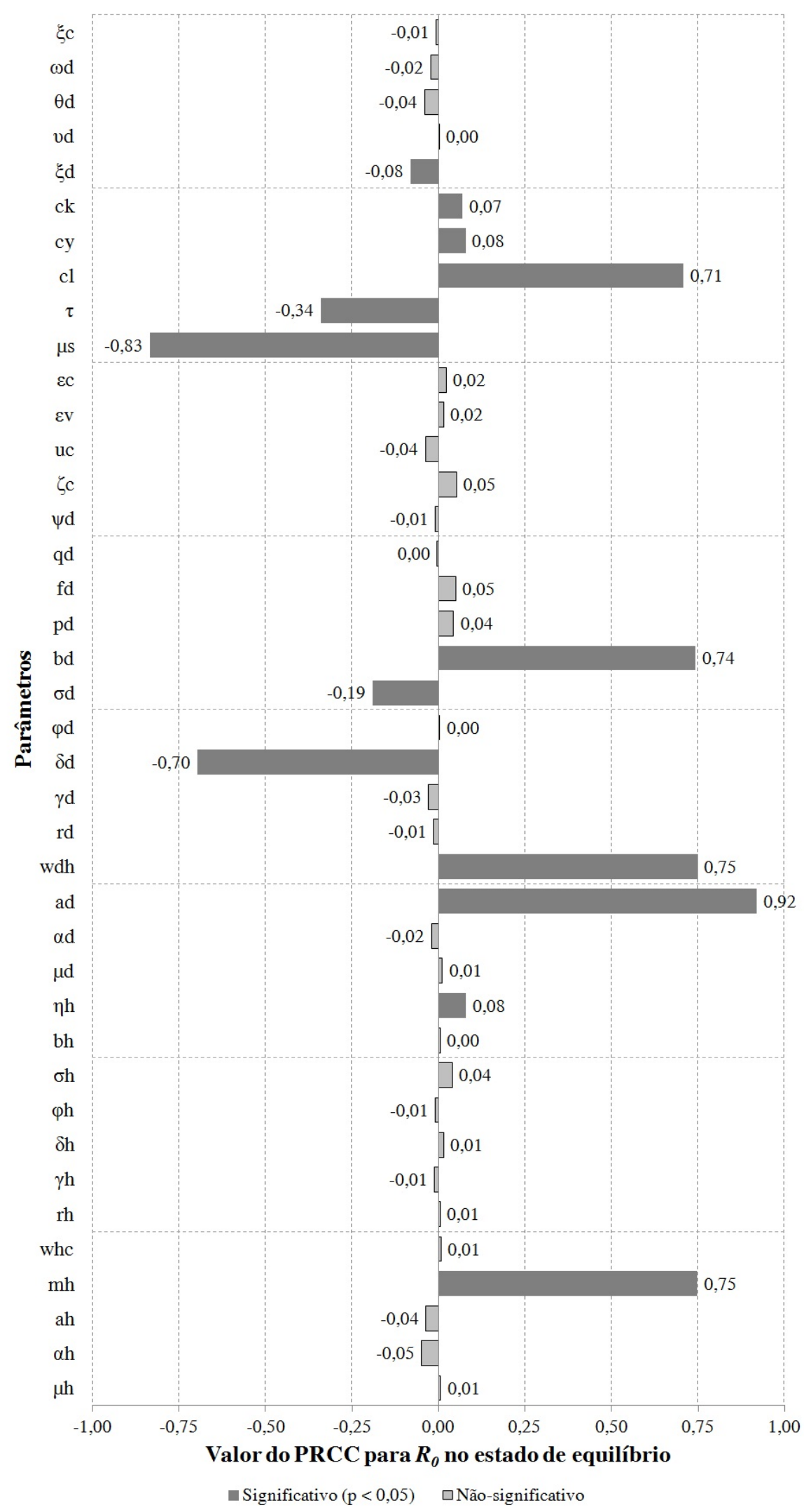

Figura 59 - Valores do PRCC para os parâmetros do modelo em relação ao número de reprodutibilidade basal $\left(\mathscr{R}_{0}\right)$. Próximo de cada barra, há o valor de PRCC para os respectivos parâmetros. Os parâmetros significantes estão em cinza escuro. 


\section{Refletir}

Todos nós cometemos muitos erros. Aprender com eles ou ignorá-fos depende da profundidade com que refletimos sobre nossos atos. O melhor é refletirmos até chegarmos às lágrimas.

[Takamori Kentetsu, Sementes do coração (2013), p.52]

$$
\text { o grande trabalho }
$$

Fazer o esforço que os outros não fazem é o que traz sucesso.

[Takamori Kentetsu, Sementes do coração (2013), p.97] 
Apêndice E - Artigos publicados

Estimating the optimal control of zoonotic visceral leishmaniasis by the use of a mathematical model 


\title{
Research Article
}

\section{Estimating the Optimal Control of Zoonotic Visceral Leishmaniasis by the Use of a Mathematical Model}

\author{
Laila Massad Ribas, ${ }^{1}$ Vera Lucia Zaher, ${ }^{1}$ Helio Junji Shimozako, ${ }^{1}$ and Eduardo Massad ${ }^{1,2}$ \\ ${ }^{I}$ School of Medicine, University of São Paulo and LIM 01-HCFMUSP, Avenida Dr. Arnaldo 455, 01246-903 São Paulo, SP, Brazil \\ ${ }^{2}$ London School of Hygiene and Tropical Medicine, University of London, UK \\ Correspondence should be addressed to Eduardo Massad; edmassad@usp.br
}

Received 30 April 2013; Accepted 9 July 2013

Academic Editors: F. Henriquez, J. F. Lindo, and J. Lorenzo-Morales

Copyright (c) 2013 Laila Massad Ribas et al. This is an open access article distributed under the Creative Commons Attribution License, which permits unrestricted use, distribution, and reproduction in any medium, provided the original work is properly cited.

We argue that the strategy of culling infected dogs is not the most efficient way to control zoonotic visceral leishmaniasis (ZVL) and that, in the presence of alternative control strategies with better potential results, official programs of compulsory culling adopted by some countries are inefficient and unethical. We base our arguments on a mathematical model for the study of control strategies against ZVL, which allows the comparison of the efficacies of 5, alternative strategies. We demonstrate that the culling program, previously questioned on both theoretical and practical grounds is the less effective control strategy. In addition, we show that vector control and the use of insecticide-impregnated dog collars are, by far, more efficient at reducing the prevalence of ZVL in humans.

\section{Introduction}

Zoonotic visceral leishmaniasis (ZVL) is one of the most important emerging parasite diseases [1]. It is endemic in rural areas of South America and is caused by Leishmania infantum (syn., L. chagasi). The parasite is transmitted by the phlebotomine sandfly, Lutzomyia longipalpis, and the domestic dog is the main reservoir of the parasite in these areas $[2,3]$. Once introduced into a community, the parasite is maintained in a dog-insect-dog peridomestic transmission cycle [1], and occasionally infected flies bite people, causing ZVL. Therefore, the prevalence and the incidence of canine ZVL are important epidemiological parameters for controlling transmission [4], and the estimation of which depends on the reliable identification of infected dogs [5]. As a result, control programs for ZVL often include elimination of infected dogs [6]. Control programs also include detection and treatment of human cases and vector control [7]. More recently, however, two additional control programs have been suggested as alternative or complementarily related to the classical approach, namely, insecticide-impregnated dog collars [8] and a transmission-blocking vaccine [9].
In the Mediterranean, where dogs are considered "valuable" [10], ZVL is both a medical and a veterinary problem. In Brazil, the country were $90 \%$ of New World's ZVL cases are reported, human cases are numerous and where human cases are many and dogs are considered "less valuable" [10], ZVL is chiefly considered to be only a medical problem. As a result, 850,000 dogs are screened annually in Brazil, and between 20,000 [11] and 25,000 [10] dogs are culled upon positive diagnosis. This perspective of undervaluing dogs is the official position of some governments like the Brazilian Health Authorities, which forbid the treatment of infected dogs with drugs of human use (Interministerial law no. 1,426 of July 11 2008, Editorial of Clinica Veterinária 83: 16-17, 2009) and impose the elimination of seropositive dogs as compulsory. Health agents threaten dog owners with heavy fines for refusing the serological analysis of their animals, and thousands of diagnosed dogs, with a high probability of being false positives, are eliminated every year without a counterproof. Hence, instead of submitting their dogs to the serological screening, owners refuse the entrance of health agents into their homes or transfer their animals to areas where there is no serological screening. Some owners even 
avoid taking their dogs to the veterinary doctors fearing some examination that could result in a death sentence to their animals [12].

From the ethical point of view, two aspects must be highlighted: the ethics of animals (from the veterinarian point of view) and the ethics of human relations, where those animals and their relationship with the human society are increasingly valued (some authors, like Singer [13], discuss the "importance" of animals on the same parameters as humans) and the human health is at risk. Conflict between these aspects should be avoided whenever possible.

In this paper we argue that the strategy of culling infected dogs is not the most efficient way to control ZVL and that in the presence of alternative control strategies with better potential results the Brazilian official program of compulsory culling is unethical. We base our arguments on a mathematical model for the study of control strategies against ZVL [14], which allows for the comparison between the efficacies of 5 alternative strategies. We demonstrate that the culling program, previously doubted both on theoretical $[10]$ and practical grounds $[15,16]$, is one of the less effective methods, and vector control and the use of insecticideimpregnated dog collars are, by far, more efficient in reducing the prevalence of ZVL in humans.

\section{Materials and Methods}

We used a mathematical model that is an adaptation of the one proposed by Burattini et al. [14] and assumes a human and a dog population, with the biological vector transmitting the infection within and between the two populations. The three populations (humans, dogs, and vectors) are assumed constants. They are divided into eleven categories that describe the proportions that are human (indexed as $h$ ) and $\operatorname{dog}$ (indexed as $d$ ), the subpopulations that are susceptible $\left(x_{h}\right.$ and $\left.x_{d}\right)$, infected but without noticeable disease ( $l_{h}$ and $l_{d}$ ) (i.e., "latent"), clinically ill ( $y_{h}$ and $\left.y_{d}\right)$, and recovered immunes $\left(z_{h}\right.$ and $\left.z_{d}\right)$ and the three possible states of the vector population: noninfected, infected but not infective, and infective individuals, denoted as $s_{1}, s_{2}$, and $s_{3}$, respectively. The set of differential equations describing the model's dynamics is

$$
\begin{gathered}
\frac{d x_{h}}{d t}=\left(l_{h}+y_{h}+z_{h}\right) \mu_{h}+\alpha_{h} y_{h}+r_{h} l_{h}+\gamma_{h} z_{h}-b a_{h} x_{h} m_{h} s_{3}, \\
\frac{d l_{h}}{d t}=b a_{h} x_{h} m_{h} s_{3}-\left(r_{h}+\mu_{h}+\delta_{h}+\varphi_{h}\right) l_{h}, \\
\frac{d y_{h}}{d t}=\varphi_{h} l_{h}-\left(\mu_{h}+\alpha_{h}+\tau_{h}\right) y_{h}, \\
\frac{d z_{h}}{d t}=\delta_{h} l_{h}+\tau_{h} y_{h}-\left(\mu_{h}+\gamma_{h}\right) z_{h} \\
\frac{d x_{d}}{d t}=\left(l_{d}+y_{d}+z_{d}\right) \mu_{d}+\alpha_{d} y_{d}+r_{d} l_{d}+\gamma_{d} z_{d} \\
-b\left(\frac{a_{d}}{\theta}\right) x_{d} m_{d} s_{3}+\omega_{d} y_{d}
\end{gathered}
$$

$$
\begin{aligned}
& \frac{d l_{d}}{d t}=b\left(\frac{a_{d}}{\theta}\right) x_{d} m_{d} s_{3}-\left(r_{d}+\mu_{d}+\delta_{d}+\varphi_{d}+\xi_{d}\right) l_{d}, \\
& \frac{d y_{d}}{d t}=\varphi_{d} l_{d}-\left(\mu_{d}+\alpha_{d}+\tau_{d}-\omega_{d}-\xi_{d}\right) y_{d}, \\
& \frac{d z_{d}}{d t}=\delta_{d} l_{d}+\tau_{d} y_{d}-\left(\mu_{d}+\gamma_{d}\right) z_{d}, \\
& \frac{d s_{1}}{d t}=\mu_{s}\left(s_{2}+s_{3}\right)-\left[\left(\frac{c}{\nu}\right)\left(\frac{a_{d}}{\theta}\right)\left(l_{d}+y_{d}\right)\right] s_{1}, \\
& \frac{d s_{2}}{d t}=\left[\left(\frac{c}{\nu}\right)\left(\frac{a_{d}}{\theta}\right)\left(l_{d}+y_{d}\right)\right] s_{1} \\
& -\left[\left(\frac{c}{v}\right) a_{d}\left(l_{d}(t-\tau)+y_{d}(t-\tau)\right)\right] \\
& \times s_{1}(t-\tau) \exp \left(-\mu_{s} \tau\right)-\mu_{s} s_{2}, \\
& \frac{d s_{3}}{d t}=\left[\left(\frac{c}{\nu}\right)\left(\frac{a_{d}}{\theta}\right)\left(l_{d}(t-\tau)+y_{d}(t-\tau)\right)\right] \\
& \times s_{1}(t-\tau) \exp \left(-\mu_{s} \tau\right)-\mu_{s} s_{3},
\end{aligned}
$$

where the definition, biological meaning, and values of each of parameter (values taken from [14]) are described in Table 1.

A brief description of the system (1) should clarify their meaning.

Let $S$ be the total number of sandflies. The number of bites inflicted in the human host population in an infinitesimal time interval $d t$ is $a_{h} S d t$, where $a_{h}$ is the biting rate on humans. The number of bites inflicted by infected flies is $a_{h} S d t S_{3} / S=a_{h} S d t s_{3}$, where $S_{3}$ is the number of infected flies.

Let now $X_{h}$ be the total number of susceptible individuals in the human population. In an infinitesimal time interval $d t$, $X_{h}$ varies as follows:

(i) a fraction of the infected bites are on uninfected individuals: $a_{h} S d t s_{3} x_{h}$; a fraction $b$ of these becomes latent, so $X_{h}$ diminishes by $b a_{h} S d t s_{3} x_{h}$;

(ii) in the same time interval $r_{h} L_{h} d t+\gamma_{h} Z_{h}$ individuals, latent and immune, revert to the susceptible condition, and $\mu_{h} X_{h} d t$ die by natural causes other than the disease;

(iii) we must add an entrance term, due to natality, which we choose to be $\alpha_{h} Y_{h} d t+\mu_{h} N_{h} d t$, where $\alpha_{h}$ is the disease-induced mortality rate, $Y_{h}$ is the number of infected humans, and $N_{h}$ is the total number of humans needed to maintain a constant population.

Therefore we have

$$
\begin{aligned}
d X_{h}= & \alpha_{h} Y_{h} d t+\mu_{h} N_{h}-b a_{h} S d t s_{3} x_{h} \\
& +\left(d_{h} L_{h} d t+\gamma_{h} Z_{h} d t\right)-\mu_{h} X_{h d t}
\end{aligned}
$$

Dividing this equation by $N_{h} d t$ and calling $S / N_{h}=m_{h}$, we get the first equation of the system (1).

Equations indexed with $d$ in the system (1) are related to the dog's subpopulation. They differ from the original 
TABLE 1: Model's parameters. Values from Burattini et al. [14]. The indexes $h, d$, and $s$ stand for humans, dogs, and sandflies, respectively.

\begin{tabular}{|c|c|c|}
\hline Parameter & Biological meaning & Values \\
\hline$\mu_{h}$ & Natural mortality rate & $4.11 \times 10^{-5}$ days $^{-1}$ \\
\hline$\alpha_{h}$ & Disease-induced lethality & $5.48 \times 10^{-3}$ days $^{-1}$ \\
\hline$a_{h}$ & Average daily biting rate & $1.25 \times 10^{-1}$ days $^{-1}$ \\
\hline$m_{h}$ & Vector density per host & $1.00 \times 10^{2}$ \\
\hline$r_{h}$ & Spontaneous recovery rate & $5.48 \times 10^{-4}$ days $^{-1}$ \\
\hline$\gamma_{h}$ & Loss of immunity rate & $5.48 \times 10^{-4}$ days $^{-1}$ \\
\hline$\delta_{h}$ & Latent recovery rate & $1.10 \times 10^{-2}$ days $^{-1}$ \\
\hline$\varphi_{h}$ & Inverse of incubation period & $4.00 \times 10^{-4}$ days $^{-1}$ \\
\hline$\sigma_{h}$ & Recovery rate of immunes & $1.81 \times 10^{-3}$ days $^{-1}$ \\
\hline$b_{h}$ & Proportion of infective bites & $1.00 \times 10^{-2}$ \\
\hline$\mu_{d}$ & Natural mortality rate & $1.81 \times 10^{-4}$ days $^{-1}$ \\
\hline$\alpha_{d}$ & Disease-induced lethality & $1.81 \times 10^{-3}$ days $^{-1}$ \\
\hline$a_{d}$ & Average daily biting rate & $1.25 \times 10^{-1}$ days $^{-1}$ \\
\hline$m_{d}$ & Vector density per host & $5.00 \times 10^{2}$ \\
\hline$r_{d}$ & Spontaneous recovery rate & $2.74 \times 10^{-4}$ days $^{-1}$ \\
\hline$\gamma_{d}$ & Loss of immunity rate & $2.74 \times 10^{-3}$ days $^{-1}$ \\
\hline$\omega_{d}$ & Treatment rate & Variable \\
\hline$v$ & Vaccination & Variable \\
\hline$\xi$ & Culling rate & Variable \\
\hline$\theta$ & Insecticide collar & Variable \\
\hline$\delta_{d}$ & Latent recovery rate & $8.22 \times 10^{-3}$ days $^{-1}$ \\
\hline$\varphi_{d}$ & Inverse of incubation period & $1.10 \times 10^{-3}$ days $^{-1}$ \\
\hline$\sigma_{d}$ & Recovery rate of immunes & $9.04 \times 10^{-4}$ days $^{-1}$ \\
\hline$b_{d}$ & Proportion of infective bites & $2.00 \times 10^{-2}$ \\
\hline$\mu_{s}$ & Natural mortality rate & $6.00 \times 10^{-2}$ days $^{-1}$ \\
\hline$\tau$ & Extrinsic incubation period & 7.00 days \\
\hline$c$ & Proportion of infective bites & $5.00 \times 10^{-2}$ \\
\hline
\end{tabular}

model by Burattini et al. [14] by including control terms. Therefore, the term $\omega$ in the fifth and seventh equations refers to the treatment rate, according to which infected dogs are removed from the infectious compartment and are transferred to the susceptible one; the term $\theta$ in the fifth and sixth equations refers to the insecticide-impregnated collars, which by repelling the vector reduce the biting rate to the dogs; and finally the term $\xi$ in the sixth and seventh equations refers to the culling of latent and infected dogs.

The last three equations of the system (1) refer to the flies. When infected, a fly remains in a latent stage for a period of time $\tau$. This time corresponds to the extrinsic incubation period of the parasite inside the vector fly. Numerically it lasts for about half the life expectancy of the flies.

Let $S_{1}$ be the number of susceptible flies. In an infinitesimal period of time $d t,\left(a_{d}\left(\left(Y_{d}+L_{d}\right) / N_{d}\right) d t\right) S_{1}$ bites due to uninfected flies occur on latent and infected dogs (humans are not considered to be infective for flies; see [1]). A fraction $c$ of the flies becomes latently infected as a result. Therefore, we have

$$
d S_{1}=\mu_{s}\left(S_{2}+S_{3}\right) d t-\left(\frac{c}{v}\right)\left(\left(\frac{a_{d}}{\theta}\right)\left(y_{d}+l_{d}\right)\right) S_{a} d t,
$$

where the term $v$ refers to the transmission-blocking vaccine, which works by the action of specific antibodies that block the process of the parasite maturation inside the vector [9], thereby reducing the infectiousness of the vector and term $\theta$ as above.

Dividing by $S=S_{1}+S_{2}+S_{3}$ and by $d t$ we get the first of the last three equations of system (1).

\section{Results}

To simulate five possible control strategies, namely, dog treatment, insecticide-impregnated collars, culling, transmissionblocking vaccine, and vector control, several parameters were added to the original model by Burattini et al. [14]. We therefore simulated the system (1) with the parameters described in Table 1, to analyze the comparative effect of each of the five control strategies, being included one by one in the model. The range of the parameters related to control was assumed to vary from 1 (without control) to 1,000.

Dog treatment with chemotherapy based on meglumine antimoniate and allopurinol is the current standard to control leishmaniasis $[17,18]$. In the model this strategy is simulated by varying the rate $\omega$ in the fifth and seventh equations, such that infected dogs are removed from the infectious compartment and are transferred to the susceptible compartment.

The use of deltamethrin-impregnated dog collars [8] was simulated by varying the term $\theta$ in the fifth and sixth equations, based on the mechanism of repelling the vector and reducing the biting rate to the dogs.

Dog culling was simulated by varying the term $\xi$ in the sixth and seventh equations, which represent an additional mortality rate to the natural mortality rate $\mu_{d}$ of dogs.

Transmission-blocking vaccines [9] act by raising antibodies in protected dogs, which impede the biding of leishmania to the sandflies midguts to curtail the transmission of the infection [19]. This strategy was simulated by varying the term $v$ in the last three equations of the system (1).

Finally, vector control, normally carried out by house spraying of insecticides [7], was simulated by simply increasing the natural mortality rate of sandflies $\mu_{s}$.

The results of the simulations described previously can be seen in Figure 1.

Note that the effectiveness of the simulated control strategies ranges from practically in the case of dog treatment to complete null in the case of vector control. Treating dogs is practically ineffective in reducing disease in humans, followed by vaccine, which has a very small impact on human prevalence. Culling dogs, the official strategy in Brazil, is the next least effective, but it is necessary to increase the natural mortality rate of dogs by one thousand times to reduce human prevalence significantly. The use of insecticide-impregnated collars is very effective in controlling the disease in humans. However, as previously discussed and demonstrated in other studies, vector control is by far the most effective strategy in controlling ZVL in humans, being more than 50 times effective than culling dogs (see Figure 1).

In the context of the present model, the central parameter related to control is the force of infection, also known as 


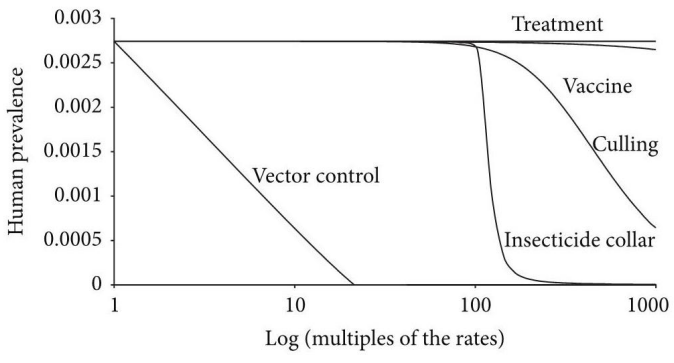

FIGURE 1: Result of the simulations of the system (1) with the parameters from Table 1 .

the incidence-density rate. This parameter is defined as the per capita number of new infections per unit time, and it is normally denoted by the Greek letter $\lambda[20]$. For a vectorborne infection, $\lambda$ is defined as [20]

$$
\lambda(t)=m_{i} a_{i} b_{i} S_{3}(t),
$$

where $i=d$ for dogs and $i=h$ for humans and the components are the same as above. From the force of infection we can calculate the risk $R$ of acquiring the infection as [21]

$$
R=1-\exp \left[-\int_{0}^{\infty} \lambda(t) d t\right]=1-\exp \left[-m_{i} a_{i} b_{i} \int_{0}^{\infty} S_{3}(t) d t\right] .
$$

It is now possible to interpret our results. Each of the tested control strategies acts on one or more of the components of (5). Therefore, treating dogs should reduce the number of infected flies; culling should reduce the number of available dogs, which would theoretically reduce the number of available dogs in the transmission chain; the transmissionblocking vaccine was assumed to interfere with the probability of infection to the flies, reducing the total number of infected vectors; insecticide-impregnated collars reduce the biting rate, which is directly related with the risk of infection; and vector control directly reduces the number of infected flies.

\section{Discussion}

Ethical, legal and societal value issues related to animals should determine the way we handle them [22]. Unfortunately, some people and governments think that questions of humanity and justice have nothing to do with our treatment of animals [22]. As mentioned by Singer [23], "once we recognize that nonhuman animals have complex emotional and social needs, we begin to see animal abuse where others might not see it."

In ecological studies, it has been demonstrated that lethal methods of controlling wildlife may present difficulties in terms of conservation, ethics, welfare, and efficacy. It is therefore imperative to develop nonlethal alternatives and the advantages they might bring [24]. Concerns over widespread culling of wildlife have led to increasing interest in nonlethal control methods that target problem animals in particular [25]. The same arguments hold for domestic animals, in particular for such species like pets, which are increasingly being considered as part of the family. Therefore, alternative methods of controlling zoonosis transmitted by dogs other than simple destruction are, among other considerations, a matter of ethics. In addition, veterinarians in charge of decisions regarding implementation of culling actions find themselves in conflict between the officially required disease control policy and a public that is increasingly critical. Those veterinarians are faced with the challenge to defend the relevant decisions against all stakeholders and also themselves [26]. This brings additional ethical considerations to the culling problem.

In a quite interesting paper, Cohen et al. [27] present a model for describing people's fundamental moral attitudes in judgment of the culling animals in the context of animal disease. The authors defend that those fundamental moral attitudes are a two-layered concept. The first layer consists of deeply felt convictions about animals. The second layer consists of convictions derived from the first layer to serve as arguments in a debate on animal issues. These authors conclude that the value of an animal's life conviction was indeed the core argument against the culling of animals.

Our model demonstrates that some alternative control methods of ZVL are not only feasible but also more effective that the culling of seropositive dogs. Two of the tested control strategies fared better than dog destruction, the use of insecticide-impregnated collars, and vector control. The latter has already been proposed in the context of other vector-borne infections [28-30], and, in spite of its logistical difficulties, vector control is the strategy with the highest impact on the infection's basic reproduction ratio [31, 32]. However, as mentioned previously, the central parameter related to control is the force of infection, and the analysis of the latter allows us to interpret our results in a straightforward way.

\section{Conclusions}

In conclusion, our model demonstrated that at least two alternative control strategies to culling dogs are more effective in reducing human prevalence of ZVL than the destruction of seropositive dogs, insecticide-impregnated collars, and vector control. It should be expected that a combination of those two strategies would have a more significant impact on human prevalence. Invariably we will not be able to put a collar on every dog or kill all the sandflies, but through a combination of both we could effectively reach the same result without needing to be as thorough with one method. Therefore, the traditional method of controlling $\mathrm{ZVL}$, the destruction of seropositive dogs, can be abandoned without any harm to the human population.

Finally, although the treatment of infected dogs is practically ineffective in reducing human prevalence of ZVL, it should be provided on ethical and humanitarian grounds.

As mentioned by Singer P et al. [23] "universal common morality only supplies the core moral concepts and principles 
on the basis of which we can and should reflect on the appropriate treatment of animals."

\section{Conflict of Interests}

The authors declare no conflict of interests.

\section{Acknowledgments}

This work was supported by the Laboratório de Investigação Médica do Hospital das Clínicas da Faculdade de Medicina da Universiidade de São Pulo -01 (IM01-HCFMUSP), Conselho Nacionla de Pesquisas (CNPq), and Fundação de Amparo à Pesquisa de São Paulo (FAPESP).

\section{References}

[1] R. B. Tesh, "Control of zoonotic visceral leishmaniasis: is it time to change strategies?" The American Journal of Tropical Medicine and Hygiene, vol. 52, no. 3, pp. 287-292, 1995.

[2] R. J. Quinnell and C. Dye, "Correlates of the peridomestic abundance of Lutzomyia longipalpis (Diptera: Psychodidae) in Amazonian Brazil," Medical and Veterinary Entomology, vol. 8 no. 3, pp. 219-224, 1994

[3] R. J. Quinnell, O. Courtenay, L. Garcez, and C. Dye, "The ep idemiology of canine leishmaniasis: transmission rates estimated from a cohort study in Amazonian Brazil," Parasitology, vol. 115, no. 2, pp. 143-156, 1997.

[4] A. Falqueto, A. L. Ferreira, C. B. Dos Santos et al., "Crosssectional and longitudinal epidemiologic surveys of human and canine Leishmania infantum visceral infections in an endemic rural area of Southeast Brazil," The American Journal of Tropical Medicine and Hygiene, vol. 80, no. 4, pp. 559-565, 2009.

[5] O. Courtenay, R. J. Quinnell, L. M. Garcez, J. J. Shaw, and C. Dye, "Infectiousness in a cohort of Brazilian dogs: why culling fails to control visceral leishmaniasis in areas of high transmission," Journal of Infectious Diseases, vol. 186, no. 9, pp. 1314-1320, 2002.

[6] D. A. Ashford, J. R. David, M. Freire et al., "Studies on control of visceral leishmaniasis: impact of dog control on canine and human visceral leishmaniasis in Jacobina, bahia, Brazil," The American Journal of Tropical Medicine and Hygiene, vol. 59, no. 1, pp. 53-57, 1998.

[7] WHO Expert Committee, "Control of the leishmaniases, World Health Organization Technical Report Series 793, 1990.

[8] R. Reithinger, P. G. Coleman, B. Alexander, E. P. Vieira, G. Assis, and C. R. Davies, "Are insecticide-impregnated dog collars feasible alternative to dog culling as a strategy for controlling canine visceral leishmaniasis in Brazil?" International Journal for Parasitology, vol. 34, no. 1, pp. 55-62, 2004.

[9] C. B. Palatnik-de-Sousa, I. Silva-Antunes, A. D. A. Morgado, I Menz, M. Palatnik, and C. Lavor, "Decrease of the incidence of human and canine visceral leishmaniasis after dog vaccination with Leishmune in Brazilian endemic areas," Vaccine, vol. 27, no. 27, pp. 3505-3512, 2009

[10] C. Dye, "The logic of visceral leishmaniasis control," The American Journal of Tropical Medicine and Hygiene, vol. 55, no. 2, pp. 125-130, 1996.

[11] J. B. Vieira and G. E. Coelho, "Visceral leishmaniasis or kalaazar: the epidemiological and control aspects," Revista do Sociedade Brasileira de Medicina Tropical, vol. 31, supplement 2, pp. 85-92, 1998.
[12] A. V. P. Barreto, "Northeastern symposium on leishmaniasis," Clinica Veterinária, vol. 84, pp. 12-13, 2010.

[13] P. Singer, Animal Liberation, Ecco, New York, NY, USA, 2nd edition, 2003.

[14] M. N. Burattini, F. A. B. Coutinho, L. F. Lopez, and E. Massad, "Modelling the dynamics of leishmaniasis considering human, animal host and vector populations," Journal of Biological Systems, vol. 6, no. 4, pp. 337-356, 1998.

[15] M. D. Braga, I. C. Coêlho, M. M. Pompeu et al., "Control of canine visceral leishmaniasis: comparison of results from a rapid elimination program of serum-reactive dogs using an immunoenzyme assay and slower elimination of serumreactive dogs using filter paper elution indirect immunofluorescence," Revista da Sociedade Brasileira de Medicina Tropical, vol. 31, no. 5, pp. 419-424, 1998.

[16] M. Paranhos-Silva, E. G. Nascimento, M. C. B. F. Melro et al., "Cohort study on canine emigration and Leishmania infection in an endemic area for American visceral leishmaniasis. Implications for the disease control," Acta Tropica, vol. 69, no. 1, pp. 75-83, 1998.

[17] A. João, M. A. Pereira, S. Cortes, and G. M. Santos-Gomes, "Canine leishmaniasis chemotherapy: dog's clinical condition and risk of Leishmania transmission," Journal of Veterinary Medicine A, vol. 53, no. 10, pp. 540-545, 2006.

[18] F. A. Ikeda-Garcia, R. S. Lopes, P. C. Ciarlini et al., "Evaluation of renal and hepatic functions in dogs naturally infected by visceral leishmaniasis submitted to treatment with meglumine antimoniate," Research in Veterinary Science, vol. 83, no. 1, pp. 105-108, 2007.

[19] E. M. Saraiva, A. D. F. Barbosa, F. N. Santos et al " "The FMLvaccine (Leishmune) against canine visceral leishmaniasis: a transmission blocking vaccine," Vaccine, vol. 24 , no. 13 , pp. 2423-2431, 2006.

[20] E. Massad, R. H. Behrens, M. N. Burattini, and F. A. B. Coutinho, "Modeling the risk of malaria for travelers to areas with stable malaria transmission," Malaria Journal, vol. 8, no. 1, article 296, 2009.

[21] N. T. J. Bailey, The Mathematical Theory of Infectious Diseases and Its Applications, Charles Griffin and Company Limited, London, UK, 1975.

[22] T. L. Beauchamp, F. B. Orlans, R. Dresser, D. B. Morton, and J. P. Gluck, The Human Use of Animals, Oxford University Press, Oxford, UK, 2008

[23] P. Singer P, "Morality, reason, and the rights of animals," in Primates and Philosophers: How Morality Evolved, S. Macedo and J. Ober, Eds., Princeton University Press, Princeton, NJ, USA, 2006.

[24] S. E. Baker, S. A. Ellwood, R. Watkins, and D. W. Macdonald, "Non-lethal control of wildlife: using chemical repellents as feeding deterrents for the European badger Meles meles," Journal of Applied Ecology, vol. 42, no. 5, pp. 921-931, 2005.

[25] J. A. Shivik, A. Treves, and P. Callahan, "Nonlethal techniques for managing predation: primary and secondary repellents," Conservation Biology, vol. 17, no. 6, pp. 1531-1537, 2003.

[26] S. Hartnack, M. G. Doherr, H. Grimm, and P. Kunzmann, "Mass culling in the context of animal disease outbreaks," Deutsche Tierarztliche Wochenschrift, vol. 116, no. 4, pp. 152-157, 2009.

[27] N. E. Cohen, F. W. A. Brom, and E. N. Stassen, "Fundamental moral attitudes to animals and their role in judgment: an empirical model to describe fundamental moral attitudes to animals and their role in judgment on the culling of healthy animals 
during an animal disease epidemic," Journal of Agricultural and Environmental Ethics, vol. 22, no. 4, pp. 341-359, 2009.

[28] E. Massad, F. A. B. Coutinho, M. N. Burattini, and L. F. Lopez, "The risk of yellow fever in a dengue-infested area," Transactions of the Royal Society of Tropical Medicine and Hygiene, vol. 95, no. 4, pp. 370-374, 2001.

[29] L. F. Lopez, F. A. B. Coutinho, M. N. Burattini, and E. Massad "Threshold conditions for infection persistence in complex host-vectors interactions," Comptes Rendus-Biologies, vol. 325, no. 11, pp. 1073-1084, 2002.

[30] F. A. B. Coutinho, M. N. Burattini, L. F. Lopez, and E. Massad, "Threshold conditions for a non-autonomous epidemic system describing the population dynamics of dengue," Bulletin of Mathematical Biology, vol. 68, no. 8, pp. 2263-2282, 2006.

[31] C. A. Marques, O. P. Forattini, and E. Massad, "The basic reproduction number for dengue fever in Sao Paulo State, Brazil: 1990-1991 epidemic," Transactions of the Royal Society of Tropical Medicine and Hygiene, vol. 88, no. 1, pp. 58-59, 1994.

[32] E. Massad, F. A. B. Coutinho, H. M. Yang, H. B. de Carvalho, F. Mesquita, and M. N. Burattini, "The basic reproduction ratio of HIV among intravenous drug users," Mathematical Biosciences, vol. 123 , no. 2, pp. 227-247, 1994 
Apêndice F - Artigos aceitos para publicação

Zoonotic visceral leishmaniasis: a novel model involving dynamic interactions of humans, dogs and sandflies 


\title{
ZOONOTIC VISCERAL LEISHMANIASIS: A NOVEL MODEL INVOLVING DYNAMIC INTERACTIONS OF HUMANS, DOGS AND SANDFLIES
}

\author{
HELIO JUNJI SHIMOZAKO
}

University of São Paulo

School of Medicine, Oscar Freire Institute

Avenida Doutor Arnaldo - 455

São Paulo - SP, 01246-000, Brazil and

York University

Ross Building, Department of Mathmatics and Statistics 4700 Keele Street

Toronto - ON, M3J1P3, Canada

Corresponding author: hjunji21@usp.br

\section{JIANHONG WU}

York University

Ross Building, Department of Mathmatics and Statistics

4700 Keele Street

Toronto - ON, M3J1P3, Canada

\section{EDUARDO MASSAD}

University of São Paulo, School of Medicine and LIM 01, HCFMUSP

Rua Teodoro Sampaio - 115

CEP: 05405-000, São Paulo, Brazil

and

London School of Hygiene and Tropical Medicine

London University, UK 
Brazil is one of the high endemic countries for visceral leishmaniasis (VL): according to the Brazilian Ministry of Health, the annual number of new human cases and deaths due to VL has been increasing for the last 20 years. In this work, we developed a novel optimization model for VL control with five potential preventive control methods: (1) insecticide-impregnated dog collar, (2) dog vaccination, (3) infected dog culling, (4) infected dog treatment and (5) sandfly population control. Using a set of differential equations we simulated the dynamic of this disease and the optimal control strategy is examined considering the best cost-benefit relationship for these five control methods. Although this model is based on the previous model from Burattini et al. (1998) and Ribas et al. (2013), here we simulated with most of parameters updated and we included new categories that represent vaccinated dogs and dogs with insecticide impregnated collar. As conclusion, we obtained a good representation of the zoonotic visceral leishmaniasis dynamics and we found the sandfly population control as the best individual strategy to reduce the human incidence of this disease.

Keywords: visceral leishmaniasis, mathematical modeling, disease control, epidemiology.

\section{Introduction}

Visceral leishmaniasis is one of the world deadliest and neglected infectious disease, according to World Health Organization. This disease is endemic in 80 countries worldwide, in which $90 \%$ of all visceral leishmaniasis cases occur in Bangladesh, Brazil, India, Nepal and Sudan. Thus, about 360 million of people are exposed to risk of infection in the world ${ }^{1,2,3,4}$. The visceral leishmaniasis is a disease of major human and veterinary medical significance that involves a complex interplay between a protozoal pathogen, arthropod vectors, environmental influence on vector distribution, a small companion animal (dog) reservoir of infection and susceptible human populations. The leishmaniasis is emerging within non-endemic areas mostly because of transportation of dogs from endemic areas and climatic changes with the expansion of the geographical range of the sandfly vector. Then, the efective control will essentially involve interdisciplinary teams of microbiologists, parasitologists, entomologists, ecologists, epidemiologists, immunologists, veterinarians, public health officers and human physicians ${ }^{5}$.

Considering only the preventive activities, the currently strategies focuses the reservoirs (dog population) and sandflies population. In order to exemplify these strategies focusing the dog population, we can mention the elimination ${ }^{6}$, application of insecticide-impregnated collars ${ }^{7}$, vaccination $^{8,9}$ and treatment ${ }^{10}$ of infected dogs. On the other hand, focusing the sandflies population, we can mention the environmental intervention by the application of chemical control and environmental sanitation. 
Besides the publication of guidelines of visceral leishmaniasis control and the investments made in general surveillance activities, the sandfly and the reservoir in urban areas remains among the major challenges for the control activities. These challenges are due to (1) the necessity to better understand the vector behavior in urban environment; (2) the operational and logistic dificulties to carry out activities in sufficient time to obtain good results; and (3) the high costs involved in these activities ${ }^{2,11}$. In addition, regarding the Americas, the specific relationship between canine and human visceral leishmaniasis is not well understood. Thus, the control of the animal reservoir is complex and frequently involves combined interventions. In particular, the Brazilian Control Program recomends a strategy based on canine culling and vector control with insecticide spraying. Insecticide-impregnated collars for dogs and canine vaccination are not currently recomended as public health control measures ${ }^{5,12}$.

In this work we propose a new model for zoonotic visceral leishmaniasis, based on the models previously published by Burattini et al. ${ }^{13}$ and Ribas et al. and we included the effect of five control methods (sandfly population control, culling dogs, vaccination, treatment of infected dogs and use of insecticide impregnated dog collar). We simulated this model without the controls and with the controls individually. Then, we compare the efficacy of each one on the human reported case rate, in terms of rate value and cost-beneffit.

\section{The model}

The basic idea of our model is based on the models published by Burattini et al. ${ }^{13}$ and Ribas et al. ${ }^{14}$. However, in our model we focused on the Zoonotic Visceral Leishmaniasis and we analysed the the effect of the preventive control methods with more details.

The mathematical model used in this study consists of a set of differential equations, where some terms are delayed terms. Those equations represents the human population (with the index $h$ ), the dog population (index $d$ ). In both human and dog population we have susceptible (indicated by $x_{i}$ ), latent (which means infected but not clinally ill) $\left(l_{i}\right)$, clinically ill $\left(y_{i}\right)$, and recovered $\left(z_{i}\right)$ individuals. In the case of dog population, we also have compartments for dogs that use insecticide impregnated collars (indicated by the superscript $C$ ) and vaccinated dogs (indicated by $v_{d}$ ).

In addition to human and dog population, we also included sandfly population, where $s_{1}$ is the non infected, $s_{2}$ is the infected but not infective, and 


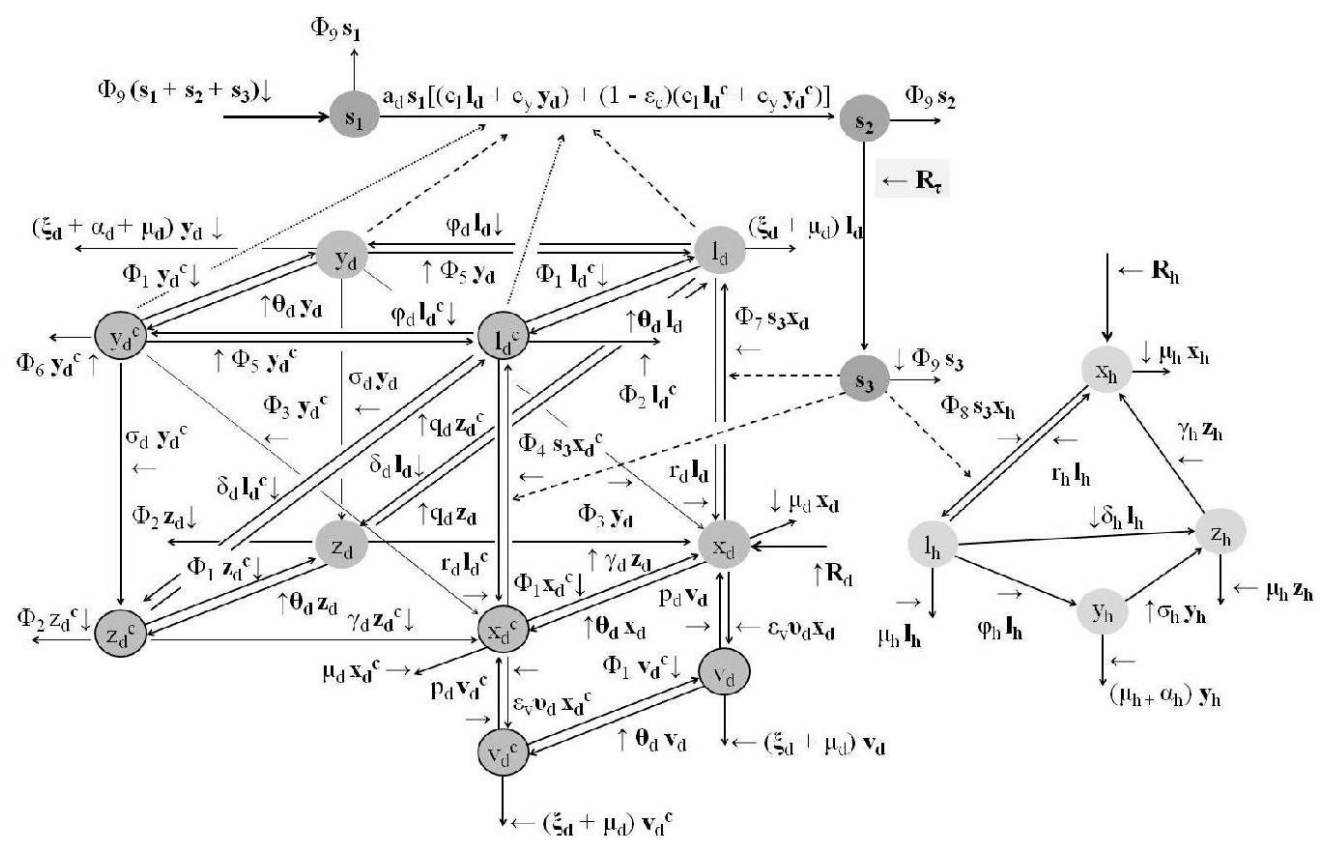

$$
\begin{aligned}
& \mathbf{R}_{\tau}=\mathbf{a}_{\mathrm{d}} \mathbf{s}_{\mathbf{1}}(\mathbf{t}-\tau)\left[\left(\mathrm{c}_{\mathrm{l}} \mathbf{l}_{\mathbf{d}}(\mathbf{t}-\tau)+\mathrm{c}_{\mathrm{y}} \mathbf{y}_{\mathbf{d}}(\mathbf{t}-\tau)\right)+\left(\mathbf{l}-\varepsilon_{\mathrm{c}}\right)\left(\mathrm{c}_{\mathbf{l}} \mathbf{l}_{\mathbf{d}}{ }^{\mathrm{c}}(\mathbf{t}-\tau)+\mathrm{c}_{\mathrm{y}} \mathbf{y}_{\mathbf{d}}{ }^{\mathbf{c}}(\mathbf{t}-\tau)\right)\right] \mathrm{e}^{-\left(\mu_{\mathrm{s}}+\xi_{\mathrm{s}}\right) \tau} \\
& \mathbf{R}_{\mathbf{d}}=\left(\xi_{\mathrm{d}}+\alpha_{\mathrm{d}}+\mu_{\mathrm{d}}\right)\left(\mathbf{y}_{\mathrm{d}}+\mathbf{y}_{\mathrm{d}}^{\mathrm{c}}\right)+\left(\xi_{\mathrm{d}}+\mu_{\mathrm{d}}\right)\left(\mathbf{l}_{\mathrm{d}}+\mathbf{l}_{\mathrm{d}} \mathrm{c}+\mathbf{z}_{\mathrm{d}}+\mathbf{z}_{\mathrm{d}}{ }^{\mathrm{c}}+\mathbf{v}_{\mathrm{d}}+\mathbf{v}_{\mathrm{d}} \mathrm{c}\right)+\mu_{\mathrm{d}}\left(\mathbf{x}_{\mathrm{d}}+\mathbf{x}_{\mathrm{d}}{ }^{\mathrm{c}}\right) \\
& \mathbf{R}_{\mathbf{h}}=\left(\mu_{\mathrm{h}}+\alpha_{\mathrm{h}_{1}}\right) \mathbf{y}_{\mathbf{h}}+\mu_{\mathrm{h}}\left(\mathbf{x}_{\mathbf{h}}+\mathbf{l}_{\mathbf{h}}+\mathbf{z}_{\mathbf{h}}\right) \\
& \Phi_{1}=\left(\mathrm{u}_{\mathrm{c}}+\zeta_{\mathrm{c}}\right) \quad \Phi_{6}=\left(\xi_{\mathrm{d}}+\alpha_{\mathrm{d}}+\mu_{\mathrm{d}}\right) \\
& \Phi_{2}=\left(\check{\xi}_{\mathbf{d}}+\mu_{\mathrm{d}}\right) \quad \Phi_{7}=\mathbf{b}_{\mathrm{d}} \mathrm{a}_{\mathrm{d}} \mathbf{m}_{\mathrm{d}} \\
& \Phi_{3}=\left(1-c_{\mathrm{k}}\right) \psi_{\mathrm{d}} \boldsymbol{\omega}_{\mathrm{d}} \quad \Phi_{8}=\mathrm{b}_{\mathrm{h}} \mathrm{a}_{\mathrm{h}} \mathbf{m}_{\mathrm{h}} \\
& \Phi_{4}=\mathrm{b}_{\mathrm{d}}\left(1-\varepsilon_{\mathrm{c}}\right) \mathrm{a}_{\mathrm{d}} \mathrm{m}_{\mathrm{d}} \quad \Phi_{9}=\left(\xi_{\mathrm{s}}+\mu_{\mathrm{s}}\right) \\
& \Phi_{5}=\mathbf{f}_{\mathrm{d}}+c_{\mathrm{k}} \psi_{\mathrm{d}} \boldsymbol{\omega}_{\mathrm{d}}
\end{aligned}
$$

Figure 1. Model compartments and the flow between them.

$s_{3}$ is the infected and infective sandfly. Thus, the sandflies in $s_{3}$ category is able to infect susceptible human and dogs.

The Figure 1 represents the compartments and the flowchart of our model.

The set of differential equations for human population is represented by Eq. (1) to (4). 


$$
\begin{aligned}
\dot{x_{h}}(t)= & \left(\mu_{h}+r_{h}\right) l_{h}(t)+\left(\mu_{h}+\alpha_{h}\right) y_{h}(t)+\left(\mu_{h}+\gamma_{h}\right) z_{h}(t) \\
& -\left(b_{h} a_{h} m_{h} s_{3}(t)\right) x_{h}(t) \\
\dot{l_{h}}(t)= & \left(b_{h} a_{h} m_{h} s_{3}(t)\right) x_{h}(t)-\left(\mu_{h}+r_{h}+\delta_{h}+\varphi_{h}\right) l_{h}(t) \\
\dot{y_{h}}(t)= & \left(\varphi_{h}\right) l_{h}(t)-\left(\mu_{h}+\alpha_{h}+\sigma_{h}\right) y_{h}(t) \\
\dot{z_{h}}(t)= & \delta_{h} l_{h}(t)+\sigma_{h} y_{h}(t)-\left(\mu_{h}+\gamma_{h}\right) z_{h}(t)
\end{aligned}
$$

Eq. (5) to (14) represent the dog population.

$$
\begin{aligned}
& \dot{x_{d}}(t)=-\left(\varepsilon_{v} \nu_{d}+\theta_{d}(t)+b_{d} a_{d} m_{d} s_{3}(t)\right) x_{d}+\left(\mu_{d}+\zeta_{d}+u_{c}\right) x_{d}^{C} \\
&+\left(\xi_{d}(t)+\mu_{d}+r_{d}\right) l_{d}(t)+\left(\xi_{d}(t)+\mu_{d}\right) l_{d}^{C}(t)+\left(\xi_{d}(t)+\mu_{d}\right) z_{d}^{C}(t) \\
&+\left(\xi_{d}(t)+\alpha_{d}+\mu_{d}+\left(1-c_{k}\right) \psi_{d} \omega_{d}(t)\right) y_{d}(t)+\left(\xi_{d}(t)+\mu_{d}\right) v_{d}^{C}(t) \\
&+\left(\xi_{d}(t)+\alpha_{d}+\mu_{d}\right) y_{d}^{C}(t)+\left(\xi_{d}(t)+\mu_{d}+p_{d}\right) v_{d}(t) \\
&+\left(\xi_{d}(t)+\mu_{d}+\gamma_{d}\right) z_{d}(t) \\
& \dot{x_{d}^{C}}(t)= r_{d} l_{d}^{C}(t)+\left(1-c_{k}\right) \psi_{d} \omega_{d}(t) y_{d}^{C}(t)+\gamma_{d} z_{d}^{C}+p_{d} v_{d}^{C}+\theta(t) x_{d}(t) \\
&-\left(\left(1-\varepsilon_{c}\right) b_{d} a_{d} m_{d} s_{3}(t)+\varepsilon_{v} \nu_{d}+\mu_{d}+\zeta_{c}+u_{c}\right) x_{d}^{C}(t) \\
& \dot{l_{d}}(t)= b_{d} a_{d} m_{d} s_{3}(t) x_{d}(t)-\left(\xi_{d}(t)+\theta_{d}(t)+r_{d}+\delta_{d}+\mu_{d}+\varphi_{d}\right) l_{d} \\
&\left(\zeta_{c}+u_{c}\right) l_{d}^{C}(t)+\left(f_{d}+c_{k} \psi_{d} \omega_{d}(t)\right) y_{d}+q_{d} z_{d} \\
& \dot{l}_{d}^{C}(t)=\left(1-\varepsilon_{c}\right) b_{d} a_{d} m_{d} s_{3}(t) x_{d}^{C}(t)+\theta_{d} l_{d}(t)+c_{k} \psi_{d} \omega_{d}(t) y_{d}(t) \\
&+q_{d} z_{d}^{C}(t)-\left(\xi_{d}(t)+\zeta_{c}+u_{c}+\mu_{d}+r_{d}+\delta_{d}+\varphi_{d}\right) l_{d}^{C}(t) \\
& \dot{y_{d}}(t)= \varphi_{d} l_{d}(t)+\left(\zeta_{c}+u_{c}\right) y_{d}^{C}(t) \\
&-\left(f_{d}+\sigma_{d}+\mu_{d}+\alpha_{d}+\mu_{d}+\theta_{d}(t)+\xi_{d}(t)+\psi_{d} \omega_{d}(t)\right) y_{d}(t) \\
& \dot{y_{d}^{C}}(t)= \varphi_{d} l_{d}^{C}(t)+\theta_{d}(t) y_{d}(t) \\
&-\left(f_{d}+\sigma_{d}+\mu_{d}+\alpha_{d}+\mu_{d}+\zeta_{c}+u_{c}+\xi_{d}(t)+\psi_{d} \omega_{d}(t)\right) y_{d}^{C}(t) \\
& \dot{z_{d}}(t)= \delta_{d} l_{d}(t)+\sigma_{d} y_{d}(t)-\left(q_{d}+\gamma_{d}+\mu_{d}+\theta_{d}(t)+\xi_{d}(t)\right) z_{d}(t) \\
&+\left(\zeta_{c}+u_{c}\right) z_{d}^{C}(t) \\
& \delta_{d} l_{d}^{C}(t)+\sigma_{d} y_{d}^{C}(t)+\theta_{d}(t) z_{d}(t)+\left(\zeta_{c}+u_{c}\right) z_{d}^{C} \\
&-\left(q_{d}+\gamma_{d}+\mu_{d}+\zeta_{c}+u_{c}+\xi_{d}(t)\right) z_{d}(t) \\
& \varepsilon_{v} \nu_{d}(t) x_{d}(t)-\left(p_{d}+\mu_{d}+\theta_{d}(t)+\xi_{d}(t)\right) v_{d}(t)+\left(\zeta_{c}+u_{c}\right) v_{d}^{C}
\end{aligned}
$$




$$
\begin{aligned}
\dot{v}_{d}^{C}(t)= & \varepsilon_{v} \nu_{d}(t) x_{d}^{C}(t)+\theta_{d}(t) v_{d}(t) \\
& -\left(p_{d}+\mu_{d}+\zeta_{c}+u_{c}+\xi_{d}(t)\right) v_{d}^{C}(t)
\end{aligned}
$$

Eq. (15) to (17) represent sandfly population.

$$
\begin{aligned}
\dot{s_{1}}(t)= & \left(\mu_{s}+\xi_{d}(t)\right)\left(s_{2}(t)+s_{3}(t)\right)-a_{d}\left(c_{l} l_{d}(t)+c_{y} y_{d}(t)+\right. \\
& \left.+\left(1-\varepsilon_{c}\right)\left(c_{l} l_{d}^{C}(t)+c_{y} y_{d}^{C}(t)\right)\right) s_{1}(t) \\
\dot{s_{2}}(t)= & a_{d}\left(c_{l} l_{d}(t)+c_{y} y_{d}(t)+\left(1-\varepsilon_{c}\right)\left(c_{l} l_{d}^{C}(t)+c_{y} y_{d}^{C}(t)\right)\right) s_{1}(t) \\
& -a_{d}\left(c_{l} l_{d}(t-\tau)+c_{y} y_{d}(t-\tau)+\left(1-\varepsilon_{c}\right)\left(c_{l} l_{d}^{C}(t-\tau)\right.\right. \\
& \left.\left.+c_{y} y_{d}^{C}(t-\tau)\right)\right) e^{-\left(\mu_{s}+\xi_{s}(t)\right) \tau} s_{1}(t-\tau)-\left(\mu_{s}+\xi_{d}(t)\right) s_{2}(t) \\
\dot{s_{3}}(t)= & a_{d}\left(c_{l} l_{d}(t-\tau)+c_{y} y_{d}(t-\tau)+\left(1-\varepsilon_{c}\right)\left(c_{l} l_{d}^{C}(t-\tau)\right.\right. \\
& \left.\left.+c_{y} y_{d}^{C}(t-\tau)\right)\right) e^{-\left(\mu_{s}+\xi_{s}(t)\right) \tau} s_{1}(t-\tau)-\left(\mu_{s}+\xi_{d}(t)\right) s_{3}(t)
\end{aligned}
$$

where the definition, the biological meaning and the values of each of the parameters used are described in Table 1. Some of those parameters were not found in the literature. Then they were just fitted in order to reproduce the disease dynamics with more realistic approach. Others were just estimated according to sources related to Brazilian Ministry of Health (as $\left.a_{h}, \varphi_{h}, \sigma_{h}, a_{d}, \mu_{s}, \tau\right)$ or according to personal communication $\left(c_{l}\right.$ and $c_{y}$ were estimated by C. N. Rossi, 2013).

A brief description of the set of Eq. (1) to (17) should clarify their meaning.

Let $S$ be the total number of sandflies. The number of bites inflicted in the human host population in an infinitesimal time interval dt is $a_{h} S d t$, where is the biting rate on humans. The number of bites inflicted by infected flies is $S=a_{h} S d t s_{3}$, where $S_{3}$ is the number of infected flies.

Let now $X_{h}$ be the total number of susceptible individuals in the human population. In an infinitesimal time interval dt, $X_{h}$ varies as follows:

- a fraction of the infected bites are on uninfected individuals: $a_{h} S d t s_{3} x_{h}$. A fraction $b_{h}$ of these becomes latent, so $X_{h}$ diminishes by $b_{h} a_{h} S d t s_{3} x_{h}$;

- in the same time interval $r_{h} L_{h} d t+\gamma_{h} Z_{h}$ individuals, latent and immune, revert to the susceptible condition, and $\mu_{h} X_{h} d t$ die by natural causes other than the disease;

- we must add an entrance term, due to natality, which we choose to be $\alpha_{h} Y_{h} d t+\mu_{h} N_{h} d t$, where $\alpha_{h}$ is the disease-induced mortality 
rate, $Y_{h}$ is the number of infected humans, and $N_{h}$ is the total number of humans needed to maintain a constant population.

Therefore we have:

$$
\begin{aligned}
d X_{h}= & \alpha_{h} Y_{h}(t) d t+\mu_{h} N_{h} d t-b_{h} a_{h} S d t s_{3}(t) x_{h}(t)-\mu_{h} X_{h}(t) d t \\
& +\left(r_{h} L_{h}(t) d t+\gamma_{h} Z_{h}(t) d t\right)
\end{aligned}
$$

Divinding this equation by Nhdt and calling $S / N_{h}=m_{h}$, we get the first Eq. (1) of our model.

Equations indexed with $d$ in the model are related to the dog's subpopulation. They differ from the original model by Burattini et al. 13 by including control terms. Therefore, the term $\omega_{d}$ refers to the treatment rate, according to which infected dogs are removed from the infectious compartment and are transferred to the susceptible and latent one; the term $\theta_{d}$ refers to the insecticide-impregnated collars, which by repelling the vector reduce the biting rate to the dogs; and finally the term $\xi_{d}$ refers to the culling of dogs diagnosed as positive by serology test (by hipotesis, all dog that had contact with the parasite or its antigen, is considered positive by serology test). We also included the term $\nu_{d}$, that means dogs vaccinated with transmission-blocking vaccine ${ }^{9}$, in which are removed from the susceptible category to the vaccinated one.

The last three equations of our model refer to the flies. When infected, a fly remains in a latent stage for a period of time $\tau$. This time corresponds to the extrinsic incubation period of the parasite inside the vector fly. Numerically it lasts for about half the life expectancy of the flies.

Let $S_{1}$ be the number of susceptible flies. In an infinitesimal period of time dt, $\left(a_{d}\left(\left(Y_{d}+L_{d}+\left(1-\varepsilon_{c}\right)\left(L_{d}^{C}+Y_{d}^{C}\right)\right) / N_{d}\right) d t\right) S_{1}$ bites due to uninfected flies occur on latent and infected dogs (humans are not considered to be infective for flies; see Tesh ${ }^{15}$ ). If the latent and infected dogs are using the insecticide impregnated collar, the probability of being bitten is reduced by $\varepsilon_{c}$. A fraction $c_{l}$ (if biting a latent $\operatorname{dog}$ ) and $c_{y}$ (if bitting a clinically ill dog) of the flies becomes latently infected as a result. Therefore, we have:

$$
\begin{aligned}
d S_{1}= & \left(S_{2}(t)+S_{3}(t)\right) d t \\
& -a_{d}\left(c_{l} l_{d}(t)+c_{y} y_{d}(t)+\left(1-\varepsilon_{c}\right)\left(c_{l} l_{d}(t)^{C}+c_{y} y_{d}^{C}(t)\right)\right) S_{1}(t) d t
\end{aligned}
$$

Dividing by $S=S_{1}+S_{2}+S_{3}$ and by $d t$ we get the first of the last three equations of the model. The term $e^{-\left(\mu_{s}+\xi_{s}(t)\right) \tau}$ accounts for sandflies infected at time $t$, but that die before producing infective sandflies. 
Table 1. Parameters used in the model, their biological meaning and numerical values. In the table, $h$ stands for humans, $d$ for $\operatorname{dogs}$ and $s$ for sandflies.

\begin{tabular}{|c|c|c|c|}
\hline Parameter & Biological meaning & Source & Numerical Value \\
\hline$\mu_{h}$ & Natural mortality rate & $\mathrm{IBGE}^{16}$ & $3.67 \times 10^{-5}$ days $^{-1}$ \\
\hline$\alpha_{h}$ & $\begin{array}{l}\text { Kalazar specific lethal- } \\
\text { ity }\end{array}$ & $\begin{array}{l}\text { World Health } \\
\text { Organization }^{4}\end{array}$ & $8.40 \times 10^{-3}$ days $^{-1}$ \\
\hline$a_{h}$ & $\begin{array}{l}\text { Average daily biting } \\
\text { rate }\end{array}$ & Estimated & $2.00 \times 10^{-1}$ days $^{-1}$ \\
\hline$m_{h}$ & Vector density per host & Fitted & 4.00 \\
\hline$r_{h}$ & $\begin{array}{l}\text { Spontaneous recovery } \\
\text { rate }\end{array}$ & Badaro ${ }^{17}$ & $5.48 \times 10^{-4}$ days $^{-1}$ \\
\hline$\gamma_{h}$ & Loss of immunity rate & Badaro et al. 18 & $2.76 \times 10^{-4}$ days $^{-1}$ \\
\hline$\delta_{h}$ & Latent recovery rate & Badaro ${ }^{17}$ & $1.20 \times 10^{-2}$ days $^{-1}$ \\
\hline$\varphi_{h}$ & $\begin{array}{l}\text { Inverse of incubation } \\
\text { period }\end{array}$ & Estimated & $4.2 \times 10^{-3}$ days $^{-1}$ \\
\hline$\sigma_{h}$ & $\begin{array}{l}\text { Recovery rate to im- } \\
\text { munes }\end{array}$ & Estimated & $5.00 \times 10^{-2}$ days $^{-1}$ \\
\hline$b_{h}$ & $\begin{array}{l}\text { Proportion of infective } \\
\text { bites }\end{array}$ & Savani et al. 19 & $5.00 \times 10^{-3}$ \\
\hline$\eta_{h}$ & $\begin{array}{ll}\text { Proportion } & \text { of } \\
\text { unreported cases } & \end{array}$ & $\begin{array}{l}\text { Maia-elkhoury et } \\
\text { al. } 40\end{array}$ & $7.05 \times 10^{-1}$ \\
\hline$\mu_{d}$ & Natural mortality rate & Selman et al. 20 & $2.28 \times 10^{-4}$ days $^{-1}$ \\
\hline$\alpha_{d}$ & $\begin{array}{l}\text { Kalazar specific lethal- } \\
\text { ity }\end{array}$ & Lanotte 22 & $1.81 \times 10^{-3}$ days $^{-1}$ \\
\hline$a_{d}$ & $\begin{array}{l}\text { Average daily biting } \\
\text { rate }\end{array}$ & Estimated & $2.00 \times 10^{-1}$ days $^{-1}$ \\
\hline$m_{d}$ & Vector density per host & Fitted & $4.00 \times 10^{1}$ \\
\hline$p_{d}$ & $\begin{array}{l}\text { Loss of immunity rate } \\
\text { (Leishmune } \\
\text { (Bvaccination) }\end{array}$ & Zoetis Brasil $\AA^{23}$ & $2.74 \times 10^{-3}$ \\
\hline$\varphi_{d}$ & $\begin{array}{l}\text { Inverse of incubation } \\
\text { period }\end{array}$ & $\begin{array}{l}\text { Fernandez-Cotrina } \\
\text { et al. } 21\end{array}$ & $4.70 \times 10^{-3}$ days $^{-1}$ \\
\hline$b_{d}$ & $\begin{array}{l}\text { Proportion of infective } \\
\text { bites }\end{array}$ & Savani et al. 19 & $5.00 \times 10^{-3}$ \\
\hline$r_{d}$ & $\begin{array}{l}\text { Spontaneous recovery } \\
\text { rate }\end{array}$ & Lanotte ${ }^{22}$ & $5.00 \times 10^{-4}$ days $^{-1}$ \\
\hline
\end{tabular}

\section{The basic reproduction number $\left(R_{0}\right)$}

According to van den Driessche and Watmough ${ }^{28}, R_{0}$ is the expected number of secondary cases produced, in a completely susceptible population, by a typical infective individual. Thus, in order to evaluate the $R_{0}$ of our model, we did not only base our calculation method on the work published by van den Driessche and Watmough ${ }^{28}$, but also considered the assumptions adopted by them. We suggest to see their work for more details ${ }^{28}$.

Here, we remark that although this work published by van den Driess- 
Table 2. Parameters used in the model, their biological meaning and numerical values. In the table, $h$ stands for humans, $d$ for dogs and $s$ for sandflies. Continuation of Table 2

\begin{tabular}{|c|c|c|c|}
\hline Parameter & Biological meaning & Source & Numerical Value \\
\hline$\gamma_{d}$ & $\begin{array}{l}\text { Loss of immunity rate } \\
\text { (recovery to suscepti- } \\
\text { ble) }\end{array}$ & $\begin{array}{l}\text { Kault and March } \\
24\end{array}$ & $2.74 \times 10^{-3}$ days $^{-1}$ \\
\hline$\sigma_{d}$ & $\begin{array}{l}\text { Recovery rate } \\
\text { from clinically ill to im- } \\
\text { munes }\end{array}$ & Lanotte $^{22}$ & $9.04 \times 10^{-3}$ days $^{-1}$ \\
\hline$\delta_{d}$ & Latent recovery rate & Lanotte $^{22}$ & $8.22 \times 10^{-3}$ days $^{-1}$ \\
\hline$f_{d}$ & $\begin{array}{l}\text { Recovery rate from } \\
\text { clinically ill to latent }\end{array}$ & Assumed & 0 \\
\hline$q_{d}$ & $\begin{array}{l}\text { Loss of immunity rate } \\
\text { (recovery to latent) }\end{array}$ & Assumed & 0 \\
\hline$\psi_{d}$ & $\begin{array}{l}\text { Proportion of dogs who } \\
\text { do not give up the } \\
\text { treatment }\end{array}$ & Assumed & 1.0 \\
\hline$u_{c}$ & $\begin{array}{l}\text { Inverse of activity pe- } \\
\text { riod of collar }\end{array}$ & Scalibor $\AA^{25}$ & $6.70 \times 10^{-3}$ days $^{-1}$ \\
\hline$\zeta_{c}$ & $\begin{array}{l}\text { Loss of insecticide im- } \\
\text { pregnated collar }\end{array}$ & Reithinger et al. ${ }^{37}$ & $6.00 \times 10^{-3}$ days $^{-1}$ \\
\hline$\mu_{s}$ & Natural mortality rate & Estimated & $5.00 \times 10^{-2}$ days $^{-1}$ \\
\hline$\varepsilon_{v}$ & Efficacy of vaccination & Saraiva et al. ${ }^{26}$ & 7.93 days $^{-1}$ \\
\hline$\varepsilon_{c}$ & $\begin{array}{l}\text { Decrease of biting rate } \\
\text { due to insecticide im- } \\
\text { pregnated collar }\end{array}$ & Halbig et al. ${ }^{27}$ & 8.00 days $^{-1}$ \\
\hline$\tau$ & $\begin{array}{l}\text { Extrinsic Incubation } \\
\text { Period }\end{array}$ & Estimated & $1.40 \times 10^{1}$ days \\
\hline$c_{l}$ & $\begin{array}{l}\text { Fraction of flies which } \\
\text { acquire the infection } \\
\text { after biting an latent } \\
\text { dog }\end{array}$ & Estimated & $9.30 \times 10^{-1}$ \\
\hline$c_{y}$ & $\begin{array}{l}\text { Fraction of flies which } \\
\text { acquire the infection } \\
\text { after biting an clini- } \\
\text { cally ill dog }\end{array}$ & Estimated & $6.70 \times 10^{-1}$ \\
\hline$c_{k}$ & $\begin{array}{l}\text { Proportion of treated } \\
\text { dogs that do not be- } \\
\text { come parasite free }\end{array}$ & Miro et al. ${ }^{35}$ & $1.54 \times 10^{-1}$ \\
\hline
\end{tabular}

che and Watmough ${ }^{28}$ does not consider the presence of delayed terms, we proceeded an adaptation on our model in order to calculate the $R_{0}$. According to J. Wu and P. van den Driessche (2014, in printing), the delayed terms in our model can be considered as non-deleyed terms (that is, we can apply $\tau=0$ ), but we need to keep the term $e^{-\mu_{s} \tau}$ (that is, for this term, we keep $\tau \neq 0$ ). 
In general, the disease free equilibrium (DFE) is the scenary where the population remains in the absence of disease. If we consider epidemiological models, they usually have a threshold parameter, known as basic reproduction number, $R_{0}$, such that ${ }^{28}$ :

- $R_{0}<1$, then the DFE is locally asymptotically stable and the disease cannot invade the population;

- $R_{0}>1$, then the DFE is unstable and invasion is always possible.

In order to compute $R_{0}$, it is important to distinguish the new infections from all other changes in population. Let's consider $F_{i}(x)$ as the rate of appearance of new infections in a compartment of this model, $V_{i}(x)^{+}$as the rate of transfer of individuals (but no including infected) into compartment $i$ by all other means, and $V_{i}(x)^{-}$as the rate of transfer of individuals (including infected) out of compartments, where $x$ is the vector of variables of our model. The index $i$ means to a category of one of the three populations. Thus, $1 \leq i \leq 4$, stands for humans, $5 \leq i \leq 14$, stands for dogs, and $15 \leq i \leq 17$, stands for sandflies. Thus, for each equation of our model, we can organize them as:

$$
\frac{d}{d t} x=F_{i}(x)-V_{i}(x)
$$

where $V_{i}(x)=V_{i}(x)^{-}-V_{i}(x)^{+}$.

From this point, we will not describe all the steps of the method. However, all the details are well explained in van der Driessche and Watmough 28. Thus, before continue, let's define:

$$
\begin{gathered}
F\left(x_{0}\right)=\left[\frac{\partial F_{i}}{\partial x_{j}}\right] \\
V\left(x_{0}\right)=\left[\frac{\partial\left(V^{-}-V^{+}\right)_{i}}{\partial x_{j}}\right]
\end{gathered}
$$

where $x_{0}$ is the vector that represents the disease free equilibrium state, $i$ is the total of variables of the model and $j$ represents the compartiments where there are infected individuals. In our model we have $j=8$ compartments with infected individuals: $l_{h}, l_{d}, l_{d}^{C}, s_{2}, y_{h}, y_{d}, y_{d}^{C}, s_{3}$. Therefore, we have to calculate the partial derivative of each expression of our model in respect of each infected compartment. 
From Eq. (21) and (22) we can apply them into the expression presented by van der Driessche and Watmough ${ }^{28}$ :

$$
R_{0}=\rho\left(F V^{-1}\right)
$$

where $\rho\left(F V^{-1}\right)$ is the spectral radius of matrix $F V^{-1}$.

Considering our model and if the control methods are not considered $\left(\theta_{d}(t)=\xi_{d}(t)=\nu_{d}(t)=\omega_{d}(t)=\xi_{d}(t)=0\right)$, we obtain (calculation is not showed):

$$
R_{0}=b_{d} a_{d}^{2} m_{d} e^{-\left(\mu_{s}+\xi_{s}(t)\right) \tau} C
$$

where:

$$
C=\frac{\left.\left(\varphi_{d} c_{y}+\left(f_{d}+\sigma_{d}+\alpha_{d}+\mu_{d}\right) c_{l}\right)\right)}{\left.\left.\left(f_{d}+\sigma_{d}+\alpha_{d}+\mu_{d}\right) c_{l}\right)\left(r_{d}+\delta_{d}+\mu_{d}+\varphi_{d}\right)-f_{d} \varphi_{d}\right) \mu_{s}}
$$

From Eq. (24) we can observe a contribution from clinically ill dogs and latent dogs on the $R_{0}$ value. Substituting the parameters by their respective values, we obtain the value of 1.65 from clinically ill dog contribution and 5.41 from latent dog contribution (thus, the total is 7.06). This difference of values between those two contributions can be explained by the integrity of the skin of those dogs. The clinically ill dog presents lesions on skin in which it becomes more difficult for a sandfly to be infected. On the other hand, the latent dog has no lesions on skin, in which allows the sandfly to be infected with a higher probability (C. N. Rossi, 2013, in printing).

\section{The Linear Chain Trick}

The entry of a leishmania protozoan into sandfly organism initiates a cascade of events that lead to the production of new parasites (the promastigota form of leishmania protozoan) (see Greene ${ }^{30}$ for more details about the physiopathology). Thus, the set of Eq. (1) to (17) considers that this process occurs instantaneously: as soon as the sandfly is infected, the physiopathological process start and new infective sandflies will appear in $\tau$ days. However, in some biological models, this hypothesis is not a good representation (this is not biologically sensible) ${ }^{29}$.

In the literature review published by Iggidr et al. ${ }^{29}$ we find that fixed delays (the discrete constant delays) are not biologically realistic, and in the context of compartmental systems continuous probability functions of lags 
(the continuously distributed delays) are far more important than discrete lags. Usually the probability density function (pdf) of the lag is not well known and approximations are used. A widely used family of functions is given by the family of gamma distributions.

In order to take into account the effect of this countinuous distributed delay, we applied the linear chain trick. The linear chain trick allows replacing system with distributed delays whose distributions are linear combinations of gamma functions, by a system of ordinary differential equations. Also, we recall for the fact that the linear chain trick does not provide us an extra or new compartmental model, since it is not a mass-balance system 29 . For details about this method and applications, we suggest to see Iggidr et al. ${ }^{29}$ and Azzan and Kane ${ }^{31}$.

Thus, we substitute the Eq. (16) and (17) by the following Eq. (26) to $(35)$.

$$
\begin{aligned}
\dot{s_{2}}(t)= & a_{d}\left(c_{l} l_{d}(t)+c_{y} y_{d}(t)+\left(1-\varepsilon_{c}\right)\left(c_{l} l_{d}^{C}(t)+c_{y} y_{d}^{C}(t)\right)\right) s_{1}(t) \\
& -\left(\frac{2}{2+\left(\mu_{s}+\xi_{d}(t)\right) \tau}\right)^{2} a_{d}\left(c_{l} E_{2}^{l d}(t)+c_{y} E_{2}^{y d}(t)\right. \\
& \left.+\left(1-\varepsilon_{c}\right)\left(c_{l} E_{2}^{l d C}(t)+c_{y} E_{2}^{y d C}(t)\right)\right)-\left(\mu_{s}+\xi_{d}(t)\right) s_{2}(t) \\
\dot{s_{3}}(t)= & \left(\frac{2}{2+\left(\mu_{s}+\xi_{d}(t)\right) \tau}\right)^{2} a_{d}\left(c_{l} E_{2}^{l d}(t)+c_{y} E_{2}^{y d}(t)\right. \\
& \left.+\left(1-\varepsilon_{c}\right)\left(c_{l} E_{2}^{l d C}(t)+c_{y} E_{2}^{y d C}(t)\right)\right)-\left(\mu_{s}+\xi_{d}(t)\right) s_{3}(t) \\
\dot{E_{1}^{l d}}(t)= & \left(\frac{2}{\tau}+\mu_{s}+\xi_{s}(t)\right)\left(l_{d}(t) s_{1}(t)-E_{1}^{l d}(t)\right) \\
\dot{E_{1}^{y d}}(t)= & \left(\frac{2}{\tau}+\mu_{s}+\xi_{s}(t)\right)\left(y_{d}(t) s_{1}(t)-E_{1}^{y d}(t)\right) \\
E_{1}^{l d d}(t)= & \left(\frac{2}{\tau}+\mu_{s}+\xi_{s}(t)\right)\left(l_{d}^{C}(t) s_{1}(t)-E_{1}^{l d c}(t)\right) \\
E_{1}^{y d c}(t)= & \left(\frac{2}{\tau}+\mu_{s}+\xi_{s}(t)\right)\left(y_{d}^{C}(t) s_{1}(t)-E_{1}^{y d c}(t)\right) \\
\dot{E_{2}^{l d}}(t)= & \left(\frac{2}{\tau}+\mu_{s}+\xi_{s}(t)\right)\left(E_{1}^{l d}(t)-E_{2}^{l d}(t)\right)
\end{aligned}
$$




$$
\begin{aligned}
E_{2}^{y d}(t) & =\left(\frac{2}{\tau}+\mu_{s}+\xi_{s}(t)\right)\left(E_{1}^{y d}(t)-E_{2}^{y d}(t)\right) \\
E_{2}^{i d d}(t) & =\left(\frac{2}{\tau}+\mu_{s}+\xi_{s}(t)\right)\left(E_{1}^{l d c}(t)-E_{2}^{l d c}(t)\right) \\
E_{2}^{y d d}(t) & =\left(\frac{2}{\tau}+\mu_{s}+\xi_{s}(t)\right)\left(E_{1}^{y d c}(t)-E_{2}^{y d c}(t)\right)
\end{aligned}
$$

\section{The disease dynamics}

In order to analyze the dynamics of the model, we numerically simulated the complete system of 25 equations. However, here we are interested to understand how the disease dynamic is. Thus, we considered this initial simulation with no control methods $\left(\xi_{s}(t)=0, \theta_{d}(t)=0, \omega_{d}(t)=0, \nu_{d}(t)=\right.$ $\left.0, \xi_{d}(t)=0\right)$. As consequence, our system of equations become simpler, composed by 15 equations. The set of parameters used is shown in Table 1. Figure 2 is the simplified compartment model and flowchart, without control methods. Since we are not considering dog vaccination neither the application of insecticide impregnated collar, there are no compartments for dogs with collar and vaccinated dogs.

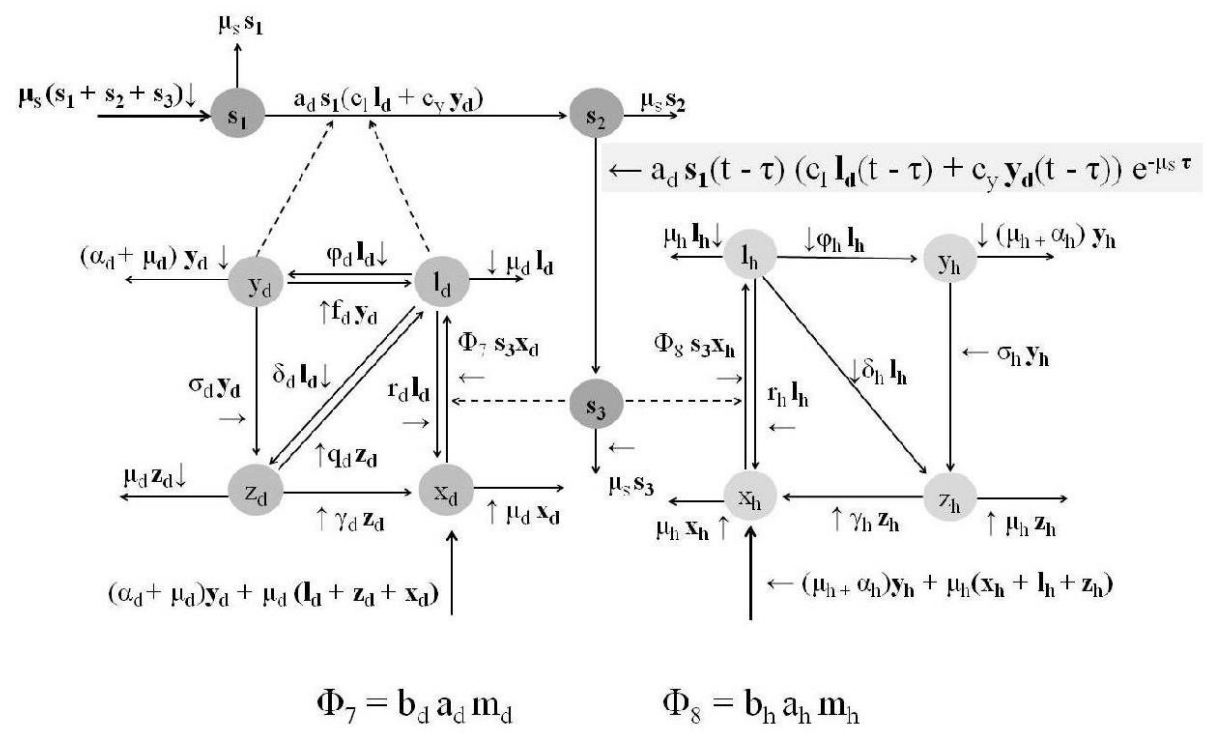

Figure 2. Model compartments and the flow between them after simplification.

Figure 3 ilustrates the dynamic of reported cases by Brazilian Ministry of Health. This dynamic was estimated by the equation: 


$$
R(t)=\left(1-\eta_{h}\right) \phi_{h} l_{h}(t)
$$

where $R(t)$ are the human reported cases, and $\eta_{h}$ is the proportion of unreported cases.

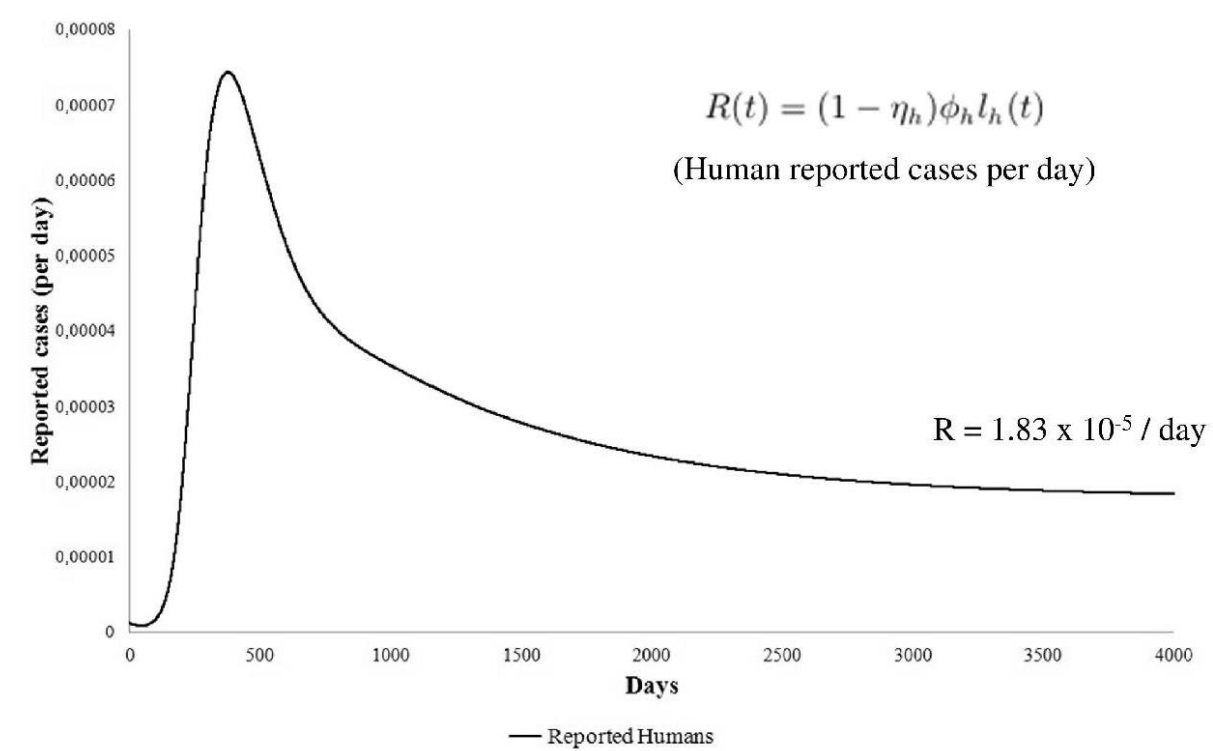

Figure 3. Human reported cases per day $\left(m_{h}=4, m_{d}=40\right)$. The rate of $1.83 \times 10^{-5}$ $d a y^{-1}$ is obtained for the equilibrium state.

The equilibrium state of human reported cases rate is around $1.83 \times$ $10^{-5}$ /day. According to data from Brazilian Ministry of Health, the rate of human reported cases was $4.72 \times 10^{-8} /$ day for 2012 year, considering the whole country. In Brazil, the distribution of zoonotic visceral leishmaniasis is not homogeneus. Thus, we can find states with no human reported cases for 2012 year (as Rio Grande do Sul state). This non-homogeneus distribution is related to geographic featuring and climate changes, in which probably has influenced on the sandfly population dynamics. Therefore, this is one of the arguments to explain the discrepancy regarding to our result and the real data. In addition, although our model used updated parameters, some of them were not able to be updated, and this can also be a reason for this unconformity. Finally, we could reach a close result if we adopt $m_{h}=0.511\left(m_{d}=5.11\right)$, however, the analysis of the disease dynamic would be difficult because of extreme low values of output. Since we are firstly interested to present this new model here, we simulated our 
model using the fitted value of $m_{h}=4\left(m_{d}=40\right)$, which we considered very real.

The Figures 4, 5 and 6 ilustrate the dynamic for human, dogs and sandflies, respectively.

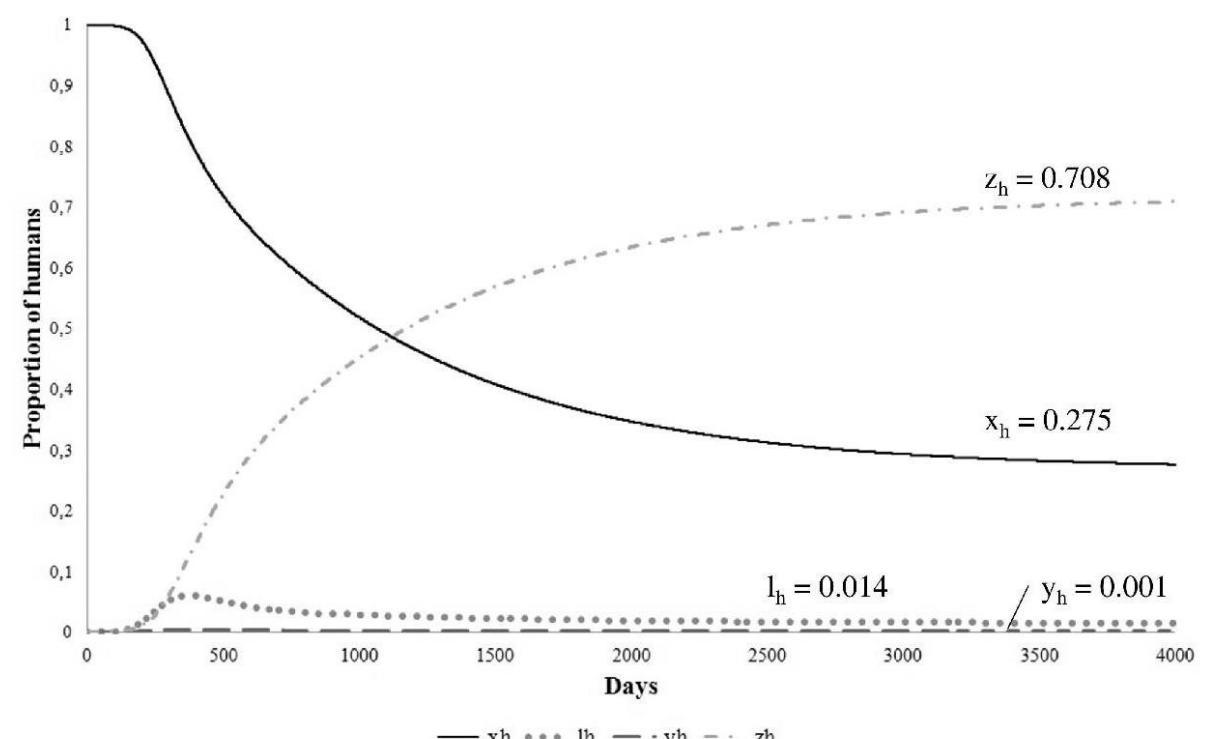

Figure 4. Numerical simulation of the model for human population. The values $x_{h}=$ $2.76 \times 10^{-1}, l_{h}=1.48 \times 10^{-2}, y_{h}=1.06 \times 10^{-3}$ and $z_{h}=7.08 \times 10^{-1}$ are the equilibrium densities.

In order to compare our results, we were able to find some descriptions about some demographic characterization of those populations regarding to zoonotic visceral leishmaniasis. For instance, our sum of latent and recovery dog was around 0.55 , which is in a good agreement with that one found by Cabral et al. ${ }^{32}$ (0.50). However, on the other hand, the sum of latent and clinically ill dogs was around 0.157 , which is different with the results from Quinnell et al. ${ }^{33}$ (0.579).

\section{The optimal control strategy}

In this model we included five preventive control methods (elimination of positive dogs, sandfly population control, use of insecticide impregnated dog collar, dog vaccination and dog treatment). However, considering the official control strategy in Brazil, the Brazilian Ministry of Health adopts the elimination of positive dogs as control method and does not preconize the other four methods mentioned here ${ }^{40}$. However, it has been usual the 


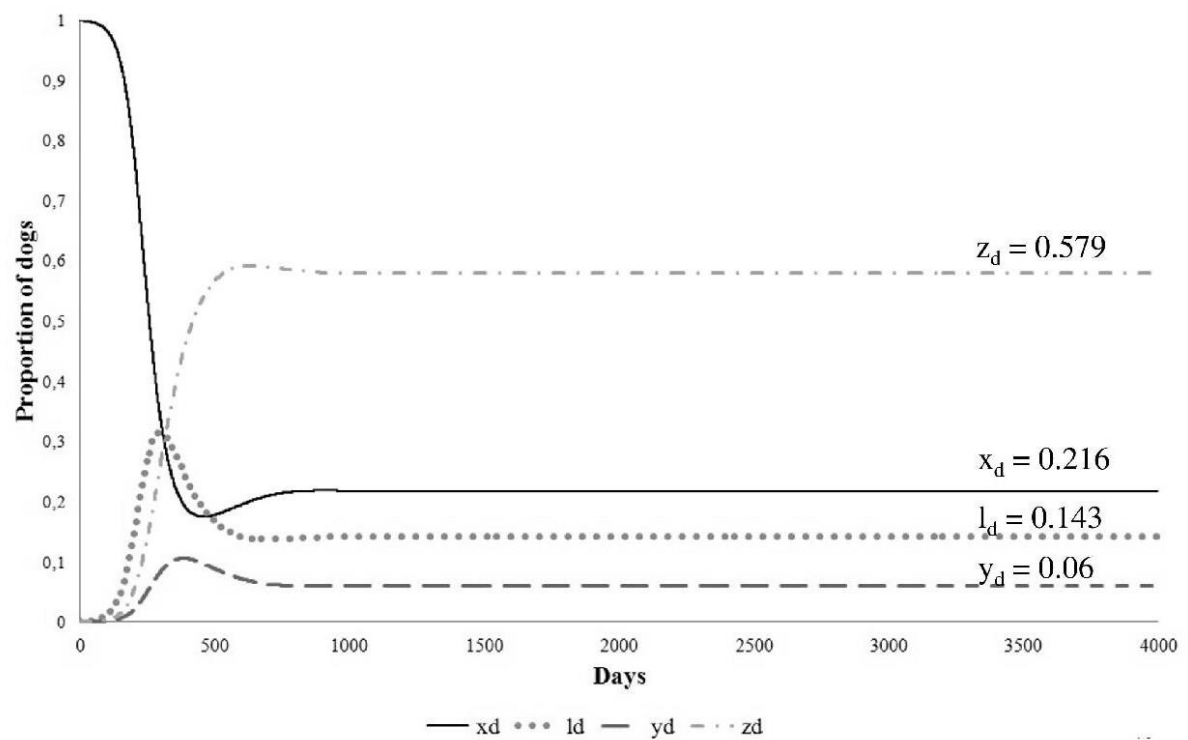

Figure 5. Numerical simulation of the model for dog population. The values $x_{d}=$ $2.17 \times 10^{-1}, l_{d}=1.42 \times 10^{-1}, y_{d}=6.00 \times 10^{-2}$ and $z_{d}=5.79 \times 10^{-1}$ are the equilibrium densities.

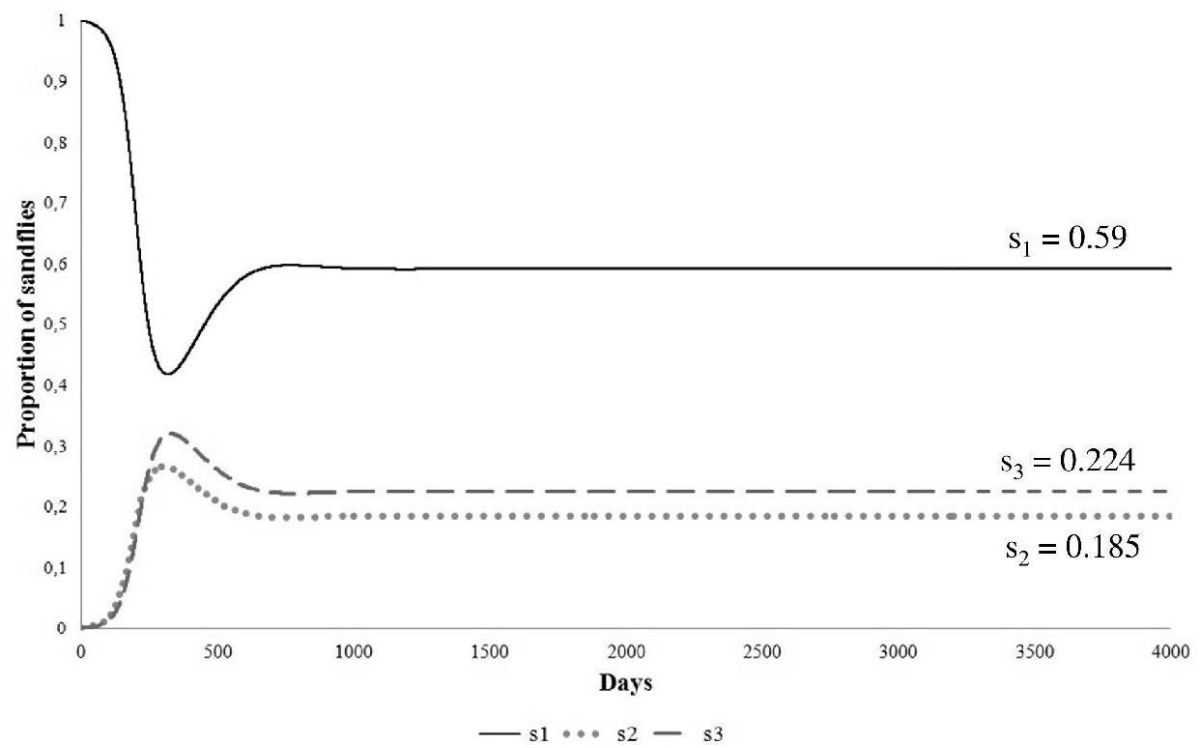

Figure 6. Numerical simulation of the model for sandfly population. The values $s_{1}=$ $5.90 \times 10^{-1}, s_{2}=1.85 \times 10^{-1}, s_{3}=2.25 \times 10^{-1}$ are the equilibrium densities.

indiscriminate elimination of dogs, instead of the selective elimination.

In order to check the efficacy of alternative control methods, we numerically simulated the model considering individually each method and 
all five control methods were evaluated for the same range. As reference of comparison, we observed the effect on the human reported cases rate regarding to the rate values (Figure 7) and the cost per rate unit (Figure 8). For those simulations, we performed with the same set of parameters in Table 1.

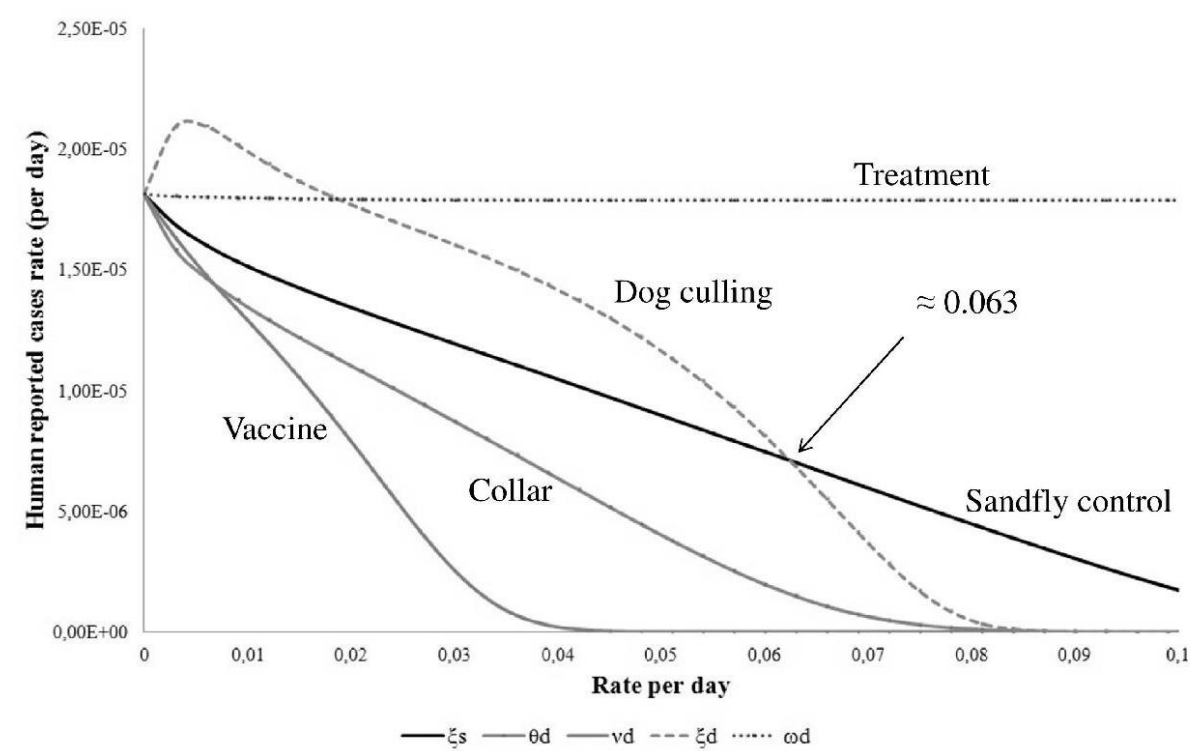

Figure 7. Effect of each control methods (if constant) on reported human cases rate after one year.

Ribas et al. ${ }^{14}$ also published a mathematical model for Zoonotic Visceral Leishmaniasis and this model was based on the previous model published by Burattini et al. ${ }^{13}$. In this model published in 2013, Ribas et al. discussed about the optimal control method among those same five methods we presented here. However, differently from Ribas et al., our model allow us to observe the dynamic and movement of dog population if we consider the use of insecticide impregnated dog collar or vaccination, since we included specific categories for them. Futhermore, if we consider the treatment, we included a proportion of dogs that were totally cleared from the parasite $\left(1-c_{k}\right)$. Finally, since the serology is the official diagnostic method adopted by Brazilian Ministry of Health and considering that this diagnostic method is not able to distinguish an recovered of vaccinated dog from the latent or clinically ill dog, we assumed that any dog who had previous contact with the parasite is eligible to be eliminated ${ }^{41}$. Regarding the sandfly population, we assume that this population is r-strategist and, thus, 


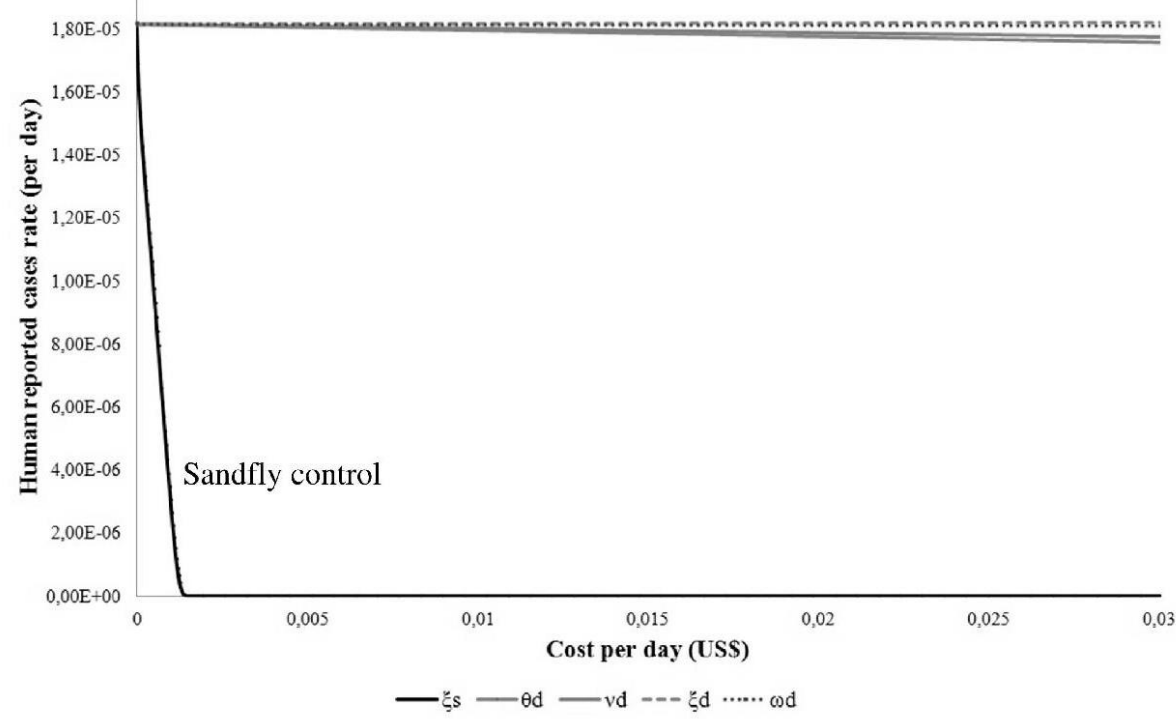

Figure 8. Impact of investment (if constant) on each of strategy control on reported human cases rate after one year.

the permanency of sandflies in such area depends on the increment of the reproduction power. Classically, the individuals that are r-strategists are small size individuals, with short life expectancy, maturity quickly reached, high mortality rate and short reproduction cycles ${ }^{34}$. Thus, we simulated the sandfly population control by adding an extra term for mortality rate $\xi_{s}(t)$.

From Figure 7 and 8 we observed two different results. If we consider only the range of rates and ignore the costs, the Figure 7 shows that the vaccination and the use of insecticide impregnated dog collar were the most efficient methods. They were followed by sandfly population control and dog elimination. The treatment of infected dogs has almost no effect on the human reported cases rate. Those results are different from the conclusions previously presented in Burattini et al. ${ }^{13}$ and Ribas et al. ${ }^{14}$. Although they made conclusions on their results on human prevalence, sandfly population control was considered the most efficient strategy of control. However, we recall here that our model has been modified and some parameter values were updated. Furthermore, we observed in our model that the vaccination of dogs causes direct decreasing on the susceptible dog category, in which consequently decreases the size of latent and clinically ill dogs categories. Also, we can observe that the application of insecticide impregnated dog collar not only remove latent and clinically ill dogs from "exposed to sandfly" 
status to a "non-exposed sandfly" status, but also protect the susceptible and recovered dogs to be bitten by flies. In those both control strategies, since we assumed the density of 40 sandflies per dog, for each dog protected from sandflies bites, we have less 40 sandflies that potentially can infect a susceptible dog or be infected by a infected dog. This is the reason about the sandfly control population was not more efficient than vaccination and insecticide impregnated dog collar.

In our model, all populations are assumed constant. Thus, the elimination of one individual in those population, we have the replacement of a new susceptible individual ${ }^{13}$. Thus, when we compare the elimination of one sandfly to one dog, we observed that elimination of sandflies is more efficient than elimination of dogs until the rate of 0.063 /day. This means that in order to obtain the elimination of infected dog as efficient (or more) than sandfly control population, we have to apply a rate of elimination of dogs higher than 0.063 dogs/day.

Finally, we have the treatment of dogs, which is the less effective strategy. Although we assumed an treatment protocol that results in the elimination of the parasites from dog organism ${ }^{35}$, our assumption is that the dog becomes to susceptible category. Thus, this not avoid the dog to became infected again and, thus, source of infection.

Now, if we observe Figure 8 , we have a different point of view about our previous conclusions. Here we analyzed the effect of the control methods on human reported cases but considering the cost per rate of each method. In this new approach, we assumed the values per rate unit of Table 3 and they were obtained from a sample of costs available in different sources (from Brazilian municipality source to company websites). We will not show the calculation of the costs, but we had to keep some featuring as assumptions and used the exchange rate of Brazilian real to American dollar of 0.41 (verified on 2014 Oct 20), according to Brazilian Central Bank (http://www.bcb.gov.br/). Thus, vaccination, dog culling and insecticide impregnated dog collar application method were budgeted considering two assistents, one veterinary and one driver. The sandfly control considered two assistents and one driver. The treatment, we considered that the medicine is provided to private veterinarians, so we supposed that the Brazilian Ministry of Health does not offer treatment but could provide the medicine to those owners who are interested to treat their dog.

According to Figure 8, by far, the sandfly control strategy is the most efficient in terms of cost effectiveness. As the methods applied on dog population showed low (or none) effect on the human reported cases rate, 
the sandfly control strategy provides an intense decrease of this rate when we observe the same cost range. However, although the sandfly control is the most cost-effective method, there are logistic implications. In this case, if the insecticide application protocol is not well followed, then it is possible to observe an inverse effect on sandfly population with the appearance of resistant sandflies.

Table 3. Cost of control methods per rate unit (calculations not shown). This estimation were based on material costs and salaries informed in Brazilian municipality source and company websites.

\begin{tabular}{cl}
\hline Description & Cost \\
\hline Total cost for sandfly control & USD $0.01 \times$ sandfly $^{-1}$ \\
Total cost for culling & USD $485.90 \times d o g^{-1}$ \\
Total cost for vaccine & USD $45.13 \times d o g^{-1}$ \\
Total cost for insecticide impregnated collar & USD $41.58 \times d o g^{-1}$ \\
Total cost for treatment & USD $20.84 \times d o g^{-1}$ \\
\hline
\end{tabular}

\section{Discussion}

The model presented in this article provided a new and interesting view about visceral leishmaniasis transmission dynamics among humans, dogs and sandflies population. Also, we developed a mathematical analysis and computer simulation of strategies control application on this system. Finally, we evaluated the optimal strategy when they are compared on the same rate value ranges and in terms of cost benefit.

The researches about control strategies rarely propose the optimization of the strategy in a general approach. That is, most of the results are more empirical than analytical. Thus, it is dificult to proceed to any extrapolation of these practical conclusions to other sceneries. The increasing trend of VL cases observed in endemic countries (like Brazil) and the spread of transmission to previously not affected areas raise doubts about the impact of ongoing control measures ${ }^{12}$. In addition, the studies about the eficacy of control strategies usually analyze them individually and discuss about the comparison with other strategies based on the results of other researches. Again, this does not allow a practical analysis, since the discussion that these articles present are about different experimental fields and/or designs.

The review written by Romero and Boelaert ${ }^{12}$ related to visceral leishmaniasis control in Latin America revealed that a lot of work remains to be 
done in order to clarify the dynamics of Leishmania transmission in human, canine and vector populations. Herein we was able to apply a simulation that predicts what could happen if the control interventions occur. Thus, our theoretical study presents a clear practical application and does not conflict with ethical procedures (since it is a theoretical study). In other hand, although it is possible to develop this optimization by field study, we would probably need to organize dozen of surveillance staffs, each one being responsible for a particular control strategy. Also, we would need a long time to obtain these results. However, this practical way is not simple to proceed, since it would be necessary to submit the study to a bureaucratic assessment by the local public health administration. In addition, we could observe a clear waste of resources and time, because it is hard to evaluate all the possible control strategies.

In our model we could estimate the proportion of the individuals in each stage of disease dynamic. This evaluation is very interesting, since the latent individuals (humans and dogs) are dificult to detect. Furthermore, here we estimated the reported human cases rate for our model $\left(1.83 \times 10^{-5} /\right.$ day $)$. Killick-Kendrick ${ }^{2}$ highlighted that the key to reach the visceral leishmaniasis control is education. Education was not considered in our model but we can see that public health education and epidemiological surveillance system are very close and work together. As example, the fact of infected people neglected the visceral leishmaniasis provides unreported cases of this disease. As consequence, few cases are reported and the organization of control programs is poorly organized. Thus, if we know the proportion of unreported cases, we could evaluate the eficacy of the surveillance service. Finally, this can indirectly influence the control programs, since the strengthening of the surveillance system capacity is essential to avoid the underreporting of human cases and to follow-up the infection behavior in canine and human population. Strong surveillance will certainly contribute to improve data quality for decision-makers in this complex scenario 12,40 .

According to the results presented here, the simulation purposed excellent results even though the culling dog strategy is not applied. We can find some authors that stress the importance of development and use of canine vaccines in order to reduce the canine reservoir of infection. Consequently, this could interrupt the transmission of Leishmania parasites to humans and could eliminate the need for euthanasia ${ }^{3,5}$. Others highlight the effectiveness of insceticide-impregnated collars ${ }^{7,36}$. Thus, we can understand this fact as evidence that the control of visceral leishmaniasis can 
be reached under ethical constraints. In addition, there are some researches that highlight the effectiveness of control of sandflies population when compared with the culling of infected $\operatorname{dog} 12,13,37$. From our results we suggested that the control of sandflies is the most effective strategy control among the five strategies considered here. The evidence of a more human and ethical control should attract the attention of most surveillance services of endemic areas that applies the culling of domestic dogs.

If a human and ethical control could be applied (that is, reducing the canine culling), we can suppose that the treatment of infected dog is also possible. Although we can find some articles that do not recommend the treatment of canine visceral leishmaniasis ${ }^{10,42,39}$ since parasitological cure has not been achieved, our model ponted that it is also possible to reach the elimination of the infection without culling infected dogs but treating them. Supposing an infected dog has an owner, the other preventive control methods have been applied and that, once the dog is infected, it would become infected for all life, the owner could be free to decide about treating or not his own dog.

As conclusion, according to our model we obtained a good representation of the zoonotic visceral leishmaniasis dynamics and we found the sandfly population control as the best individual strategy to reduce the human incidence of this disease. However, as upcoming work, the nonupdated parameters should be reviewed, and it should be interesting to evaluate the optimization of the control strategy, but when all methods are concomitantly applying.

\section{References}

1. P. N. Acha and B. Szyfres, Zoonoses and Communicable Diseases Common to Man and Animals, Pan American Health Organization, Washington, D.C. (2001).

2. R. Killick-Kendrick, Bull. World Health Organ., 88, 11 (2010).

3. M. S. Duthie, V. S. Raman, F. M. Piazza and S. G. Reed, Vaccine, 30, 134 (2012).

4. World Health Organization, Available in http ://http ://www.who.int/en/ (2013).

5. C. B. Palatnik de Souza and M. J. Day, Parasites $\&$ Vectors., 4(1), 197 (2011).

6. C. M. Caris-Nunes, V. M. F. de Lima, H. B. de Paula, S. H. Perri, A. M. Andrade, F. E. Dias and M. N. Burattini, Veterinary Parasitology, 153, 19 (2008).

7. A. S. Mazloumi Gavgani, M. H. Hodjati, H. Mohite and C. R. Davies, THE LANCET, 360, 374 (2002).

8. C. B. Palatnik de Souza, Vaccine, 26, 1709 (2008). 
9. C. B. Palatnik de Souza, J. Silva-Antunes, A. A. Morgado, I. Menz, M. Palatnik and Lavor C., Vaccine, 27, 3503 (2008).

10. L. V. Athanasiou, M. N. Saridomichelakis, V. I. Kontos, G. Spanakos and T. S. Rallis, Veterinary Parasitology, 192, 91 (2013).

11. A. N. S. Maia-Elkhoury, W. A. Alves, M. L. Souza-Gomes, J. M. Sena and E. A. Luna, Cad. Saude Publica, 24(12), 2941 (2008).

12. G. A. S. Romero and M. Boelart, PLoS Negl. Trop. Dis., 4(1), e584 (2010).

13. M. N. Burattini, F. A. B. Coutinho, L. F. Lopez and E. Massad, J. Biol. Syst., 6(4), 337 (1998).

14. L. M. Ribas, V. L. Zaher, H. J. Shimozako, E. Massad, The Scientific World Journal, 2013, Article ID 810380, http://dx.doi.org/10.1155/2013/810380 (2013).

15. R. B. Tesh, Am. J. Trop. Med. Hyg., 3(52), 42 (1995).

16. Brazilian Institute of Geography and Statistics (IBGE), Life expectancy at birth was 74.6 years in 2012 (2013) (in Portuguese). Accessed on 2014 Oct 15, Avaiable in http://cod.ibge.gov.br/1XSXA

17. R. Bardaro, T. C. Jones, E. M. Carvalho, D. Sampaio, S. G. Reed, A. Barral, R. Teixeira and W. R. Johnson J. Infect. Dis., 154(6), 1003 (1986).

18. R. Bardaro, E. M. Carvalho, M. G. O. Orge, R. S. Teixeira, H. Rocha Revista da Sociedade Brasileira de Medicina Tropical, 18, 77 (1985).

19. E. S. M. M. Savani, V. L. B. Nunes, E. A. B. Galati, T. M. Castilho, R. A. Zampieri, L. M. Floeter-Winter Veterinary Parasitology, 160, 18 (2009).

20. C. Selman, D. H. Nussey, P. Monaghan Current Biology, 10, R451 (2013). DOI: $10.1016 /$ j.cub.2013.04.005

21. J. Fernandez-Cotrina, V. Iniesta, S. Belinchon-Lorenzo, R. Munoz-Madrid, F. Serrano, J. C. Parejo, L. Gomez-Gordo, M. Soto, C. Alonso, L. C. GomezNieto, Veterinary Parasitology 192, 118 (2013).

22. G. Lanotte, J. A. Rioux, J. Perieres and Y. Vollhardt, Ann. Parasitol., 3(54), 7 (1979).

23. Zoetis Brasil website. Accessed on 2015 Jan 15, Avaiable in https://www.zoetis.com.br/node/19883

24. D. A. Kault and K. M. Marsh, Math. Biosc., 103, 103 (1991).

25. Scalibor website. Accessed on 2014 Oct 15, Avaiable in https://www.medicanimal.com/medicanimal/images/products/PDF/Scalibor' 20Client\% 20DL\% 20Leaflet.pdf

26. E. M. Saraiva, A. F. Barbosa, F. N. Santos, G. P. Borja-Cabrera, D. Nico, L. O. P. Souza, C. O. Mendes-Aguiar, E. P. de Souza, P. Fampa, L. E. Parra, I. Menz, J. G. Dias Jr., S. M. de Oliveira, C. B. Palatnik-de-Sousa, Vaccine, 13, 2423 (2006).

27. P. Halbig, H. M. Hodjati, A. S. Mazloumi-Gavgani, H. Mohite, C. R. Davies, Med Vet Entomol., 14(2), 223 (2000).

28. P. van den Driessche, J. Watmough, Mathematical Biosciences 180, 29 (2013).

29. A. Iggidr, J Mbang, S Gauthier, Mathematical Biosciences 209, 1, 51 (2013).DOI: $10.1016 /$ j.mbs.2007.01.008

30. C. Greene, Infectious Diseases of the Dog and Cat, Saunders, (2011). 
31. C. Azzam, J. N. Kane, Fundamental Mathematics of the Delay Differential Equations in the HIV-1 Virus Model, Accessed on 2014 Oct 15, Avaiable in https://mathbio.colorado.edu/index.php/MBW:Fundamental_Mathematics _of_the_Delay_Differential_Equations_in_the_HIV-1_Virus_Model

32. M. Cabral, J. E. O'Grady, S. Gomes, J. C. Sousa, H. Thompson, J. Alexander, Veterinary Parasitology 76, 173. 1998.

33. R. J. Quinnell, O. Courtenay, S. Davidson, L. Garcez, B. Lambson, P. Ramos, J. J. Shaw, M.-A. Shaw, C. Dye, Parasitology 122, 122, 2000.

34. O. P. Forattini, Ecology, Epidemiology and Society, Artes Medicas, Sao Paulo (2011) (in Portuguese).

35. G. Miro, R. Galvez, C. Fraile, M. A. Descalzo, R. Molina, Parasit Vectors 4(52), (2011) doi: 10.1186/1756-3305-4-52

36. M. Maroli, V. Mizzoni, C. Siragusa, A. D'Orazi and L. Gradoni, Medical and Veterinary Entomology, 15, 358 (2001).

37. R. Reithinger, P. G. Coleman, B. Alexander, E. P. Vieira, G. Assis and C. R. Davies, International Journal for Parasitology, 34, 55 (2004).

38. H. M. Andrade, V. P. C. P. Toledo, M. B. Pinheiro, T. M. P. D. Guimares, N. C. Oliveira, J. A. Castro, R. N. Silva, A. C. Amorim, R. M. S. S. Brando, M. Yoko, A. S. Silva, K. Dumont, M. L. Ribeiro Jr, W. Barthewsky and S. J. H. Monte, Veterinary Parasitology, 181, 83 (2011).

39. S. Rougier, L. Hasseine, P. Delaunay, G. Michel and P. Marty, Veterinary Parasitology, 17(1), 42 (1974).

40. A. N. Maia-Elkhoury, E. H. Carmo, M. L. Souza-Gomes and E. Mota, Rev. Saude Publica, 6(41), 913 (2007).

41. M. Marcondes, V. M. F. de Lima, M. de F. L. de Araujo, R. M. Hiramoto, J. E. Tolezano, R. F. C. Vieira, A. W. Biondo, Veterinary Parasitology, 197, 649 (2013).

42. R. M. Anderson and R. M. May, Infectious Diseases of Humans, Oxford University Press Inc., New York (1991). 